\title{
Desarrollo de una prótesis regenerativa de tendón
}

\author{
Tesis presentada por \\ María del Carmen Araque Monrós \\ para optar al título de Doctor por la Universitat Politècnica de \\ València \\ Dirigida por: \\ Dr. Manuel Monleón Pradas \\ Dr. Jorge Más Estellés
}

Valencia, 2013 



\section{Miembros del tribunal}

Presidente del tribunal

Dr. Jose Luis Gomez Ribelles

Departamento de Termodinámica Aplicada

Universitat Politècnica de València, España

\section{Secretaria}

Dra. Ana Vidaurre Garayo

Departamento de Física Aplicada

Universitat Politècnica de València, España

\section{Vocales}

\section{Dr. Carlos Barrios Pitarque}

Departamento de Patología del Aparato Locomotor

Universidad Católica de Valencia, España

\section{Dr. José Antonio Andrades Gómez}

Departamento de Biología Celular, Genética y Fisiología

Universidad de Málaga, España

\section{Dr. Mariano García Arranz}

Departamento de Cirugía General y Laboratorio de Terapia Celular Universidad Autónoma de Madrid, España 



\section{Agradecimientos}

Agradecer a la Asociación de investigación de industriales del textil, AITEX, por financiar parcialmente el trabajo de la presente tesis doctoral mediante el proyecto de investigación "Desarrollo de biomateriales trenzados para aplicaciones biomédicas", concedido al profesor Jorge Más Estellés como principal investigador.

Quisiera además agradecer a los investigadores del Laboratorio de Bioingeniería y Regeneración Tisular (LABRET), de la Universidad de Málaga, en especial al profesor Jose Antonio Andrades y a mis compañeros Silvia y Pedro, por la ayuda y guía profesional durante mi estancia en dicho centro.

Al equipo de técnicos de microscopía electrónica de la Universitat Politècnica de València por su contínua asesoría.

Un agradecimiento especial a mis directores de tesis Manuel Monleón Pradas y Jorge Más Estellés por su ayuda, experiencia y profesionalidad durante todos estos años y al Dr. Luis Gil Santos por su colaboración en la realización de la presente tesis.

Agradacer a mis compañeros del Centro de Biomateriales e Ingeniería Tisular, Cristina G, Miriam H, Harmony, Pepe, Manu, Virginia, Carmen A., Amparo B, Irene, Amparo G, María, Gabriela, y en general a todos con 
los que he compartido momentos muy buenos tanto dentro como fuera del centro.

Agradacer especialmente a Marco, Myriam L. y Cristina M., por ayudarme en todo momento, sobre todo al final de la tesis. También agradezco a todos los profesores del centro todo el apoyo que me han ofrecido, en especial a Ana Vidaurre por animarme, aconsejarme y en cada instante.

Agradecer especialmente a Jorge, Dunia, Tatiana y Javi por toda la ayuda que me han prestado, tanto profesional como personalmente durante todos estos años. Su apoyo me ha transmitido la fuerza necesaria para finalizar este trabajo y se han convertido en verdaderos amigos para mí. Agradecer a todos mis amigos, especialmente a mis amigas Sonia, Carmen, Marta, Pili, MํJe, Lorena, Amparo, Laura, María y Lorena P., por estar conmigo en todo momento.

Agradacer a toda mi familia, en especial a mi padre César y a su compañera Tere, por todo el cariño, apoyo y ánimo que me han dado en cada instante. A mi querida hermana Cristina y a mi cuñado Moises, que los quiero con locura y siempre han estado a mi lado ayudándome absolutamente en todo. A mis sobrinos, Marc y Ana, por alegrarme la vida y sobre todo a mi abuela Teresa, la persona más fuerte y luchadora que he conocido en mi vida. Le agradezco el cariño y la confianza que me ha dado y todo lo que ha hecho y sigue haciendo por mí. 


\section{Índice}

RESUMEN I

$\begin{array}{lll}\text { RESUM IV } & \text { IV }\end{array}$

$\begin{array}{ll}\text { ABSTRACT } & \text { VI }\end{array}$

CAPÍTULO 1 INTRODUCCIÓN 2

1.1 FISIOPATOLOGÍA DEL TENDÓN Y TERAPIAS ACTUALES ............. 3

1.1.1 El tendón: estructura, composición y biomecánica ..............................3

1.1.2 Nutrición, inervación y cicatrización tendinosa ...............................13



1.1.4 Soluciones terapéuticas...............................................................22

1.2 INGENIERÍA TISULAR DEL TENDÓN ........................................... 25

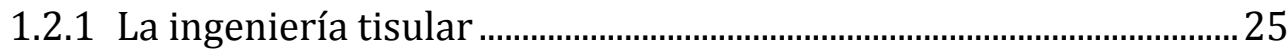

1.2.2 Estrategias de la ingeniería tisular del tendón ...................................32

1.3 PROTOTIPO DE PRÓTESIS REGENERATIVA DE TENDÓN......... 45

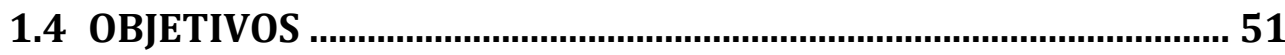

CAPÍTULO 2 MATERIALES Y MÉTODOS 53

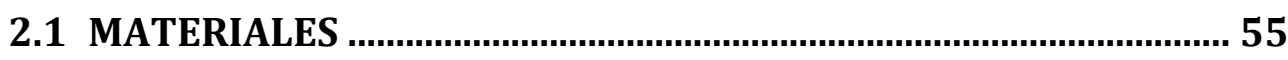




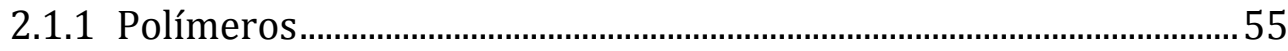

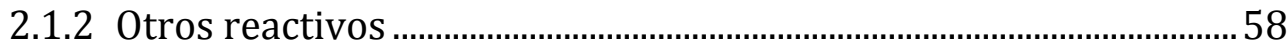

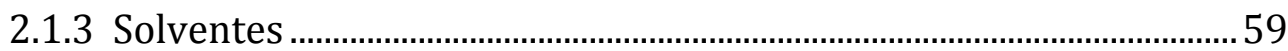

2.1.4 Células, medios de cultivo y tampones utilizados en los ensayos

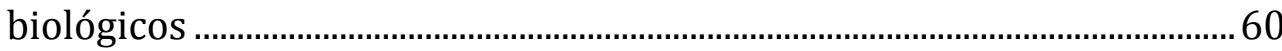

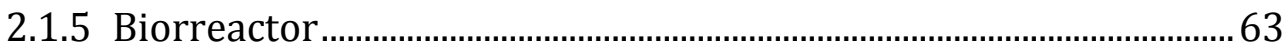

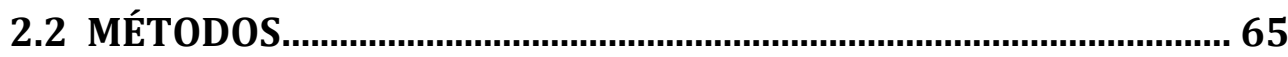

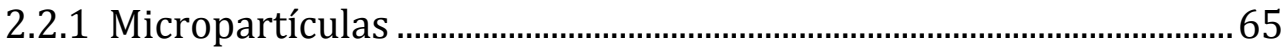

2.2.1.1 Método de obtención de micropartículas de PLLA ........................ 66

2.2.1.2 Método de obtención de micropartículas de CHT ........................ 67

2.2.1.3 Método de obtención de micropartículas de HA............................ 68

2.2.2 Recubrimiento del material trenzado .................................................70

2.2.3 Técnicas de caracterización fisicoquímica de los materiales.........71



2.3.1 Citotoxicidad del material trenzado ........................................................8

2.3.2 Cultivo in vitro de fibroblastos de ratón (L929) en los

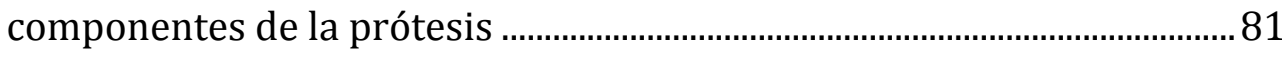

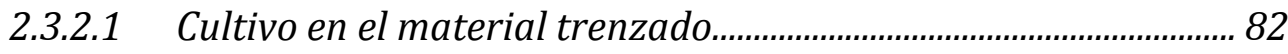


2.3.3 Cultivo in vitro de células mesenquimales humanas de médula ósea ( $h M S C s$ ) en los componentes de la prótesis .83

\subsubsection{Cultivo en el material trenzado y sobre las micropartículas}

sintetizadas.

2.3.3.2 Diferenciación de las células hMSCs a tenocitos en la trenza de PLA y en las micropartículas de PLLA. 85

2.3.4 Cultivo in vitro en el prototipo de prótesis en régimen estático y dinámico .86

2.3.4.1 Verificación de la funcionalidad del biorreactor............................. 86

2.3.4.2 Cultivo del prototipo de prótesis mediante L929 ........................... 89

2.3.4.3 Cultivo del prototipo mediante ADSC ............................................. 92

2.3.5Técnicas de caracterización biológica .................................................92

2.4 ANÁLISIS ESTADÍSTICOS DE LOS RESULTADOS ........................101

$\begin{array}{lll}\text { CAPÍTULO } 3 & \text { RESULTADOS Y DISCUSIÓN } & 97\end{array}$

3.1 DETERMINACIÓN DE LAS PROPIEDADES FISICO-QUÍMICAS Y MECÁNICAS DE LOS MATERIALES ....................................................105

3.1.1 Caracterización del material trenzado de PLA ................................. 105 
3.1.2 Estudio de la degradación hidrolítica del material trenzado ...... 114

3.1.3 Caracterización de las micropartículas............................................ 128

3.1.4 Caracterización del recubrimiento ................................................. 132

3.2 EVALUACIÓN BIOLÓGICA DE LOS MATERIALES QUE FORMAN

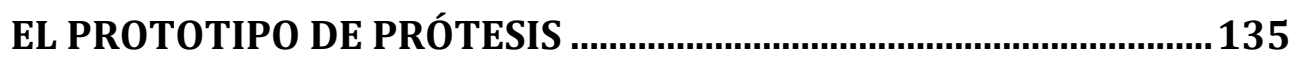

3.2.1 Estudio del comportamiento in vitro de las L929 sobre los distintos componentes de la prótesis ......................................................... 136

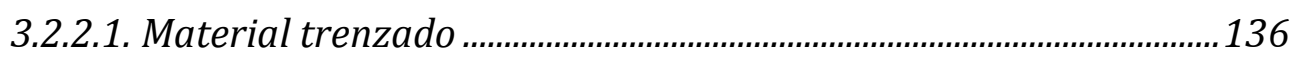

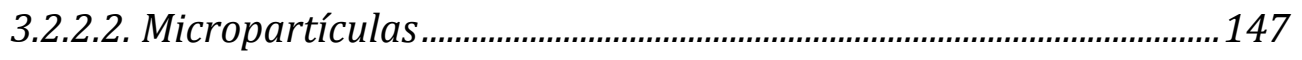

3.2.2 Estudio del comportamiento de las hMSCs in vitro en los distintos

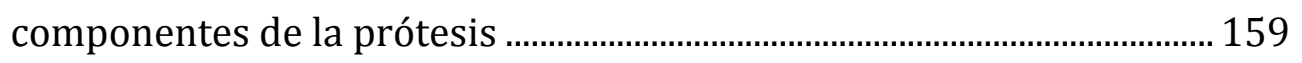

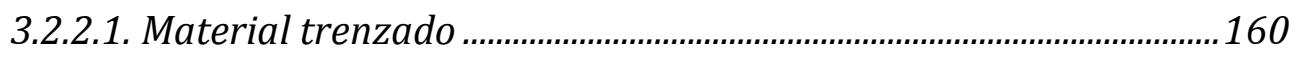

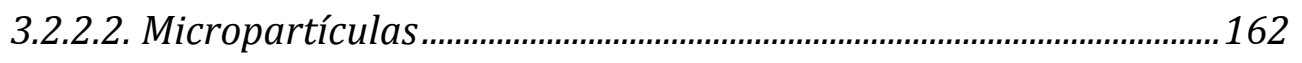

3.2.3 Estudio de diferenciación tenocítica................................................ 170

3.3 COMPORTAMIENTO BIOLÓGICO DEL PROTOTIPO DE PRÓTESIS EN RÉGIMEN ESTÁTICO Y DINÁMICO ............................................... 186

3.3.1 Verificación de la funcionalidad del biorreactor .............................. 187 
3.3.2 Estudio del comportamiento in vitro de las L929 en el prototipo de prótesis final 192

3.3.2.1 Ensayo de viabilidad y análisis morfológico del prototipo. ......192

3.3.2.2 Cultivo de fibroblastos en el prototipo de prótesis en régimen

estático y dinámico. 194

3.3.3 Estudio del comportamiento in vitro de $A D S C$ de oveja en el prototipo de prótesis 202

DISCUSIÓN FINAL 207

CONCLUSIONES 211

ABREVIATURAS

217

LISTADO DE FIGURAS

220

LISTADO DE TABLAS

233

REFERENCIAS

235 



\section{RESUMEN}

Los tendones son los encargados de transmitir las fuerzas del músculo al hueso. Estos tejidos poseen una actividad celular escasa y poca capacidad de regenerarse; por ello cuando sufren una lesión grave y parte del tejido se ha perdido, se requiere el uso de prótesis. Debido a los numerosos problemas que presentan las prótesis actuales, el gran reto de este trabajo ha sido el desarrollo de un nuevo concepto de prótesis tendinosa diseñada siguiendo las estrategias de la Ingeniería Tisular del tendón. El objetivo que persigue esta tesis es el diseño y fabricación de una prótesis biodegradable que cuente con las propiedades mecánicas y biológicas adecuadas que la hagan apta para la regeneración de cualquier tendón. Como el tejido del ligamento es muy similar al del tendón, esta prótesis podría ser también un punto de partida para una prótesis de ligamento.

El prototipo de prótesis consta de un trenzado hueco de ácido poliláctico (PLA), que reproduce el comportamiento mecánico del tendón natural. El hueco del trenzado va relleno de una combinación de micropartículas de ácido poli(L-láctico) PLLA y ácido hialurónico (HA), que sirven de soporte (scaffold) a las células que promoverán la regeneración del tejido. La parte exterior del trenzado lleva un recubrimiento de HA que evita las adherencias de la prótesis con los tejidos circundantes, permitiendo además, el suministro de nutrientes a las células del interior de la trenza. 
Para verificar que el nuevo concepto de prótesis era apto para la regeneración del tendón, los distintos componentes que forman la prótesis fueron inicialmente sintetizados y caracterizados física, mecánica y biológicamente. Se comprobó que las estructuras tridimensionales y los polímeros seleccionados mostraban adecuadas propiedades para la regeneración del tendón. Además fueron realizados cultivos de células madre mesenquimales provenientes de médula ósea humana sobre algunos de los soportes tridimensionales (micropartículas de PLLA y trenza) del prototipo, obteniendo como resultado la diferenciación de las células madre a tenocitos.

Por último, se caracterizó el comportamiento celular en el prototipo de prótesis y se comprobó que, una vez ensamblado (trenza con relleno de células más micropartículas) las células continuaban viables y proliferando. También se estudió el comportamiento celular en el prototipo de prótesis bajo un estímulo mecánico (régimen dinámico) durante 14 días. Para este ensayo se diseñó y fabricó un biorreactor capaz de transmitir estímulos de tracción al prototipo de prótesis evaluado. Al comparar la respuesta celular debida al estímulo mecánico con ensayos realizados en régimen estático se observó que el biorreactor afectaba positivamente el comportamiento de las células generando diferencias morfológicas, incrementando la producción de matriz extracelular, y estimulando además el alineamiento celular. Todos estos factores sugieren que el prototipo de prótesis diseñado 
aunado con un adecuado estímulo mecánico puede ser considerado una alternativa viable para estimular la regeneración tendinosa. 


\section{RESUM}

Els tendons són els encarregats de transmetre les forces del múscul a l'os. Aquests teixits posseeixen una activitat cel-lular escassa i poca capacitat de regenerar-se; a causa d'açò quan pateixen una lesió greu i part del teixit s'ha perdut, es requereix l'ús de pròtesis. A causa dels nombrosos problemes que presenten les pròtesis actuals, el gran repte d'aquest treball ha sigut el desenvolupament d'un nou concepte de pròtesi tendinosa dissenyada seguint les estratègies de l'Enginyeria Tissular del tendó. L'objectiu que persegueix aquesta tesi és el disseny i fabricació d'una pròtesi biodegradable que compte amb les propietats mecàniques i biològiques adequades que la facen apta per a la regeneració de qualsevol tendó. Com el teixit del lligament és molt similar al del tendó, aquesta pròtesi podria ser també un punt de partida per a una pròtesi de lligament.

El prototip de pròtesi consta d'un trenat buit d'àcid polilàctic (PLA), que reprodueix el comportament mecànic del tendó natural. El buit del trenat va farcit d'una combinació de micropartícules d'àcid poli(Llàctic) PLLA i àcid hialurònic (HA), que serveixen de suport (scaffold) a les cèl-lules que promouran la regeneració del teixit. La part exterior del trenat porta un recobriment d'HA que evita les adherències de la pròtesi amb els teixits circumdants, permetent a més, el subministrament de nutrients a les cèl-lules de l'interior de la trena. 
Per a verificar que el nou concepte de pròtesis era apte per a la regeneració del tendó, els diferents components que formen la pròtesi van ser inicialment sintetitzats i caracteritzats física, mecànica i biológicament. Es va comprovar que les estructures tridimensionals i els polímers seleccionats mostraven adequades propietats per a la regeneració del tendó. A més van ser realitzats cultius de cèl·lules mare mesenquimales provinents de medul·la òssia humana sobre alguns dels suports tridimensionals (micropartícules de PLLA i trena) del prototip, obtenint com resultat la diferenciació de les cèl-lules mare a tenocitos.

Finalment, es va caracteritzar el comportament cel·lular del prototip de pròtesis i es va comprovar que una vegada assemblat (trena amb farciment de cèl·lules més micropartícules), les cèl·lules continuaven viables i proliferant. També es va estudiar el comportament cel·lular en el prototip de pròtesi sota un estímul mecànic (règim dinàmic) durant 14 dies. Per a aquest assaig es va dissenyar i es va fabricar un biorreactor capaç de transmetre estímuls de tracció al prototip de pròtesi avaluat. En comparar la resposta cel·lular deguda a l'estímul mecànic amb assajos realitzats en règim estàtic es va observar que el biorreactor afectava positivament el comportament de les cèl-lules generant diferències morfològiques, incrementant la producció de matriu extracel-lular, i a més estimulant l'alineament cel·lular. Tots aquests factors suggereixen que el prototip de pròtesi dissenyat conjuminat amb un adequat estímul mecànic pot ser considerat una alternativa viable per a estimular la regeneració tendinosa. 


\section{ABSTRACT}

Tendons are responsible for transmitting the forces from muscle to bone. These tissues have a low cellular activity and reduced capacity for regeneration. Thus, when tendons suffer a serious injury and some tissue is lost, the use of prosthesis is required. The prosthesis currently available in the market show many problems. Hence, the great challenge of this work has been the development of a new concept of tendon prosthesis designed following the strategies of tissue engineering of tendon. The main objective of this thesis is the design and manufacture of a biodegradable prosthesis with the appropriate mechanical and biological properties that make it suitable for tendon regeneration. As ligament tissue is very similar to that of tendon, this prosthesis could be also a starting point for ligament prosthesis.

The tendon prototype prosthesis consists of a hollow braided polylactic acid (PLA), which reproduces the mechanical behaviour of natural tendon. This hollow braided is filled with a combination of microparticles of poly(L-lactide) PLLA and hyaluronic acid (HA), which acts as a hosting structure (scaffold) for the cells that will promote the tendon regeneration. The outer of the braid is covered with a HA coating in order to prevent adhesion of the prosthesis with the surrounding tissues, but also allowing the supply of nutrients to the cells inside of the braid. 
In order to verify that the new concept of prosthesis was suitable for tendon regeneration, the components of the prosthesis were synthesized and physical, mechanical and biologically characterized. In order to validate whether the properties of the components were adequate for tendon regeneration, analysis of the three-dimensional structures and polymers selected was performed. Mesenchymal stem cells from human bone marrow were seeded in vitro on some of the 3D components of the prototype (PLLA microparticles and braid), promoting stem cell differentiation to tenocytes.

Finally, cellular behaviour was characterized on the assembled prototype prosthesis (braid with microparticles and cells), showing that cells remained viable and proliferative. The cellular behaviour in the prototype of prosthesis under a mechanical stimulus (dynamic conditions) along 14 days was also studied. For this test a bioreactor capable of transmitting straightening stimulus to the evaluated prototype prosthesis was designed and manufactured. Comparison of the cellular response due to mechanical stimulation with appropriate tests under static conditions showed that the designed bioreactor positively affected the behaviour of cells generating morphological differences, increasing extracellular matrix production, and stimulating cell alignment. All these factors suggest that the prosthesis prototype designed can be considered a viable alternative to stimulate tendon regeneration. 

Capítulo 1 Introducción 



\subsection{FISIOPATOLOGÍA DEL TENDÓN Y TERAPIAS ACTUALES}

Los ligamentos y los tendones juegan un papel clave en la mecánica articular. Estas estructuras se caracterizan por la abundancia de haces de colágeno y una actividad celular escasa. Además poseen una estructura, una morfología y un comportamiento biomecánico muy similar. Este capítulo se va a centrar en describir brevemente el comportamiento biológico y mecánico de los tendones, así como su respuesta a una lesión y las terapias utilizadas actualmente.

\subsubsection{El tendón: estructura, composición y biomecánica}

\section{Estructura y composición}

El tendón es una estructura especializada del tejido conectivo denso regular situado entre el músculo y el hueso (Fig. 1.1). Es el responsable de la transmisión de las fuerzas del músculo al hueso, y al hacerlo, permite el movimiento y mejora la estabilidad de la articulación [1].

Desde el punto de vista macroscópico, los tendones sanos son blancos y brillantes, firmes al tacto pero flexibles. Su grosor, longitud y morfología varían en función de la potencia muscular y de su localización; así, los tendones cercanos al tronco son gruesos y cortos, mientras que los localizados en las zonas acras (como los de manos y pies) son tendones estrechos y muy largos. Microscópicamente, el 
tendón se compone principalmente de células (tenocitos) y de matriz extracelular compuesta de colágeno, elastina y sustancia fundamental.

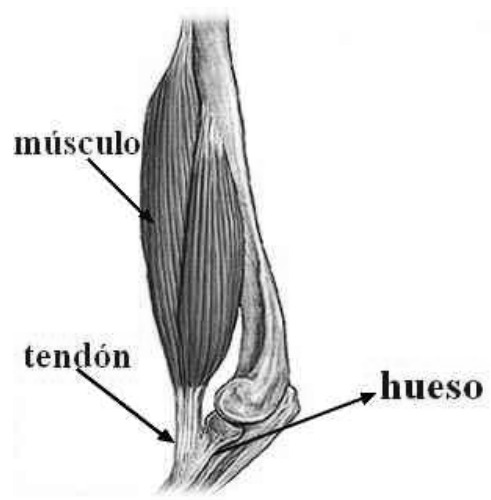

Fig. 1.1 Fijación del tendón al músculo y al hueso.

Los tenocitos son las células constituyentes del tejido tendinoso que producen todos los componentes extracelulares del tendón. Estas células son fibroblastos (células del tejido conectivo) adaptados en su morfología y función a las condiciones de vida que les brinda el tendón. Son poco numerosos, y su morfología es diversa: alargada, circular e incluso triangular, para adaptarse al espacio que les queda entre las fibras de colágeno. Las células tendinosas se ocupan de la formación y renovación tanto de la sustancia fundamental como de las fibras de colágeno gracias a la actuación de complejas vías metabólicas, que acontecen intracelular y extracelularmente.

La matriz extracelular constituye la mayor parte del volumen del tendón y proporciona la resistencia a la tracción y la flexibilidad propias 
de esta estructura anatómica. Considerando el peso en seco del tendón el colágeno está presente en un 75 a 90\%; la elastina fibrosa alrededor de un 2\%; y los mucopolisacáridos ácidos: ácido hialurónico y condroitínsulfato en un 1\% [2].

El colágeno como principal constituyente del tendón, está presente en diferentes tipos, siendo el más abundante el colágeno tipo I, el cual constituye el $95 \%$ del colágeno total. El 5\% restante pertenece al colágeno tipo III y al colágeno tipo V. Se trata de una proteína fibrosa, que tiene la propiedad del autoensamblaje, y que se presenta organizada en todos los niveles, desde el microscópico al macroscópico.

La unidad estructural del colágeno es el tropocolágeno, que a su vez proviene del procolágeno formado en el retículo endoplasmático rugoso de los tenocitos y está constituido por tres cadenas polipeptídicas, dos cadenas $\alpha 1$ y una cadena $\alpha 2$. En general, los aminoácidos que forman la cadena $\alpha$ siguen la secuencia, glicina-x-y, donde en la mayoría de los casos, " $\mathrm{x}$ " es prolina e " $y$ " hidroxiprolina; esta secuencia se repite una y otra vez. El procolágeno, en el aparato de Golgi, adquiere forma de hélice y posteriormente es transportado hasta la membrana celular, desde donde se secreta al exterior. En la matriz extracelular, el procolágeno se convierte en tropocolágeno insoluble. Finalmente, cinco moléculas de tropocolágeno se unen para formar la unidad estructural más pequeña del tendón, la microfibrilla (Fig. 1.2). 


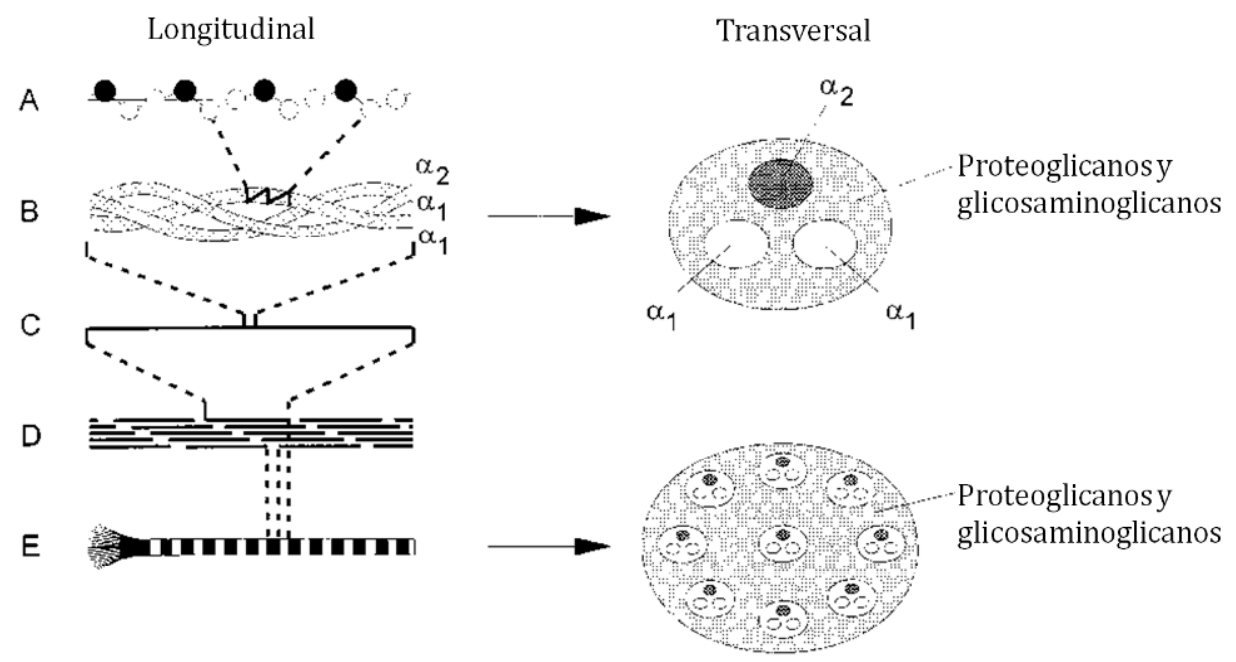

Fig. 1.2 Formación de una fibrilla de colágeno tipo I: A) aminoácidos unidos formando una cadena $\alpha$, donde la glicina ocupa la tercera posición (círculos en negro), B y C) tres cadenas $\alpha$ formando la triple hélice de la molécula de procolágeno. Estas cadenas están rodeadas por una fina capa de proteoglicanos y glicosaminoglicanos, D) el procolágeno se convierte en tropocolágeno que se une para formar microfibrillas, E) microfibrillas rodeadas por proteoglicanos y glicosaminoglicanos. (Figura modificada de [2])

Una vez formadas las microfibrillas, éstas se unen entre sí dando lugar a la fibrilla de colágeno. Las fibrillas, a su vez, se unen en haces para formar fibras, adoptando una estructura ondulada planar, y orientándose según la dirección de la carga cuando son sometidas a un esfuerzo. Estas fibras se unen en haces para formar fascículos, y estos a su vez se unen para dar lugar al tendón. Por lo tanto, los tendones están 
formados por haces densos de fibras que siguen un orden jerárquico específico que define su comportamiento mecánico [3] (Fig. 1.3).

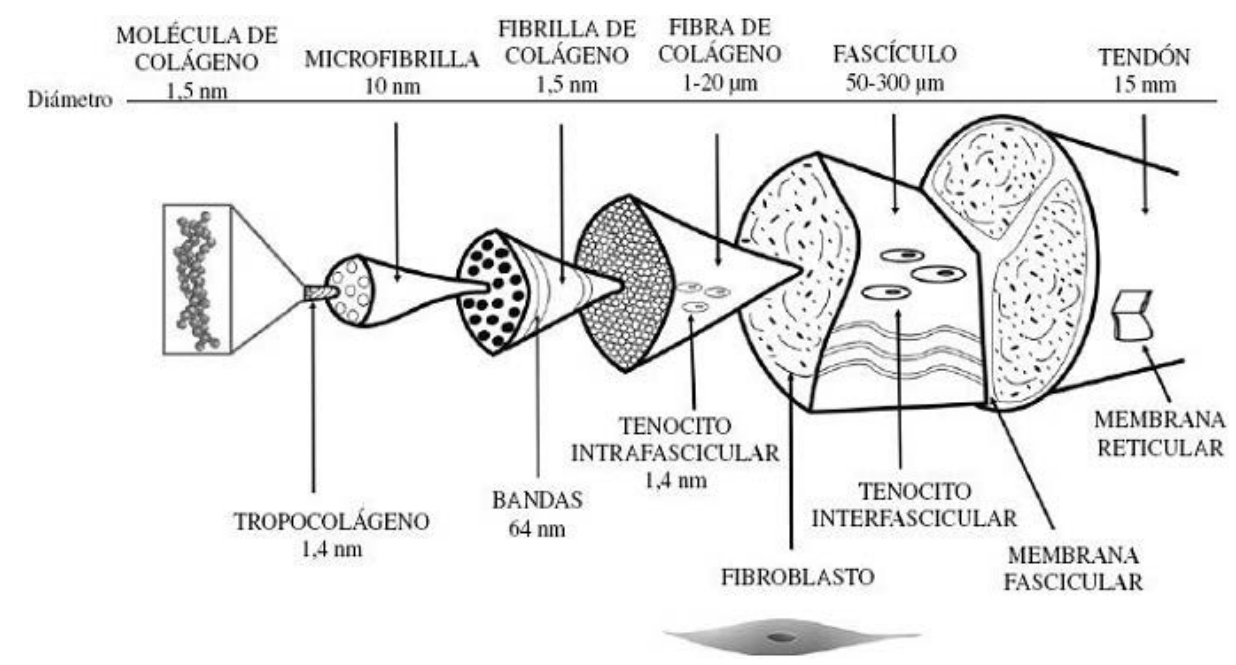

Fig. 1.3 Organización estructural y funcional del tendón [3].

Tal y como se muestra en la Fig. 1.4, el tendón se subdivide en haces de colágeno primarios que se agregan en grandes haces secundarios o fascículos. Tanto los haces primarios como los fascículos están rodeados de un tejido conjuntivo que recibe el nombre de endotendón. Este tejido transporta los vasos sanguíneos, los vasos linfáticos y los nervios hasta el tendón y a través del mismo. La superficie externa del tendón está cubierta por el epitendón, una capa fibrosa muy celular. Rodeando al tendón queda un tejido conjuntivo suelto, el paratendón, que contribuye al soporte vascular y permite el deslizamiento sobre los 
tejidos circundantes. En algunas áreas, como la vaina flexora de la mano, el paratendón se sustituye por una vaina sinovial, compuesta por dos capas distintas de células escamosas, separadas por un líquido sinovial viscoso que facilita la nutrición de los tendones. Esto constituye la diferencia entre los llamados tendones extrasinoviales y los tendones intrasinoviales (Fig. 1.4).

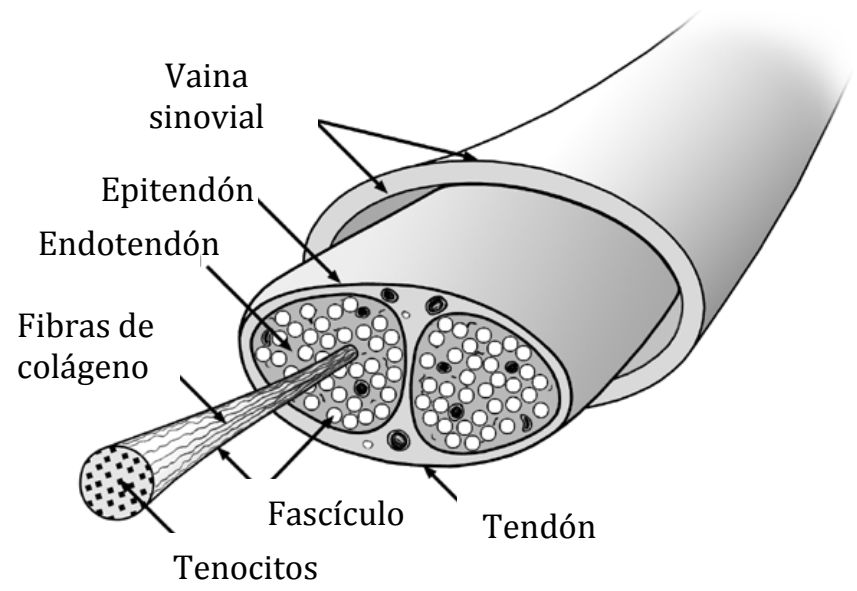

Fig. 1.4 Estructura del tendón. (Figura modificada [4])

La elastina es otro de los constituyentes de la matriz extracelular. Representa una pequeña, pero importante, parte del tendón normal (2\% de la masa seca del tendón) y es la responsable de su flexibilidad. La elastina es una proteína insoluble de gran estabilidad, rica en aminoácidos hidrófobos y que guarda una estrecha relación con el tenocito. Es el principal componente de las fibras elásticas. Se caracteriza por un alto contenido en aminoácidos apolares como la 
prolina y la valina y tiene un alto contenido en aminoácidos no cargados como la glicina [5]. Contiene además dos aminoácidos exclusivos: desmosina e isodesmosina, que se encargan de formar los enlaces covalentes que unen las moléculas de elastina entre sí. Posee una gran extensibilidad recuperable que parece que es fundamental en el proceso de recuperación de las deformaciones sufridas por los haces de colágeno.

El tercer componente importante que forma parte de la matriz extracelular del tendón es la denominada sustancia fundamental, la cual rodea las células y las fibras del tendón. Es histológicamente amorfa, es decir carece de estructura, y está constituida por distintos proteoglicanos (macromoléculas complejas, constituidas por un eje proteico de longitud variable), a los que se unen covalentemente cadenas de glicosaminoglicanos (polímeros lineales de unidades repetidas de disacáridos), fundamentalmente: ácido hialurónico, condroitínsulfato 4 y 6 . La hidrolización de los grupos carboxílicos de los ácidos urónicos y del sulfato de la condroitina, junto con la presencia de enlaces cruzados constituye una malla tridimensional en la que queda atrapada el agua, formando un gel por el que difunden nutrientes y desechos celulares.

Los proteoglicanos se presentan en pequeñas cantidades, siendo su contenido variable según la ubicación del tendón y de las condiciones de carga que soporta. Dentro de los proteoglicanos existentes se puede encontrar agrecanos y decorina. Los agrecanos retienen el agua dentro 
del fibrocartílago y ayudan a soportar las fuerzas de compresión. La decorina, representa la mayor parte de proteoglicanos del tendón y se caracteriza por poseer una región rica en leucina, con una cadena de glicosaminoglicanos que bien puede ser del tipo condroitín sulfato o bien del tipo dermatán sulfato. La decorina se encuentra en la superficie de las porciones medias de las fibrillas de colágeno y se cree que facilita el deslizamiento durante la deformación mecánica fibrilar [6].

Además existen varias glicoproteínas presentes en la matriz extracelular del tendón, como son la fibronectina y la tenascina C. La fibronectina se encuentra en la superficie de colágenos, y su síntesis aumenta para facilitar la curación de heridas. La tenascina $\mathrm{C}$, es una proteína que se encuentra alrededor de las células y las fibras de colágeno del tendón. Contribuye a la estabilidad mecánica de la matriz extracelular a través de su interacción con las fibrillas de colágeno y es más abundante en las zonas de unión del tendón: las uniones osteotendinosas y miotendinosas [7].

\section{Biomecánica del tendón}

Una vez conocida la estructura y la composición del tendón es importante conocer su comportamiento biomecánico. Los tendones actúan como un muelle que almacena la energía del movimiento, y transfieren eficientemente la fuerza hasta el hueso con una pérdida de energía mínima. La respuesta mecánica del tendón a las fuerzas es 
variable y por ello, la mecánica tendinosa debe ser considerada para cada tendón en particular.

Gracias a la sustancia fundamental, los tendones son estructuras que siguen un comportamiento viscoelástico. Estas características mecánicas de los tendones se pueden expresar en términos de tensióndeformación. La relación entre la tensión y la deformación está bien descrita por la curva tensión-deformación de la Fig. 1.5, en donde se observan tres zonas distintas [1]:

- Región pie o zona toe (en inglés), en la que se observa la absorción inicial de la fuerza y representa el estiramiento de la ondulación del tendón. Esta ondulación de las fibras afecta a las propiedades mecánicas del tendón, observándose que fibras con poco ángulo de ondulación fallan antes que las que presentan mayor ángulo de ondulación [8]. En esta zona, el tendón sufre una elongación inicial, una deformación del 2-3\% de su longitud. Es una zona de bajo módulo, donde el tendón sigue un comportamiento de un material elástico y las fibras de colágeno se van estirando y se recuperan una vez ha desaparecido la fuerza.

- Región lineal, es la parte de la curva donde las fibras pierden su ondulación. La pendiente de esta zona se corresponde con el módulo de Young del tendón. En esta región lineal, el comportamiento mecánico del tendón está gobernado esencialmente por el estiramiento de las fibras de colágeno. Si las tensiones sobrepasan el rango fisiológico, las fibras empiezan a sufrir las primeras microroturas. 


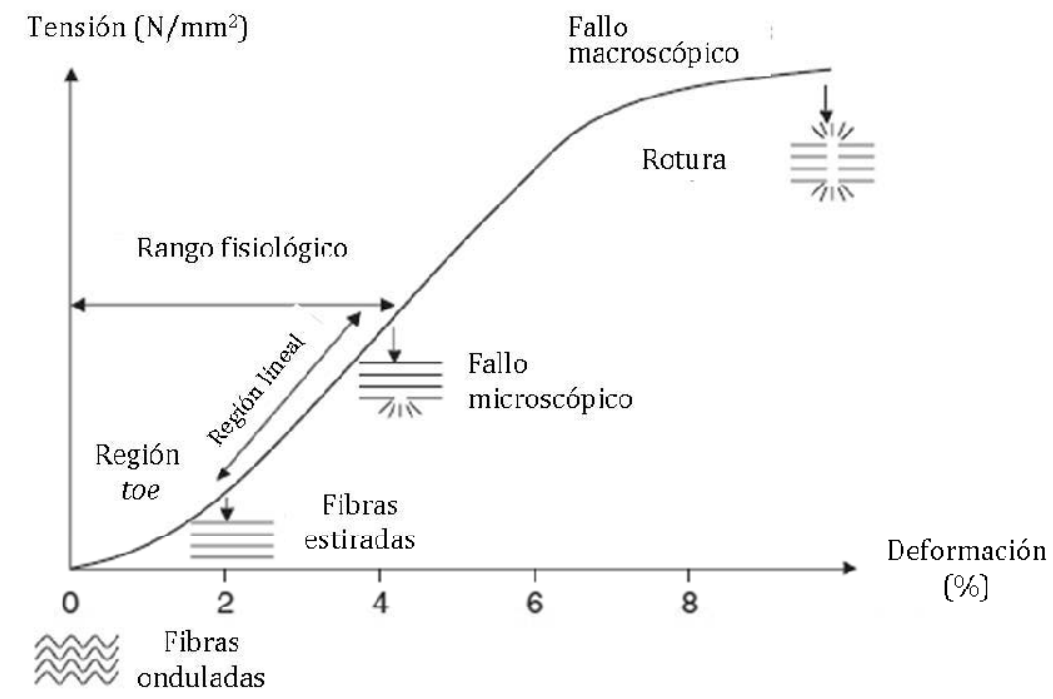

Fig. 1.5 Curva típica de tensión-deformación de un tendón [1].

- Región de rotura, en esta zona se observa una progresiva elongación del tejido ante mínimas fuerzas de tracción. Esto ocurre por haber llegado a la máxima capacidad de las propiedades biomecánicas de elasticidad, plasticidad y viscosidad del tejido. A partir de aquí aparece la rotura de las fibras.

En resumen, un tendón sometido a solicitaciones de tensión sigue en primer lugar un comportamiento de tipo elástico hasta alcanzar una elongación aproximada entre 2\% y 3\%. A continuación, en la segunda parte de la curva, se necesita grandes tensiones para provocar pequeñas deformaciones en el tejido, y por último, la rotura del tendón, 
que se produce entre los 3 y 11,5 $\mathrm{Kg} / \mathrm{mm}^{2}$, dependiendo de cada uno de los tendones. Las fuerzas fisiológicas a las que está sometido el tendón durante su actividad músculotendinosa habitual se encuentra dentro de la primera y parte de la segunda región de la curva tensióndeformación pudiendo alcanzar valores de entre 6-8\% de deformación [9].

\subsubsection{Nutrición, inervación y cicatrización tendinosa}

\section{Nutrición}

El tendón es una estructura relativamente avascular, pero la cantidad de vasos que contiene es suficiente para sus necesidades metabólicas. La irrigación del tendón puede provenir de tres puntos: la unión miotendinosa o proximal, la unión osteotendinosa o distal y los vasos del tejido conjuntivo circundante. La unión miotendinosa es una zona especializada que permite la transmisión de la fuerza, del cambio de flexibilidad y del tamaño tisular, estos cambios hacen que sea una zona vulnerable a las lesiones, denominadas distensiones musculares. En esta zona la vascularización se origina a nivel de la unión músculotendinosa de arterias musculares y vasos procedentes de la reflexión de la vaina tendinosa. Otra de las zonas de vascularización, es la unión osteotendinosa, que penetra a nivel de las inserciones periósticas del tendón. En esta zona se produce la inserción del tendón en el hueso (éntesis) y es un punto donde se produce un cambio gradual en las características mecánicas desde el tendón flexible hasta el hueso rígido. 
Se han descrito dos tipos de éntesis: la éntesis fibrocartilaginosa y la éntesis fibrosa. En esta zona, el tendón se transforma gradualmente en hueso a través de una secuencia de capas, desde tendón normal hasta fibrocartílago, después a fibrocartílago mineralizado y finalmente a hueso. Por último la irrigación puede producirse desde los vasos del tejido conjuntivo circundante [10].

Hay que señalar que, en función del tipo de tendón, se pueden diferenciar en general dos patrones vasculares; uno para tendones extrasinoviales y otro para tendones intrasinoviales. En los tendones extrasinoviales como en el caso del tendón de Aquiles y el tendón patelar, entre otros, presentan una buena vascularización y los vasos llegan por todos los puntos de su circunferencia y recorrido. Para los intrasinoviales, como los flexores de los dedos de las manos, la vascularización es más pobre y se realiza dentro de la vaina tendinosa por una serie de vínculas (plieges del mesotendón portadores de vasos)[11].

\section{Inervación}

El tendón como estructura altamente especializada biomecánicamente, necesita sensores adecuados y por tanto está abundantemente inervado. Dispone fundamentalmente de cuatro tipos de formaciones nerviosas: corpúsculos de Ruffini, que son receptores de presión y reaccionan lentamente a los cambios de presión; corpúsculos de Paccini, que también reaccionan a la presión pero son 
de adaptación rápida, ya que intervienen en la detección de movimientos de aceleración y desaceleración; terminaciones de Golgi, que son mecanoreceptores colocados en serie, relacionados con el estiramiento y tensión del tendón y distribuidas por todo el tendón predominando a nivel de la unión miotendinosa; y las terminaciones nerviosas libres, que son receptores del dolor de adaptación lenta. La mayoría de las terminaciones nerviosas aferentes, también conocidas como receptoras, se sitúan en la unión miotendinosa. Por lo tanto, la inervación de la porción intermedia del tendón puede ser mínima y puede comprometer la detección de procesos patológicos [12].

Tanto la vascularización como la inervación del tendón son importantes para que se produzca una correcta cicatrización y regeneración del tejido tendinoso tras una lesión.

\section{Cicatrización tendinosa}

Fisiológicamente, cuando se produce una lesión tendinosa, el cuerpo inicia una cascada de acontecimientos para reparar el tejido dañado que implica tres etapas: la inflamación del tejido, la reparación y la remodelación (Fig. 1.6). 


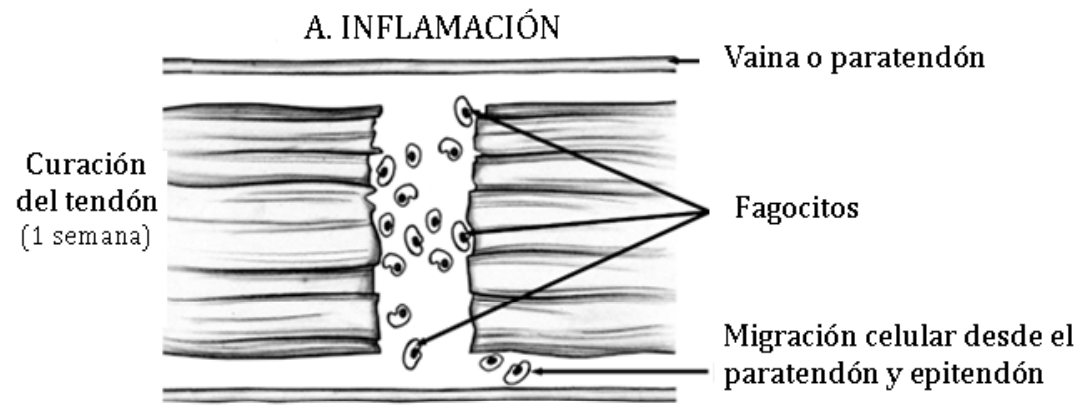

Tendón inmovilizado

B. REPARACIÓN

Tendón movilizado
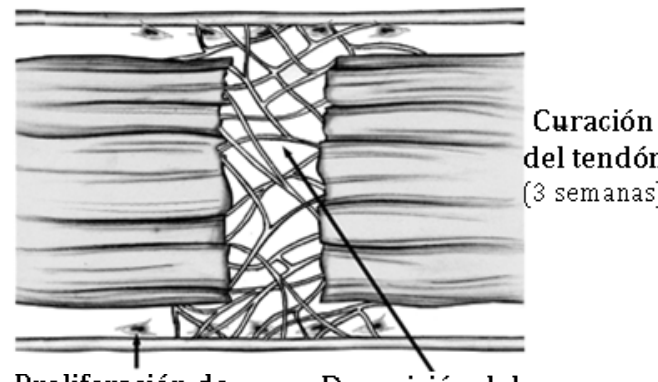

Proliferación de Deposición del

fibroblastos desde el colágeno al azar paratendón o de la vaina C. REMODELACIÓN

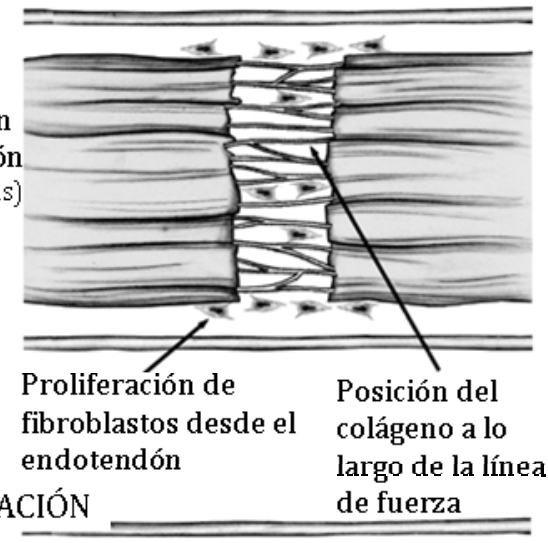

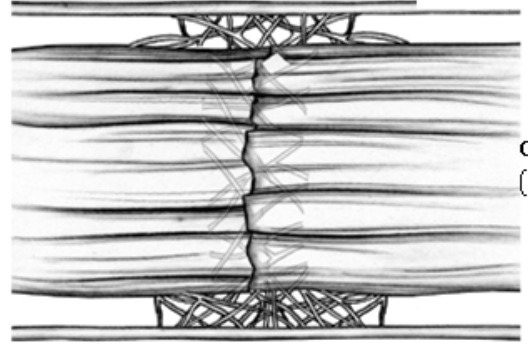

Curación con adherencias

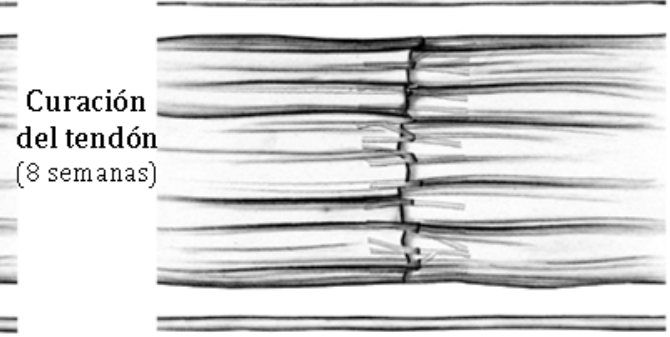

Curación sin adherencias

Fig. 1.6 Fases de la curación natural del tendón. (Figura modificada [4]) 
En la primera etapa, la inflamación, una vez formado el hematoma se activa la liberación de agentes quimiotácticos que atraen a células inflamatorias que migran hacia la zona lesionada. Estas células proceden del tejido circundante lesionado y de células intrínsecas que surgen de la proliferación de células del epitendón. Estas células migran a la laceración y comienzan a sintetizar diversos componentes de la matriz extracelular. Además se produce un aumento en la actividad fagocítica mejorando la eliminación de los restos celulares. En la siguiente etapa, la reparación, se continúa con el reclutamiento de los fibroblastos, los cuales sintetizan colágeno, proteoglicanos y otros componentes de la matriz extracelular de manera desorganizada y se liberan factores de crecimiento. Al final de esta fase, el tejido contiene grandes cantidades de células, agua y matriz extracelular. La última fase, la remodelación, comienza a las 6-8 semanas después de la lesión. Esta fase se caracteriza por una disminución de células y contenido vascular, una reorganización de las fibras de colágeno, disminuyendo la cantidad de colágeno III y aumentando el colágeno I y por la síntesis de componentes de la matriz extracelular como la decorina, los agrecanos y los biglicanos [4].

Actualmente no existe un acuerdo total respecto a la procedencia de los fibroblastos responsables de la cicatrización tendinosa. Existen distintas teorías sobre el origen de las células responsables de la cicatrización existiendo tres posibles casos: la cicatrización extrínseca, la cicatrización intrínseca y la cicatrización mixta. La teoría de la 
cicatrización extrínseca sostiene, que debido a la falta de capacidad interna a sanar por sí mismo, el tendón dañado requiere la formación de adherencias, siendo éstas inevitables y necesarias para su cicatrización. La teoría de la cicatrización intrínseca argumenta que las adherencias no son necesarias para la obtención de una cicatriz adecuada. Sostiene que se produce una emigración celular desde el epitendón hacia el interior de la zona lacerada a lo largo de un lecho de fibrina mientras las fibras de colágeno, formadas por los fibroblastos del endotendón y epitendón, son capaces de establecer un puente en el sitio de laceración, bastándose para permitir una cicatrización adecuada. Por último, la teoría de la cicatrización mixta supone la posibilidad de una combinación de ambos procesos de cicatrización. Así, en primer lugar, se efectuaría una proliferación de células extrínsecas para posteriormente, a partir del cuarto día, producirse una proliferación de células del tendón $[11,13]$.

Independientemente de la teoría de la cicatrización, diversos estudios clínicos [14], han demostrado que tal y como se observa en la Fig. 1.6, la movilización temprana en la fase de reparación del tendón mejora significativamente el proceso de curación y cicatrización evitando adherencias. Los tendones movilizados muestran una mejora en la alineación de colágeno, en las células y en el aumento de tensión de rotura del tejido cicatrizado. No ocurre lo mismo en el caso de los tendones inmovilizados, donde se produce una desorganización de las 
fibrillas de colágeno y por lo tanto una disminución de la tensión en la zona cicatrizada, además de producirse adherencias en la superficie.

Es importante señalar que durante la fase de reparación varios factores de crecimiento están implicados en la activación y regulación de la respuesta celular. Los factores de crecimiento más importantes asociados a la formación y regeneración del tendón descritos por Molloy et al. [15] son:

\begin{tabular}{|c|c|}
\hline Fact & Función \\
\hline $\begin{array}{l}\text { TGF- } \beta \text { s, factor de } \\
\text { crecimiento transformante } \beta \text {. }\end{array}$ & $\begin{array}{l}\text { Promueve la proliferación, la migración, } \\
\text { la adhesión celular y la producción de } \\
\text { colágeno. }\end{array}$ \\
\hline $\begin{array}{l}\text { IGF-I, factor de crecimiento } \\
\text { insulínico. }\end{array}$ & $\begin{array}{l}\text { Estimula la producción de matriz } \\
\text { extracelular y promueve la proliferación } \\
\text { y la migración celular. }\end{array}$ \\
\hline $\begin{array}{l}\text { PDGF, factor de crecimiento } \\
\text { derivado de plaquetas. }\end{array}$ & $\begin{array}{l}\text { Regula la síntesis de proteínas y de ADN } \\
\text { en el sitio de la lesión y regula la } \\
\text { expresión de otros factores de } \\
\text { crecimiento. }\end{array}$ \\
\hline $\begin{array}{l}\text { VEGF, factor de crecimiento } \\
\text { endotelial vascular. }\end{array}$ & Promueve la angiogénesis. \\
\hline $\begin{array}{l}\text { bFGF, factor de crecimiento } \\
\text { fibroblástico. }\end{array}$ & $\begin{array}{l}\text { Promueve la migración celular y la } \\
\text { angiogénesis. }\end{array}$ \\
\hline $\begin{array}{l}\text { BMPs, proteínas } \\
\text { morfogenéticas óseas. }\end{array}$ & $\begin{array}{l}\text { Estimula la proliferación, la producción } \\
\text { de matriz extracelular y los marcadores } \\
\text { relacionados con la tendogénesis. }\end{array}$ \\
\hline
\end{tabular}

Tabla 1.1 Factores de crecimiento relacionados con la formación del tendón. 
Del mismo modo, estos factores de crecimiento regulan la expresión de genes específicos que sirven de marcadores de la tendogénesis como [16]:

\begin{tabular}{|l|l|}
\hline Marcadores específicos & \multicolumn{1}{|c|}{ Función } \\
\hline Escleraxis & $\begin{array}{l}\text { Proteína que se produce durante la } \\
\text { diferenciación del tenocito. }\end{array}$ \\
\hline Smad8 & Involucrado en la diferenciación tenocítica. \\
\hline Tenomodulina & $\begin{array}{l}\text { Glucoproteína transmembrana que regula } \\
\text { la proliferación, la diferenciación celular, y } \\
\text { la maduración de las fibrillas de colágeno. }\end{array}$ \\
\hline Decorina & $\begin{array}{l}\text { Promueve el proceso de fibrilogénesis } \\
\text { uniéndose a las fibrillas de colágeno tipo I, } \\
\text { jugando un importante papel en el } \\
\text { ensamblaje de la matriz extracelular. }\end{array}$ \\
\hline Tenascina & $\begin{array}{l}\text { Proteína de la matriz extracelular que se } \\
\text { expresa durante el desarrollo embrionario } \\
\text { yen el desarrollo del tendón. }\end{array}$ \\
\hline Fibromodulina & $\begin{array}{l}\text { Facilita la formación de las fibras de } \\
\text { colágeno. }\end{array}$ \\
\hline Colágeno I & $\begin{array}{l}\text { Proporciona fuerza al tejido. } \\
\text { Promueve la fibrilogénesis del colágeno } \\
\text { tipo I. }\end{array}$ \\
\hline Colágeno III & S
\end{tabular}

Tabla 1.2. Moléculas asociadas en el desarrollo y formación del tendón.

Una vez expuestas las características fisiológicas y mecánicas requeridas para mantener el buen desempeño de los tendones, se presentan en la siguiente sección, las alteraciones que pueden afectar al 
tejido tendinoso y las soluciones que se han adoptado para mejorar la calidad de vida de las personas que las padecen.

\subsubsection{Tendinopatías}

Las tendinopatías se definen como el conjunto de patologías que afectan a la estructura tendinosa. Este tipo de lesiones son muy comunes entre la población adulta y afectan a la calidad de vida de las personas que las padecen [17]. Se dividen en las siguientes categorías:

- Paratendonitis, es la inflamación aislada del paratendón debido a un conflicto entre el tendón y el tejido de deslizamiento.

- Tendinosis, es un proceso degenerativo intratendinoso por atrofia.

- Paratendonitis con tendinosis, es una inflamación del paratendón con degeneración intratendinosa.

- Tendinitis, es la degeneración sintomática del tendón con rotura tendinosa y vascular y respuesta inflamatoria de reparación.

Los síntomas comunes generados en estas lesiones provocan dolor, pérdida de fuerza, disfunción, sensibilidad local y posibles hematomas, entre otras afecciones. 
Las lesiones tendinosas se clasifican generalmente en agudas y crónicas: las lesiones tendinosas agudas ocurren de forma repentina y tienen una causa o un comienzo claramente definidos. Se producen principalmente por una contusión, un traumatismo, una herida con un objeto punzante, mediante lesiones deportivas, etc. Las lesiones crónicas, se desarrollan de forma gradual y son a menudo el resultado de la sobrecarga de una tensión aguda y microtraumatismos repetitivos por el sobreuso [13]. Las lesiones pueden originarse por factores de riesgo intrínsecos como: irregularidades anatómicas, genéticas, la edad, enfermedades degenerativas, etc. y/o por factores extrínsecos como la dieta, accidentes, movimientos repetitivos en el puesto de trabajo, deporte, malas posturas corporales, etc. [18].

\subsubsection{Soluciones terapéuticas}

La terapia aplicada en una lesión tendinosa dependerá del grado de dicha lesión. Como se ha nombrado anteriormente, las lesiones tendinosas se clasifican en lesiones tendinosas agudas y crónicas. Estas lesiones pueden tratarse mediante tratamientos convencionales o mediante tratamientos quirúrgicos. Dentro de los tratamientos convencionales cabe mencionar el uso de antiinflamatorios, de analgésicos, inyección de corticoides, de ejercicios fisioterapéuticos, de ultrasonidos, de crioterapia, de refuerzo muscular y estiramientos, entre otros. El tratamiento inicial suele ser un tratamiento 
convencional. Estos tratamientos brindan un alivio meramente sintomático, siendo necesaria la cirugía si la patología persiste.

En las lesiones donde se ha perdido parte del tejido, los injertos biológicos pueden ser necesarios para reemplazar los tendones dañados. Sin embargo, en la mayoría de los casos, los injertos no proporcionan una resistencia mecánica adecuada durante el proceso de remodelación. Los autoinjertos son una metodología utilizada actualmente para reparar el tendón afectado aunque pueden provocar la morbilidad y la discapacidad funcional en la zona de la extracción. Los aloinjertos son también terapias alternativas para la reparación del tendón pero presentan serias limitaciones debido a la escasez de donantes de tejidos, la posibilidad de reacciones inmunes o la posibilidad de transferencia de agentes patógenos $[19,20]$.

Otra de las soluciones terapéuticas utilizadas con mayor frecuencia desde hace décadas son las prótesis. En la actualidad, existen prótesis comerciales para tendón y ligamento provenientes de fuentes biológicas (Tabla 1.3). Las complicaciones más comunes encontradas en los estudios clínicos realizados con estas prótesis han sido rechazos, derrames y respuestas inflamatorias. 


\begin{tabular}{|c|c|c|}
\hline Prótesis biológicas & Fuente & Referencia \\
\hline Restore $^{\mathrm{TM}}$ & Submucosa intestinal porcina & {$[21]$} \\
\hline CuffPatch $囚$ & Submucosa intestinal porcina & {$[22]$} \\
\hline GraftJacket@ & Dermis de cadáver humano & [23] \\
\hline Zimmer ${ }^{\circledR}$ o Permacol ${ }^{\mathrm{TM}}$ & Dermis porcina & {$[24]$} \\
\hline TissueMend® & Dermis fetal de bovino & [25] \\
\hline OrthADAPT® & Pericardio equino & [26] \\
\hline
\end{tabular}

Tabla 1.3. Prótesis biológicas comerciales.

Debido a estos inconvenientes, también existen en el mercado diversas prótesis sintéticas de tipo no absorbibles como Gore-Tex®

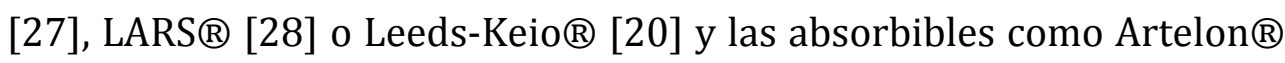
y Sportmesh ${ }^{\mathrm{TM}}$. Aunque estos productos a corto plazo muestran resultados satisfactorios, estudios a largo plazo revelan muchas complicaciones asociadas a infecciones, rupturas, rigidez o incremento de laxitud. El principal problema de una prótesis sintética permanente donde no hay regeneración del tejido es que con el tiempo, se produce un fallo mecánico. Cuando se compara la calidad de los tendones reparados quirúrgicamente, con la de los tendones sanos, se observa que los primeros están funcionalmente debilitados. Esto implica un mayor riesgo de fallo mecánico y la posible recurrencia de una segunda cirugía [29]. Por estas razones, la Ingeniería Tisular se presenta como una alternativa a emplear para obtener substitutos de tendones que 
puedan restaurar las características estructurales y las funciones fisiológicas del tejido natural.

\subsection{INGENIERÍA TISULAR DEL TENDÓN}

Una vez estudiada la composición y la biomecánica del tendón, así como las lesiones y las terapias actuales utilizadas para la reparación de estos tejidos, en esta sección, se va a presentar las diferentes estrategias que plantea la ingeniería tisular del tendón para mejorar la reparación y regeneración de estos tejidos. Antes de centrarnos en las distintas estrategias de la ingeniería tisular del tendón, se hará una breve introducción de la ingeniería tisular.

\subsubsection{La ingeniería tisular}

Es un campo interdisciplinar que aplica los principios de la ingeniería y de la biología para el desarrollo de sustitutos biológicos que restauren, mantengan o mejoren la función tisular [30]. La ingeniería tisular se constituye en una terapia que utiliza como principales componentes la combinación de células, biomateriales y factores bioquímicos para reparar tejidos lesionados o enfermos (Fig. 1.7). 


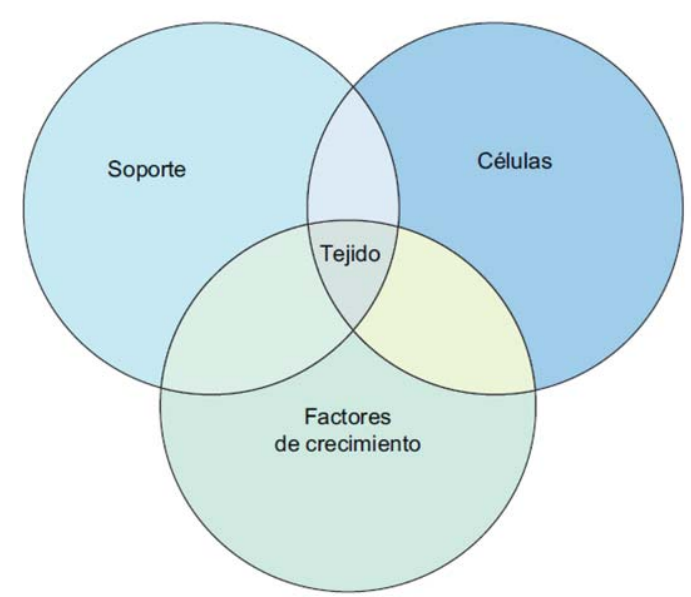

Fig. 1.7 Principales componentes de la ingeniería tisular [31].

Las estrategias que adopta la ingeniería tisular se pueden clasificar en tres grupos: (a) la implantación de células aisladas o de células sustitutas dentro del organismo; (b) la liberación de sustancias que induzcan la regeneración de tejido; y (c) un aporte celular en el interior de una matriz utilizada como soporte o scaffold.

Con respecto a la primera estrategia, la implantación de células, la ingeniería tisular se centra en el uso de las células madre. Estas células son capaces de dividirse y diferenciarse a distintos tipos de células especializadas, no sólo morfológicamente sino también de forma funcional (Fig. 1.8). Estas células se pueden clasificar según su potencial de diferenciación en: células madre totipotenciales, las cuales son capaces de producir tejido embrionario y extraembrionario; células madre pluripotenciales que tienen la habilidad de diferenciarse a 
tejidos procedentes de cualquiera de las tres capas embrionarias; y las células madre multipotenciales, que son capaces de diferenciarse a distintos tipos celulares procedentes de la misma capa embrionaria [32].

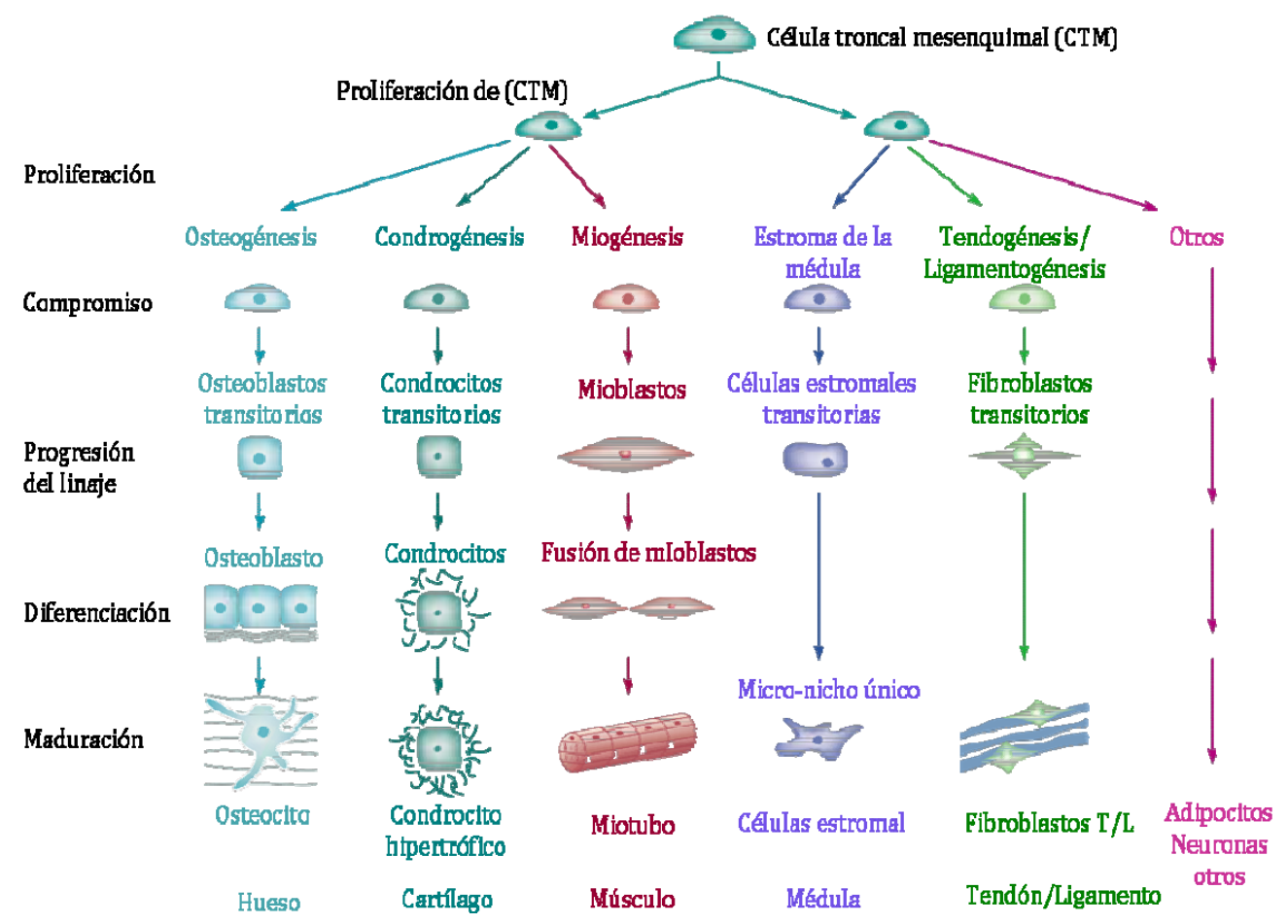

Fig. 1.8 Diferenciación de células madre mesenquimales en múltiples linajes mesodérmicos. (Figura modificada [33])

Las células madre mesenquimales adultas (MSC) son más utilizadas que las células madre embrionarias pues, no plantean ninguna barrera ética ya que se encuentran en muchos puntos del organismo, tales como la médula ósea, el tejido adiposo, la placenta, el ligamento periodontal, 
el periostio y el hueso trabecular, entre otros. Además no tienen problemas inmunológicos y han demostrado una efectividad superior a las células embrionarias [34].

Sin embargo, no se dispone de unos criterios fenotípicos bien definidos que caractericen a las MSC. No se conoce que un marcador de superficie único identifique correctamente y con seguridad a estas células. Por ello, es necesario efectuar tinciones fenotípicas, positivas y negativas, que permitan identificar a estas células. Las $M S C$ expresan varios tipos de marcadores de superficie como: CD9, CD10, CD13, CD44, CD54, CD55, CD90, CD105, CD166, D7-FIB y son negativas para los marcadores: CD14, CD34, CD45 y CD133 [34].

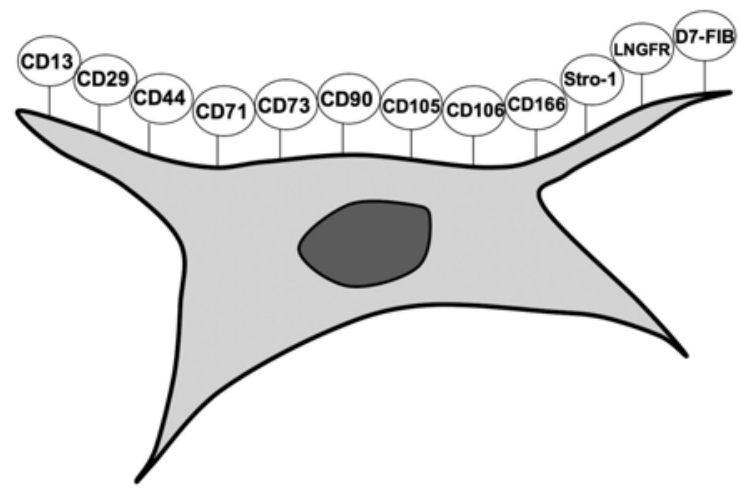

Fig. 1.9 Proteínas de superficie positivas que expresan las células mesenquimales [34].

Las MSC provenientes de médula ósea y del tejido adiposo son fuentes celulares muy utilizadas en terapias para la regeneración de tendones y ligamentos [35], hueso y cartílago [36], entre otros. El tejido 
adiposo puede disponerse en grandes cantidades a través de una liposucción. Los depósitos subcutáneos de tejido adiposo son accesibles, abundantes y renovables, por lo que suponen una reserva potencial de células madre adultas en cada individuo.

Otra de las estrategias utilizadas en la ingeniería tisular es el uso de los factores de crecimiento. Son sustancias de naturaleza polipeptídica secretadas por las células, cuya función forma parte de la inmensa red de comunicaciones intercelulares actuando en puntos críticos como: la división celular, la síntesis de matriz y la diferenciación tisular. Los factores de crecimiento inician su acción mediante la unión a su receptor en la superficie de la célula diana. Dependiendo de la proximidad entre los lugares de síntesis y de acción, los factores de crecimiento se clasifican en autocrinos (el factor de crecimiento actúa sobre la misma célula que lo segrega); endocrinos (el factor actúa en una célula que es diferente en el fenotipo y está distante); y paracrinos (el factor influye sobre la célula cercana con diferente fenotipo). Por consiguiente, un factor de crecimiento puede tener efecto en múltiples tipos de células e inducir diferentes funciones celulares en una gran variedad de tejidos $[37,38]$. Los factores de crecimiento más implicados en la proliferación celular y en la reparación de los tejidos se encuentran recogidos en la Tabla 1.1 citada anteriormente. 
Tanto las células como los factores de crecimiento pueden estar combinados en el interior de un scaffold siendo esta estrategia la que más se asocia con el concepto de ingeniería tisular. Es decir, la combinación de células vivas sembradas en un scaffold para reproducir una estructura tridimensional que sea funcional y semejante al tejido que debe reemplazar [39].

El scaffold es una estructura tridimensional que juega un papel muy importante en la regeneración de los tejidos y debe desempeñar todas o algunas de las funciones siguientes: a) promover las interacciones células-biomaterial, la adhesión celular y la producción de matriz extracelular; b) permitir el transporte de nutrientes, gases, células y factores de regulación tanto dentro del scaffold como entre éste y el medio circundante para favorecer la supervivencia, la proliferación y la diferenciación celular; c) debe tener una biodegradabilidad controlada que se aproxime a la tasa de regeneración del tejido; y d) debe provocar un grado mínimo de inflamación o toxicidad in vivo [40]. Para que estas funciones se desempeñen de forma satisfactoria, el scaffold debe desarrollarse con las características más adecuadas según su aplicación, siendo fácilmente controlables y reproducibles en scaffolds poliméricos de origen natural o sintético [41]. Las características que deben poseer los scaffolds son [42]: 
o Biodegradabilidad ajustable con la tasa de degradación.

o Biocompatibilidad antes, durante y después de la degradación.

o Buenas propiedades mecánicas y mantenimiento de la resistencia mecánica durante el proceso de regeneración de los tejidos.

o Biofuncionalidad: capacidad para soportar la proliferación y diferenciación celular, secreción de la matriz extracelular y formación de tejido.

o Procesabilidad: capacidad de ser procesados para formar arquitecturas apropiadas según su destino.

Existen numerosos métodos de fabricación de scaffolds, los cuales dependen de la estructura tridimensional deseada. Para la obtención de estructuras esféricas tipo micropartículas se han desarrollado diferentes metodologías: el método de evaporación/extracción del solvente [43], el secado por atomización (spray-drying) [44, 45] y la coacervación o separación de fases [46]. Para la fabricación de scaffolds nanofibrosos, la técnica más empleada y con resultados más prometedores es la de electrospinning [47, 48]. Entre las técnicas utilizadas para elaborar estructuras tridimensionales con elevada porosidad y poros interconectados se encuentra: la evaporación del solvente [49], la eliminación del porógeno [50], el espumado [51] y la extracción del solvente en frío [52]. En ingeniería tisular también se emplean hidrogeles biodegradables que se obtienen mediante 
reticulación a través de enlaces covalentes o mediante entrecruzamientos físicos [53].

Una vez descrito los principios en que se basa la ingeniería tisular, en la siguiente sección se expondrán las estrategias desarrolladas por la ingeniería tisular para la regeneración del tendón. Estas estrategias surgen en respuesta a dos necesidades importantes: 1) mejorar los tratamientos actuales que se aplican en las lesiones tendinosas y 2) encontrar un sustituto funcional de tendón que sea viable.

\subsubsection{Estrategias de la ingeniería tisular del tendón}

La ingeniería tisular del tendón ha desarrollado diferentes estrategias con el objetivo de lograr la recuperación de estos tejidos lesionados. Para ello se estableció como punto de partida el uso de una pequeña porción de tejido del donante como una fuente de células, las cuales se aíslan y se expanden a un número clínicamente significativo. Estas células una vez aisladas se pueden inyectar en la zona afectada, cuando la lesión tendinosa lo permite. También se puede estimular la regeneración del tejido dañado activando la producción de señales bioquímicas de estas células mediante el uso de factores de crecimiento, o alternativamente estas células expandidas pueden cultivarse en un scaffold para obtener sustitutos funcionales que a su vez pueden ser estimulados utilizando sistemas físicos que buscan imitar ambientes similares al del tendón fisiológico, como los biorreactores (Fig. 1.10). 


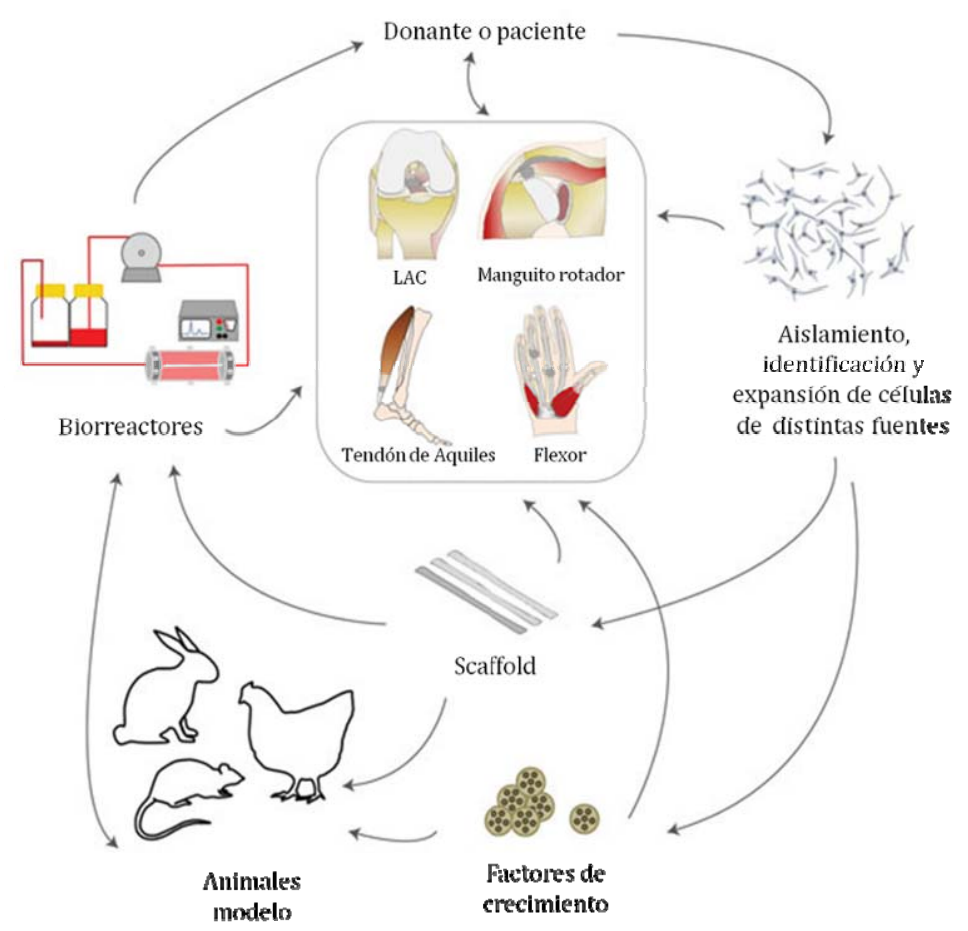

Fig. 1.10 Representación esquemática de las estrategias de reparación y regeneración de la ingeniería tisular del tendón y ligamento. (Figura modificada [29])

A continuación se explicará con mayor detalle las diferentes estrategias que han sido utilizadas en el campo de la regeneración del tendón.

\section{A) Fuentes celulares y terapia celular}

El primer componente de la triada en la ingeniería tisular del tendón, lo constituye la determinación de una fuente óptima de células que 
promuevan la regeneración tendinosa. Existen diversas fuentes celulares utilizadas en la ingeniería del tendón, una de ellas son los tenocitos [19], los cuales se han aislado y cultivado de distintos sitios anatómicos como el tendón de Aquiles [54], el tendón patelar[55] y el manguito rotador [56], entre otros. Otra de las fuentes celulares utilizadas son los fibroblastos dérmicos [57]. Estas células han sido comparadas con los tenocitos por diversos investigadores como Liu et al. [58] y Gigante et al. [59] y han demostrado que los fibroblastos dérmicos tienen un gran potencial para la ingeniería del tendón con respecto a los tenocitos, no sólo por sus buenos resultados experimentales sino por la facilidad con que se obtienen en comparación con los tenocitos, los cuales están presentes en muy baja densidad y pueden provocar un defecto en la zona de la extracción.

Numerosos trabajos apuntan hacia el uso de las células madre mesenquimales como principal fuente celular utilizando sobre todo células madre provenientes de la médula ósea [60], del tejido adiposo [61] o del líquido sinovial [62]. Pacini et al. [63], demostraron que la inyección de una suspensión de células madre autólogas indiferenciadas provenientes de médula ósea en una lesión del tendón flexor digital equino, daba lugar a una recuperación clínica significativa. En otro estudio realizado por Nixon et al. [64] muy similar al anterior pero utilizando como fuente celular, células madre mesenquimales provenientes de tejido adiposo equino, se observó que no hubo diferencias en la expresión génica, producción de colágeno y el DNA 
total entre los ejemplares tratados con células con respecto a los no tratados. Sin embargo sí se encontró una mejoría significativa en los ejemplares tratados con células con respecto al tamaño del tendón y a la linealidad en las fibras, concluyendo que estas células tenían un efecto regenerador.

Aparte de los ensayos in vitro también se han realizado estudios clínicos en humanos utilizando terapia celular en lesiones tendinosas. Gomes et al. [65] realizó un estudio clínico en 14 pacientes con completo desgarro del manguito rotador inyectando en los puntos de sutura, células madre mesenquimales autólogas de médula ósea obtenidas de la cresta ilíaca antes de proceder a la cirugía. Después de 12 meses de seguimiento se observó que la implantación de estas células en la zona de las suturas mejoraba sustancialmente la regeneración del tejido frente a las suturas sin implantación de células.

\section{B) Scaffolds}

En lesiones tendinosas importantes, la ingeniería tisular del tendón utiliza la estrategia más completa y a la vez la más compleja donde puede combinar o no, todos los elementos de la ingeniería tisular. Para ello utiliza estructuras tridimensionales, los scaffolds, como vehículos para transportar a un punto concreto de nuestro organismo las células y las sustancias químicas necesarias para su reparación.

Los scaffolds de origen natural han mostrado resultados satisfactorios en la ingeniería del tendón. La seda es un material 
biodegradable y biocompatible con características mecánicas intrínsecas. Fang et al. [66], desarrollaron un scaffold trenzado de seda como sustituto para el tendón de Aquiles evidenciando resultados prometedores para futuras aplicaciones clínicas. Este material ha sido estudiado por otros autores para mejorar la regeneración del ligamento anterior cruzado aportando buenos resultados [67]. Existen otros materiales de origen natural, como el colágeno y la fibrina, que han sido considerados como alternativas para reparación de pequeñas lesiones tendinosas pero debido a sus reducidas propiedades mecánicas no se consideran como una alternativa aceptable para la reparación de roturas completas del tendón. Varios estudios han demostrado la aplicabilidad de geles [68, 69], membranas [69] e incluso scaffolds realizados con fibras de colágeno [70] para la reparación del tendón aportando buenos resultados. La fibrina es una proteína fibrosa de origen natural implicada en la coagulación de la sangre, que al polimerizar da lugar a la formación de un coágulo biodegradable y bioreabsorbible que se puede utilizar para mejorar la fibrilogénesis de colágeno en los defectos tendinosos [71] o para la liberación controlada de factores de crecimiento estimulando la regeneración del tendón [72].

Los scaffolds de origen sintético, son ampliamente utilizados en la ingeniería del tendón debido a que se consideran más versátiles que los naturales, ya que se pueden controlar sus propiedades físicas, químicas y morfológicas. Los materiales más utilizados para la fabricación de estos scaffolds son los poliésteres. El ácido poliglicólico (PGA), el ácido 
poliláctico (PLA) y su copolímero, el ácido poliláctico-co-glicólico (PLGA) son polímeros biodegradables y sus productos de degradación, el ácido glicólico y el ácido láctico, son metabolitos naturales que están normalmente presentes en el cuerpo humano. Por otra parte, estos poliésteres son fácilmente procesables y poseen buenas propiedades mecánicas [73]. Se han reportado estudios realizados con scaffolds trenzados de PLGA para la regeneración del tendón y del ligamento. En esta línea Cooper et al. [74] utilizó este biomaterial trenzado para un estudio in vitro relacionado con la reparación del ligamento anterior cruzado. En este estudio se considera este material adecuado para una reconstrucción ligamentosa por los buenos resultados observados en las propiedades mecánicas y biológicas. En otros estudios, Ouyang et al. $[60,75]$ demostraron que scaffolds trenzados de PLGA sembrados previamente con células madre mesenquimales de médula ósea, aceleraban la regeneración del tendón de Aquiles tanto histológica como mecánicamente. Estos scaffolds mejoraban la producción de colágeno tipo I y de tipo III, reforzando de este modo las propiedades mecánicas.

Scaffolds de fibras de PGA también se han utilizado en aplicaciones en la ingeniería del tendón. Deng et al. [57] realizaron un cultivo in vitro bajo tensión estática con fibras sin trenzar de PGA sembradas con dos fuentes celulares de origen humano: tenocitos y fibroblastos dérmicos. Se observó que las muestras cultivadas bajo una tensión estática presentaban las fibras de colágeno más alineadas y organizadas que las 
muestras no sometidas a tensión. En otro estudio, Cao et al. [76] desarrollaron un scaffold sin trenzar de fibras de PGA y fue sembrado in vitro bajo tensión constante con tenocitos procedentes de gallina. Los resultados mostraron que se podía generar tejido tendinoso in vitro con buenas propiedades mecánicas. Curiosamente, en el tendón diseñado con tensión constante se obtuvo una reducción en el diámetro con respecto al tendón que no estaba sometido a tensión. También se observó que las fibras de colágeno estaban altamente compactadas, lo que sugiere que la tensión constante no es un medio óptimo de carga mecánica y propone la aplicación de una carga mecánica en estado dinámico mediante el uso de un biorreactor. Xu et al. [77], mostraron como una lámina de fibras de PGA sin trenzar cultivada con tenocitos de gallina e insertada en un defecto provocado en la vaina del tendón flexor, formó un tejido similar al tejido nativo tras 12 semanas de implantación. Es importante destacar, que aunque los resultados obtenidos utilizando scaffolds fabricados con PGA han sido importantes, se han visto limitado por fragilidad mecánica.

Los biomateriales trenzados de PLLA también han sido empleados para numerosos estudios en la ingeniería del tendón. Kimura et al. [78], realizaron un estudio con un scaffold trenzado de PLLA combinado con un gel de gelatina que liberaba de forma controlada bFGF. Este trenzado iba envuelto con una membrana de colágeno. El espécimen se utilizó para la reconstrucción del ligamento anterior cruzado de conejos. Los resultados aportaron mayor producción de colágeno y por ello mayor 
resistencia mecánica frente a los controles. Además se observó que la liberación de bFGF indujo a la osteointegración mejorando la resistencia en los puntos de anclaje al hueso.

Lu et al. [79] realizaron un estudio comparativo entre los trenzados de PGA, PLGA, y PLLA. Estos trenzados fueron sumergidos en una solución de fibronectina para mejorar la adhesión celular y posteriormente fueron sembrados con células procedentes del ligamento anterior cruzado de conejo. Tras 14 días de cultivo se observó que las células sembradas en los trenzados de PLLA y PLGA producían más cantidad de matriz extracelular en comparación con las células sembradas en el trenzado de PGA. Además se observó que en los trenzados de PGA se había reducido significativamente el número de células en comparación con los otros dos. Los autores concluyeron que tanto los trenzados de PLLA y de PLGA eran eficaces para la ingeniería de tejido del tendón y del ligamento, pudiendo ser más apropiado el trenzado de PLLA debido a su tasa de degradación más lenta. Laurencin et al. $[80,81]$, también realizó un estudio con un trenzado de PLLA para reparar el ligamento anterior cruzado obteniendo resultados esperanzadores. Además diversos estudios realizados con estructuras nanofibrosas alienadas de PLLA, obtenidas mediante electrospinnig, han demostrado que estos scaffolds proporcionan un microambiente adecuado para la regeneración tanto de tendón como de ligamento [82, 83]. 


\section{C) Factores estimulantes}

\section{$\underline{\text { Factores de crecimiento }}$}

Se han realizado estudios in vivo en animales, donde los factores de crecimiento se han inyectado directamente en la zona lesionada. Cuando se liberan estos factores de crecimiento, pueden promover la proliferación, la migración, la diferenciación celular y la producción de matriz extracelular pudiendo desempeñar un papel clave en la reparación de estos tejidos. Chan et al. [84] realizaron un estudio inyectando directamente bFGF en una lesión del tendón patelar de rata. Tras 7 y 14 días observaron un aumento en la proliferación celular y en la producción de colágeno tipo III, frente a especímenes no tratados con el factor. En otro estudio realizado por Kurtz et al. [85] donde inyectaron IGF-I en una lesión del tendón de Aquiles de ratón observaron que la inflamación iba desapareciendo y se aceleraba la curación de la zona dañada en comparación con las lesiones no tratadas con el factor. Dahlgren et al. [86], también realizaron una inyección intratendinosa de IGF-I en una lesión del tendón flexor equino observando tras dos meses, que la proliferación celular, el contenido de colágeno y la rigidez habían incrementado en los tendones tratados con el factor en comparación con los tendones no tratados.

Otra forma de suministrar factores de crecimiento en tendones lesionados es mediante la inyección de plasma rico en plaquetas. Las plaquetas, células anucleadas de la sangre, contienen en su interior 
gránulos ricos en factores de crecimiento y otras proteínas bioactivas, que influyen en la curación de los tendones [87].

Una alternativa para suministrar los factores de crecimiento de una manera más localizada sobre la zona lesionada es mediante su introducción en una matriz polimérica. Esta matriz mientras se va degradando libera de forma controlada estos factores. En diversos estudios realizados se ha demostrado que una liberación controlada sobre las lesiones tendinosas produce una aceleración en el proceso curativo [72, 88, 89].

Además, los factores de crecimiento también se han utilizado para pretratar a las células antes de ser inyectadas o sembradas en un scaffold. Schneider et al. [90] realizaron un estudio de diferenciación tenocítica, donde se trató células madre mesenquimales procedentes de tejido adiposo canino con IGF-I, con TGF- $\beta 1$, y con una combinación de ambos factores, IGF-I/TGF- $\beta 1$. Se concluyó que las mesenquimales poseen un gran potencial de diferenciación a tenocitos, donde los mejores resultados se obtienen usando la combinación de los factores con respecto al uso de un único factor de crecimiento. Otros investigadores como Violini et al. [91], realizaron un estudio de diferenciación tenocítica utilizando células madre mesenquimales procedentes de médula ósea equina en combinación con la proteína BMP-12. Se demostró que las células tenían capacidad de diferenciarse a tenocitos y expresaban marcadores específicos del tendón como la tenomodulina y la decorina. 
Como se ha demostrado en numerosos estudios, los factores de crecimiento tienen el potencial de mejorar las respuestas de regeneración en tendones lesionados. Sin embargo, algunos de los métodos para aplicar los factores de crecimiento en el sitio de la lesión durante un periodo largo son insuficientes. La terapia génica es una solución a este problema ya que, mediante una modificación genética de las células antes de su implantación pueden producir y liberar una mayor cantidad de un factor deseado. De esta manera, la exposición a los factores de crecimiento es más prolongada [92].

\section{Biorreactores}

Son dispositivos que simulan in vitro las condiciones fisiológicas que se presentan en el entorno biológico. En estos dispositivos los procesos biológicos y bioquímicos se desarrollan bajo un seguimiento y control de las condiciones ambientales y experimentales, tales como: $\mathrm{pH}$, temperatura, suministro de nutrientes y tensiones mecánicas, entre otros [93].

Durante el desarrollo de los cultivos in vitro se puede incluir la aplicación de un estímulo mecánico al scaffold mediante el uso de un biorreactor. El estrés mecánico aplicado al scaffold antes de que sea implantado in vivo desempeña un papel significativo en la actividad, diferenciación y función celular, por ello, en las estrategias de la ingeniería tisular del tendón, los biorreactores se consideran una 
herramienta importante para el desarrollo de injertos funcionales para este tipo de tejido.

Yang et al.[94] cultivaron fibroblastos humanos procedentes del tendón patelar en ausencia de suero sobre discos de silicona. Estos discos fueron sometidos a una carga cíclica uniaxial con una frecuencia de $0.5 \mathrm{~Hz}$ y 4 h de duración constante aplicando una deformación de un 0\%, 4\%, y un 8\%. Se observó que las células sometidas al estímulo tenían una morfología más alargada y se encontraban más alineadas en comparación con las no estimuladas mecánicamente. Además en las células estimuladas se registró un incremento en la producción de colágeno I y de TGF- $\beta 1$, teniendo un incremento más significativo las muestras con una deformación aplicada del 8\%. Estos resultados sugirieron que el estiramiento mecánico modulaba la proliferación celular y aumentaba la producción de colágeno tipo I. Otros estudios realizados por Skutek et al. [95] y Petersen et al. [96], demostraron que la aplicación de un estímulo cíclico uniaxial sobre un scaffold cultivado con células favorece el incremento de las concentraciones de factores de crecimiento como TGF- $\beta 1$, bFGF, PDGF y VEGF. En esta línea Surrao et al. [97] reportaron la influencia que tiene el estímulo mecánico en la producción de matriz extracelular de fibroblastos bovinos cultivados sobre scaffolds fibrosos de ácido poli(L-láctico-co-D,L-lactico) realizados mediante elestrospinnig con dos morfologías diferentes: alineada u ondulada. Se observó tras 15 y 30 días que tanto la síntesis de colágeno tipo I y tipo III, como la de proteoglicanos sulfatados 
aumentaban en los scaffolds ondulados y estimulados mecánicamente. Además, los fibroblastos sembrados en las fibras onduladas y estimuladas mecánicamente parecían formar aglomerados de fibras que se asemejaban a los fascículos tendinosos.

A pesar de que se han desarrollado diferentes aproximaciones para crear sustitutos funcionales del tendón en la ingeniería de tejidos, aún se continúa trabajando en encontrar una solución efectiva y eficaz, capaz de reconstruir estos tejidos lesionados y así solventar la creciente demanda de prótesis biodegradables. La siguiente sección se centrará en presentar el desarrollo de un nuevo prototipo de prótesis biodegradable de tendón fabricada siguiendo las directrices de la ingeniería tisular, aunque cabe anotar que por su diseño podría servir también para la regeneración del ligamento. 


\subsection{PROTOTIPO DE PRÓTESIS REGENERATIVA DE TENDÓN}

Nuestro concepto de "prótesis regenerativa para tendón" trata de combinar en un solo constructo el soporte de las cargas y la capacidad de regenerar el tejido perdido. Dado que los tendones y ligamentos necesitan movilidad inmediata para evitar adherencias, la transferencia de carga a las células progenitoras presentes en el constructo desencadenará una regeneración guiada del neotejido. Con esta hipótesis en mente, se combina una trenza hueca, que contiene en su interior células progenitoras. Estas células pueden cultivarse en el constructo previamente o durante el implante. Preferentemente, se ha pensado que la fuente celular inductora de la regeneración sea células mesenquimales del propio paciente provenientes de médula ósea o del tejido adiposo. Estas células como están en el interior del constructo estarán protegidas y serán mantenidas en el lugar de la lesión de manera más eficiente que en el caso de ser sembradas en la superficie del constructo. Las células serán suministradas por micropartículas que actúan como portadores de células y como un scaffold tridimensional. Para acelerar esta regeneración se puede hacer uso de factores estimulantes, tales como factores de crecimiento (BMP-12, TGF- $\beta$, IGF1, VEGF o bFGF) o mediante el uso de un biorreactor. Una de las hipótesis que se plantea en la presente tesis es que el uso de los factores estimulantes en el espécimen antes de ser implantado mejorará una 
serie de acontecimientos como el incremento de producción de matriz extracelular y la orientación de las fibras de colágeno entre otros, favoreciendo la regeneración del tejido que se quiera reemplazar. Por último, a fin de evitar adherencias indeseables de los tejidos circundantes, el exterior de la trenza está recubierto por una película no adherente basada en ácido hialurónico. Todos los componentes del constructo son biodegradables, y deben ser completamente reabsorbidos en el transcurso del tiempo. Para adaptar el concepto de prótesis a un tendón específico se debe ajustar la realización del trenzado, controlando las dimensiones de la trenza y las características de la misma (número de hilos y ángulo de trenzado).

A continuación, se presenta el desarrollo del prototipo de prótesis biodegradable elaborado en el Centro de Biomateriales e Ingeniería Tisular (CBIT). Para la fabricación del prototipo se han combinado las buenas propiedades tanto de polímeros sintéticos como naturales. Para asegurar el aporte de buenas propiedades mecánicas se ha elegido el ácido poliláctico (PLA), el cual ha sido utilizado en numerosos estudios relacionados con la regeneración tendinosa y además está aprobado por la FDA (Food and Drug Administration). El PLA es un biomaterial semicristalino, con una temperatura de fusión entre $170-183^{\circ} \mathrm{C}$ y una temperatura de transición vítrea entre $55-65^{\circ} \mathrm{C}$. Tiene una densidad de 1.25-1.29 g/cc y es soluble en disolventes orgánicos. 
Entre los polímeros naturales se encuentran dos polisacáridos: el quitosano (CHT) y el ácido hialurónico (HA). El CHT es un biopolímero policatiónico que se obtiene a partir de la desacetilación alcalina de la quitina. La quitina es uno de los biopolímeros naturales más abundantes en la naturaleza. Forma parte de las conchas de los crustáceos, del exoesqueleto de los insectos y de las paredes celulares de los hongos. Químicamente la quitina está formada por unidades de $\mathrm{N}$-acetil-D-glucosamina y glucosamina unidas mediante enlaces glucosídicos $\beta$ (1-4). Dependiendo del proceso de desacetilación de la quitina, el quitosano obtenido puede tener un peso molecular (Mw) y un grado de desacetilación distintos, parámetros que influyen en las características del biomaterial. Este polímero es insoluble en agua, pero la presencia de grupos amino hace que sea soluble en soluciones ácidas con $\mathrm{pH}$ por debajo de 6,5 $[98,99]$. Un método para obtener una red de quitosano es mediante el uso de un agente entrecruzador. El genipin es un entrecruzador muy utilizado en biomedicina debido a su baja toxicidad, se extrae de los frutos de la Gardenia jasminoides Ellis y reacciona con los grupos amina dando lugar a la formación de pigmentos de color azul $[100,101]$.

El HA es un polisacárido aniónico perteneciente a la familia de los glicosaminoglicanos, formado por unidades alternadas de $\mathrm{N}$-acetil glucosamina y ácido glucurónico. Forma parte de la matriz extracelular del cartílago, el condón umbilical, el humor vítreo y el tejido conectivo. Debido a la gran cantidad de grupos hidroxilo $-\mathrm{OH}$ existentes en su 
molécula, posee alta capacidad de lubricación, absorción y retención de agua [102, 103]. Debido a sus características de hidrogel, algunas aplicaciones de ingeniería tisular requieren de una modificación química para lograr que el material permanezca más tiempo sin disolverse o sufrir los efectos de la degradación [104, 105].

Teniendo en cuenta los materiales seleccionados para la fabricación de la prótesis, a continuación se presenta un esquema de la misma que comprende: a) un material trenzado de soporte; b) micropartículas en el interior del trenzado; y c) un recubrimiento, como se observa en la Fig. 1.11.

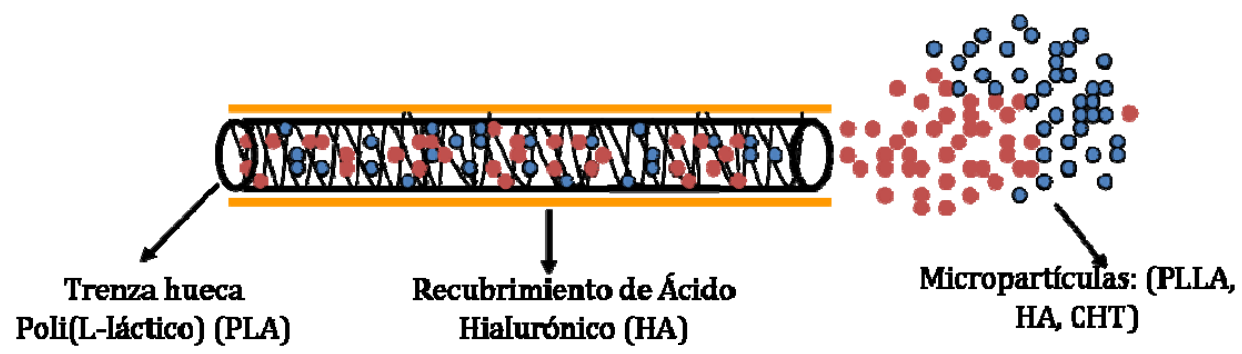

Fig. 1.11 Esquema del diseño de la prótesis biodegradable

\section{a) Material trenzado}

El material trenzado es una de las partes más importantes de la prótesis, y su función principal es la de soportar las cargas mecánicas. El material trenzado de la prótesis tiene un diseño característico basado en una malla de forma tubular o trenza hueca. La estructura trenzada permite ajustar las propiedades mecánicas del trenzado resultante, 
según el modo en que se haga la trenza. Este material debe reproducir la curva característica del comportamiento mecánico de un tendón natural presentado las tres zonas típicas del tejido a reemplazar (zona toe, zona lineal y zona de rotura) como se mencionó en el apartado 1.1.1. Es importante indicar que el material trenzado utilizado para esta parte de la prótesis debe poseer un módulo de Young en la zona de comportamiento lineal similar a los valores citados en la literatura (1000-2000 MPa). Para su fabricación se ha elegido PLA.

\section{b) Micropartículas}

Las micropartículas, son otra parte importante de la prótesis debido a que tienen la función de transportar y distribuir las células inductoras de la regeneración del tejido a subsanar por el interior del material trenzado. Estas micropartículas se inyectarán en el interior del material trenzado, por lo tanto, tendrán un diámetro inferior al diámetro interno de la trenza, preferentemente entre 50 y $100 \mu \mathrm{m}$. Los materiales elegidos para la fabricación de las micropartículas son el ácido poli(L-láctico), y dos polisacáridos, el quitosano y el ácido hialurónico. Se elegirá entre las micropartículas de PLLA o de CHT aquellas que demuestren un mejor comportamiento celular. Las micropartículas elegidas como soporte se combinarán con las micropartículas de HA. 


\section{c) Recubrimiento}

El recubrimiento en la prótesis tiene como función principal evitar adherencias con los tejidos circundantes, proteger el material trenzado, y preferentemente, ha de ser resistente a la abrasión. Este recubrimiento se puede realizar sobre el propio material trenzado o mediante la fabricación de un tubo o vaina, donde seguidamente se puede introducir el material trenzado. Deberá de ser permeable para permitir la difusión de nutrientes a las células. Preferentemente, el recubrimiento será de ácido hialurónico reticulado debido a su carácter antiadherente. 


\subsection{OBJETIVOS}

La presente tesis plantea como objetivo principal el desarrollo de una prótesis de tendón biodegradable totalmente regenerativa. Esta prótesis debe tener un diseño innovador y debe crearse con polímeros biodegradables. Para conseguir este fin, fueron planteados dos grupos de objetivos específicos: el primero permitirá el diseño y la caracterización fisicoquímica de la prótesis y en el segundo se evaluará el comportamiento celular sobre las estructuras tridimensionales desarrolladas.

Grupo A: Caracterización físico-química de la prótesis

1) Caracterizar de forma física, química y mecánica la parte principal de la prótesis, una trenza hueca de ácido poliláctico.

2) Sintetizar y caracterizar micropartículas de diferentes materiales: ácido poli(L-láctico),quitosano y ácido hialurónico.

3) Obtener el recubrimiento del material trenzado utilizando ácido hialurónico.

4) Diseñar y construir un prototipo de biorreactor. 
Grupo B: Comportamiento celular in vitro sobre los componentes de la prótesis.

1) Caracterizar biológicamente el material trenzado y las diferentes micropartículas utilizando una línea comercial y células mesenquimales.

2) Emplear factores de crecimiento para promover la diferenciación tenocítica en algunas estructuras tridimensionales utilizadas (micropartículas y trenza).

3) Evaluar el efecto producido por el uso de la estimulación mecánica sobre la estructura trenzada.

4) Caracterizar biológicamente el prototipo de prótesis final en régimen estático y dinámico. 
Capítulo 2 Materiales y métodos 



\subsection{MATERIALES}

\subsubsection{Polímeros}

- Material trenzado de ácido poli(láctico) (PLA), suministrado por la Asociación de Industriales del Textil (AITEX) como parte de la elaboración del proyecto denominado "Desarrollo de biomateriales trenzados para aplicaciones biomédicas". Las microfibras de PLA con una densidad lineal de 0.22 tex $(1$ tex $=$ 1g/1000m), constituidas por poli-L-láctico (PLLA), mezclado con $1.4 \%$ de poli-D-láctico (PDLA), fueron suministradas por Ingeo ${ }^{\mathrm{TM}}$ Lactides, Natureworks LLC, USA. Estas microfibras fueron utilizadas para fabricar una trenza tubular hueca por dentro usando una máquina de trenzado Herzog NG2/12-120 (Oldenburg, Alemania). La trenza se fabricó con 12 hilos, cada hilo estaba compuesto por 4 fibras con 150 microfibrillas cada fibra, (7200 microfibras en total). La densidad lineal de la trenza resultante fue de 1612.8 tex. Las microfibras fueron trenzadas alrededor de un hilo de PLA de 330 tex, posteriormente eliminado para obtener la forma de trenza hueca. Tanto la sección transversal de las microfibras como la sección transversal efectiva de la trenza fueron calculadas a partir de sus densidades lineales (M/L), dadas en tex, a través de la ecuación (1): 


$$
S=\frac{V}{L}=\frac{M}{L \rho_{P L L A}}
$$

La densidad del PLA fue tomada de la literatura $\rho_{\mathrm{PLA}}=1,24 \mathrm{~g} / \mathrm{ml}$ [106].

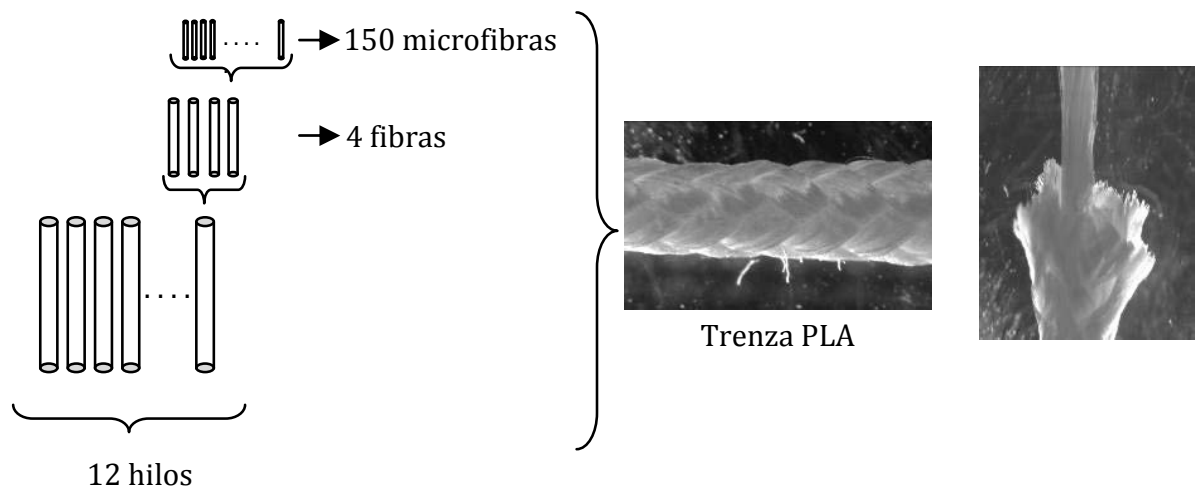

Fig. 2.1 Esquema de la trenza de PLA suministrada por AITEX.

- Ácido poli(L-láctico) (PLLA), suministrado por Cargill Dow, EEUU, con peso molecular $124 \mathrm{kDa}$, un contenido del isómero Lláctico del 99.6\% y un índice de polidispersión de Mw/Mn= 1.83<smiles>C[C@H](OCCO)[C@@H](C)O</smiles>

Fig. 2.2 Estructura química del ácido poli (L-láctico (PLLA). 
- Quitosano (CHT), suministrado por Sigma-Aldrich, EEUU, con un grado de desacetilación del 75\% y un peso molecular de 150 kDa

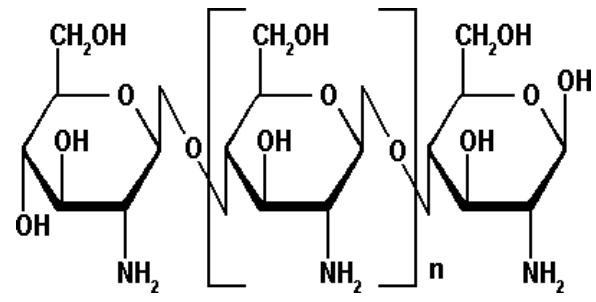

Fig. 2.3 Estructura química del quitosano (CHT).

- Ácido hialurónico (HA) (sal sódica de ácido hialurónico de Streptococcus equi sp.), suministrado por Sigma-Aldrich con peso molecular de $1.63 \times 10^{3} \mathrm{KDa}$

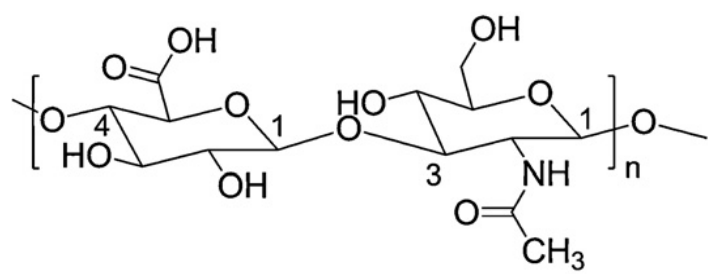

Fig. 2.4 Estructura química del ácido hialurónico (HA). 


\subsubsection{Otros reactivos}

- Polivinil alcohol (PVA), utilizado como tensioactivo en la fabricación de micropartículas de PLLA, suministrado por Celanese Chemicals Iberica SL, España.

- Tween 80, tensioactivo utilizado en la fabricación de micropartículas de CHT, suministrado por Scharlab, España.

- Genipin, agente entrecruzador utilizado en la fabricación de micropartículas de CHT, suministrado por Wako, Japón,

- Divinil sulfona (DVS) del 97\% de pureza, utilizado como agente entrecruzador del HA, suministrado por Sigma-Aldrich.

- Aceite mineral, suministrado por Sigma-Aldrich.

- Isooctano del 99\% de pureza, suministrado por Sigma-Aldrich.

- 1-Heptanol del 98\% de pureza, suministrado por Sigma-Aldrich.

- Sodio bis(2-etihexil) sulfosuccinato, del 98\% de pureza, suministrado por Sigma-Aldrich.

- Azida de sodio $\left(\mathrm{NaN}_{3}\right)$ suministrada por Sigma-Aldrich. 


\subsubsection{Solventes}

- Ácido acético glacial, $\mathrm{CH}_{3} \mathrm{COOH}$, en solución acuosa al 1\%, suministrado por Scharlab, utilizado para disolver el quitosano a $25^{\circ} \mathrm{C}$.

- Solución de hidróxido sódico, $(\mathrm{NaOH})$ suministrado por Scharlab, utilizado con una concentración de $0.2 \mathrm{M}$ para disolver el ácido hialurónico.

- Diclorometano $\left(\mathrm{CH}_{2} \mathrm{Cl}_{2}\right)$, utilizado como solvente del PLA, suministrado por Scharlab.

- Tetrahidrofurano (THF), para cromatografía de permeabilidad en gel, GPC, estabilizado con 250 ppm de BHT, suministrado por Sigma-Aldrich.

- N, N-Dimetilformamida (DMF), suministrada por Sigma-Aldrich con un grado de pureza del 99,8\%.

- Agua destilada $\left(\mathrm{H}_{2} \mathrm{O}\right)$ suministrada por Scharlab.

- Etanol (EtOH) con 99.5\% de pureza, suministrado por SigmaAldrich. 
- Ácido clorhídrico ( $\mathrm{HCl}$ ) del $37 \%$ de pureza, suministrado por Scharlab.

\subsubsection{Células, medios de cultivo y tampones utilizados en los ensayos biológicos}

- Fibroblastos de ratón de tejido conectivo (línea celular L929), suministrada por Sigma-Aldrich.

- Células mesenquimales del tejido adiposo, siendo sus siglas en inglés $A D S C$, provenientes de oveja y proporcionadas por Pompidou Hospital, Laboratory of Biosurgical Research (LRB) de París. Estas células fueron obtenidas tras realizar una biopsia en la zona pericárdica del animal.

- Células madre mesenquimales humanas, siendo sus siglas en inglés, $h M S C s$, provenientes de medula ósea proporcionadas por el Hospital Costa del Sol de Marbella (Málaga). Estas células fueron obtenidas por aspiración en los pacientes tras someterse a una cirugía de reemplazo de cadera, con previo consentimiento y de acuerdo con los procedimientos aprobados por el comité de ética local. Las células fueron utilizadas en los ensayos realizados in vitro en el Laboratorio de Bioingeniería y Regeneración Tisular (LABRET) de la Universidad de Málaga (UMA). 
- Dulbecco's Modified Eagle Medium, DMEM (Fisher, España), con $4.5 \mathrm{~g} / \mathrm{l} \mathrm{D}$-glucosa, suplementado con un $10 \%$ de suero bovino fetal, FBS (Fisher), un 1\% de penicilina/estreptomicina y un 1\% de L-glutamina (Lonza, Suiza), fue utilizado como medio de cultivo para el mantenimiento y la proliferación de las células L929.

- Minimum Essential Medium Eagle, $\alpha$-MEM (Sigma), suplementado con un $10 \%$ de FBS, un $1 \%$ de penicilina/estreptomicina, un 1\% de L-glutamina, un $1 \%$ de Amphotericin B Solution (Sigma) y $5 \mu \mathrm{g} / \mathrm{ml}$ de Plasmocin (InvivoGen, EEUU), fue utilizado en la preparación del medio de cultivo para los ensayos in vitro de las células ADSC de oveja.

- Dulbecco's Modified Eagle Medium, DMEM (Sigma) con 4.5 g/l D-glucosa, suplementado con un $10 \%$ de FBS, un $1 \%$ de penicilina/estreptomicina, un $1 \%$ de L-glutamina y un $0.5 \%$ de Amphotericin B Solution fue utilizado como medio de cultivo para el mantenimiento y la proliferación de las hMSCs.

- Medio de cultivo utilizado para hMSCs suplementado con 0.1 $\mathrm{mg} / \mathrm{ml}$ de la proteína morfogenética ósea, BMP-12 suministrada por BioVision, EEUU, fue utilizado en la preparación del medio de diferenciación tenocítica. 
- Medio de cultivo utilizado para hMSCs suplementado con 50 $\mu \mathrm{g} / \mathrm{ml}$ del factor de crecimiento transformante $\beta$ (TGF- $\beta 1$ ) y con $1 \mathrm{mg} / \mathrm{ml}$ del factor de crecimiento insulínico (IGF-1), ambos factores suministrados por Sigma, fue utilizado en la preparación del medio de diferenciación tenocítica.

- Medio de cultivo DMEM, preparado sin rojo fenol y sin FBS se mezcló con el reactivo (3-(4,5-dimetiltiazol-2-il)-5-(3carboximetoxifenil)-2(4-sulfofenil)-2H tetrazolium) (MTS), suministrado por Promega, en relación 5:1 para obtener el medio MTS utilizado en los ensayos de viabilidad celular.

- Buffer fosfato salino (PBS) de Dulbecco, suministrado por Invitrogen, EEUU.

- Tampón TBS, preparado mediante Tris(hidroximetil) aminometano $1 \mathrm{M}$, Cloruro sódico $2 \mathrm{M}$ y $50 \mathrm{mM}$ de cloruro cálcico, suministrados por Sigma.

- Tampón de lavado PB 0.1 M, se preparó mediante sodio dihidrógeno fosfato 2-hidratado (3.12 g/l) y disodio hidrógeno fosfato anhidro (11.3 g/l), ambas suministradas por Sigma. 


\subsubsection{Biorreactor}

Un prototipo de biorreactor fue diseñado en el Centro de Biomateriales e Ingeniería Tisular (CBIT) de la Universitat Politècnica de València. Los materiales utilizados en la fabricación fueron acero inoxidable y vidrio. Sus dimensiones son de $11 \mathrm{~cm}$ de largo, $8 \mathrm{~cm}$ de ancho y $5 \mathrm{~cm}$ de alto. Posee dos rodillos de acero de $1 \mathrm{~cm}$ de diámetro. Estos rodillos están recubiertos por un tubo de vidrio de $2.5 \mathrm{~cm}$ de diámetro para evitar que el acero se ponga en contacto con el medio de cultivo, ver Fig. 2.5.

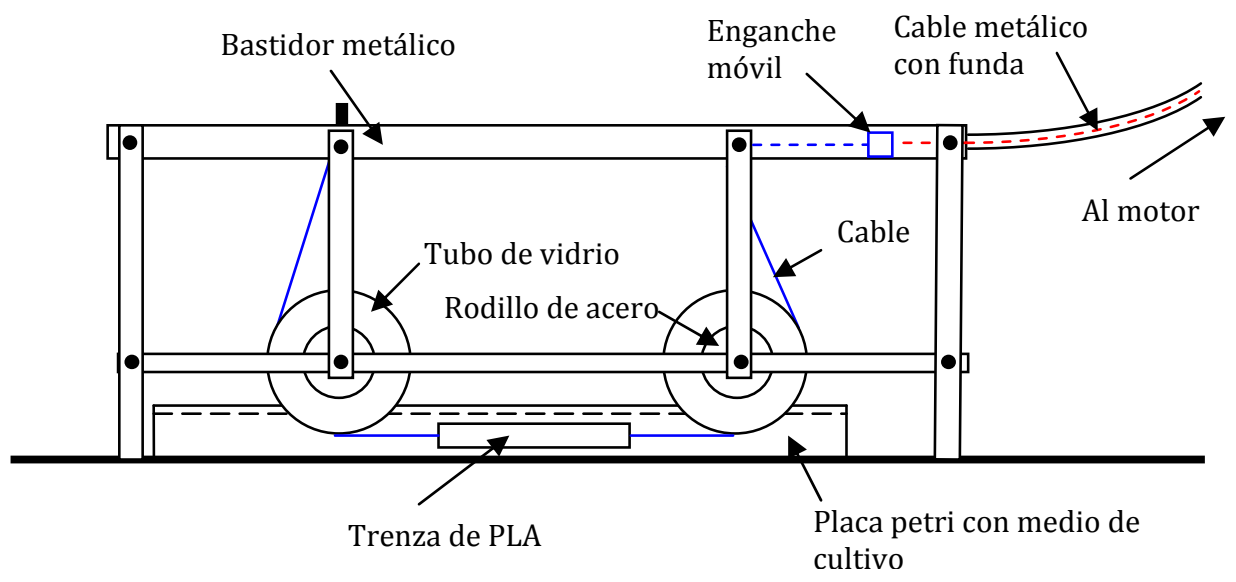

Fig. 2.5 Vista de perfil del biorreactor donde se observa la disposición de la placa petri y el material trenzado de PLA.

El biorreactor está diseñado para experimentar con tres trenzas. Las muestras trenzadas quedan sumergidas en el medio de cultivo colocado 
en una placa petri, tal y como se muestra en la Fig. 2.5. Estas trenzas se fijan por un extremo a unos enganches fijos y por el otro extremo, se fijan a unos enganches colocados en una pieza móvil. Esta pieza móvil está conectada a un cable que le proporciona el estímulo mecánico de tracción a las muestras fijadas mediante la ayuda de un motor de $12 \mathrm{~V}$ (ver Fig. 2.6).

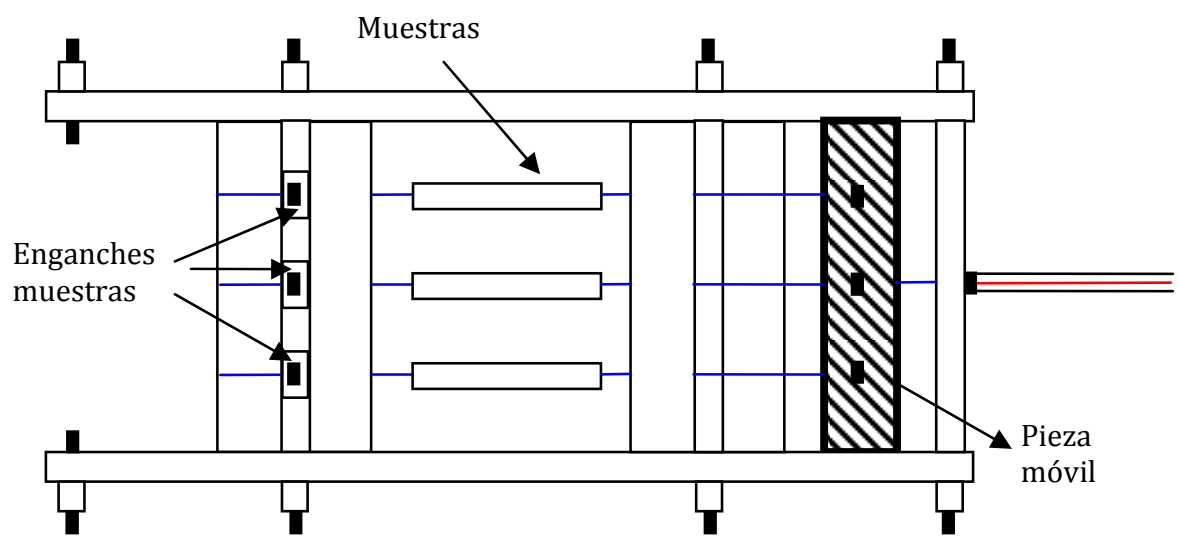

Fig. 2.6 Vista de planta del biorreactor. Muestras trenzadas fijadas mediante unos enganches fijos en el extremo izquierdo y en el extremo derecho, fijadas a una pieza móvil.

El diseño del biorreactor era capaz teóricamente, de aplicar a las muestras fuerzas del orden de $200 \mathrm{~N}$ a una frecuencia de $2 \mathrm{~Hz}$ y con una deformación de amplitud $2 \mathrm{~mm}$. No obstante, dado que la cadena de trasmisión de fuerzas no era completamente rígida, y tras una 
verificación del aparato, se comprobó que podía aplicar fuerzas de $10 \mathrm{~N}$ a una frecuencia de $0.5 \mathrm{~Hz}$ con una amplitud de deformación de $1 \mathrm{~mm}$ (entre el 1\% y $2 \%$ de la longitud de la muestra).

El biorreactor está diseñado para que sea fácilmente esterilizable, con materiales resistentes para que puedan aguantar varios ciclos de esterilización. Además se diseñó y fabricó una caja de metacrilato de dimensiones $22 \mathrm{~cm}$ de largo, $18 \mathrm{~cm}$ de ancho y $8 \mathrm{~cm}$ de alto, para minimizar el riesgo de contaminación del cultivo y facilitar el transporte del biorreactor desde el incubador a la campana de flujo laminar.

\subsection{MÉTODOS}

En esta sección se describirán las diferentes técnicas empleadas para obtener las estructuras poliméricas que forman parte del prototipo de prótesis, es decir, micropartículas de distintos materiales y el recubrimiento de la trenza; posteriormente se detallará como se ensambla cada una de las partes de que consta la prótesis para obtener el prototipo final.

\subsubsection{Micropartículas}

Las micropartículas de ácido poli(L-láctico) (PLLA) y quitosano (CHT) como parte esencial del prototipo de prótesis diseñado fueron 
fabricadas con la finalidad de utilizarse a modo de medio de transporte y soporte celular. Asimismo, fueron elaboradas micropartículas de ácido hialurónico (HA) para ser empleadas en combinación con una de las micropartículas anteriores con el propósito de mejorar la regeneración del tejido a reemplazar.

\subsubsection{Método de obtención de micropartículas de PLLA}

Las micropartículas de PLLA con un diámetro de entre 50-100 $\mu \mathrm{m}$, fueron preparadas utilizando el método de emulsión simple de aceite en agua (oil in water, 0/W) [107]. Para ello, el PLLA se disolvió en diclorometano $\left(\mathrm{CH}_{2} \mathrm{Cl}_{2}\right)$ en una concentración del 5\% $(1 \mathrm{~g} / 20 \mathrm{ml})$. Esta disolución, la fase orgánica, se dejó gotear con un flujo de $1 \mathrm{ml} / \mathrm{min}$ sobre una fase acuosa de polivinilalcohol (PVA) al $0.5 \%$ en peso y se agitó durante 24 h a 1350 rpm. Durante este tiempo, el solvente orgánico, volátil, se evaporó a través de la fase acuosa, obteniéndose las micropartículas de polímero sólidas en suspensión Transcurrido este tiempo las micropartículas obtenidas fueron lavadas con agua destilada repetidas veces, centrifugadas y liofilizadas. A continuación, en la Fig. 2.7 se muestra el diagrama de flujo seguido para la obtención de las micropartículas. 


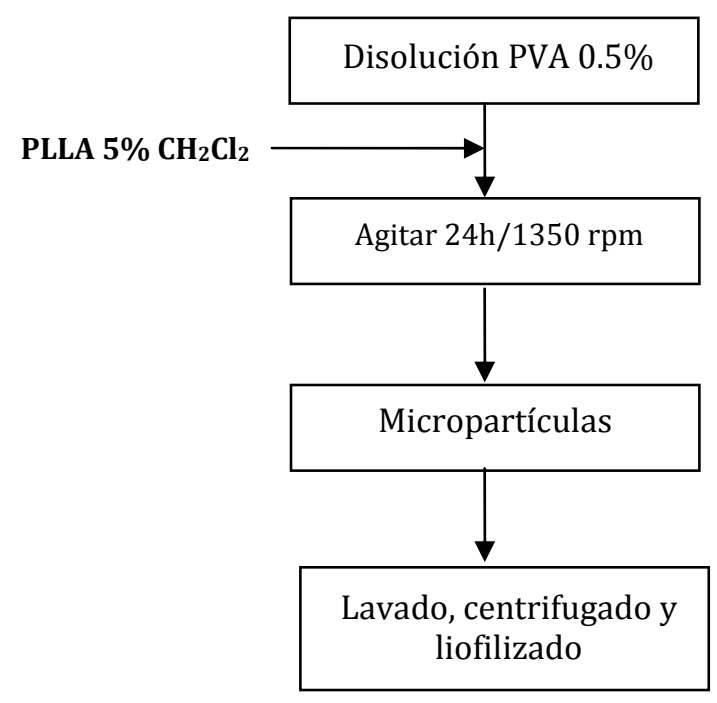

Fig. 2.7 Diagrama de flujo de la fabricación de micropartículas de PLLA.

\subsubsection{Método de obtención de micropartículas de CHT}

Las micropartículas de CHT con un diámetro de entre 50-100 $\mu \mathrm{m}$, fueron preparadas utilizando el método de emulsión, agua en aceite (water in oil, W/O) y posterior reacción de entrecruzamiento [108], como se indica en la Fig. 2.8. Para ello, se preparó una disolución de CHT al 2\%, pesando $2 \mathrm{~g}$ de quitosano que fueron disueltos en $100 \mathrm{ml}$ de una disolución de ácido acético $\left(\mathrm{CH}_{3} \mathrm{COOH}\right)$ al 1\%. Esta disolución se hizo gotear a una velocidad de $10 \mathrm{ml} / \mathrm{h}$ sobre la fase orgánica compuesta de $100 \mathrm{ml}$ de aceite mineral y $1 \mathrm{ml}$ de Tween 80. Se agitó durante $30 \mathrm{~min}$ a $1750 \mathrm{rpm}$. A continuación, se envolvió el reactor en papel de aluminio y se añadió $10 \mathrm{ml}$ de una disolución de genipin con 
una concentración de $30 \mathrm{mM}$, (0.068 g de genipin en $10 \mathrm{ml}$ de agua destilada) con un flujo de $1 \mathrm{ml} / \mathrm{min}$. La oscuridad es necesaria para evitar reacciones parásitas del genipin, debido a que es un compuesto fotosensible. Se agitó durante 15 horas a $1750 \mathrm{rpm}$. Las micropartículas obtenidas fueron lavadas con etanol absoluto y centrifugadas repetidas veces.

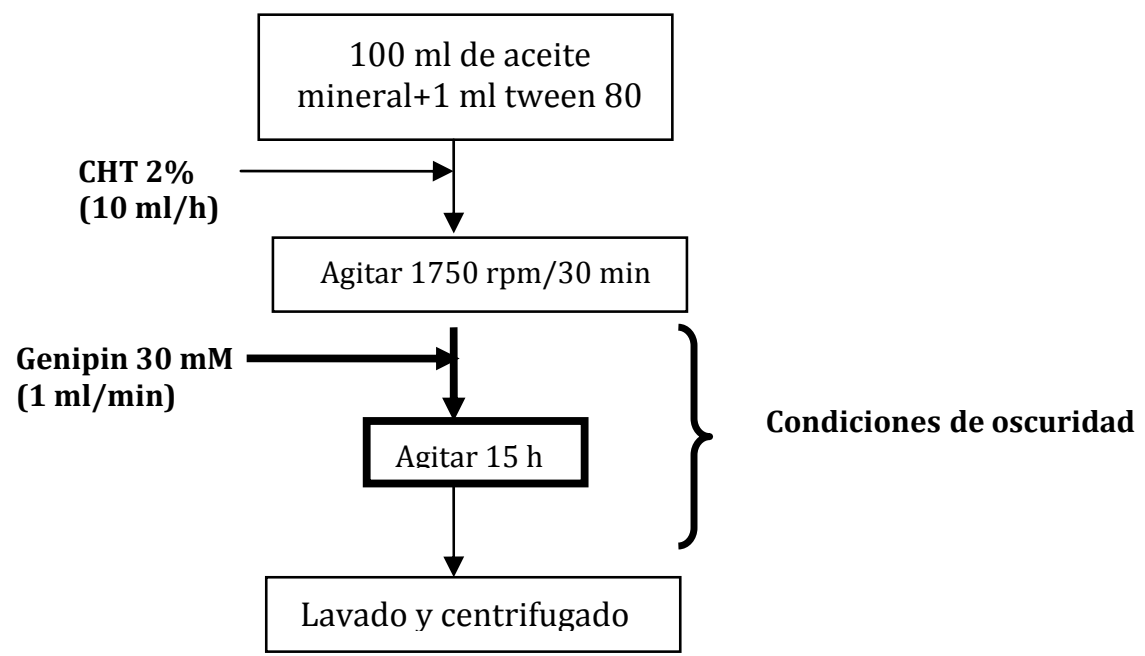

Fig. 2.8 Diagrama de flujo de la fabricación de micropartículas de CHT.

\subsubsection{Método de obtención de micropartículas de HA}

Las micropartículas de HA con un diámetro de entre 5-20 $\mu \mathrm{m}$, fueron preparadas utilizando el método de emulsión, en este caso, fase acuosa sobre fase orgánica (W/0) [109]. Para ello, se preparó una disolución de ácido hialurónico al 5\% (0.5 g de HA en $10 \mathrm{ml}$ de $\mathrm{NaOH} 0.2 \mathrm{M}$ ) y se 
añadió con una velocidad de $10 \mathrm{ml} / \mathrm{h}$ sobre una disolución compuesta de: $100 \mathrm{ml}$ de isooctano, $1.7 \mathrm{ml}$ de heptanol y $1.34 \mathrm{~g}$ de sodio bis(2etihexil) sulfosuccinato. Se agitó a $1300 \mathrm{rpm}$ durante $15 \mathrm{~min}$ y seguidamente se inició el proceso de entrecruzamiento al añadir $112 \mu \mathrm{l}$ de divinil sulfona (DVS). Transcurridos $20 \mathrm{~min}$, las partículas fueron lavadas con acetona repetidas veces, centrifugadas y liofilizadas. A continuación en la Fig. 2.9, se muestra el diagrama de flujo seguido para la obtención de las micropartículas.

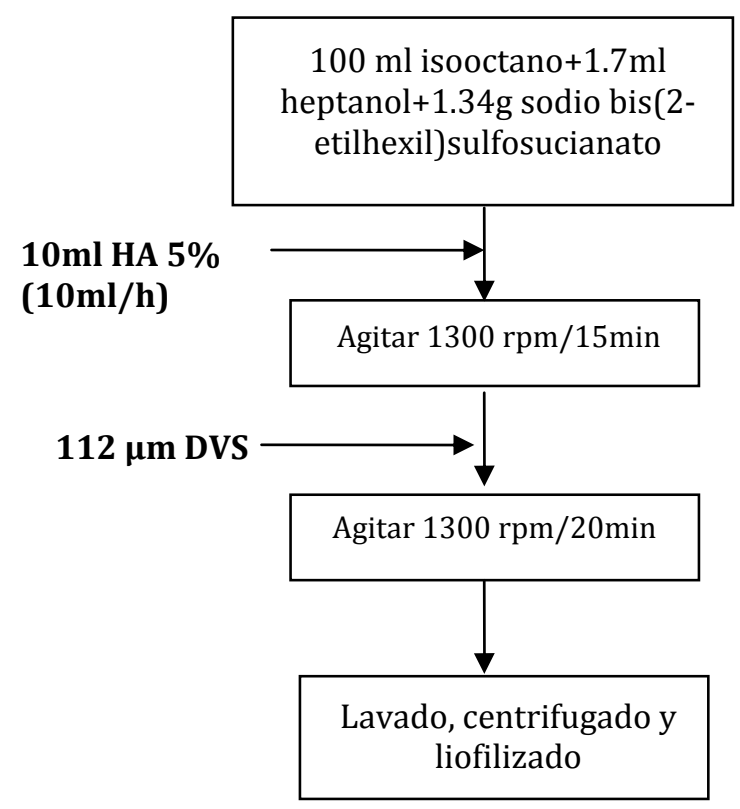

Fig. 2.9 Diagrama de flujo de la fabricación de micropartículas de HA. 


\subsubsection{Recubrimiento del material trenzado}

El material trenzado utilizado como parte del prototipo de prótesis final, fue recubierto con ácido hialurónico con el fin de evitar adherencias de los tejidos adyacentes. El recubrimiento se realizó por deposición mediante la técnica de electrospinning como se muestra en la Fig. 2.10. Se utilizó dos bombas de jeringa conectadas entre sí. En una de ellas se colocó $10 \mathrm{ml}$ de una solución de ácido hialurónico 0.28 g de $\mathrm{HA}$ fue disuelto en $7.98 \mathrm{~g}$ de $\mathrm{H}_{2} \mathrm{O}$ destilada, $5.32 \mathrm{~g}$ de $\mathrm{N}, \mathrm{N}-$ Dimetilformamida y $1.48 \mathrm{~g}$ de EtOH absoluto) con un flujo de $5 \mathrm{ml} / \mathrm{h}$. En la otra, una la solución del entrecruzante (DVS, $49.2 \mu \mathrm{l}$ en $4.8 \mathrm{ml}$ de $\mathrm{NaOH} 0.2 \mathrm{M}$ ) con una velocidad de $1.6 \mathrm{ml} / \mathrm{h}$. Una vez eyectadas las soluciones, se unen en un punto entre sí, manteniéndose la mezcla el tiempo suficiente para que el entrecrudazor reaccione con el HA. Esta mezcla final se electrodeposita alrededor del material trenzado, gracias a la rotación de $360^{\circ}$ del mismo sobre un eje Se evaluó distintos tiempos de electrodeposición (20 y 30 min) utilizando un voltaje de $27 \mathrm{kV}$. 


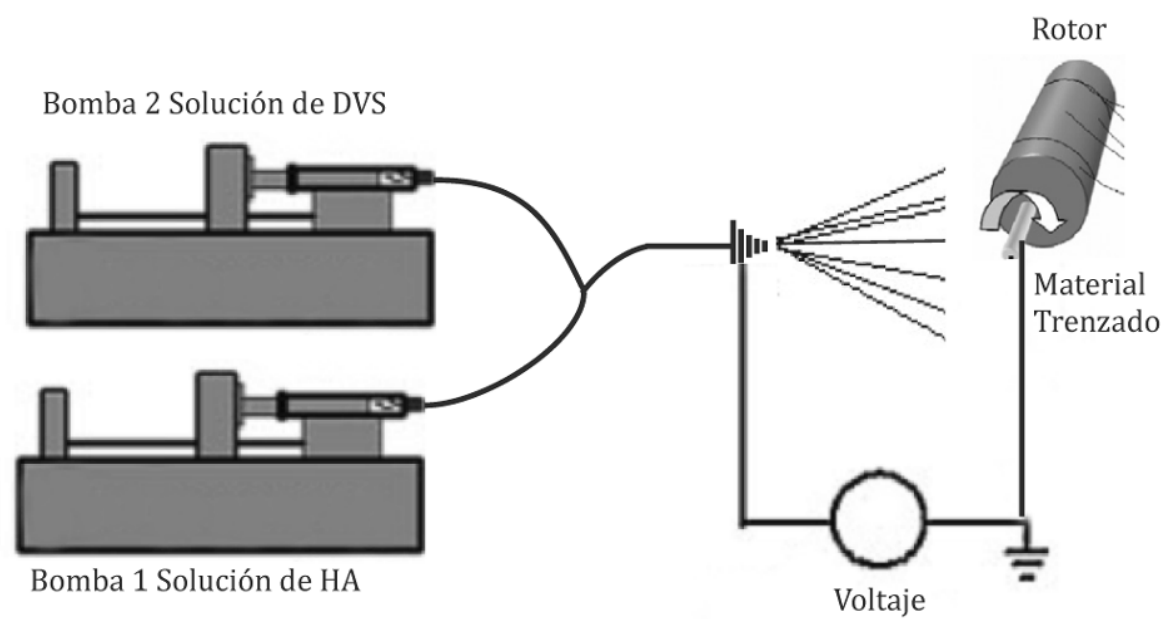

Fig. 2.10 Montaje de electrospinning utilizado para realizar el recubrimiento con HA sobre el material trenzado.

\subsubsection{Técnicas de caracterización fisicoquímica de los materiales}

\section{- Calorimetría diferencial de barrido (DSC)}

Para analizar las propiedades térmicas del material trenzado de PLA, muestras de entre 5 y $10 \mathrm{mg}$ fueron medidas con un calorímetro (METTLER TOLEDO, modelo DSC 823e, Suiza) utilizando nitrógeno como gas de purga $(20 \mathrm{ml} / \mathrm{min})$. La temperatura del equipo fue calibrada con indio, y la entalpía de fusión del indio fue utilizada para calibrar el flujo de calor. Las muestras trenzadas fueron sometidas a un barrido de calentamiento entre 0 y $210^{\circ} \mathrm{C}$ a $10^{\circ} \mathrm{C} / \mathrm{min}$. Los distintos parámetros fueron determinados a partir del termograma obtenido y fueron analizados con la ayuda del software del equipo: la temperatura 
de transición vítrea, $\mathrm{T}_{\mathrm{g}}$, la temperatura de fusión, $\mathrm{T}_{\mathrm{f}}$, la entalpía de fusión correspondiente a la cristalización $\Delta \mathrm{H}_{\mathrm{c}}$ y la entalpía de fusión $\Delta \mathrm{H}_{\mathrm{f}}$. La cristalinidad del material trenzado de PLA $\left(X_{c}\right)$ se determinó de acuerdo a la ecuación (2) haciendo uso de la entalpía de fusión teórica reportada en la literatura, siendo de $\Delta \mathrm{H}^{\circ}$ PLLA $=93.7 \mathrm{~J} / \mathrm{g}[110]$

$$
X_{c}=\frac{\Delta H_{f}}{\Delta H_{f}^{o}} \times 100 \%
$$

\section{- Análisis termogravimétrico (TGA)}

La degradación térmica de los materiales de que consta el prototipo de prótesis fue evaluada utilizando el equipo SDT-Q600 system (TAInstruments, USA). La trenza de PLA, los polímeros puros (PLLA; CHT y HA) y las micropartículas de PLLA, CHT y HA, fueron pesadas entre 5-10 mg y fueron sometidas a un rango de temperatura entre $25^{\circ} \mathrm{C}$ a $600^{\circ} \mathrm{C} \mathrm{y}$ a una velocidad de calentamiento de $10^{\circ} \mathrm{C} / \mathrm{min}$ en atmosfera de nitrógeno con un flujo de $100 \mathrm{ml} / \mathrm{min}$. La masa de la muestra se registró en función de la temperatura. El \% de la pérdida de masa, se calculó mediante la proporción entre el peso de las muestras en cada instante y el peso inicial.

\section{- Ensayos de tensión-deformación del material trenzado}

Las propiedades mecánicas de la trenza de PLA fueron caracterizadas mediante dos tipos de ensayos mecánicos: ensayos de tensión-deformación y ensayos dinámicos. Ambos fueron realizados en 
una máquina electromecánica (MICROTEST SCM 4000 98, España) con una célula de carga de $400 \mathrm{~N}$. Las medidas fueron realizadas a temperatura ambiente por triplicado.

Los ensayos de tensión-deformación del material trenzado y de 4 hilos obtenidos al destrenzar la trenza de PLA, cada hilo compuesto de 4 fibras con 150 microfibras (600 microfibras en total), fueron realizados a una velocidad de deformación de $5 \mathrm{~mm} / \mathrm{min}$, registrándose los valores de carga y deformación a 1 dato/s. El módulo de Young se calculó a partir de la pendiente de la región lineal de la curva obtenida de acuerdo con la ecuación (3):

$E=\frac{\sigma}{\varepsilon}=\frac{\Delta F / S}{\Delta l / l}$

donde $\Delta \mathrm{F}$ es la fuerza aplicada, $\mathrm{S}$ es la sección transversal efectiva de la muestra, $\mathrm{l}$ es la longitud y $\Delta \mathrm{l}$ es la deformación de la muestra trenzada. Tanto la sección transversal de las microfibras como la sección transversal efectiva de la trenza fueron calculadas mediante la ecuación (1) anteriormente citada.

La extensión de zona toe, $\varepsilon_{\text {toe, }}$ (parte no lineal de la curva previa a la zona del comportamiento lineal) se define como la deformación a la que la línea tangente trazada en la parte lineal de la curva se separa de la curva. El límite de linealidad $\left(\sigma_{\lim }\right)$ se tomó como la mayor tensión alcanzada cuando cesa el comportamiento lineal. Trenzas tal y como fueron recibidas y trenzas después de ser sometidas a degradación después de diferentes tiempos fueron sometidas a ensayos de tensión- 
deformación del tipo descrito anteriormente hasta alcanzar la rotura, con el fin de determinar la tensión de rotura y el \% de elongación. En la Fig. 2.11 se muestra la curva típica de tensión deformación de un tendón.

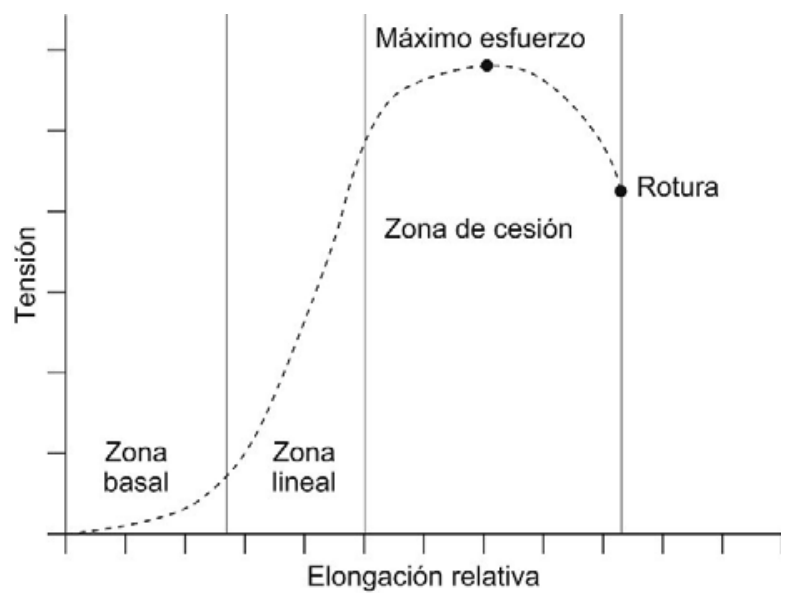

Fig. 2.11 Gráfica típica de tensión-deformación de un tendón representado las zonas típicas: basal, lineal y de cesión [111].

Los ensayos dinámicos de la trenza de PLA fueron realizados seleccionando los valores de fuerza aplicada con el fin de asegurar deformaciones dentro de la región lineal del material, entre $30 \mathrm{~N}-90 \mathrm{~N}$, lo que corresponde a tensiones de entre 20 y $70 \mathrm{MPa}$. Se aplicó una fuerza de tracción a $5 \mathrm{~mm} / \mathrm{min}$ hasta $60 \mathrm{~N}$ de carga y alcanzada esta fuerza se aplicó 100 ciclos de carga sinusoidal de amplitud $30 \mathrm{~N}$ a una frecuencia de $0.5 \mathrm{~Hz}$. Se registró 5 de los 10 ciclos tomando 20 datos/s. La pérdida de energía por unidad de volumen en cada ciclo se calculó a partir de la 
zona del ciclo de histéresis mecánica debido al desfase entre la tensión y la deformación, mediante la ecuación (4):

$\%$ Histeresis $=\frac{W_{c}}{W_{T}} .100$

donde $W_{c}$ es el área de superficie encerrada en el ciclo de histéresis y $W_{T}$ el área encerrada entre la curva de tracción del ciclo y el eje de deformación. Los datos que se aportan son el promedio de tres muestras ensayadas.

\section{- Ensayos de degradación del material trenzado}

Se estudió la degradación hidrolítica de la trenza hueca de PLA en tres medios distintos: una solución tampón de fosfato salino, PBS, con pH 7.4, una solución de $\mathrm{NaOH} 0.01 \mathrm{~N}$ con pH 11 y una solución de $\mathrm{HCl}$ $0.001 \mathrm{~N}$ con $\mathrm{pH} 3$ a $37^{\circ} \mathrm{C}$. El ensayo de las trenzas inmersas en medio neutro tuvo una duración de 12 meses, mientras que el ensayo de las trenzas inmersas en medio ácido y en medio básico duró un mes. Fueron preparadas tres réplicas para cada tiempo, teniendo trenzas de $10 \mathrm{~cm}$ para la caracterización mecánica y trenzas de $1 \mathrm{~cm}$ para el resto de la caracterización. Antes de empezar el estudio se pesó cada muestra obteniendo la masa inicial $\left(m_{0}\right)$, mediante el uso de una balanza analítica (XS Excellence, USA). La solución neutra fue renovada semanalmente y las soluciones ácida y básica, cada $48 \mathrm{~h}$. El pH de la solución se midió en cada cambio de medio mediante un pH-metro (Eutech Instrumentos modelo PH1500, Singapur) para asegurar que se 
mantenía estable el pH de las soluciones. En el caso de la degradación en PBS, las muestras fueron retiradas mensualmente hasta los 6 meses, después fueron retiradas cada dos meses hasta llegar al año. En el caso de la degradación básica y ácida fueron retiradas a 2, 4, 7, 14 y 30 días. El grupo de trenzas extraído, se lavó con agua destilada a $50^{\circ} \mathrm{C}$ para no afectar a las propiedades del material y para eliminar posibles sales de la superficie y se secó a $37^{\circ} \mathrm{C}$ y vacío hasta peso constante antes de proceder a la caracterización. El peso de las trenzas después de la degradación $\left(m_{d}\right)$ permitió calcular la pérdida de peso mediante la ecuación (5):

Pérdida de peso $(\%)=\frac{\left(\mathrm{m}_{0}-m_{d}\right)}{m_{0}} .100$

Las propiedades mecánicas de las trenzas degradadas en distintos tiempos fueron determinadas como se ha explicado anteriormente, obteniéndose el módulo de Young, el límite de linealidad $\left(\sigma_{\lim }\right)$, la tensión de rotura y el \% de elongación.

\section{- Cromatografía de permeabilidad en gel (GPC)}

Para determinar la distribución de los pesos moleculares en la trenza de PLA, se utilizó la técnica de cromatografía de permeabilidad en gel (GPC), mediante el uso del software del Cromatógrafo HPLC_GPC, (modelo Waters 1525) con el detector del índice de refracción. Las muestras fueron disueltas en tetrahidrofurano, grado ACS (THF) (Sharlab) $6 \mathrm{mg} / \mathrm{ml}$. Para la calibración fueron utilizados patrones de 
poliestireno. A partir de la distribución de los pesos moleculares se obtuvo: el peso molecular promedio en peso $\left(\mathrm{M}_{\mathrm{w}}\right)$, el peso molecular promedio en número $\left(\mathrm{M}_{\mathrm{n}}\right)$ y el índice de polidispersión (PDI), obtenido del cociente entre $M_{w} / M_{n}$.

\section{- Cálculo del volumen inyectable en el interior del material trenzado}

La cantidad de volumen que puede albergar el interior de la trenza de PLA, ver Fig. 2.12, de diámetro externo $2 \mathrm{~mm}$, diámetro interno 0.9 mm y longitud $4 \mathrm{~cm}$, se calculó mediante la ecuación (6):

$$
V_{\text {cilindro }}=\pi \cdot r^{2} \cdot h
$$

Siendo $\mathrm{r}$ el radio del cilindro interno y $\mathrm{h}$ la longitud de la muestra.

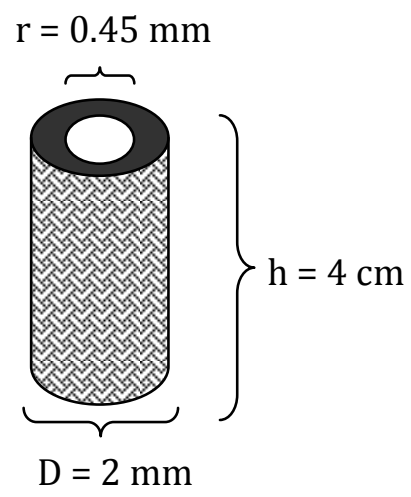

Fig. 2.12 Dimensiones de la trenza hueca de PLA. 


\section{- Microscopía electrónica de barrido (SEM)}

La morfología de los materiales de que consta el prototipo de prótesis: material trenzado, recubrimiento y micropartículas, fue observada mediante el microscopio electrónico de barrido (SEM, modelo JEOL JSM-5410, Japón) con un voltaje de $10 \mathrm{kV}$. Previamente, las muestras después de ser montadas en portas de cobre mediante una cinta conductiva con grafito fueron recubiertas con una fina capa de oro mediante la técnica de pulverización. Con respecto a la morfología de la trenza de PLA, el diámetro interior y exterior de la trenza, el ángulo de trenzado y el diámetro de las microfibras fueron medidas a partir de las imágenes $(\mathrm{n}=3)$ calculándose el valor promedio.

\section{- Distribución de tamaños de las micropartículas}

La distribución de tamaños de las distintas micropartículas se obtuvo mediante el método basado en análisis de imágenes $(n=3)$ adquiridas mediante lupa (Leica MZ APO, Alemania). Se midió el diámetro de 250300 micropartículas aproximadamente y se calculó el diámetro promedio. Se representó la distribución de tamaños obteniendo el \% de frecuencia del diámetro promedio de cada rango.

\section{- Consistencia del recubrimiento}

La morfología del recubrimiento del material trenzado de PLA realizado a distintos tiempos mediante la técnica de electrospinning, se observó mediante el microscopio electrónico de barrido (SEM). 
Asimismo, se midió el espesor del recubrimiento en distintas zonas a partir de las imágenes obtenidas en SEM $(n=2)$ calculándose el valor promedio. Además, las trenzas de PLA recubiertas con HA fueron sumergidas en $\mathrm{H}_{2} \mathrm{O}$ durante $24 \mathrm{~h}$. Transcurrido este tiempo las trenzas fueron fotografiadas mediante una cámara digital calculándose el espesor del recubrimiento en estado hinchado. 


\subsection{CULTIVOS CELULARES}

\subsubsection{Citotoxicidad del material trenzado}

El ensayo de citotoxicidad celular del material trenzado esterilizado con distintos medios, se llevó a cabo siguiendo la norma UNE-EN IS010993-5 mediante el método indirecto. El ensayo se basa en el estudio de la viabilidad celular en un medio de cultivo que había estado previamente en contacto con el material durante $24 \mathrm{~h}$ a $37^{\circ} \mathrm{C}$ y constante agitación, $60 \mathrm{rpm}$, en condiciones estériles. Para ello, la trenza de PLA fue sometida a diferentes métodos de esterilización: 1) la inmersión en una solución acuosa de etanol al 70\%, (EtOH 70\%) durante 4 h con cambios cada $30 \mathrm{~min}, 2$ ) la exposición a una irradiación ultravioleta de 30W (UV) durante la noche, y 3) autoclave (Mocom Proxima, Alemania), durante $30 \mathrm{~min}$ a $120^{\circ} \mathrm{C}$. Hay que añadir, que el método (1), etanol al 70\%, no era considerado un método de esterilización, era un método de desinfección. No obstante, se comparó con los otros dos métodos de esterilización con el fin de elegir la metodología del estudio.

Las células utilizadas para el ensayo fueron los fibroblastos de ratón de la línea celular L929. El látex fue utilizado como material de control positivo y un pocillo vacío de la placa de cultivo se utilizó como control negativo. 
Para obtener los extractos, $1 \mathrm{~g}$ de trenza y $1 \mathrm{~g}$ de látex fueron incubados por separado en $20 \mathrm{ml}$ de DMEM con $4.5 \mathrm{~g} / \mathrm{l} \mathrm{D}$-glucosa, suplementado con un $10 \%$ de FBS, un 1\% penicilina/estreptomicina y un $1 \%$ L-glutamina, sin rojo de fenol, durante $24 \mathrm{~h}$ a $37^{\circ} \mathrm{C}$ a $60 \mathrm{rpm}$. Seguidamente, 3500 células/pocillo fueron sembradas en placas de 48 pocillos; a las 24 h de cultivo se reemplazó el medio por los extractos: en el caso del control positivo, fueron incubadas con el medio de látex, en el caso del control negativo, medio normal. Posteriormente las placas fueron incubadas a $37^{\circ} \mathrm{C}$ y $5 \% \mathrm{CO}_{2}$, manteniendo el extracto como medio de cultivo los 14 días de la duración del ensayo. Las muestras fueron extraídas a 1, 3, 7 y 14 días.

\subsubsection{Cultivo in vitro de fibroblastos de ratón (L929) en los componentes de la prótesis}

Los cultivos in vitro sobre los distintos materiales del prototipo de prótesis, material trenzado, los tres tipos de micropartículas y combinaciones entre ellas fueron realizados a distintos tiempos 1, 7 y 14 días. Se estudió la viabilidad, la adhesión y la proliferación celular. Para la realización de los cultivos, las células fueron cultivadas en flascones de $75 \mathrm{~cm}^{2}$ utilizando el medio de cultivo para las L929, DMEM con $4.5 \mathrm{~g} / \mathrm{l}$ D-glucosa, suplementado con un 10\% de FBS, un 1\% penicilina/estreptomicina y un 1\% L-glutamina. Una vez llegado a una confluencia mayor del $80 \%$, las células fueron desprendidas 
enzimáticamente del flascón utilizando $5 \mathrm{ml}$ de tripsina y fueron contadas en una cámara de Neubauer (Labor Optik, China).

\subsubsection{Cultivo en el material trenzado}

Una vez desinfectado el material trenzado de PLA de $8 \mathrm{~mm}$ de longitud, con EtOH 70\% y acondicionado 24 h en DMEM con 4.5 g/l Dglucosa sin FBS, se procedió a realizar el cultivo con las L929. Posteriormente, $50 \mu$ de una suspensión celular de $11 \times 10^{3}$ células fueron sembradas sobre la superficie de cada trenza de PLA. Las muestras fueron incubadas a $37^{\circ} \mathrm{C}$ y $5 \% \mathrm{CO}_{2}$ durante $1 \mathrm{~h}$ con el fin de promover la adhesión celular y después se añadió medio de cultivo. El cultivo en los pocillos de la placa de P48 fue utilizado como control. Cada experimento se realizó por triplicado. Trenzas sin células fueron procesadas bajo las mismas condiciones y utilizadas como referencia. El medio de cultivo se renovó cada 3 días. Los tiempos de ensayo fueron 1, 7 y 14 días.

\subsubsection{Cultivo sobre las micropartículas}

Las micropartículas de distintos materiales (PLLA, CHT y HA) y combinaciones de PLLA:HA en proporción 1:2 y 2:1, fueron pesadas y desinfectadas con EtOH 70\% antes de realizar el cultivo con las L929 en los microtubos de $1.5 \mathrm{ml}$. Las muestras fueron acondicionadas $24 \mathrm{~h}$ en 
DMEM con 4.5 g/l D-glucosa sin FBS. Transcurrido dicho tiempo se añadió $100 \mu \mathrm{l}$ de la suspensión celular con una concentración de $1 \times 10^{5}$ células/50 mg de micropartículas. Éstas fueron mantenidas $1 \mathrm{~h}$ sin añadir más medio de cultivo con el fin de mejorar la adhesión celular. Seguidamente, se completó medio de cultivo hasta alcanzar los $1000 \mu$ l. El medio de cultivo se renovó cada 3 días en ambiente de $37^{\circ} \mathrm{C}$ y $5 \%$ de $\mathrm{CO}_{2}$. Cada experimento se realizó por triplicado, y se utilizó como control el cultivo en un microtubo y como referencia, micropartículas sin células procesadas bajo las mismas condiciones. Los tiempos de ensayo fueron 1,7 y 14 días.

Por otra parte, con el fin de averiguar a qué tiempo se formaban los primeros aglomerados de células-micropartículas, se realizó un cultivo a tiempos cortos, 1, 2, 3, y 6 h sobre micropartículas de PLLA siguiendo los pasos anteriores.

\subsubsection{Cultivo in vitro de células mesenquimales humanas de médula ósea (hMSCs) en los componentes de la prótesis}

Para el estudio fueron realizados cultivos in vitro a tiempos largos sobre el material trenzado y los tres tipos de micropartículas, PLLA, CHT y HA. Se evaluó y comparó la viabilidad, la morfología y la proliferación celular de las $h M S C s$, en los diferentes soportes. Por último se realizó un estudio de diferenciación de las hMSCs a tenocitos en la trenza de PLA y en las micropartículas de PLLA mediante el uso de 
BMP-12 y un combinado de IGF-I con TGF- $\beta 1$ (medios de diferenciación tenocítica descritos en el apartado 2.1.4 del presente capítulo). Se estudió la morfología adoptada de las células en los substratos mediante SEM y confocal. Para estudiar la diferenciación se analizó la expresión en las células de colágeno tipo I y tenomodulina mediante inmunofluorescencia. También fueron cuantificadas la tenomodulina y la decorina mediante la técnica de reacción en cadena de la polimerasa (q-PCR).

Para ello, una vez las células fueron recogidas, la fracción enriquecida en $h M S C$ fue separada en Percoll (Sigma) mediante un gradiente de sedimentación de 20.000 g durante 15 min y suspendida en medio Dulbecco's Modified Eagle Medium, con $4.5 \mathrm{~g} / \mathrm{l}$ D-glucosa (DMEM, Sigma). Las $h M S C s$ en pase 0 fueron cultivadas en flascones de $75 \mathrm{~cm}^{2}$ utilizando el medio Dulbecco's Modified Eagle Medium, DMEM (Fisher) $4.5 \mathrm{~g} / \mathrm{l} \mathrm{D}$-glucosa, suplementado con $10 \%$ de suero bovino fetal FBS (Fisher), 1\% penicilina/estreptomicina, 1\% L-glutamina (Lonza) y un $0.5 \%$ de Amphotericin B Solution (Sigma). El medio se renovó dos veces por semana y fueron seleccionadas aquellas células capaces de adherirse, eliminando las células flotantes en el medio a las primeras $72 \mathrm{~h}$. Una vez llegado a una confluencia del $80 \%$ aproximadamente, las células fueron desprendidas de los flascones usando tripsina y fueron suspendidas en DMEM con $10 \%$ de FBS. Estos ensayos fueron realizados en el Laboratorio de Bioingeniería y Regeneración Tisular (LABRET) de la Universidad de Málaga (UMA). 


\subsubsection{Cultivo en el material trenzado y sobre las micropartículas}

\section{sintetizadas.}

Una vez esterilizado todos los materiales y acondicionados $24 \mathrm{~h}$ en DMEM con 4.5 g/l D-glucosa sin FBS, se procedió a su cultivo. Tanto el material trenzado como los diferentes tipos de micropartículas (PLLA, CHT y HA) fueron cultivados siguiendo el procedimiento tal y como se describe en los apartados 2.3.2.1 y 2.3.2.2 con la diferencia de que las células utilizadas fueron las $h M S C s$.

\subsubsection{Diferenciación de las células hMSCs a tenocitos en la trenza de PLA y en las micropartículas de PLLA}

El cultivo se efectuó sobre la trenza de PLA y sobre las micropartículas de PLLA. El cultivo se realizó siguiendo las mismas condiciones del ensayo anterior, con la diferencia de que a partir del día 7 el medio de cultivo utilizado fue el medio diferenciador. Por una parte se experimentó muestras cultivadas con medio de cultivo de las células hMSCs suplementado con BMP-12 y por otra parte se experimentó con muestras cultivadas con medio de cultivo de las hMSCs suplementado con una mezcla de TGF- $\beta 1$ y IGF-1. El cultivo se realizó a 1, 7, 14 y 21 días en ambiente de $37^{\circ} \mathrm{C}$ y $5 \%$ de $\mathrm{CO}_{2}$. El medio de cultivo se renovó cada 3 días hasta alcanzar 7 días de cultivo. Transcurrido ese tiempo, se renovó cada 48 h hasta finalizar el ensayo. 


\subsubsection{Cultivo in vitro en el prototipo de prótesis en régimen estático y dinámico}

Los cultivos in vitro de las células L929 tanto en régimen estático como en régimen dinámico fueron realizados durante un período de 14 días con el fin de evaluar y comparar como responden las células tras el estímulo mecánico aplicado. Las células fueron cultivadas en la prótesis utilizando el soporte seleccionado, una combinación de micropartículas de PLLA:HA con células pre-sembradas. Como muestra control se utilizó la trenza de PLA recubierta con HA y cultivada mediante la inyección de una suspensión celular. Finalmente, se realizó el ensayo tanto en régimen estático como en régimen dinámico utilizando células mesenquimales provenientes del tejido adiposo, $A D S C$, de oveja. El cultivo se realizó en el prototipo de prótesis con relleno de células en combinación de micropartículas de PLLA:HA con células presembradas.

Se caracterizó la morfología celular mediante SEM y la tinción del citoesqueleto de actina. Se cuantificó la producción de componentes de la matriz extracelular (colágeno tipo I y glicosaminoglicanos (GAGs)).

\subsubsection{Verificación de la funcionalidad del biorreactor}

Con respecto a los ensayos en régimen dinámico, antes de realizar los ensayos con el prototipo de prótesis, se realizó un ensayo dinámico a 7 y 14 días para demostrar que el prototipo de biorreactor diseñado 
transmitía el estímulo mecánico a las células y para adaptar y mejorar el manejo del mismo. El cultivo de las L929 se realizó en la superficie del material trenzado. Aunque el biorreactor está diseñado para colocar tres muestras, los ensayos fueron realizados con dos.

Inicialmente el biorreactor se esterilizó mediante el autoclave junto con el resto del material necesario para proceder a su montaje (carcasa del biorreactor, cable, funda del cable, destornillador y llaves Allen, entre otros). Una vez esterilizado se procedió al cultivo.

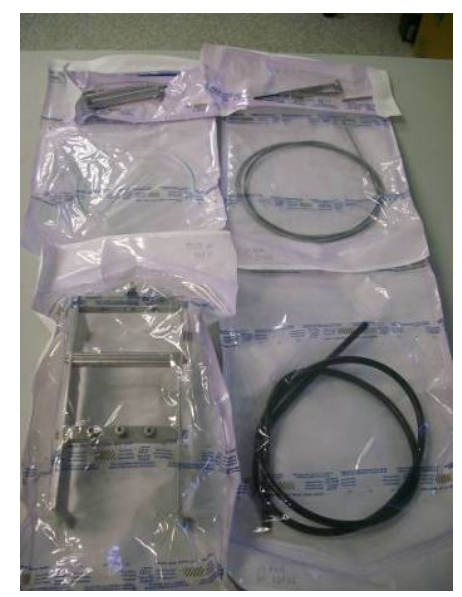

Fig. 2.13 Biorreactor y material de montaje a utilizar en el ensayo antes de proceder al cultivo (carcasa del biorreactor, cable, funda del cable, destornillador, llaves Allen y placa petri).

La trenza de PLA de $10 \mathrm{~cm}$ de longitud fue unida en ambos extremos a una trenza de Kevlar de $5 \mathrm{~cm}$. Una vez realizada la unión, el material se desinfectó con EtOH 70\%, se acondicionó con PBS durante una noche 
y con DMEM con 4.5g/l D-glucosa sin FBS durante $24 \mathrm{~h}$ antes de proceder al cultivo. Posteriormente, $100 \mu \mathrm{l}$ de una suspensión celular ( $1 \times 10^{5}$ células) fueron sembradas sobre la superficie del material trenzado, tal y como se muestra en la Fig. 2.14 a, e incubadas a $37^{\circ} \mathrm{C}$ y $5 \% \quad \mathrm{CO}_{2}$ durante $1 \mathrm{~h}$. Transcurrido dicho tiempo se procedió a montarlas en el biorreactor previamente esterilizado (ver Fig. 2.14b), y se añadió medio de cultivo hasta cubrir las muestras, $110 \mathrm{ml}$ aproximadamente, Fig. 2.14c. Finalmente se trasladó al incubador y se conectó al motor, Fig. 2.14d. El tiempo de ensayo fue de 7 y 14 días con dos réplicas por tiempo $(\mathrm{n}=2)$. El medio de cultivo se renovó semanalmente en ambiente de $37^{\circ} \mathrm{C}$ y $5 \%$ de $\mathrm{CO}_{2}$. 

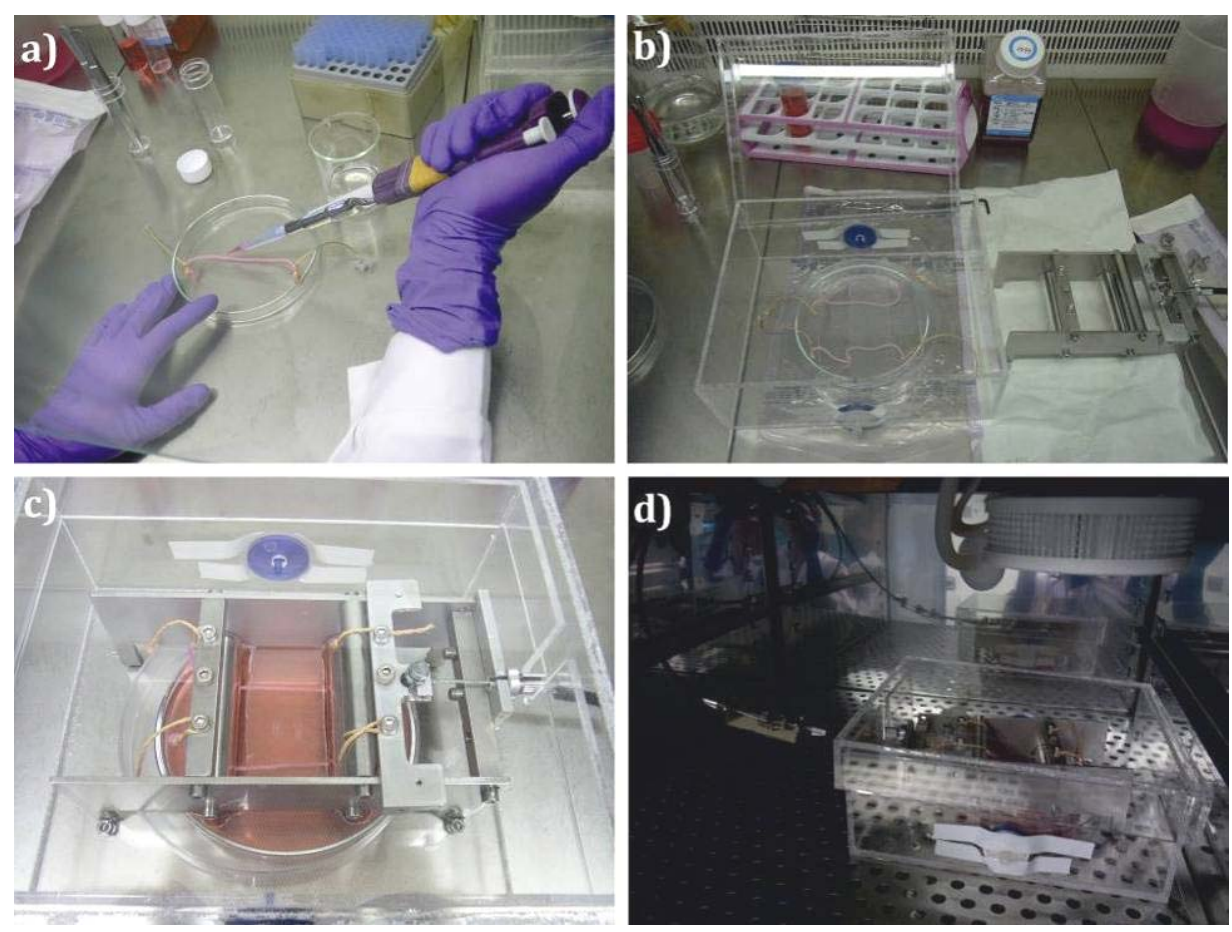

Fig. 2.14 Ensayo in vitro en régimen dinámico del cultivo de L929 sobre el material trenzado a 7 y 14 días. a) Siembra sobre la trenza de PLA, b) montaje de las trenzas en el biorreactor, c) Añadir medio de cultivo y d) conexión del biorreactor al motor desde dentro del incubador.

\subsubsection{Cultivo del prototipo de prótesis mediante L929}

La trenza de PLA fue recubierta con HA mediante la técnica de electrospinning durante $30 \mathrm{~min}$, tal y como se describe en el apartado 2.2.2. Para los ensayos en régimen estático fueron utilizadas trenzas recubiertas de HA de $4 \mathrm{~cm}$ de longitud mientras que en los ensayos en régimen dinámico, las trenzas empleadas fueron de $10 \mathrm{~cm}$ de longitud. 
En la Fig. 2.15 se muestran los pasos seguidos para realizar el cultivo en el prototipo de prótesis final. Inicialmente, la trenza de PLA recubierta con HA se desinfectó con EtOH al 70\% y se realizó un intercambio controlado de EtOH 70\% a PBS (Fig. 2.15a). Después de que la trenza recubierta de HA estuviera en PBS durante una noche se procedió a acondicionarla con DMEM $4.5 \mathrm{~g} / \mathrm{l}$ D-glucosa y sin FBS durante 24 h. Posteriormente, se procedió a la inyección del relleno, células pre-sembradas durante $4 \mathrm{~h}$ sobre micropartículas de PLLA:HA en proporción 2:1, utilizando una jeringa y una aguja de $0.5 \mathrm{~mm}$ de diámetro. El relleno se inyectó por ambos extremos de la trenza de PLA, con el fin de distribuir el relleno de una forma homogénea (Fig. 2.15b y Fig. 2.15c).

Una vez realizado el cultivo, las muestras fueron incubadas durante $1 \mathrm{~h}$ a $37^{\circ} \mathrm{C}$ y $5 \%$ de $\mathrm{CO}_{2}$. Transcurrido este tiempo, las muestras destinadas al ensayo con el biorreactor fueron ubicadas en el mismo, (Fig. 2.15d y Fig. 2.15e). El estímulo mecánico fue aplicado durante 9 h/día como valor promedio. Las muestras para el ensayo en régimen estático fueron cultivadas en una placa petri (Fig. 2.15f).

Como muestra control se utilizó el material trenzado recubierto con HA y se inyectó una suspensión celular $\left(1 \times 10^{5}\right.$ células suspendidas en $100 \mu \mathrm{l}$ de medio de cultivo). Los ensayos fueron realizados durante 14 días a $37^{\circ} \mathrm{C}$ y $5 \%$ de $\mathrm{CO}_{2}$. El medio se renovó cada 3 días. 

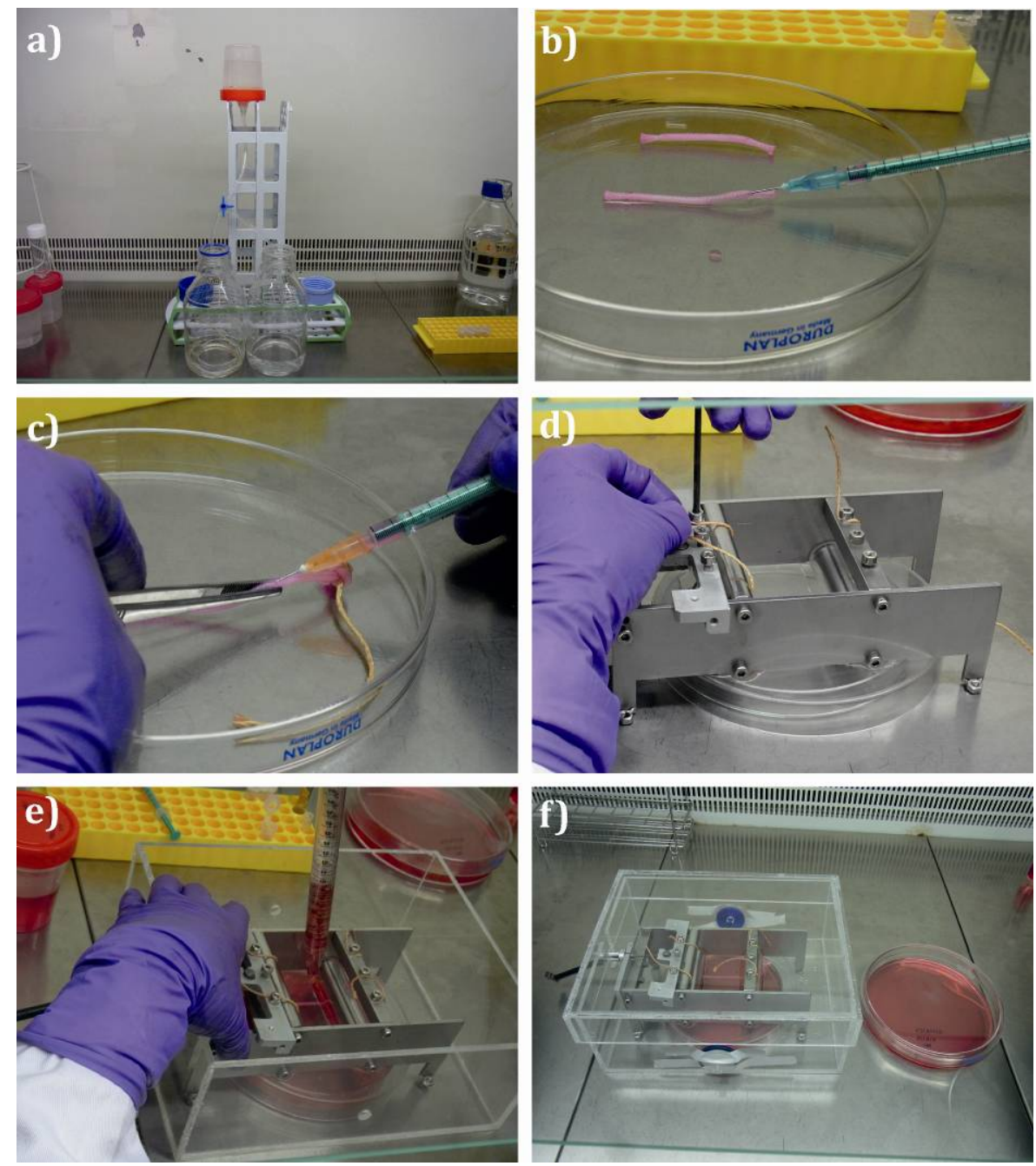

Fig. 2.15 Cultivo del prototipo de prótesis. a) Intercambio de EtOH 70\% a PBS del material trenzado recubierto con $\mathrm{HA}$, b) inyección del relleno en la prótesis para el ensayo en estático, c) inyección del relleno en la prótesis para el ensayo en dinámico, d) ajuste de la prótesis en el biorreactor, e) adición de medio de cultivo y f) cultivo en el biorreactor y en placa petri para ensayo en régimen estático y dinámico a 14 días de cultivo. 


\subsubsection{Cultivo del prototipo mediante ADSC}

El cultivo del prototipo de prótesis en régimen estático y dinámico, utilizando como relleno una combinación de micropartículas (PLLA:HA) pre-sembradas con las $A D S C$ de oveja, se efectuó siguiendo los mismos pasos que en el apartado 2.3.4.2.

\subsubsection{Técnicas de caracterización biológica}

\section{- Estudio de la viabilidad celular mediante MTS}

La viabilidad celular se evaluó utilizando (3-(4,5-dimetiltiazol-2-il)5-(3-carboximetoxifenil)-2(4-sulfofenil)-2H-tetrazolio), mediante el Cell Titer 96 Aqueous One Solution Cell Proliferation Assay, MTS (Promega). Se analiza mediante un método colorimétrico que determina el número de células vivas debido a la bio-reducción del reactivo de Owen, por la acción de las co-enzimas NADPH (Nicotinamida-Adenina Dinucleotido fosfato) o NADH producidas en las enzimas deshidrogenasas presentes en las células metabólicamente activas. Como consecuencia se obtiene un producto coloreado, el formazán, el cual es soluble en el medio de cultivo y puede ser cuantificado midiendo la absorbancia. Una vez transcurrido el tiempo de cultivo, el material trenzado (trenza-células) fue transferido a placas de 48 pocillos y lavado repetidas veces con PBS; las micropartículas fueron lavadas en los mismos microtubos. El medio de cultivo DMEM, 
pero esta vez sin rojo fenol y sin FBS se mezcló con el reactivo MTS en relación 5:1 y posteriormente fue añadido hasta cubrir totalmente los materiales. Tras 3 horas de incubación con $5 \%$ de $\mathrm{CO}_{2}$ a $37^{\circ} \mathrm{C}$ y en ausencia de luz, fueron extraídos $100 \mu$ de medio y depositados en placas de 96 pocillos para medir la absorbancia a $490 \mathrm{~nm}$ utilizando un lector multiplacas (Victor 3, PerkinElmer, EEUU). El ensayo se realizó por triplicado.

\section{- Estudio de la adhesión y de la morfología celular mediante SEM}

Para estudiar la adhesión y la morfología adoptada por las células cultivadas sobre los distintos soportes: trenza de PLA, diferentes micropartículas y prototipo de prótesis se empleó el microscopio electrónico de barrido con un voltaje de $10 \mathrm{kV}$. Las muestras fueron lavadas 2 veces con PBS y fijadas con una disolución de glutaraldehido al $2.5 \%$ durante $1 \mathrm{~h}$ a $4^{\circ} \mathrm{C}$. Transcurrido dicho tiempo fueron lavadas con PBS 3-4 veces en intervalos de 5 min. Previamente a la observación en SEM las muestras fueron deshidratadas realizando cambios a distintas concentraciones de $\mathrm{EtOH}$ (30\%, 40\%, 50\%, 60\%, 70\%, 80\%, $90 \%, 98 \%, 100 \%$ ) cada 5 min. Las muestras fueron secadas por el método del punto crítico y fueron recubiertas con oro para su posterior análisis. Para analizar la morfología celular en el interior del prototipo, la muestra se cortó con la ayuda de un bisturí. 
- Estudio de la morfología y de la diferenciación celular mediante ensayos inmunofluorescencia

Se estudió la morfología celular mediante la tinción del citoesqueleto de actina y se evaluó la expresión de colágeno tipo I y de la tenomodulina contenido en la matriz extracelular. Para ello, cumplido el tiempo de cultivo, las muestras fueron lavadas 1 vez con PBS, fijadas con una disolución de formalina al $10 \%$ durante $1 \mathrm{~h}$ a $4^{\circ} \mathrm{C}$ y finalmente lavadas 3 veces con PBS.

Para la preparación de la tinción del citoesqueleto de actina, las muestras fueron lavadas con tampón fosfato (PB) $0.1 \mathrm{M}$ durante $5 \mathrm{~min}$ a temperatura ambiente. Seguidamente, se añadió el tampón bloqueo (TB) que contenía $8.9 \mathrm{~mL}$ de PB (0.1 M), $1 \mathrm{~mL}$ de FBS (10\%) y $0.1 \mathrm{~mL}$ de triton X-100 al $0.1 \%$ durante $2 \mathrm{~h}$ a temperatura ambiente. Posteriormente, se añadió el tampón bloqueo junto con $10 \mu \mathrm{l}$ de bodipy-FL phallacidin (Invitrogen) por cada muestra y se mantuvo durante toda la noche a $4^{\circ} \mathrm{C}$ y en ausencia de luz. Transcurrido dicho tiempo, se eliminó esta disolución y se realizó tres lavados con PB 0.1 M cada 5 min. Seguidamente se procedió al montaje en el portaobjetos y se adicionó una gotita de medio de montaje con 4'6-diamino-2fenilindol (DAPI) incorporado (Vectashield, Vector Laboratories, Inglaterra) que permitió teñir los núcleos celulares. 
Para la preparación de la inmunofluorescencia del colágeno tipo I (Col I) (Chemicon) las muestras fueron lavadas con PB $0.1 \mathrm{M}$ durante 5 min a temperatura ambiente. Seguidamente se añadió el tampón bloqueo (TB) durante 2 h. Posteriormente, se añadió la mezcla madre preparada de anticuerpo (Ac) primario en proporción 1:40 (Col I:TB), $150 \mu \mathrm{l}$ en el material trenzado y $100 \mu \mathrm{l}$ en las micropartículas. Se dejó incubando toda la noche a temperatura ambiente. Se eliminó esta disolución y fueron realizados tres lavados con PB $0.1 \mathrm{M}$ cada 5 min. Se preparó la mezcla madre del Ac secundario Cy3 (Abcam) en TB en proporción 1:200 (Сy3:TB) añadiendo $10 \mu \mathrm{l}$ de bodipy-FL phallacidin por cada muestra. Una vez resuspendida toda la mezcla, se adicionó 150 $\mu \mathrm{l}$ en el material trenzado y $100 \mu \mathrm{l}$ en las micropartículas. Las muestras fueron mantenidas entre 2-3 horas a temperatura ambiente y en ausencia de luz. Después se eliminó la solución madre y las muestras fueron lavadas 3 veces con solución PB $0.1 \mathrm{M}$ cada cinco minutos a temperatura ambiente. Seguidamente los núcleos celulares fueron teñidos con una disolución de DAPI en proporción 1:1000 (DAPI: $\mathrm{H}_{2} \mathrm{O}$ ) y las muestras fueron incubadas entre $15-30 \mathrm{~min}$ en ausencia de luz. Transcurrido el tiempo, se eliminó esta solución y fueron realizados tres lavados con PB $0.1 \mathrm{M}$ cada $5 \mathrm{~min}$. Seguidamente se procedió al montaje en el portamuestras adicionando una gota de medio de montaje. Las imágenes de las inmunofluorescencias fueron adquiridas mediante microscopio confocal Leica TCS SP2 AOBS con láser invertido, usando un objetivo de aceite. 
Para la detección de la tenomodulina (Santa Cruz Biotechnology, Inc) se siguió los mismos pasos que para la detección del colágeno tipo I utilizando las mismas proporciones del anticuerpo primario 1:40 (Tn:TB) y del secundario 1:200 (Су3:TB).

\section{- Evaluación de distintos marcadores de la membrana celular mediante citometría de flujo}

Se evaluó la expresión de distintos marcadores de superficie celular expresados por las hMSCs mediante citometría de flujo usando las células previamente cultivadas sobre las micropartículas de distintos materiales. El ensayo se realizó a 14 días sobre las micropartículas de: quitosano, ácido hialurónico y ácido poli(L-láctico) y a 21 días utilizando los medios de diferenciación sobre las hMSCs en las micropartículas de ácido poli(L-láctico). Los marcadores utilizados fueron el CD44, HLA-DR y CD166. El CD44 es el receptor del ácido hialurónico y es un marcador expresado también por los tenocitos, siendo así mismo un control positivo de la diferenciación, el HLA-DR se utiliza como marcador negativo en estas células mientras que el CD166 está relacionado con la adhesión celular.

Para la preparación del ensayo, una vez transcurrido el tiempo de estudio se procedió a tripsinizar las células de cada uno de los materiales. Para ello todas las micropartículas de un mismo material fueron transferidas a un tubo de $50 \mathrm{ml}$, fueron lavadas tres veces con PBS e incubadas con $0.5 \%$ de tripsina durante 5 min a $37^{\circ} \mathrm{C}$. 
Seguidamente se inactivó la tripsina mediante la adición de medio y se procedió al filtrado. Para ello, se filtró la solución de células y micropartículas por tamices celulares de: $100 \mu \mathrm{m}, 70 \mu \mathrm{m}$ y $40 \mu \mathrm{m}$ (Becton, Dickinson and Company), para eliminar las micropartículas. Una vez filtrado, se centrifugó y se recogió los pellets correspondientes de cada material. Cada uno de los pellets, fueron lavados dos veces con el tampón FACS que consiste en 10 mM de HEPES (Gibco), 1\% de penicilina/estreptomicina y un $0.2 \%$, albumina de suero bovino BSA (Sigma) en L-15 de Leibovitz (Gibco). Después del lavado, alícuotas de $1 \times 10^{6}$ células fueron incubadas en tampón FACS conteniendo anticuerpos monoclonales: Anti-CD44 y HLA-DR humano (BD Pharmingen TM), y Anti-CD166 (AbD Serotec). Después de 30 minutos en ausencia de luz y en hielo, las células fueron lavadas de nuevo en tampón FACS antes del análisis de citometría de flujo. Quinientos mil eventos por muestra fueron analizaron en un MoFlo ${ }^{\circledR}$ SP1338 (DakoCytomation, Dinamarca) utilizando software Summit. Las células muertas fueron excluidas mediante la tinción con 7-amino-actinomicina D (7-AAD, BD Pharmigen).

El tampón FACS también se utilizó para estudiar la diferenciación tenocítica. Se analizó la expresión de CD44, CD166 y HLA-DR en las células cultivadas en micropartículas de PLLA después de 21 días en medio de diferenciación. 


\section{- Estudio de cuantificación de proteínas mediante q-PCR}

El ensayo de PCR (Reacción en cadena de la polimerasa) cuantitativa, fue realizado por el Laboratorio de Investigación del Hospital Virgen de la Victoria de Málaga, Fundación IMABIS. Se realizó sobre las micropartículas de ácido poli(L-láctico) en contacto con los medios de diferenciación después de 21 días de cultivo. Se estudió y se cuantificó la expresión génica de dos proteínas: la decorina y la tenomodulina, ambas presentes en los tenocitos.

\section{- Estudio de cuantificación de glicosaminoglicanos (GAGs)}

Previo a la cuantificación, se realizó una digestión enzimática. Para ello, las muestras fueron colocadas en un microtubo y se les adicionó $1 \mathrm{ml}$ de agua destilada. Las muestras fueron mantenidas en incubación a $4^{\circ} \mathrm{C}$ durante toda la noche, se eliminó el agua y se adicionó $500 \mu \mathrm{l}$ de ácido acético $50 \mathrm{mM}$, y después $50 \mu \mathrm{l}$ de solución de pepsina $10 \mathrm{mg} / \mathrm{ml}$, (Sigma-Aldrich) en ácido acético $50 \mathrm{mM}$, todo se llevó a agitación a 60 rpm durante 72 horas a $4^{\circ} \mathrm{C}$. Tras este tiempo se adicionó $50 \mu \mathrm{l}$ de TBS 10X sobre cada muestra y se ajustó el pH a 8.0, después se adicionó en cada muestra $50 \mu \mathrm{l}$ de solución de elastasa pancreática $1 \mathrm{mg} / \mathrm{ml}$ (Sigma-Aldrich) solubilizada en TBS $1 X$, todo se mantuvo en agitación a $60 \mathrm{rpm}$ a $4^{\circ} \mathrm{C}$ durante 48 horas. Se centrifugó las muestras a $10000 \mathrm{rpm}$ durante 5 minutos a $4^{\circ} \mathrm{C}$.

El contenido de glicosaminoglicanos en el prototipo de prótesis en régimen estático y dinámico, se determinó utilizando el kit Blyscan 
(Biocolor, RU), siguiendo el protocolo del fabricante. Este ensayo consiste en teñir con azul de dimetilmetileno los componentes de polisacáridos sulfatados. Para el desarrollo del ensayo se utilizó diferentes concentraciones $(0,2,5,10,15,20$ y $30 \mu \mathrm{g} / \mathrm{ml})$ de 4-sulfato de condroitina bovina como estándares para preparar la curva de calibración. Una vez las muestras se encontraban a temperatura ambiente se aplicó vortex durante unos segundos. En un microtubo se depositó $1 \mathrm{ml}$ de blyscan dye reagent y se adicionó $100 \mu \mathrm{l}$ de muestra o estándares, luego los tubos fueron agitados mecánicamente durante 1 hora protegiéndolos de la luz; tras la reacción fueron centrifugadas las muestras a $12000 \mathrm{rpm}$ durante 10 minutos, luego se eliminó el sobrenadante y se adicionó $700 \mu \mathrm{l}$ de reactivo de disociación en cada microtubo. Tras la dilución del colorante (10 min aprox.), se depositó $200 \mu \mathrm{l}$ de la dilución resultante en placa de 96 pocillos y se midió la absorbancia a una longitud de onda de $656 \mathrm{~nm}$ en un espectrofotómetro multiplaca Victor 3, Perkin Elmer.

\section{- Estudio de cuantificación del DNA}

Después de digerir las muestras como se ha detallado en el apartado anterior, el contenido total de ácido desoxirribonucleico (DNA) de las células cultivadas en el prototipo de prótesis fue determinado usando el kit de cuantificación PicoGreen dsDNA (Invitrogen), siguiendo las indicaciones del fabricante. En una placa de 96 pocillos se mezcló $28.7 \mu \mathrm{l}$ de sobrenadante de cada muestra con $71.3 \mu \mathrm{l}$ de Picogreen 
solution y $100 \mu \mathrm{l}$ de buffer TE $1 \mathrm{X}$. Posteriormente las placas fueron incubadas durante 10 min protegidas de la luz y fueron realizadas las medidas de fluorescencia en un lector de multiplacas Victor 3 a una longitud de onda de $490 \mathrm{~nm}$. Cada muestra se midió por triplicado y la concentración de DNA fue obtenida a partir de una curva patrón elaborada a partir de diferentes concentraciones.

\section{- Estudio de cuantificación de colágeno tipo I}

Una vez digeridas las muestras como en los ensayos anteriores, la cuantificación de colágeno tipo I en el prototipo de prótesis fue determinado usando el kit de cuantificación Mouse type I collagen detection kit (Chondrex, EEUU), siguiendo el protocolo del fabricante. En una placa de 96 pocillos se añadió $100 \mu \mathrm{l}$ del anticuerpo de captura y se incubó a $4^{\circ} \mathrm{C}$ toda la noche. Para el desarrollo del ensayo se utilizó diferentes concentraciones $(0,0.08,0.16,0.32,0.63,1.25,2.5 \mu \mathrm{g} / \mathrm{ml}) \mathrm{de}$ una solución estándar de mouse type I collagen para preparar la curva de calibración. Se añadió a cada pocillo $100 \mu \mathrm{l}$ de los estándares y las muestras y fueron incubadas durante $2 \mathrm{~h}$ a temperatura ambiente. Los pocillos fueron lavados tres veces con un buffer de lavado y se añadió $100 \mu \mathrm{l}$ de una solución de estreptavidina peroxidasa por 1 h. Se repitió el lavado y se adicionó $100 \mu \mathrm{l}$ de una solución OPD durante $30 \mathrm{~min}$ a temperatura ambiente. Trascurrido este tiempo se detuvo la reacción añadiendo $50 \mu \mathrm{l}$ de una solución $2 \mathrm{~N}$ de ácido sulfúrico. Finalmente se 
midió la absorbancia a una longitud de onda de $490 \mathrm{~nm}$ en un lector multiplacas Victor 3, Perkin Elmer.

\subsection{ANÁLISIS ESTADÍSTICOS DE LOS RESULTADOS}

Los valores obtenidos fueron representados como un valor promedio con su respectiva desviación estándar. El estudio estadístico fue realizado mediante el programa SPSS 16.0 utilizando $t$ Student y ANOVA. Se consideró un valor de significación estadística con $\mathrm{p}<0.05$. 

Capítulo 3 Resultados y discusión 



\subsection{DETERMINACIÓN DE LAS PROPIEDADES FISICO- QUÍMICAS Y MECÁNICAS DE LOS MATERIALES}

El estudio de las propiedades de los materiales que van a formar parte del prototipo de prótesis se muestra en esta sección. En primer lugar se presenta la caracterización y el estudio de degradación hidrolítica del material trenzado de PLA. Una vez caracterizada la trenza, se muestra la caracterización de los distintos soportes celulares que se han fabricado, las micropartículas de PLLA, de CHT y de HA y del recubrimiento.

\subsubsection{Caracterización del material trenzado de PLA}

La morfología de la trenza hueca de PLA puede observarse en la Fig. 3.1, donde se muestra el aspecto general y los detalles relevantes tales como: el ángulo de trenzado y las dimensiones de la trenza. La trenza está formada por 12 hilos, cada hilo mide $500 \mu \mathrm{m}$ (Fig. 3.1c), y está compuesto por cuatro fibras de 150 microfibrillas. El diámetro observado de las microfibrillas fue de $15 \pm 0,5 \mu \mathrm{m}$ como se observa en la Fig. 3.1d; mientras que los diámetros externo e interno de la trenza fueron de $1.9 \pm 0.2 \mathrm{~mm}$ y $0.9 \pm 0.03 \mathrm{~mm}$ (Fig. 3.1b) respectivamente. El ángulo del trenzado fue medido a partir de las imágenes y el valor obtenido fue de $80 \pm 7^{\circ}$. 


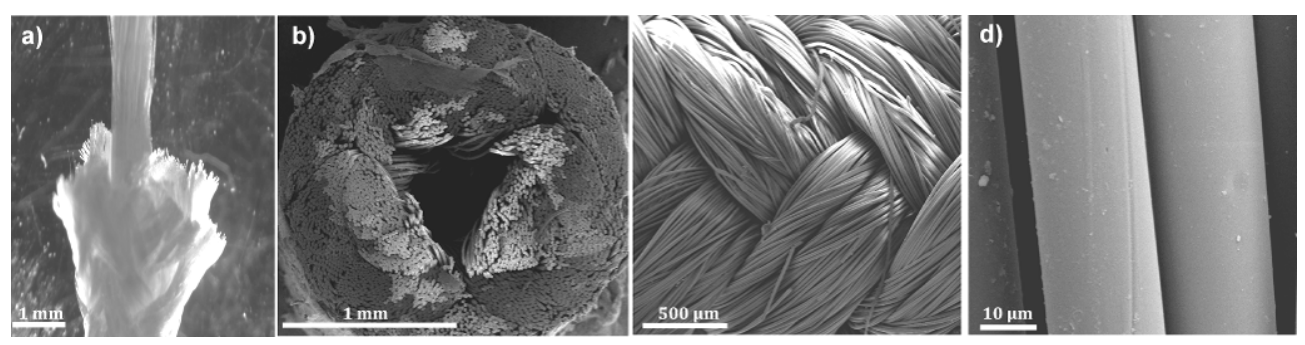

Fig. 3.1 Trenza de PLA utilizada en el estudio: a) aspecto macroscópico de la trenza, b) sección transversal, c) ángulo de trenzado y d) microfibrillas.

La morfología de la trenza es un aspecto importante a considerar, ya que las dimensiones de la trenza, el número de fibras y el ángulo de trenzado determinarán la correcta adaptación de la misma al tendón que se quiera reemplazar. Estudios realizados por Freeman et al. [81], demuestran que solamente modificando el ángulo de trenzado las propiedades mecánicas del material pueden variar.

Se realizó un ensayo de DSC a la trenza hueca de PLA para analizar la calidad química del PLA utilizado por el fabricante. La Fig. 3.2 muestra el termograma obtenido durante el barrido de calentamiento del material tal y como fue recibido. Se observa que a temperatura ambiente, el material se encuentra en estado vítreo (por debajo de su $\mathrm{T}_{\mathrm{g}}$ ). La transición vítrea ocurre aproximadamente a $62^{\circ} \mathrm{C}$; inmediatamente, por encima de esta temperatura se manifiesta claramente en la curva un pico exotérmico, debido a la cristalización de las cadenas, las cuales estaban previamente atrapadas en el estado 
cristalino, y ahora adquieren suficiente movilidad para reacomodarse y cristalizar. A temperaturas aún más elevadas, el material finalmente se funde, y el termograma muestra el típico pico de fusión endotérmico. A partir del termograma la entalpía de cristalización y de fusión se pueden obtener por los procedimientos estándar. Una comparación entre la entalpía de fusión obtenida con la entalpía de fusión del PLA cristalino, nos permite obtener el grado de cristalinidad del material; con el fin de determinar el valor de esta cantidad para el material recibido, la entalpía de cristalización se restó de la entalpía de fusión y el resultado se divide por el valor de la entalpía de fusión del PLA cristalino. Todas estas cantidades se muestran en la Tabla 3.1; y coinciden con los valores de PLA reportado en la literatura [112]. Puesto que la $\mathrm{T}_{\mathrm{g}}$ calculada del material, está unos $25^{\circ} \mathrm{C}$ por encima de la temperatura corporal, los procesos que ocurren en el estado vítreo pueden suponerse con seguridad que estarán ausentes o tendrán lugar a un ritmo muy lento, por lo que la trenza hueca de PLA puede considerarse como un material físicamente estable a temperatura corporal. 


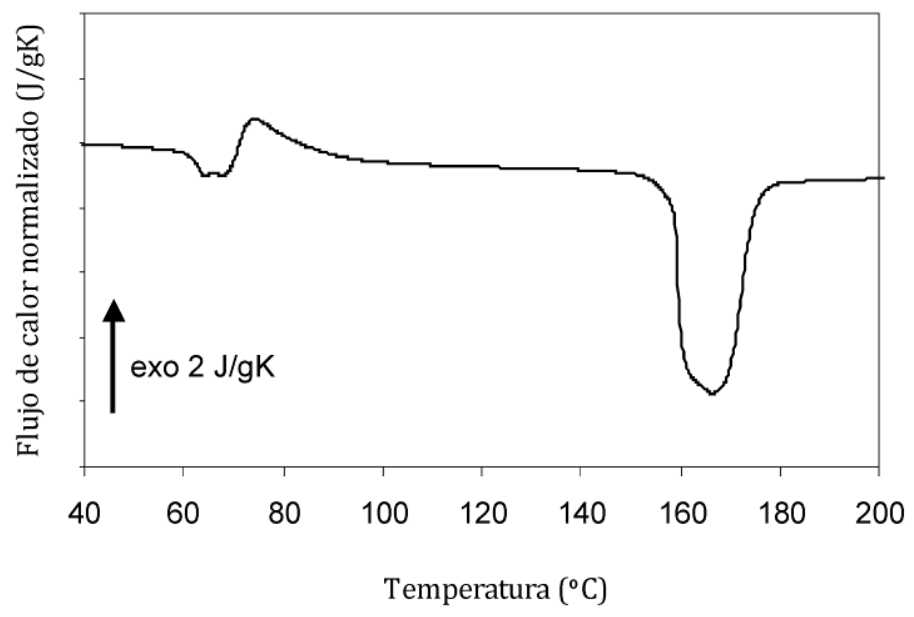

Fig. 3.2 Curvas de DSC de la trenza de PLA.

Los datos de $\mathrm{T}_{\mathrm{g}}, \mathrm{T}_{\mathrm{f}}, \Delta \mathrm{H}_{\mathrm{c}}, \Delta \mathrm{H}_{\mathrm{f}} \mathrm{y} \% X_{c}$ obtenidos se recogen en la siguiente tabla:

\begin{tabular}{|c|c|c|c|c|}
\hline $\mathbf{T}_{\mathbf{g}}\left({ }^{\circ} \mathbf{C}\right)$ & $\Delta \mathbf{H}_{\mathbf{c}}\left(\mathbf{J g}^{-1}\right)$ & $\Delta \mathbf{H}_{\mathbf{f}}\left(\mathbf{J g}^{-1}\right)$ & $\mathbf{T}_{\mathbf{f}}\left({ }^{\circ} \mathbf{C}\right)$ & $\boldsymbol{X}_{\boldsymbol{c}} \mathbf{( \% )}$ \\
\hline 62.4 & 10.7 & 43.8 & 167 & 35.9 \\
\hline
\end{tabular}

Tabla 3.1. Temperaturas de transición vítrea $\left(\mathrm{T}_{\mathrm{g}}\right)$, entalpía de cristalización de cristalización $\left(\Delta \mathrm{H}_{\mathrm{c}}\right)$, entalpía de fusión $\left(\Delta \mathrm{H}_{\mathrm{f}}\right)$, y cristalinidad $\left(X_{c}\right)$ de la trenza de PLA tal y como fue recibida. 
Para confirmar la calidad del PLA utilizado por el fabricante se realizó un estudio de degradación térmica mediante termogravimetría (TGA) a la trenza hueca de PLA. La Fig. 3.3 muestra la derivada de la pérdida de peso obtenida en el ensayo termogravimétrico de la trenza de PLA. Se observa que la degradación térmica empieza aproximadamente en $250^{\circ} \mathrm{C}$ y se completa en los $400^{\circ} \mathrm{C}$, observándose un máximo de velocidad de degradación a $360^{\circ} \mathrm{C}$. Estos valores coinciden con los reportados en la literatura [113].

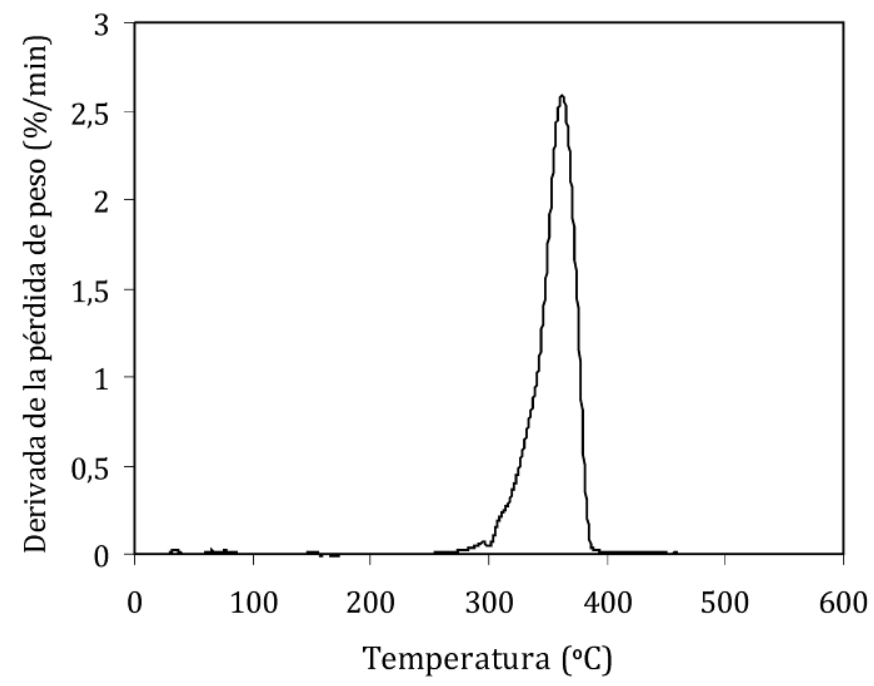

Fig. 3.3 Degradación térmica de la trenza de PLA.

Además del análisis químico realizado a la trenza de PLA, también fueron caracterizadas las propiedades mecánicas tanto de los hilos que componen la trenza, como de la trenza hueca. En la Fig. 3.4 se 
representa la curva típica de tensión-deformación de hilos de la trenza de PLA (a) y de la trenza de PLA (b).

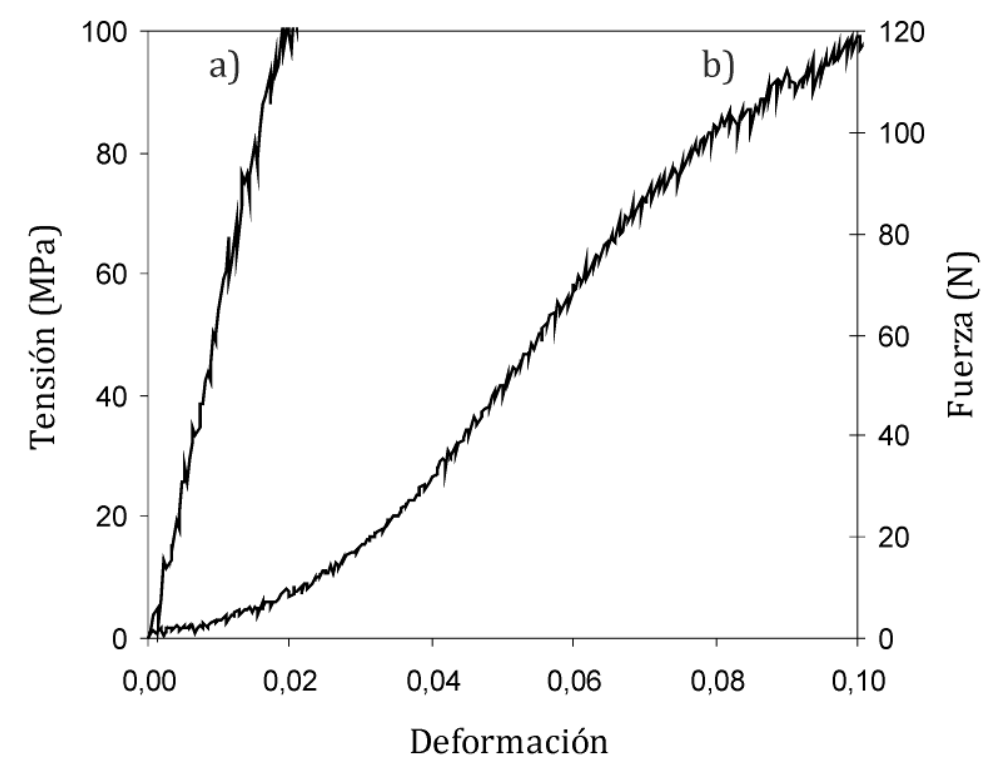

Fig. 3.4 Típica curva tensión (fuerza) - deformación de 4 hilos pertenecientes a la trenza de PLA (a) y de la trenza de PLA (b).

La gráfica muestra que los hilos presentan un comportamiento lineal tras la aplicación de una deformación de $5 \mathrm{~mm} / \mathrm{min}$, el cual difiere del comportamiento no lineal de la trenza hueca. El módulo de Young de los hilos de PLA obtenido en la región lineal es de $5 \pm 0.15 \mathrm{GPa}$. Con respecto a la trenza hueca de PLA, cuando se le aplica una carga, los hilos que la forman empiezan a alinearse en la misma dirección de la carga aplicada, incrementando la deformación con pequeñas cargas, y dando lugar a la primera región de la curva conocida como región toe; el límite de esta 
región es de $\varepsilon_{\text {toe }} 3 \pm 0.1 \%$. Si los hilos siguen orientándose en la dirección de la carga aplicada, la trenza se vuelve más rígida debido al estiramiento de un gran número de hilos, hasta que todos ellos se estiran alcanzando la deformación lineal. El módulo de Young en esta región es de $1370 \pm 90 \mathrm{MPa}$. El comportamiento lineal se pierde para valores de carga mayores que $\sigma_{\lim } 77.5 \pm 0.7 \mathrm{MPa}$; desde este punto, si la carga se incrementa, el módulo de Young disminuye. Se observa que el comportamiento de tensión-deformación de la trenza de PLA es similar al del ligamento y el tendón [114].

Cuando el material se somete a régimen dinámico y se estira bajo ciclos de la misma carga, se observa un incremento de la deformación no recuperable (Fig. 3.5a), siendo el \% de elongación del orden del 7\% después de 90 ciclos. Teniendo en cuenta que el porcentaje de histéresis mecánica es un indicador de la pérdida de energía en cada ciclo, la gráfica Fig. 3.5b muestra una tendencia decreciente estabilizándose alrededor del 9\% después de 50 ciclos. Esta pérdida de energía se debe atribuir tanto a la viscoelasticidad del material como a la fricción entre las microfibras mientras se orientan. 

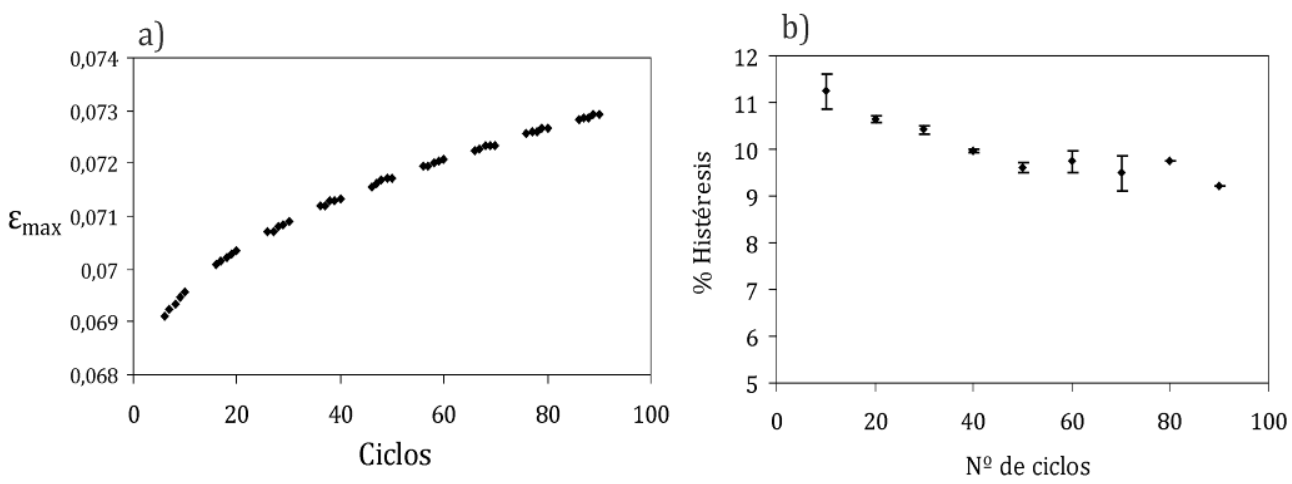

Fig. 3.5 Propiedades mecánicas de la trenza hueca de PLA en el ensayo dinámico. a) Incremento de la máxima deformación con el número de ciclos. b) Decrecimiento de la histéresis mecánica con el número de ciclos.

Se ha reportado que los tendones trabajan normalmente entre la región toe y la primera parte de la región lineal [115], donde el tendón tiene valores del módulo de Young sobre 1-2 GPa [116]. La curva de tensión-deformación de nuestra trenza de PLA mostró valores de $\varepsilon_{\text {toe }} \mathrm{y}$ de módulo de Young muy similares a los del tendón natural. Además, los trenzados analizados mostraron un comportamiento mecánico lineal hasta tensiones muy superiores a las máximas estimadas para tendones naturales, que son alrededor de 30 y $67 \mathrm{MPa}[117,118]$. Es importante destacar que cuando se necesite ajustar las propiedades mecánicas del material a un tendón en particular, se puede intervenir en las características de su trenzado $[81,118]$. 
Asimismo, la histéresis mecánica estimada en las trenzas (9\%) se mostró dentro del rango de valores reportados para los tendones, entre $3 \%$ y $38 \%[119,120]$. Esta propiedad es de importancia funcional para el comportamiento dinámico del tendón, teniendo relación con la cantidad de energía metabólica que puede estar almacenando durante la locomoción. No obstante, la aplicación de cargas cíclicas entorno al límite de linealidad, provocó deformaciones no recuperables dando a conocer la necesidad de realizar un preacondicionamiento del material previo al implante. Estos resultados obtenidos con respecto a las propiedades mecánicas validan la utilización de la trenza de PLA desde el punto de vista de su uso inicial, es decir proporcionar la fuerza necesaria tras la implantación in vivo.

A continuación se presenta la caracterización de la degradación hidrolítica de la trenza de PLA in vitro. Como se ha citado en la sección 1.3, la prótesis es biodegradable y por ello será reabsorbida in vivo mientras que el neotejido vaya creciendo. Debido a eso, es importante conocer cómo afecta la degradación hidrolítica a las propiedades del trenzado. 


\subsubsection{Estudio de la degradación hidrolítica del material trenzado}

Los ensayos de degradación hidrolítica del material trenzado fueron llevados a cabo en varios medios con diferentes condiciones de pH. Los ensayos fueron realizados en una solución tampón de fosfato, PBS, a pH 7.4 que contenía $0.2 \mathrm{mg} / \mathrm{ml}$ de azida de sodio, una solución básica con pH 12 y una solución ácida con pH 3.

La pérdida de masa de la trenza de PLA tras su degradación en los distintos medios se presenta en función del tiempo en la Fig. 3.6. Los resultados muestran que las trenzas expuestas a un medio básico presentan una pérdida de masa de un 21\% en 30 días. Mientras que las muestras degradadas en medio ácido y PBS muestran una pérdida de masa muy pequeña, $0.65 \%$ después de 30 días en medio ácido y menos de 1\% después de un año en PBS. El análisis estadístico mediante $t$ Student indica que las muestras en medio básico presentan una pérdida de masa significativa a partir del séptimo día de ensayo mientras que las muestras inmersas en medio ácido no muestran un cambio significativo. Las trenzas en PBS después de dos meses presentan una pequeña pérdida de masa, sin embargo los cambios de masa después de este periodo no son significativos. 

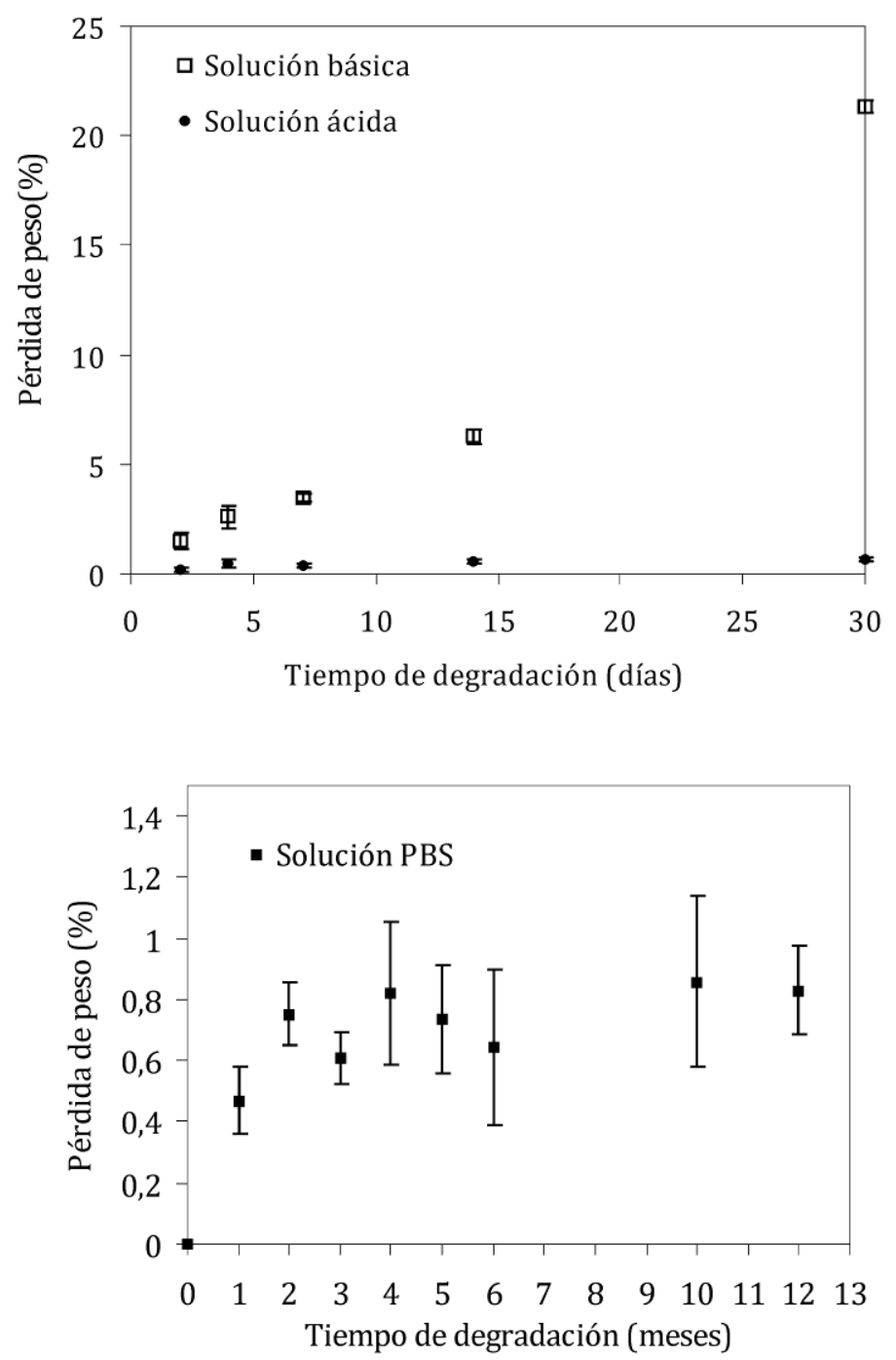

Fig. 3.6 Pérdida de masa del material trenzado de PLA con respecto del tiempo de degradación en distintos medios. a) muestras inmersas en medio básico y ácido durante un mes, b) muestras inmersas en medio PBS a $37^{\circ} \mathrm{C}$ durante un año. 
Esta diferencia tan notable de pérdida de masa en los distintos medios se debe a que el mecanismo asociado con la hidrólisis del grupo éster en medio básico se produce por el ataque del ión hidroxilo a los carbonos del carbonilo. Este ión hidroxilo tiene un fuerte efecto catalítico que acelera la degradación provocando un incremento de grupos hidroxilo $(-\mathrm{OH})$ y grupos carboxílicos $(-\mathrm{COOH})$ en la superficie de la trenza haciéndola más hidrófila y más expuesta a la degradación. Sin embargo, las trenzas sometidas a medio PBS y medio ácido tienen una pérdida de masa muy pequeña, esto sugiere que los pequeños fragmentos formados de la rotura de los enlaces éster iniciada mediante los iones hidronios $\left(\mathrm{H}_{3} \mathrm{O}^{+}\right)$produce cadenas de bajo peso molecular que quedan atrapadas dentro de la estructura, probablemente entrelazados de una manera que impide su difusión al medio [121]. Tsuji et al. [122124] en sus estudios de degradación hidrolítica del PLA demostraron que en el medio básico el material era degradado por una erosión superficial provocando una importante pérdida de masa, mientras que en medio ácido y medio PBS la erosión era en bloque mostrando una pérdida de masa muy pequeña. 
En la Fig. 3.7 se muestran micrografías correspondientes a 6 meses de degradación en PBS de la trenza de PLA. La trenza antes de ser degradada $\left(\mathrm{T}_{0}\right)$ presenta una superficie lisa y bastante regular. Tras $4 \mathrm{y}$ 6 meses de degradación, las fibras de PLA tenían un aspecto más rugoso comparándolo con el inicio del ensayo $\left(\mathrm{T}_{0}\right)$.
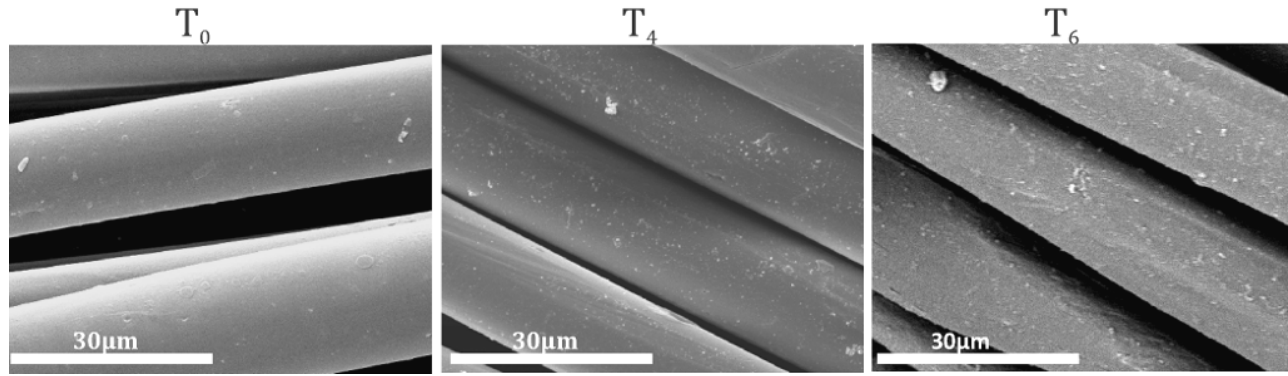

Fig. 3.7 Micrografías de SEM de la trenza de PLA antes y después de ser degradada en PBS a distintos tiempos. $\mathrm{T}_{0}$, muestra sin degradar, $\mathrm{T}_{4}$ después de 4 meses y $\mathrm{T}_{6}$ después de 6 meses de degradación a $37^{\circ} \mathrm{C}$.

La morfología de la trenza antes y después de ser expuestas a 15 y 30 días en medio básico y ácido puede verse en la Fig. 3.8. Después de 15 días de estudio, la trenza en medio básico presenta en la superficie de las microfibras las primeras grietas que sugieren degradación, mientras que en las trenzas sometidas a medio ácido no se observan imperfecciones. Transcurridos 30 días del ensayo, los cambios en la superficie del material trenzado sometido a medio básico se muestran más notables, observándose múltiples perforaciones en la superficie de las microfibras. En medio ácido aparecen microfibras con irregularidades y grietas en dirección transversal. 


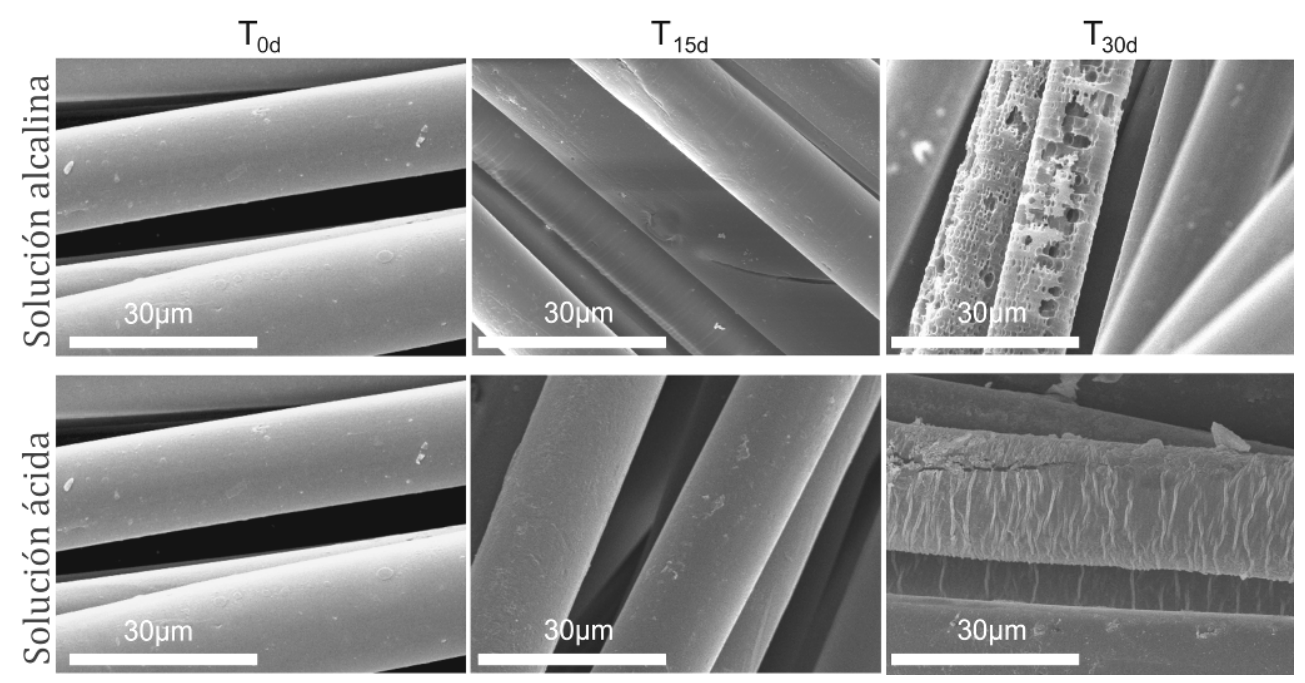

Fig. 3.8 Micrografías de SEM de la trenza de PLA antes y después de ser expuesta a medio básico y ácido durante distintos tiempos. $\mathrm{T}_{0}$, indica el inicio del ensayo, $\mathrm{T}_{15 \mathrm{~d}}$ tras 15 días de degradación y $\mathrm{T}_{30 \mathrm{~d}}$ después de 30 días de degradación a $37^{\circ} \mathrm{C}$.

Esta morfología adquirida en las microfibras degradadas con distintos medios indica la posibilidad de que se esté produciendo una erosión superficial en la muestra sometida a medio básico y una erosión en bloque en las trenzas sometidas a PBS y a medio ácido. Estos resultados son similares a los reportados por Yuan et al. [125, 126] después de estudiar la degradación hidrolítica de fibras de PLA. 
Para corroborar la degradación hidrolítica que sufre la trenza a pH neutro, fueron estudiados los cambios del peso molecular de la trenza mediante GPC. La distribución de los pesos moleculares de la trenza antes y después de producirse la degradación hidrolítica se muestra en la Fig. 3.9. Cuando la degradación está en proceso, los pesos moleculares se desplazan hacia valores de $M_{w}$ menores. La base de la curva se vuelve más ancha indicando un incremento de cadenas de menor peso molecular.



Fig. 3.9 Curvas de GPC de la trenza de PLA antes y después de la degradación hidrolítica para distintos tiempos en PBS. $\mathrm{T}_{0}$, muestra sin degradar, $\mathrm{T}_{6}$ después de 6 meses y $\mathrm{T}_{12}$ después de 12 meses de degradación. 
En la Tabla 3.2, se muestra el peso molecular promedio de la trenza de PLA degradada en PBS a distintos tiempos. Aplicando el test estadístico $t$ Student con una $\mathrm{p}<0.05$ no se observa cambios significativos de $\mathrm{M}_{\mathrm{w}}$ hasta el octavo mes de degradación, sin embargo aparecen cambios significativos para $M_{n}$ en el tercer mes. El $M_{w}$ promedio es el $50 \%$ del valor inicial y el $\mathrm{M}_{\mathrm{n}}$ promedio es el $60 \%$ del valor inicial tras 12 meses de degradación. El índice PDI va aumentando a lo largo del ensayo.

\begin{tabular}{|c|c|c|c|}
\hline $\begin{array}{c}\text { Tiempo de } \\
\text { degradación } \\
\text { (meses) }\end{array}$ & $\mathbf{M}_{\mathbf{w}} \mathbf{( g ~ m o l}^{-\mathbf{1}}$ ) & $\mathbf{M}_{\mathbf{n}} \mathbf{g ~ m o l}^{-\mathbf{1}}$ ) & PDI \\
\hline 0 & $(1.6 \pm 0.02) \times 10^{5}$ & $(7.7 \pm 0.5) \times 10^{4}$ & $2.1 \pm 0.16$ \\
\hline 1 & $(1.4 \pm 0.01) \times 10^{5}$ & $(5.9 \pm 0.8) \times 10^{4}$ & $2.4 \pm 0.34$ \\
\hline 3 & $(1.2 \pm 0.07) \times 10^{5}$ & $(5.3 \pm 1.2) \times 10^{4}$ & $2.3 \pm 0.39$ \\
\hline 6 & $(1.3 \pm 0.3) \times 10^{5}$ & $(3.9 \pm 1.1) \times 10^{4}$ & $3.3 \pm 0.18$ \\
\hline 8 & $(7.4 \pm 1.3) \times 10^{4}$ & $(3.2 \pm 0.7) \times 10^{4}$ & $2.4 \pm 0.14$ \\
\hline 10 & $(7.9 \pm 0.7) \times 10^{4}$ & $(3.2 \pm 0.4) \times 10^{4}$ & $2.5 \pm 0.03$ \\
\hline 12 & $(7.9 \pm 0.3) \times 10^{4}$ & $(3.1 \pm 0.2) \times 10^{4}$ & $2.5 \pm 0.22$ \\
\hline
\end{tabular}

Tabla 3.2 Valores de GPC del peso molecular promedio en peso $\left(\mathrm{M}_{\mathrm{w}}\right)$, en número $\left(\mathrm{M}_{\mathrm{n}}\right)$ y el índice de polidispersión (PDI) de la trenza de PLA, antes y después de distintos periodos de degradación en PBS a $37^{\circ} \mathrm{C}$.

Los datos obtenidos de la distribución de pesos moleculares mediante GPC debidos a la degradación hidrolítica de la trenza de PLA en medio básico y ácido se muestran en la Tabla 3.3 y en la Tabla 3.4. El $\mathrm{M}_{\mathrm{w}}$ de la trenza de PLA degradada en ambos medios desciende 
significativamente al segundo mes ( $t$ Student con $\mathrm{p}<0.05)$; el mismo comportamiento se refleja en $\mathrm{M}_{\mathrm{n}}$. El índice PDI va aumentando levemente durante el periodo de degradación en ambos medios.

\begin{tabular}{|c|c|c|c|}
\hline \multirow{2}{*}{$\begin{array}{c}\text { Tiempo de } \\
\text { degradación } \\
\text { (días) }\end{array}$} & \multicolumn{3}{|c|}{ Solución básica } \\
\hline & $M_{w}\left(\mathrm{~g} \mathrm{~mol}^{-1}\right)$ & $\mathrm{M}_{\mathrm{n}}\left(\mathrm{g} \mathrm{mol}^{-1}\right)$ & PDI \\
\hline 0 & $(1.6)$ & $10^{4}$ & 2. \\
\hline 2 & $(1.33 \pm 0$. & $(6.8 \pm 0.4) \times 10^{4}$ & $1.96 \pm 0.06$ \\
\hline 4 & $(1.31 \pm 0)$. & $(6.4 \pm 1.0) \times 10^{4}$ & $2.01 \pm 0.24$ \\
\hline 7 & $(1.30 \pm 0.05) \times 10^{5}$ & $(5.8 \pm 1.2) \times 10^{4}$ & $2.33 \pm 0.35$ \\
\hline 14 & $(1.28 \pm 0.04) \times 10^{5}$ & $(6.3 \pm 0.8) \times 10^{4}$ & $2.05 \pm 0.22$ \\
\hline 30 & $(1.26 \pm 0.02) \times 10^{5}$ & $(5.3 \pm 0.9) \times 10^{4}$ & $2.44 \pm 0.35$ \\
\hline
\end{tabular}

Tabla 3.3 Peso molecular promedio en peso $\left(\mathrm{M}_{\mathrm{w}}\right)$, en número $\left(\mathrm{M}_{\mathrm{n}}\right)$ y el índice de polidispersión (PDI) de la trenza de PLA, antes y después de distintos periodos de degradación en $\mathrm{NaOH}$ pH 12 a $37^{\circ} \mathrm{C}$

\begin{tabular}{|c|c|c|c|}
\hline \multirow{2}{*}{$\begin{array}{c}\text { Tiempo de } \\
\text { degradación } \\
\text { (días) }\end{array}$} & \multicolumn{3}{|c|}{ Solución ácida } \\
\cline { 2 - 4 } & $\mathbf{M}_{\mathbf{w}} \mathbf{( \mathbf { g ~ m o l } ^ { - 1 } \mathbf { ) }}$ & $\mathbf{M}_{\mathbf{n}} \mathbf{~} \mathbf{g ~ m o l}^{-1} \mathbf{)}$ & PDI \\
\hline 0 & $(1.61 \pm 0.02) \times 10^{5}$ & $(7.7 \pm 0.5) \times 10^{4}$ & $2.10 \pm 0.16$ \\
\hline 2 & $(1.27 \pm 0.06) \times 10^{5}$ & $(5.5 \pm 0.5) \times 10^{4}$ & $2.18 \pm 0.23$ \\
\hline 4 & $(1.32 \pm 0.01) \times 10^{5}$ & $(5.6 \pm 0.9) \times 10^{4}$ & $2.40 \pm 0.18$ \\
\hline 7 & $(1.30 \pm 0.05) \times 10^{5}$ & $(5.9 \pm 1.4) \times 10^{4}$ & $2.21 \pm 0.20$ \\
\hline 14 & $(1.25 \pm 0.04) \times 10^{5}$ & $(5.8 \pm 0.8) \times 10^{4}$ & $2.18 \pm 0.28$ \\
\hline 30 & $(1.25 \pm 0.05) \times 10^{5}$ & $(5 \pm 0.80) \times 10^{4}$ & $2.52 \pm 0.20$ \\
\hline
\end{tabular}

Tabla 3.4 Peso molecular promedio en peso $\left(\mathrm{M}_{\mathrm{w}}\right)$, en número $\left(\mathrm{M}_{\mathrm{n}}\right)$ y el índice de polidispersión (PDI) de la trenza de PLA, antes y después de distintos periodos de degradación en $\mathrm{HCl}$ pH 3 a $37^{\circ} \mathrm{C}$. 
La rotura de los enlaces ésteres producida por la degradación hidrolítica en los distintos medios da lugar a la formación de cadenas de bajo peso molecular. El aumento de estas cadenas se reflejó en el descenso considerable del $\mathrm{M}_{\mathrm{w}} \mathrm{y} \mathrm{M}_{\mathrm{n}}$ del material trenzado siendo de un $12 \%$ y un $23 \%$ en medio PBS, un $22 \%$ y un $35 \%$ para medio ácido y un $22 \%$ y un $31 \%$ para las muestras sometidas a medio básico. El descenso del peso molecular no se corresponde con la pérdida de masa de las muestras observada en la Fig. 3.6. Este comportamiento es debido a que las muestras expuestas a un medio básico se vuelven más hidrófilas facilitando la difusión de cadenas de bajo peso molecular al medio, mientras que las muestras degradadas en los otros medios permanecen hidrófobas dificultando la difusión de las cadenas al medio.

Para determinar las propiedades térmicas de la trenza de PLA antes y después de la degradación hidrolítica a $37^{\circ} \mathrm{C}$ se utilizó la técnica de DSC. La $\mathrm{T}_{\mathrm{g}}, \Delta \mathrm{H}_{\mathrm{c}}, \Delta \mathrm{H}_{\mathrm{f}}, \mathrm{T}_{\mathrm{f}}$ y la $X_{\mathrm{c}}$ de las trenzas de PLA expuestas a los distintos medios de degradación, fueron estimados mediante los termogramas obtenidos. Los resultados obtenidos del barrido de calentamiento de la trenza de PLA degradada en PBS a lo largo de 12 meses se observan en la Tabla 3.5. Se observa que $\Delta \mathrm{H}_{\mathrm{f}}, \mathrm{T}_{\mathrm{g}}$ y la $X_{\mathrm{c}}$ aparentemente aumenta con el tiempo de degradación, mientras que $\mathrm{T}_{\mathrm{f}}$ y $\Delta \mathrm{H}_{\mathrm{c}}$ disminuye. 


\begin{tabular}{|c|c|c|c|c|c|}
\hline \multirow{2}{*}{$\begin{array}{c}\text { Tiempo de } \\
\text { degradación }\end{array}$} & \multicolumn{5}{|c|}{ Solución PBS } \\
\cline { 2 - 6 } (meses) & $\mathbf{T}_{\mathbf{g}}\left({ }^{\circ} \mathbf{C}\right)$ & $\boldsymbol{\Delta}_{\mathbf{c}} \mathbf{( J g - 1 )}$ & $\boldsymbol{\Delta}_{\mathbf{f}}\left(\mathbf{J g}^{-\mathbf{1}} \mathbf{~}^{-}\right.$ & $\left.\mathbf{T}_{\mathbf{f}}{ }^{\circ} \mathbf{C}\right)$ & $\boldsymbol{X}_{\boldsymbol{c}}(\mathbf{( \% )}$ \\
\hline 0 & 62.4 & 10.7 & 43.8 & 167.6 & 36 \\
\hline 1 & 77.0 & 5.81 & 48.0 & 170.2 & 42.2 \\
\hline 3 & 76.8 & 5.66 & 48.0 & 168.0 & 42.3 \\
\hline 6 & 77.1 & 5.26 & 50.7 & 168.4 & 45.4 \\
\hline 8 & 76.8 & 5.56 & 48.5 & 164.7 & 42.9 \\
\hline 12 & 76.5 & 4.76 & 48.1 & 163.9 & 43.6 \\
\hline
\end{tabular}

Tabla 3.5 Propiedades térmicas de la trenza de PLA antes y después de la degradación en PBS a $37^{\circ} \mathrm{C}$ durante 12 meses de estudio.

La Tabla 3.6 muestra las propiedades térmicas del material trenzado de PLA degradado en solución básica y ácida. En ambos medios, se observa que $\Delta \mathrm{H}_{\mathrm{f}}, \mathrm{T}_{\mathrm{g}} \mathrm{y}$ la $X_{\mathrm{c}}$ del material incrementan en función del tiempo de degradación, mientras que $\Delta \mathrm{H}_{\mathrm{c}}$ disminuye con el tiempo. $\mathrm{T}_{\mathrm{f}}$ no muestra una tendencia clara.

\begin{tabular}{|c|c|c|c|c|c|c|c|c|c|c|}
\hline \multirow{2}{*}{$\begin{array}{c}\text { Tiempo } \\
(\mathbf{d i ́ a s )}\end{array}$} & $\begin{array}{c}\mathbf{T}_{\mathbf{g}} \\
\left({ }^{\circ} \mathbf{C}\right)\end{array}$ & $\begin{array}{c}\Delta \mathbf{H}_{\mathbf{c}} \\
(\mathbf{J g}-\mathbf{1})\end{array}$ & $\begin{array}{c}\Delta \mathbf{H}_{\mathbf{f}} \\
(\mathbf{J g}-\mathbf{1})\end{array}$ & $\begin{array}{c}\mathbf{T}_{\mathbf{f}} \\
\left({ }^{\circ} \mathbf{C}\right)\end{array}$ & $\begin{array}{c}\boldsymbol{X}_{\boldsymbol{c}} \\
(\mathbf{\%})\end{array}$ & $\begin{array}{c}\mathbf{T}_{\mathbf{g}} \\
\left({ }^{\circ} \mathbf{C}\right)\end{array}$ & $\begin{array}{c}\Delta \mathbf{H}_{\mathbf{c}} \\
\left(\mathbf{J g}^{-1} \mathbf{1}\right.\end{array}$ & $\begin{array}{c}\Delta \mathbf{H}_{\mathbf{f}} \\
\left(\mathbf{J g}^{-1}\right)\end{array}$ & $\begin{array}{c}\mathbf{T}_{\mathbf{f}} \\
\left({ }^{\circ} \mathbf{C}\right)\end{array}$ & $\begin{array}{c}\boldsymbol{X}_{\boldsymbol{c}} \\
(\mathbf{\%})\end{array}$ \\
\hline 0 & 62.4 & 10.7 & 43.8 & 167.6 & 36 & 62.4 & 10.7 & 43.8 & 167.6 & 36 \\
\hline 2 & 69.0 & 7.45 & 46.6 & 164.6 & 39.2 & 75.5 & 7.46 & 47.1 & 167.2 & 39.6 \\
\hline 14 & 75.9 & 6.58 & 48.9 & 167.1 & 42.3 & 75.9 & 7.18 & 48.1 & 167.3 & 40.9 \\
\hline 30 & 77.1 & 5.28 & 47.9 & 167.3 & 42.6 & 77.1 & 6.23 & 47.3 & 164.9 & 41.1 \\
\hline
\end{tabular}

Tabla 3.6 Propiedades térmicas de la trenza de PLA antes y después de la degradación en medio básico y en medio ácido a $37^{\circ} \mathrm{C}$ durante 1 meses de estudio. 
La fragmentación de las cadenas poliméricas influye en las propiedades térmicas del material. Los datos obtenidos mostraron un incremento de la cristalinidad en todos los medios utilizados. Resultados similares han sido observados en estudios de degradación de membranas de PLA [127, 128]. El incremento de la cristalinidad puede ser atribuido a que los principales efectos de la degradación ocurren en la fase amorfa, provocando una reorganización de las cadenas de bajo peso molecular dando lugar a nuevas zonas cristalinas. Estas nuevas regiones cristalinas son menos estables que la estructura cristalina del material, debido a ello se observó un decrecimiento de la temperatura de fusión

Para conocer los efectos de la degradación hidrolítica en las propiedades mecánicas de la trenza hueca de PLA fueron realizados ensayos de tracción. La Fig. 3.10, muestra las curvas tensióndeformación obtenidas de las trenzas después de estar expuestas en los distintos medios de degradación. Se observa que la trenza degradada en PBS (Fig. 3.10a) muestra un notable descenso del módulo de Young a los 2 meses de degradación. La misma tendencia se observa en las trenzas sometidas a medio básico y medio ácido después de 15 días de degradación (Fig. 3.10b y Fig. 3.10c). Es importante destacar que la $\varepsilon_{\text {toe }}$, es mucho mayor en las muestras degradadas que en las no degradadas. Los rangos pasan de $\varepsilon_{\text {toe, }} 3 \% \pm 0.1$ a $\varepsilon_{\text {toe }} 8 \% \pm 1.5$ en trenzas degradadas en PBS durante 12 meses de estudio, a $\varepsilon_{\text {toe }}$ de $10 \% \pm 0.1$ y $\varepsilon_{\text {toe }} 7 \% \pm 0.6$ en 
muestras expuestas a medio básico y ácido respectivamente después un mes de estudio. Este incremento de la $\varepsilon_{t o e}$ es debido a la fragmentación de las cadenas poliméricas que facilita la deformación de la muestra.


Fig. 3.10 Curvas tensión-deformación de la trenza de PLA antes y después de la degradación a $37^{\circ} \mathrm{C}$ en a) medio básico, b) medio ácido y c) medio en PBS

También fueron estimados a partir de las curvas tensióndeformación el módulo de Young, la tensión de rotura y el \% de 
elongación de las trenzas de PLA degradadas en los distintos medios. Los datos obtenidos se recogen en la Tabla 3.7 y Tabla 3.8.

\begin{tabular}{|c|c|c|c|}
\hline $\begin{array}{c}\text { Tiempo de } \\
\text { degradación } \\
\text { (meses) }\end{array}$ & $\begin{array}{c}\text { Módulo } \\
\text { de Young } \\
\text { (MPa) }\end{array}$ & $\begin{array}{c}\text { Tensión } \\
\text { de rotura } \\
\text { (N) }\end{array}$ & $\begin{array}{c}\text { Elongación } \\
\text { (\%) }\end{array}$ \\
\hline 0 & $1268 \pm 87$ & $217 \pm 0.1$ & $4 \pm 0.5$ \\
\hline 2 & $341 \pm 27$ & $190 \pm 8$ & $28 \pm 4$ \\
\hline 4 & $311 \pm 16$ & $186 \pm 6$ & $30 \pm 4$ \\
\hline 12 & $282 \pm 13$ & $152 \pm 5$ & $32 \pm 8$ \\
\hline
\end{tabular}

Tabla 3.7 Módulo de Young, tensión de rotura rotura y \% de elongación de la trenza de PLA, antes y después de distintos periodos de degradación en PBS a $37^{\circ} \mathrm{C}$

\begin{tabular}{|c|c|c|c|c|c|c|}
\hline \multirow{2}{*}{$\begin{array}{c}\text { Tiempo } \\
\text { (días) }\end{array}$} & $\begin{array}{c}\text { Módulo } \\
\text { de Young } \\
\text { (MPa) }\end{array}$ & $\begin{array}{c}\text { Tensión } \\
\text { de rotura } \\
\text { (N) }\end{array}$ & $\begin{array}{c}\text { Elonga- } \\
\text { ción } \\
\text { (\%) }\end{array}$ & $\begin{array}{c}\text { Módulo } \\
\text { de Young } \\
\text { (MPa) }\end{array}$ & $\begin{array}{c}\text { Tensión } \\
\text { de rotura } \\
\text { (N) }\end{array}$ & $\begin{array}{c}\text { Elonga- } \\
\text { ción } \\
\text { (\%) }\end{array}$ \\
\hline 0 & $1268 \pm 87$ & $217 \pm 0,1$ & $4 \pm 0.5$ & $1268 \pm 87$ & $217 \pm 0.1$ & $4 \pm 0,5$ \\
\hline 15 & $427 \pm 13$ & $211 \pm 15$ & $28 \pm 2$ & $403 \pm 15$ & $214 \pm 12$ & $28 \pm 1$ \\
\hline 30 & $392 \pm 17$ & $199 \pm 11$ & $33 \pm 2$ & $414 \pm 27$ & $202 \pm 8$ & $29 \pm 0.02$ \\
\hline
\end{tabular}

Tabla 3.8 Módulo de Young, tensión de rotura y \% de elongación de la trenza de PLA, antes y después de distintos periodos de degradación en $\mathrm{NaOH}$ y $\mathrm{HCl}$

Los datos muestran que tanto el módulo de Young como la tensión de rotura de las trenzas de PLA degradadas decrecen con respecto del tiempo en todos los medios de degradación. El módulo de Young de la trenza después de dos meses de degradación en PBS desciende un 75\% 
con respecto del valor inicial. En medio ácido después de un mes de degradación disminuye en un 70\% y un 71\% en medio básico. Con respecto a este descenso de las propiedades mecánicas del material, se ha reportado en diversos estudios realizados in vivo con materiales trenzados para la regeneración del tendón de Aquiles, que las bajas propiedades mecánicas del material se refuerza con la producción de colágeno I y colágeno III segregado por las células [60, 75]. En esta línea Surrao et al. [97] demostraron que la producción de matriz extracelular incrementaba en los cultivos in vitro de scaffolds fibrosos cuando se les aplicaba un estímulo mecánico. Previos estudios han reportado que la degradación hidrolítica afecta considerablemente las propiedades mecánicas del PLA $[125,126,129,130]$, estando en concordancia con nuestros resultados.

El estudio de degradación hidrolítica realizado nos mostró la evolución de los cambios de las propiedades morfológicas, térmicas y mecánicas de la trenza de PLA. Hay que tener en cuenta, que la degradación completa de la trenza de PLA en el cuerpo puede tardar un tiempo que es difícil de estimar cuando se habla de los tendones, y que puede tardar varios años tal y como muestra la experiencia quirúrgica en otros tejidos [131]. Acerca de los fragmentos liberados en la segmentación de las cadenas del polímero, se ha reportado que pueden ser eliminados del cuerpo humano sin causar respuesta inflamatoria [132]. 


\subsubsection{Caracterización de las micropartículas}

Las distintas micropartículas de PLLA, CHT y HA, fueron preparadas mediante el método de emulsión [43] siguiendo los pasos descritos en el apartado 2.2.1 de materiales y métodos. El objetivo era obtener micropartículas con un diámetro aproximado entre 50-100 $\mu \mathrm{m}$ para utilizarlas como soporte celular en el caso de PLLA o CHT y como relleno en combinación de una de las anteriores, las micropartículas de HA.

La Fig. 3.11 muestra imágenes realizadas con la lupa de las distintas micropartículas (PLLA, CHT y HA) y los histogramas del \% de frecuencia obtenido del diámetro de las mismas. El diámetro se midió sobre las imágenes realizadas con la lupa y se calculó el tamaño promedio siendo de $60 \pm 24 \mu \mathrm{m}$ para las micropartículas de PLLA, $70 \pm 32 \mu \mathrm{m}$ para las micropartículas de CHT y $60 \pm 20 \mu \mathrm{m}$ para las de HA que fueron hinchadas previamente durante $5 \mathrm{~h}$ en agua. 
a)

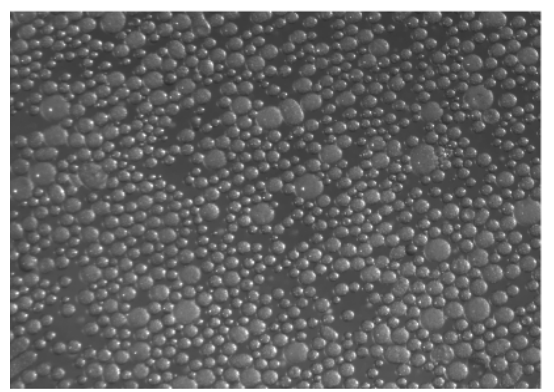

b)

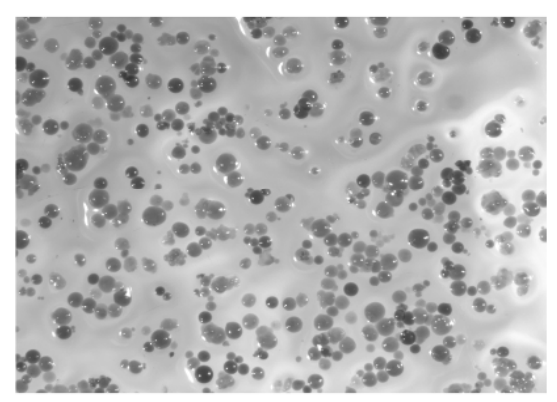

c)

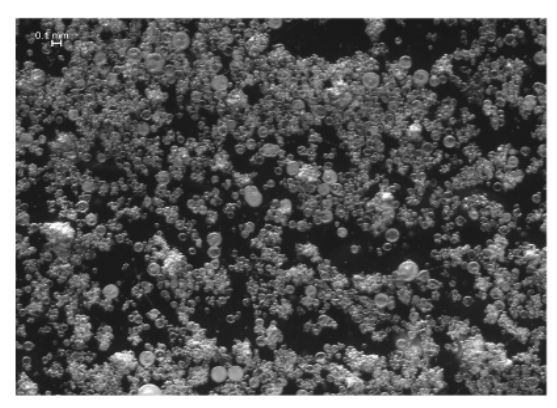

PLLA

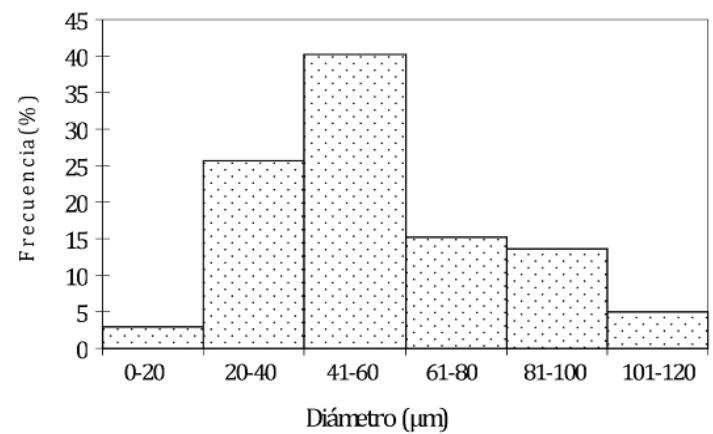

CHT

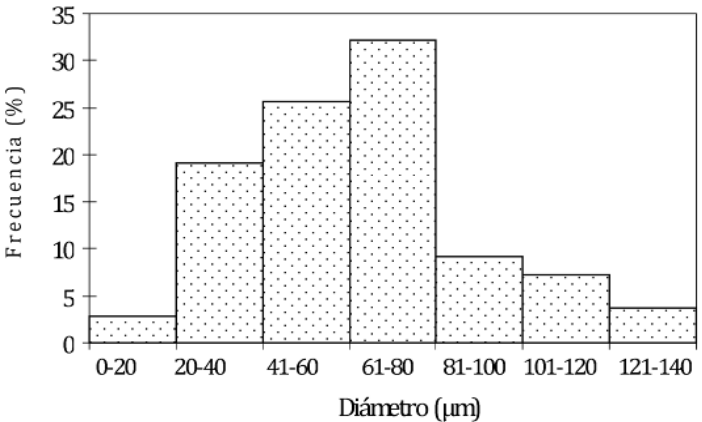

HA

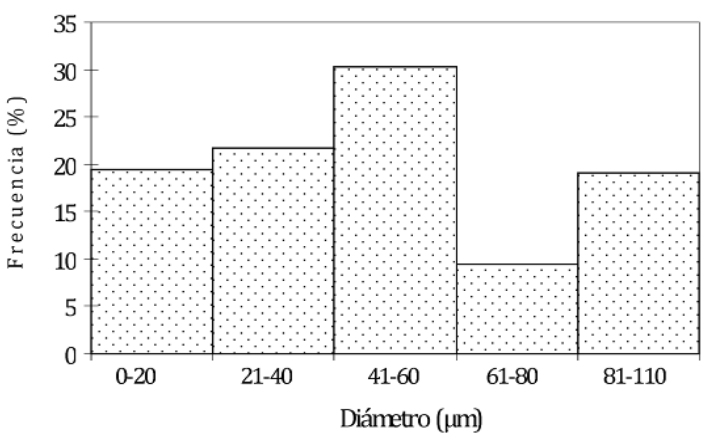

Fig. 3.11 Fotografías realizadas con lupa para medir diámetros de micropartículas y respectivo histograma del tamaño de las micropartículas de: a) PLLA, b) CHT y c) HA. 
La morfología de las micropartículas obtenidas fue examinada mediante imágenes realizadas con SEM, Fig. 3.12. Las micrografías muestran que las micropartículas de PLLA son esféricas y presentan una superficie lisa. Las micropartículas de CHT y de HA, presentan irregularidades en la superficie que pueden ser debidas al proceso de deshidratación utilizado para realizar las micrografías. Sin embargo, todas las morfologías estudiadas poseen una superficie lisa y una geometría redondeada cuando están hinchadas.


Fig. 3.12 Micrografías de SEM de micropartículas de PLLA, HA y CHT.

La Fig. 3.13 muestra el \% de pérdida de peso obtenido en los ensayos termogravimétricos de las diferentes micropartículas comparado con el de los polímeros puros respectivamente. Entre el rango $0-100^{\circ} \mathrm{C}$, los termogramas de las micropartículas de PLLA y de CHT comparados con los termogramas de sus respectivos polímeros puros, muestran un comportamiento muy similar, mostrando ausencia de trazas de disolventes provenientes del proceso de fabricación. Los termogramas de las micropartículas de HA con respecto al del HA puro muestra 
diferencias por debajo de $100^{\circ} \mathrm{C}$ debido a la humedad absorbida durante el almacenamiento y la manipulación.

Con respecto a la degradación térmica de las diferentes micropartículas, se observa que las de PLLA se degradan entre el rango de temperaturas de $260^{\circ} \mathrm{C}$ a $400^{\circ} \mathrm{C}$ aproximadamente, teniendo la máxima velocidad de degradación en $370^{\circ} \mathrm{C}$. Asimismo, las micropartículas de CHT presentan un rango de degradación entre $200^{\circ} \mathrm{C}$ y $450^{\circ} \mathrm{C}$, apareciendo su máxima velocidad de degradación a $300^{\circ} \mathrm{C}$. Por último, el rango de temperaturas de degradación de las micropartículas de $\mathrm{HA}$ se encuentra entre $150^{\circ} \mathrm{C}$ a $450^{\circ} \mathrm{C}$, presentando un máximo de degradación en $250^{\circ} \mathrm{C}$. Al final de la degradación, se observa que las micropartículas de PLLA no dejan residuo, sin embargo las de CHT y HA dejan un 37\% y un 23\% respectivamente. 

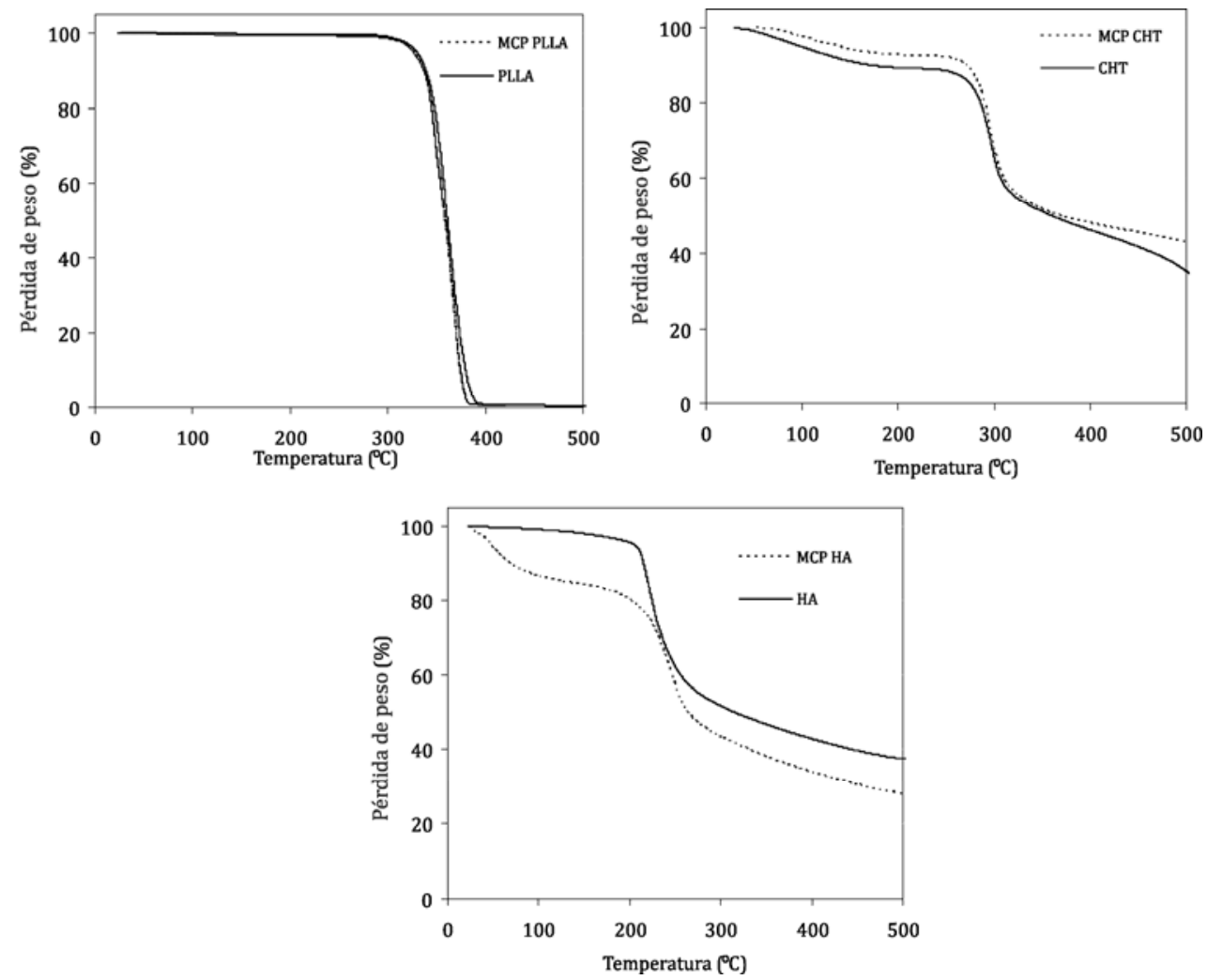

Fig. $3.13 \%$ de pérdida de peso en función de la temperatura de las micropartículas de PLLA, CHT y HA comparada con los polímeros puros.

\subsubsection{Caracterización del recubrimiento}

El recubrimiento se realizó mediante la técnica de electrospinnig tal y como se describe en el apartado 2.2.2 de materiales y métodos. En la Fig. 3.14 se muestran imágenes del espesor y de la morfología de los recubrimiento de HA realizados sobre el material trenzado de PLA a distintos tiempos (20 y $30 \mathrm{~min}$ ). A $20 \mathrm{~min}$ el espesor promedio obtenido es de $31 \pm 9 \mu \mathrm{m}$ y a $30 \mathrm{~min}$ es espesor promedio es de $33 \pm 5 \mu \mathrm{m}$. Las 
imágenes a mayores aumentos muestran que a mayor tiempo de electrodeposición de HA sobre el material trenzado (30 min), el recubrimiento parece presentar una morfología más tupida.
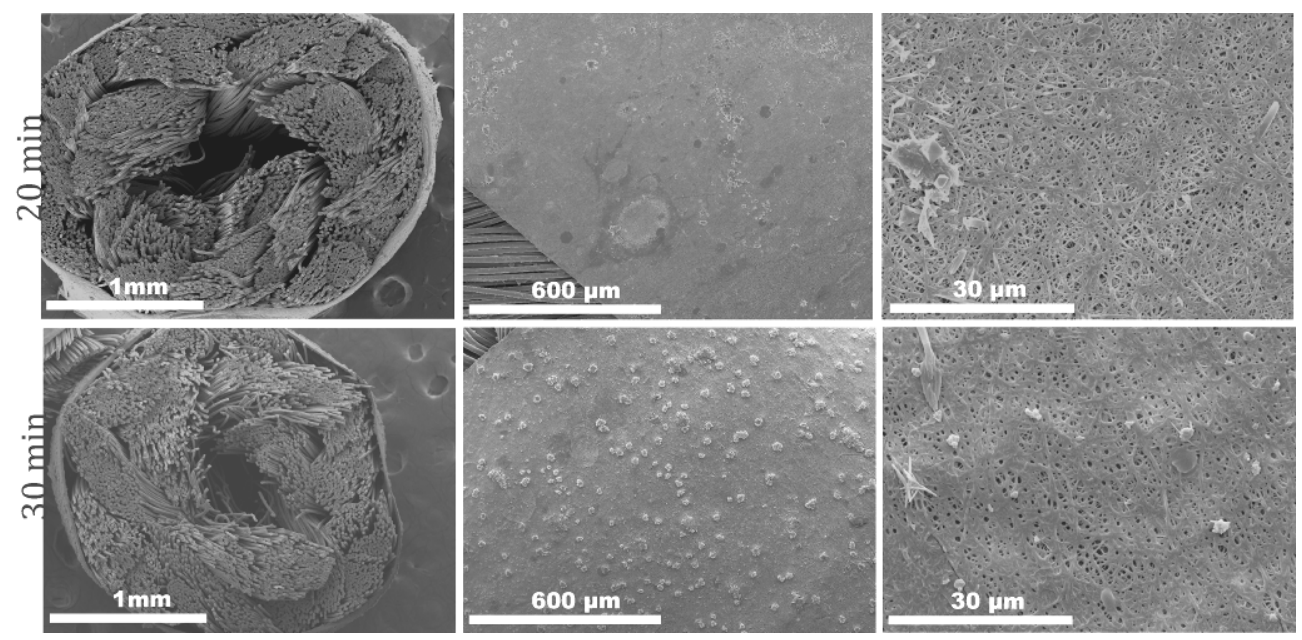

Fig. 3.14 Micrografías de SEM del recubrimiento de HA realizado con electrospinnig a distintos tiempos.

Para observar la consistencia del recubrimiento las muestras fueron inmersas en $\mathrm{H}_{2} \mathrm{O}$ durante 24 h. En la Fig. 3.15 se muestran las imágenes del recubrimiento de HA realizado a 20 y 30 min después de estar inmerso en $\mathrm{H}_{2} \mathrm{O}$ durante $24 \mathrm{~h}$. Se observa que a $30 \mathrm{~min}$ el recubrimiento permanece bien adherido al material mostrando un espesor promedio de $270 \pm 0.04 \mu \mathrm{m}$. A 20 min no se pudo medir el espesor. 

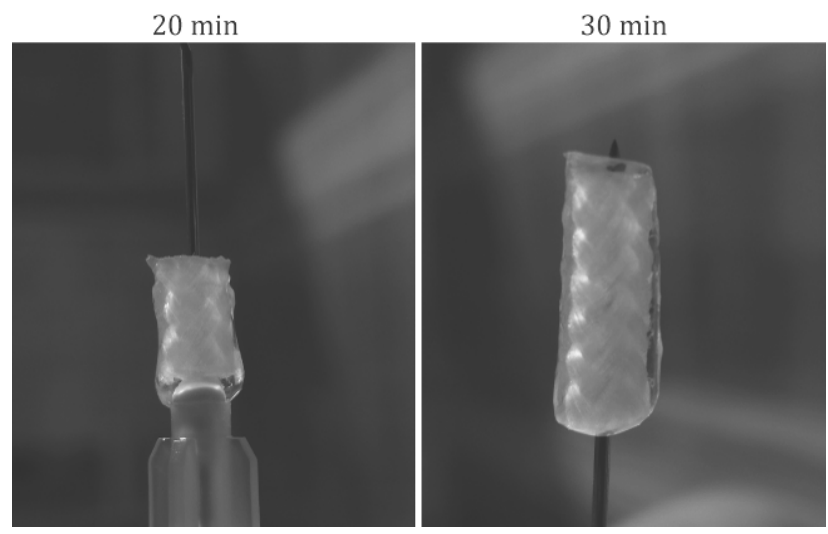

Fig. 3.15 Trenza de PLA hinchada en PBS después de 1 día.

Aunque los espesores medidos para 20 y 30 min mostraron una morfología y un espesor muy similar, el ensayo de hinchado durante 24 h mostró que la muestra recubierta con HA durante 30 min presentaba mejor consistencia. Por ello, se seleccionó este tiempo para los ensayos posteriores. Este recubrimiento de HA además de evitar adherencias del material trenzado de PLA con los tejidos adyacentes $[133,134]$, permite gracias a su permeabilidad la difusión de nutrientes desde el medio. 


\subsection{EVALUACIÓN BIOLÓGICA DE LOS MATERIALES QUE FORMAN EL PROTOTIPO DE PRÓTESIS}

Después de realizar la caracterización de los materiales en cuanto a sus propiedades físico-químicas y mecánicas, en este apartado se presentan los resultados obtenidos de los ensayos biológicos realizados sobre los materiales que componen el prototipo de prótesis. Para ello, se han utilizado dos tipos celulares de diferente procedencia: (i) fibroblastos de ratón (de la línea celular L929) y (ii) células madre mesenquimales provenientes de médula ósea humana. Los fibroblastos han sido utilizados como modelo biológico y además porque junto con los tenocitos, son las células mayoritarias que se encuentran en el tendón ejerciendo una función de síntesis y mantenimiento de la matriz extracelular.

Por otra parte y teniendo en cuenta que en un futuro, el prototipo de prótesis está destinado para una aplicación clínica, se optó por utilizar células madre mesenquimales provenientes de médula ósea humana, hMSCS, para analizar el comportamiento celular in vitro de estas células sobre los componentes de que consta la prótesis. El uso de las hMSCs, representa un mayor acercamiento a las condiciones que simulan el entorno fisiológico in vivo donde se implantará el material desarrollado. En un futuro próximo, se espera poder utilizar células mesenquimales del propio paciente durante la intervención quirúrgica en el momento de implantar la prótesis. 


\subsubsection{Estudio del comportamiento in vitro de las L929 sobre los} distintos componentes de la prótesis

Para analizar la respuesta biológica de los fibroblastos sobre los diferentes sustratos entre los que se incluyen: la trenza de PLA, las micropartículas (de quitosano, de ácido hialurónico y de PLLA) y distintas combinaciones entre las dos últimas, fueron realizados cultivos durante 1, 7 y 14 días. La viabilidad y la proliferación celular fueron evaluadas mediante ensayos de MTS. La adhesión y morfología de las células fueron examinadas mediante microscopía electrónica de barrido y microscopía de fluorescencia.

\subsubsection{Material trenzado}

Debido a que el material trenzado es un producto comercial, fabricado por la Asociación de Industriales del Textil (AITEX), como ensayo previo a los cultivos celulares se realizó un ensayo de citotoxicidad in vitro. Para ello, se siguió el procedimiento detallado en el apartado 2.3.1 de materiales y métodos según la norma UNE-EN IS010993-5. Asimismo, se evaluó también la idoneidad de diferentes técnicas de esterilización entre las que se incluyen, esterilización por ultravioleta (UV) y autoclave y desinfección con etanol (EtOH) al 70\%.

Para seleccionar el método de esterilización más adecuado fueron evaluados dos parámetros fundamentales: la viabilidad y la morfología 
de las células. La adhesión y morfología de los fibroblastos fue analizada mediante microscopía óptica (Fig. 3.16) y la viabilidad celular se determinó mediante un ensayo de MTS (Fig. 3.17).

Las células cultivadas utilizando el medio que ha estado en contacto con el látex (control positivo citotóxico) y el material trenzado esterilizado por UV y en el autoclave muestran una morfología redondeada a diferencia de las células cultivadas utilizando el medio que ha estado en contacto con el material trenzado desinfectado con EtOH 70\%, donde las células están bien adheridas al sustrato (placa de cultivo) y muestran una morfología alargada en forma de huso incluso a los 14 días de cultivo (Fig. 3.16). La morfología de las células en el control negativo (no citotóxico) es muy similar al de las células cultivadas con el medio que ha estado en contacto con el material trenzado esterilizado en $\mathrm{EtOH} \mathrm{70 \% ,} \mathrm{lo} \mathrm{cual} \mathrm{nos} \mathrm{sugiere} \mathrm{que} \mathrm{dicho}$ método es hasta el momento el más adecuado. 


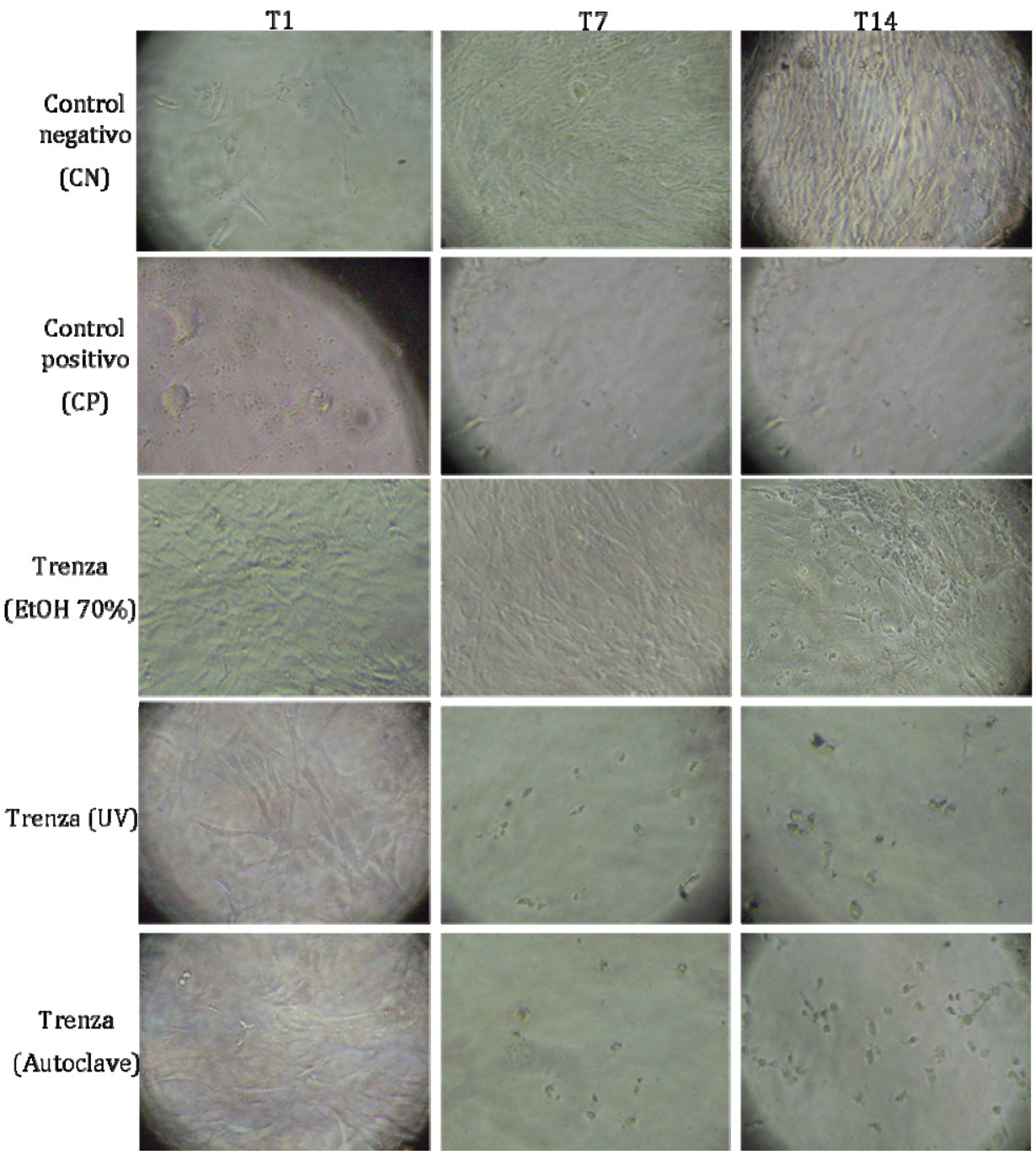

Fig. 3.16 Imágenes del microscopio óptico de células L929 cultivadas durante 1, 7 y 14 días con: medio de cultivo suplementado con 10\% FBS (CN), medio que ha estado en contacto con las trenzas esterilizadas por diferentes técnicas (EtOH 70\%, UV y autoclave), y medio en contacto con el látex (CP). 
Una vez analizada la morfología de las células se determinó también la viabilidad celular mediante un ensayo de MTS a los diferentes tiempos de cultivo, 1, 7 y 14 días. Como se muestra en la Fig. 3.17 las células cultivadas utilizando el medio que ha estado en contacto con el material trenzado en $\mathrm{EtOH} \mathrm{70 \%} \mathrm{permanecen} \mathrm{viables} \mathrm{durante} \mathrm{los} 14$ días del ensayo. El número de células viables aumenta con el tiempo de cultivo de manera similar a lo que ocurre en el control negativo, no siendo así en el control positivo (látex) y en los materiales esterilizados por UV y en el autoclave, donde el número de células viables disminuye significativamente a partir de los 7 días de cultivo. Analizando en conjunto los resultados obtenidos podemos decir que las técnicas de esterilización por UV y en el autoclave no son adecuadas probablemente porque alteran las propiedades físico-químicas del material trenzado, siendo el proceso de esterilización por autoclave más agresivo que por UV debido a que el material se somete a altas temperaturas durante el proceso de esterilización cristalizándolo y volviéndolo más rígido. Por otra parte, la esterilización por UV puede que no esté siendo efectiva debido al grosor de la trenza de PLA y a la gran cantidad de microfibras que la componen impidiendo que la radiación UV penetre en todo el volumen de la trenza. 
Estos resultados validaron la elección de EtOH al 70\% como la técnica de desinfección más eficaz con respecto a las alternativas estudiadas. Aunque el EtOH al 70\% no esteriliza completamente, es ampliamente utilizado en estudios realizados in vitro debido a su facilidad de uso, su eficacia y porque posee la ventaja de no alterar las propiedades del material [135].

En análisis estadístico mostró que la viabilidad celular obtenida en el cultivo con el medio que había estado en contacto con el material desinfectado con EtOH $70 \%$ fue significativamente mayor que la viabilidad celular mostrada en el control positivo a 1 día de cultivo y mayor para 7 y 14 días de cultivo con respecto al UV y al autoclave. 


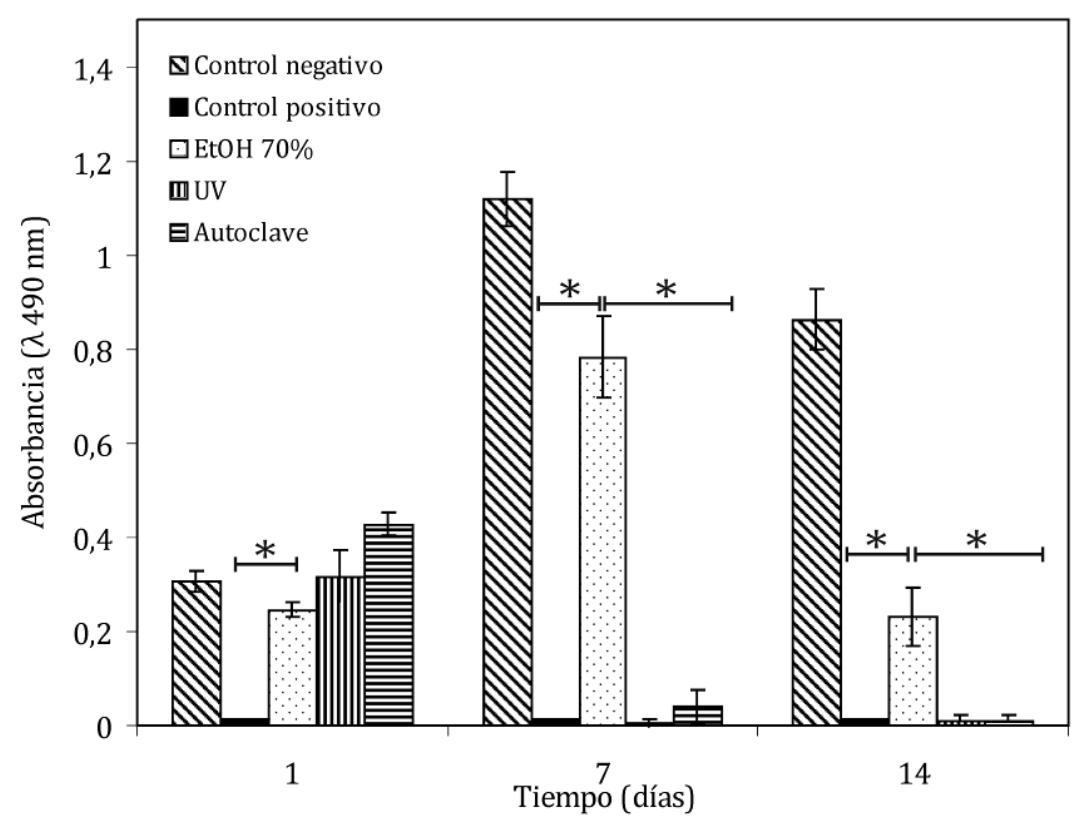

Fig. 3.17 Ensayo de MTS de las L929 cultivadas durante 1, 7 y 14 días para el ensayo de citotoxicidad de la trenza de PLA con: medio de cultivo suplementado con 10\% FBS sin estar en contacto con el material (Control negativo), el medio que ha estado en contacto con las trenzas esterilizadas por diferentes técnicas (EtOH 70\%, UV y autoclave), y medio en contacto con el látex (Control positivo). ( $p<0,05$, *significa que hay diferencia significativa entre las diferentes muestras en un mismo tiempo).

Una vez corroborado que el material trenzado no era citotóxico, se procedió al cultivo de fibroblastos sobre el material trenzado tal y como se describe en el apartado 2.3.2.1 de materiales y métodos. Se evaluó la viabilidad, la morfología y la adhesión celular después de 1, 7 y 14 días de cultivo. 
Después de sembrar y cultivar en la trenza de PLA, se observa que el número de células viables incrementa con el tiempo tal y como revelan los resultados obtenidos del ensayo de MTS (Fig. 3.18). El número de células viables en el material trenzado de PLA aumenta significativamente con el tiempo de cultivo llegando a alcanzar la misma viabilidad de las células cultivadas en el pocillo de la placa de cultivo.

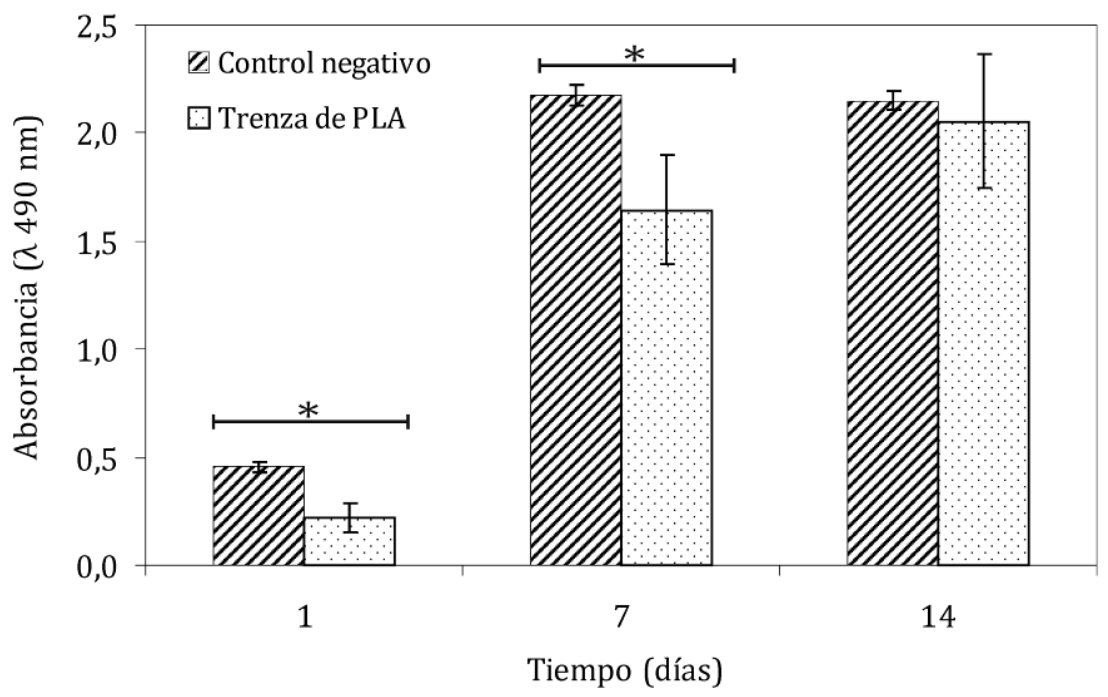

Fig. 3.18 Ensayo de MTS de los fibroblastos cultivados sobre las trenzas de PLA después 1,7 y 14 días de tiempo de cultivo. ( $p<0,05$, *significa que hay diferencia significativa entre las diferentes muestras en un mismo tiempo).

La morfología y la adhesión celular de los fibroblastos L929 cultivados sobre el material trenzado durante 1, 7 y 14 días de cultivo cambian en el tiempo como se puede apreciar en la Fig. 3.19. A las 24 horas de cultivo (1 día) las células muestran una morfología 
redondeada, sin embargo a los 7 días de cultivo muestran una morfología fusiforme. A tiempos largos (14 días), las células crecen orientándose longitudinalmente a la fibra, recubriéndola por completo y estableciendo entre ellas puentes celulares (uniones célula-célula) que llegan a compactar las fibras. La propagación del citoplasma revelado en las micrografías, es indicativo de una buena adhesión de las células a las microfibras de PLA a través de extensiones citoplasmáticas.

Con el fin de analizar la distribución de las células en el material se realizó un ensayo de tinción del citoesqueleto de actina (Fig. 3.20). Como se observa en la Fig. 3.20 las células exhiben una forma redondeada después del primer día de cultivo, para tiempos de cultivo más largos (7 y 14 días), las células se orientan longitudinalmente en la dirección de las fibras, mostrando una morfología alargada con un citoesqueleto de actina bien desarrollado y núcleos bien definidos. A los 14 días de cultivo se observan interacciones célula-célula que llegan a fusionar varias fibras. Además, se observa una tinción verde (citoesqueleto de actina) que recubre completamente el material trenzado. La actina es una proteína del citoesqueleto que proporciona andamiaje a las células; capaz de reorganizarse dependiendo de las características del entorno creando microfilamentos necesarios para la migración celular.

El citoesqueleto de actina bien desarrollado evaluado mediante fluorescencia indicó que las células se adhirieron perfectamente y fueron capaces de migrar y colonizar todo el material trenzado. La 
caracterización de la trenza hueca de PLA, indica que posee unas características físicas, químicas y morfológicas que permiten una excelente adhesión y supervivencia celular que se incrementa con el tiempo de cultivo. Resultados similares fueron obtenidos sembrando fibroblastos procedentes del ligamento anterior cruzado en trenzados compactos de PLA [79]. 


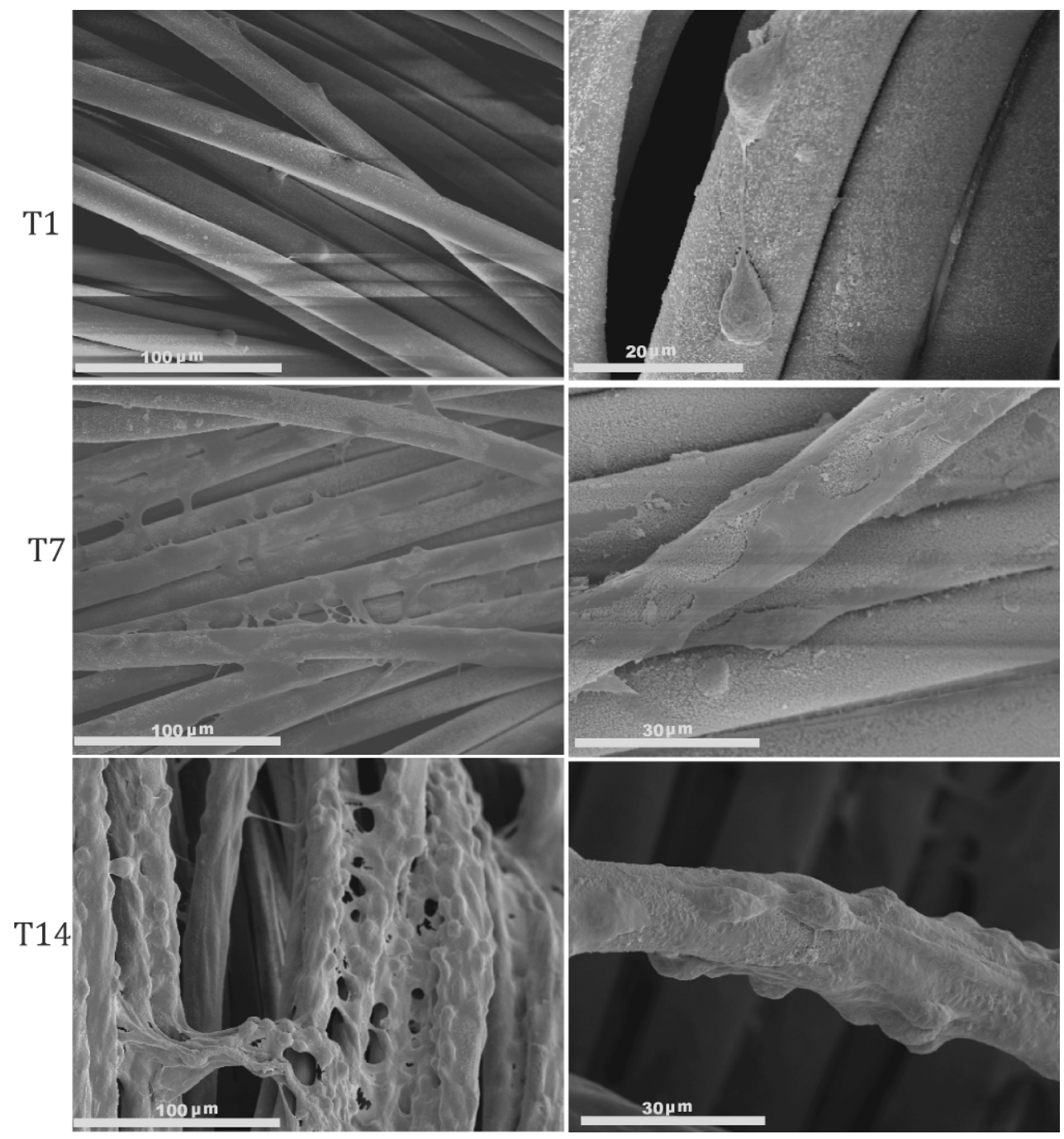

Fig. 3.19 Imágenes de SEM de la morfología del fibroblasto en la superficie del material trenzado de PLA a 1, 7 y 14 días de cultivo. 


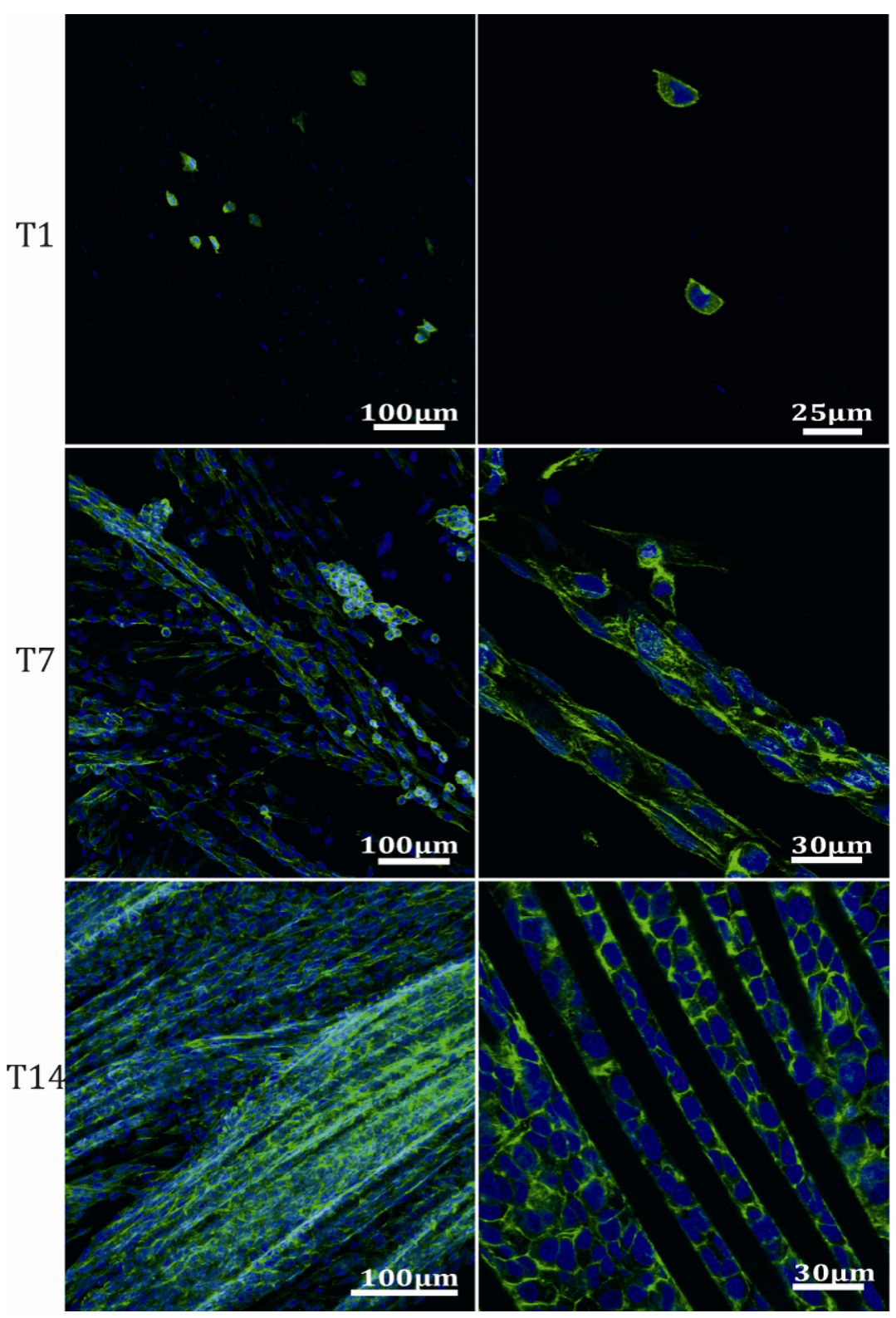

Fig. 3.20 Tinción del citoesqueleto de actina (verde) y núcleos celulares (azul) de los fibroblastos L929 a 1, 7 y 14 días de cultivo sobre la trenza de PLA. 


\subsubsection{Micropartículas}

En este apartado se analizará el comportamiento biológico de las células L929 en diferentes micropartículas con el objetivo de seleccionar el soporte más adecuado, micropartículas de CHT o PLLA, para transportar las células en el interior del material trenzado. Posteriormente, el soporte celular seleccionado se combinará con micropartículas de HA, que actuarán de relleno junto con el soporte portador de las células. El HA es uno de los componentes de la matriz extracelular del tejido conectivo, promueve la angiogénesis potenciando así la regeneración del tejido lesionado [136]. Es de gran importancia realizar una buena elección de las micropartículas portadoras de las células inductoras a la regeneración, ya que estos sustratos deben expandir y transportar a las células por el interior de la trenza de PLA.

Para ello, las células L929 fueron sembradas sobre las micropartículas de CHT, PLLA y HA durante 1, 7 y 14 días, siguiendo los pasos descritos en el apartado 2.3.2.2 de materiales y métodos. 
La viabilidad celular sobre las diferentes micropartículas estimada mediante el ensayo de MTS (Fig. 3.21) revela un incremento en el número de células viables en función del tiempo. Las micropartículas de HA y CHT tienen un comportamiento muy similar a lo largo de todo el estudio. El número de células viables sobre las micropartículas de PLLA es mayor comparado con las micropartículas de HA y CHT, aunque a los 14 días de cultivo no se observan diferencias significativas.

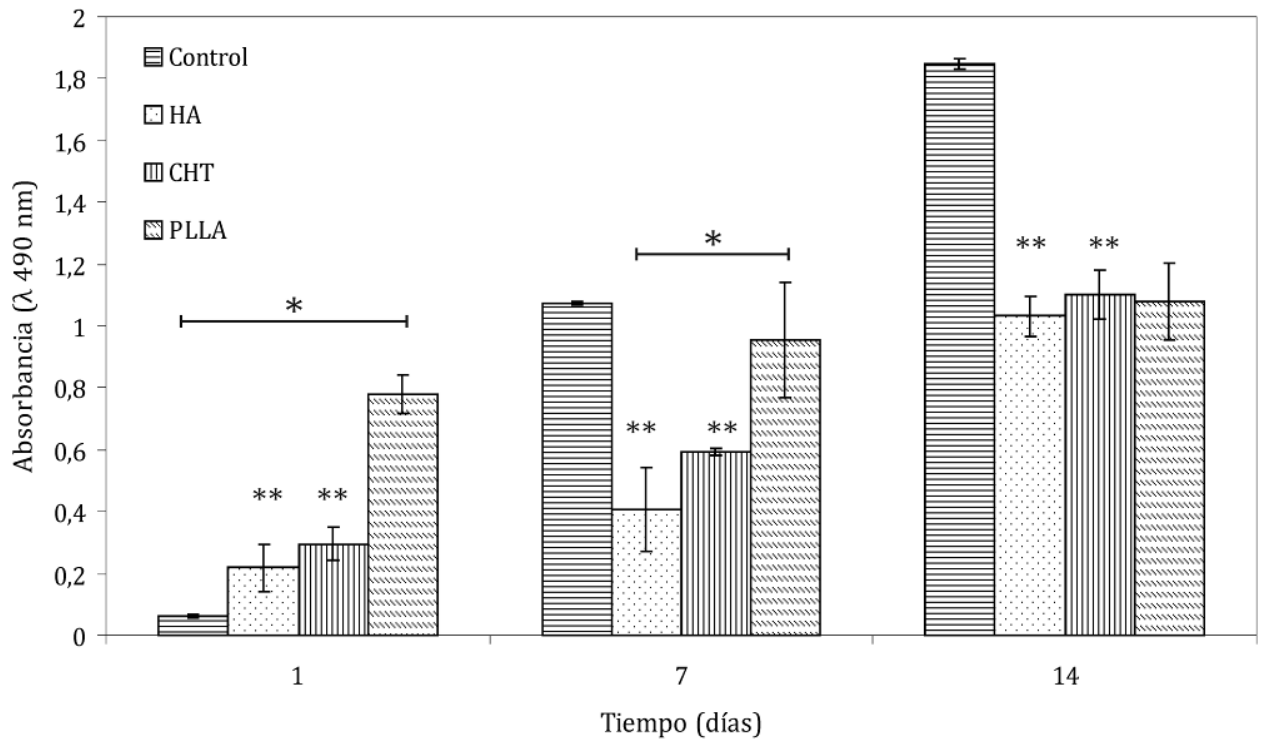

Fig. 3.21 Ensayo de MTS de los fibroblastos cultivados en las distintas micropartículas después de 1, 7 y 14 días de cultivo. ( $p<0,05$, *significa que hay diferencia significativa entre las diferentes muestras en un mismo tiempo $\mathrm{y}^{* *}$ entre la misma muestra a distintos tiempos de cultivo). 
Es de destacar que en las micropartículas de PLLA a tiempos cortos (1 día), se observa un mayor número de células viables con respecto a las micropartículas de CHT y HA. La viabilidad celular en el control (suspensión celular) es significativamente superior con respecto a todas las micropartículas, lo cual es indicativo de que las células en suspensión proliferan más rápido que las adheridas a un soporte físico. Por ello, las células cultivadas sobre los soportes con superficie hidrófila, (CHT y HA) se adhieren inicialmente con mayor dificultad al material pero al haber más contacto célula-célula hay un crecimiento más rápido que las cultivadas en el soporte con una superficie hidrófoba, PLLA, donde las células se adhieren inicialmente con mucha facilidad al material ralentizando el crecimiento celular [137].

La morfología de las células sobre las distintas micropartículas a 1 y 14 días de cultivo se analizó mediante SEM (Fig. 3.22). Las células sobre las micropartículas de PLLA se adhieren bastante bien adoptando una morfología extendida desde el primer día de cultivo (Fig. 3.22a). Sin embargo, sobre las micropartículas de HA y CHT la adhesión celular es más pobre a tiempos cortos exhibiendo una morfología redondeada (Fig. 3.22b y c). Con la evolución del cultivo las células muestran una morfología más fusiforme con un citoplasma bien extendido tanto en las micropartículas de PLLA como en las de CHT (Fig. 3.22a y c). Además, en todos los soportes (micropartículas de HA, PLLA y CHT) se observa la formación de agregados de células-micropartículas. Excepcionalmente, sobre las micropartículas de HA las células exhiben 
una morfología redondeada independientemente del tiempo de cultivo (Fig. 3.22b).

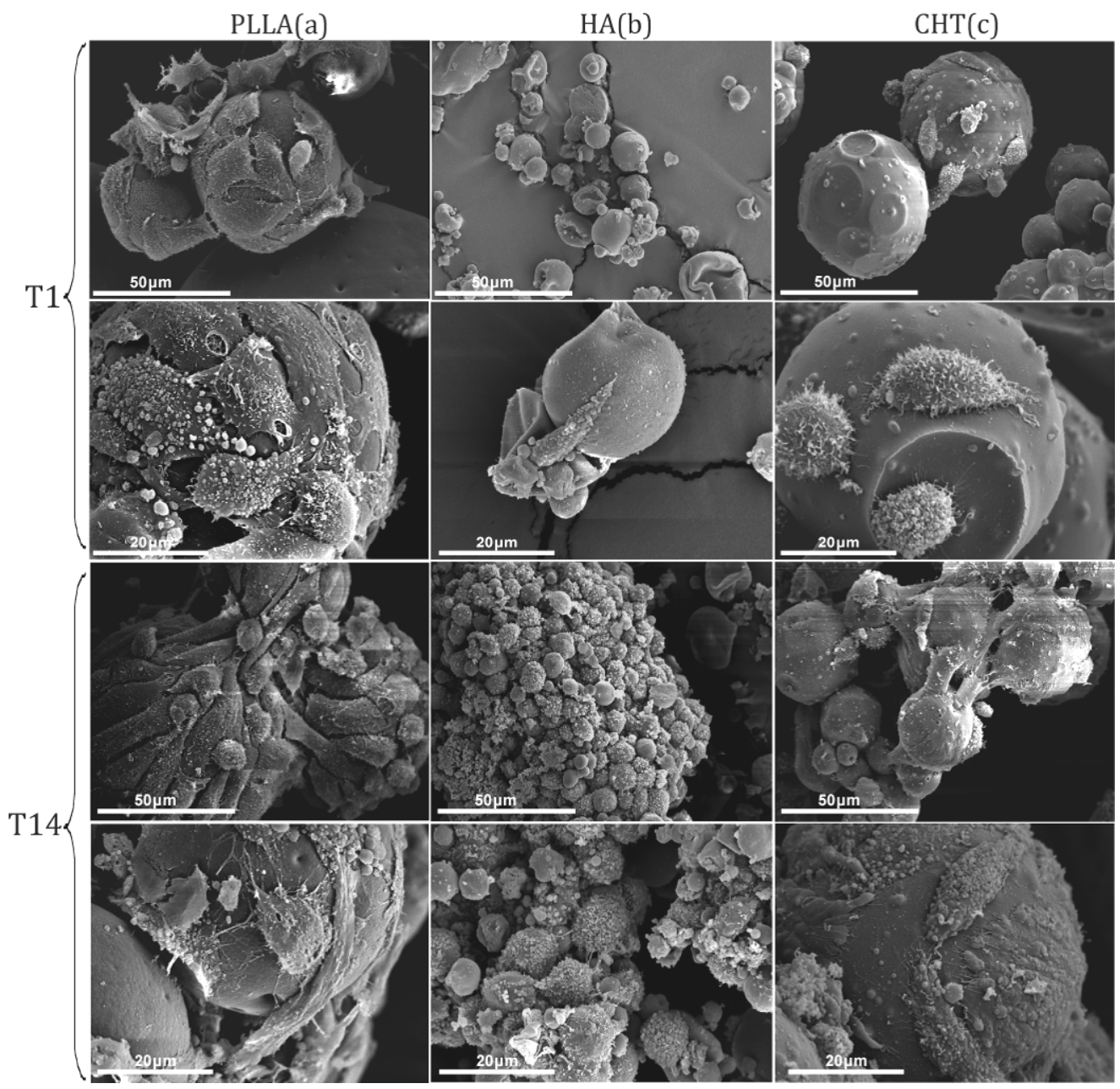

Fig. 3.22 Imágenes de SEM de la morfología de las L929 sobre las diferentes micropartículas siendo (a) las de PLLA, (b) las de HA, y (c) las de CHT a 1 y 14 días de cultivo. Se representa por cada tiempo una imagen panorámica y otra a mayores aumentos (T1 y T14). 
También fueron realizados ensayos de tinción del citoesqueleto de actina como se muestra en la Fig. 3.23. Las células sobre las micropartículas de PLLA y CHT muestran un citoesqueleto de actina bien desarrollado, llegándose a distinguir la formación de agregados células-micropartículas. Los resultados obtenidos coinciden con los de SEM y viabilidad celular.
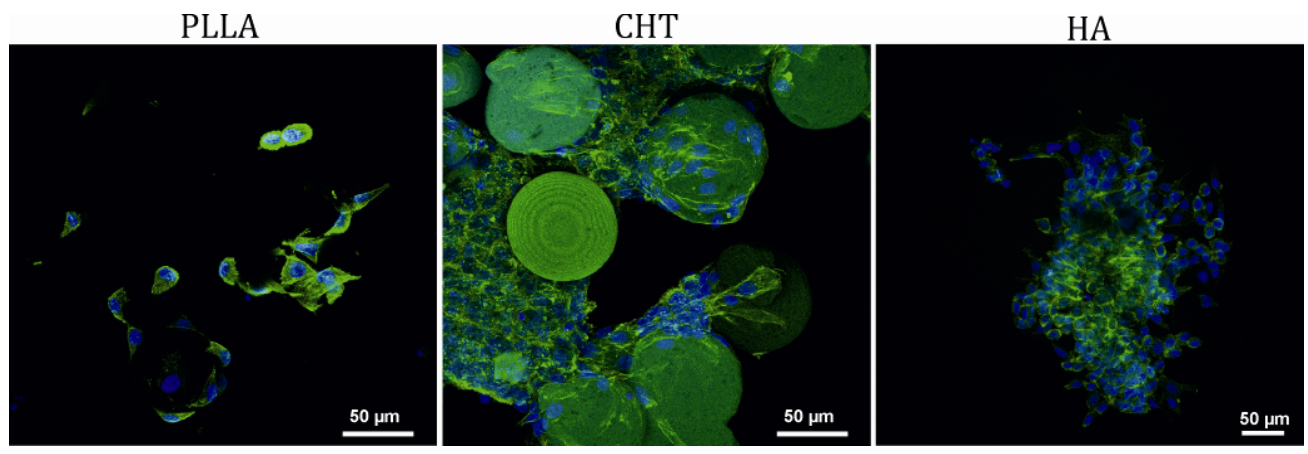

Fig. 3.23 Tinción del citoesqueleto de actina de las células L929 después de 7 días de cultivo sobre las micropartículas de PLLA, CHT y HA. Los núcleos fueron teñidos con DAPI.

La morfología que adopta la célula sobre los distintos soportes (PLLA, CHT y HA) está relacionada con la interacción célula-material. El proceso de adhesión de las células sobre diferentes sustratos (micropartículas) está mediado por distintos mecanismos. Por una parte están las características de la superficie como la topografía y el carácter hidrófilo o hidrófobo, entre otros, los cuales juegan un papel muy importante y tienen una gran influencia en la interacción célula- 
material [138]. Dependiendo de las características físicas o químicas de la superficie del material, las proteínas se adsorben de forma distinta tanto en cantidad, como el tipo de proteínas que se adsorbe, la orientación que toma o la configuración de éstas al ser adsorbidas.

Teniendo en cuenta estas características, la variación de la morfología observada sobre las micropartículas de PLLA, morfología extendida, y una morfología más redondeada sobre las micropartículas de CHT coincide con los estudios realizados por García et al. [139] donde se demuestra que en el CHT las proteínas se adsorben inicialmente con una conformación globular y en el PLLA con una conformación extendida, influyendo de este modo en la adhesión y morfología de las células. Con respecto a las de HA, la mayoría de las células no se adhirieron en su superficie, formaron aglomerados. En la literatura está reportado que este material se utiliza en aplicaciones para liberación controlada de factores de crecimiento[140] y de fármacos [141] principalmente.

Después de analizar los resultados en conjunto de todos los ensayos realizados sobre las diferentes micropartículas, se seleccionó las micropartículas de PLLA frente a las de CHT como soporte celular debido a que inicialmente manifestaron mayor afinidad por este sustrato mostrando una buena interacción célula-material. 
Como se ha mencionado anteriormente, el soporte seleccionado se cultivará con las células apropiadas ( $h M S C s$ ) y se inyectará mediante una jeringa y una aguja de $500 \mu \mathrm{m}$ de diámetro en el interior del material trenzado. Debido a que las células tienden a formar agregados con las micropartículas, se decidió evaluar el tiempo de cultivo a partir del cual se empiezan a formar agregados células-micropartículas, con el objetivo de poder inyectar fácilmente el relleno (células y micropartículas) en el interior del material trenzado sin bloquear la jeringa. Para conocer este parámetro, se realizó un ensayo de adhesión a tiempos cortos a 1, 2, 3 y 6 horas, con fibroblastos (células L929) sobre las micropartículas de PLLA y se evaluó su morfología mediante SEM.

En la Fig. 3.24 se muestran las micrografías de SEM obtenidas después de 1, 2, 3 y 6 horas de cultivo. Como se puede apreciar a partir de las 6 horas de cultivo aparecen los primeros agregados de célulasmicropartículas de aproximadamente $100 \mu \mathrm{m}$. Teniendo en cuenta el resultado obtenido se decidió que el tiempo de cultivo previo a la inyección debería ser menor que 6 horas para evitar problemas de obstrucción de la jeringa. En concreto, se ha determinado que el tiempo de cultivo previo a la inyección sería de 4 h. 
$\mathrm{T} 1 \mathrm{~h}$

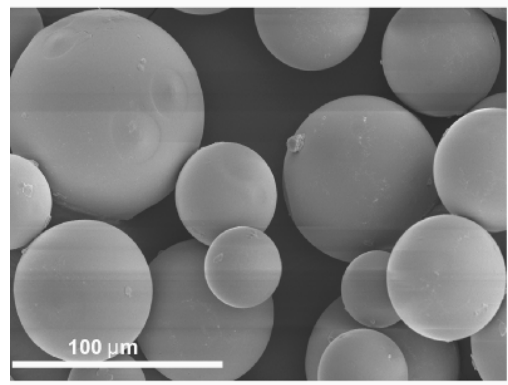

T3h

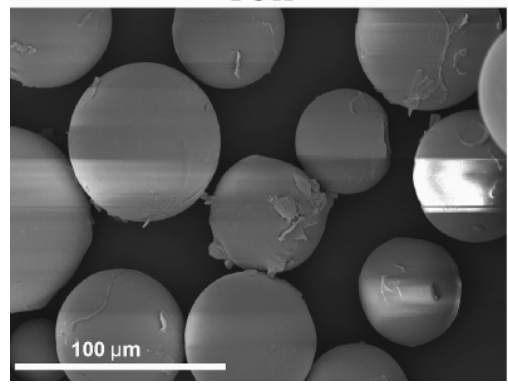

$\mathrm{T} 2 \mathrm{~h}$

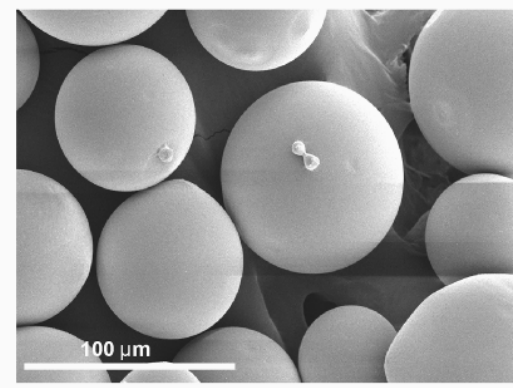

T6h

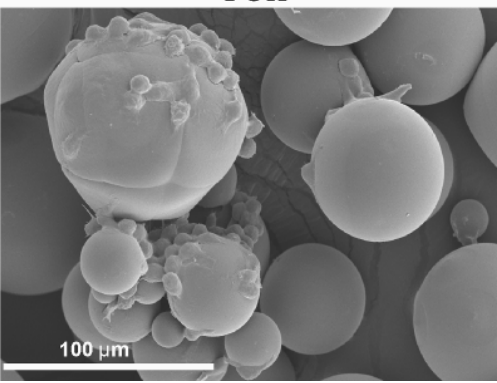

Fig. 3.24 Micrografías de SEM de las micropartículas de PLLA sembradas con L929 durante 1, 2 ,3 y 6 horas.

Una vez elegido el soporte celular, micropartículas de PLLA, y estimado el tiempo de cultivo antes de inyectar, las micropartículas de PLLA fueron combinadas con las micropartículas de HA en dos proporciones diferentes: 2PLLA:1HA y 1PLLA:2HA. En este caso, se evaluó la viabilidad y morfología de las células en cada grupo. 
En la Fig. 3.25, se muestran los resultados obtenidos del ensayo de MTS. A tiempos cortos (1 día), el número de células viables sobre las micropartículas de PLLA es mayor respecto a los dos grupos ensayados, lo cual coincide con los resultados esperados. Sin embargo, a los 14 días de cultivo el número de células viables en los dos grupos (2:1 y 1:2, PLLA:HA) es mayor que en las micropartículas de PLLA y HA e incluso mayor que en el control. Este comportamiento puede deberse a que el HA proporciona un efecto potenciador cuando se combina con el PLLA aumentando la velocidad de proliferación celular. Por una parte, se encuentran las células adheridas a las micropartículas de PLLA y por otro lado hay más cantidad de células que están en contacto entre sí, tal y como sucedía cuando se cultivaron sobre HA, favoreciendo de este modo la proliferación. 


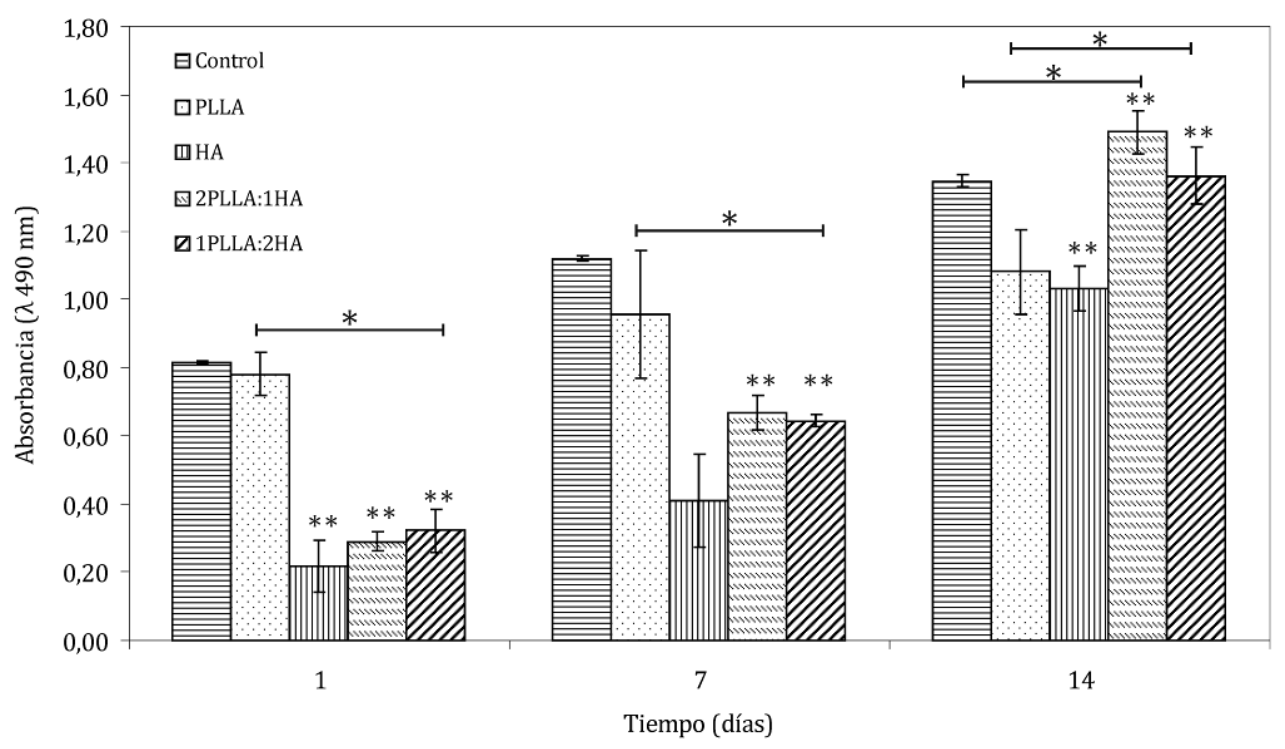

Fig. 3.25 Ensayo de MTS de los fibroblastos cultivados en las micropartículas (PLLA y HA) y en las combinaciones entre ellas (2:1 y 1:2, PLLA:HA) a 1, 7 y 14 días de cultivo. ( $p<0,05$, *significa que hay diferencia significativa entre las diferentes muestras en un mismo tiempo $\mathrm{y}^{* *}$ entre la misma muestra a distintos tiempos de cultivo).

La morfología de las células L929 sobre los dos grupos de micropartículas, 2PLLA:1HA y 1PLLA:2HA, se muestran en la Fig. 3.26 después de 1, 7 y 14 días de cultivo. Como era de esperar, se observa una diferencia evidente en la morfología de las células sobre las micropartículas de PLLA (células fusiformes) y las de HA (células redondeadas). En ambos casos se forman agregados célulasmicropartículas como se ha visto anteriormente. 
Los resultados obtenidos en ambos grupos (2:1 y 1:2, PLLA:HA) muestran que la combinación de ambas micropartículas mejora la proliferación celular respecto a un único tipo de micropartículas. Como a tiempos iniciales las micropartículas de PLLA muestran una mejor adhesión, se ha seleccionado la combinación de micropartículas con mayor proporción de PLLA o sea, la combinación 2PLLA:1HA. 


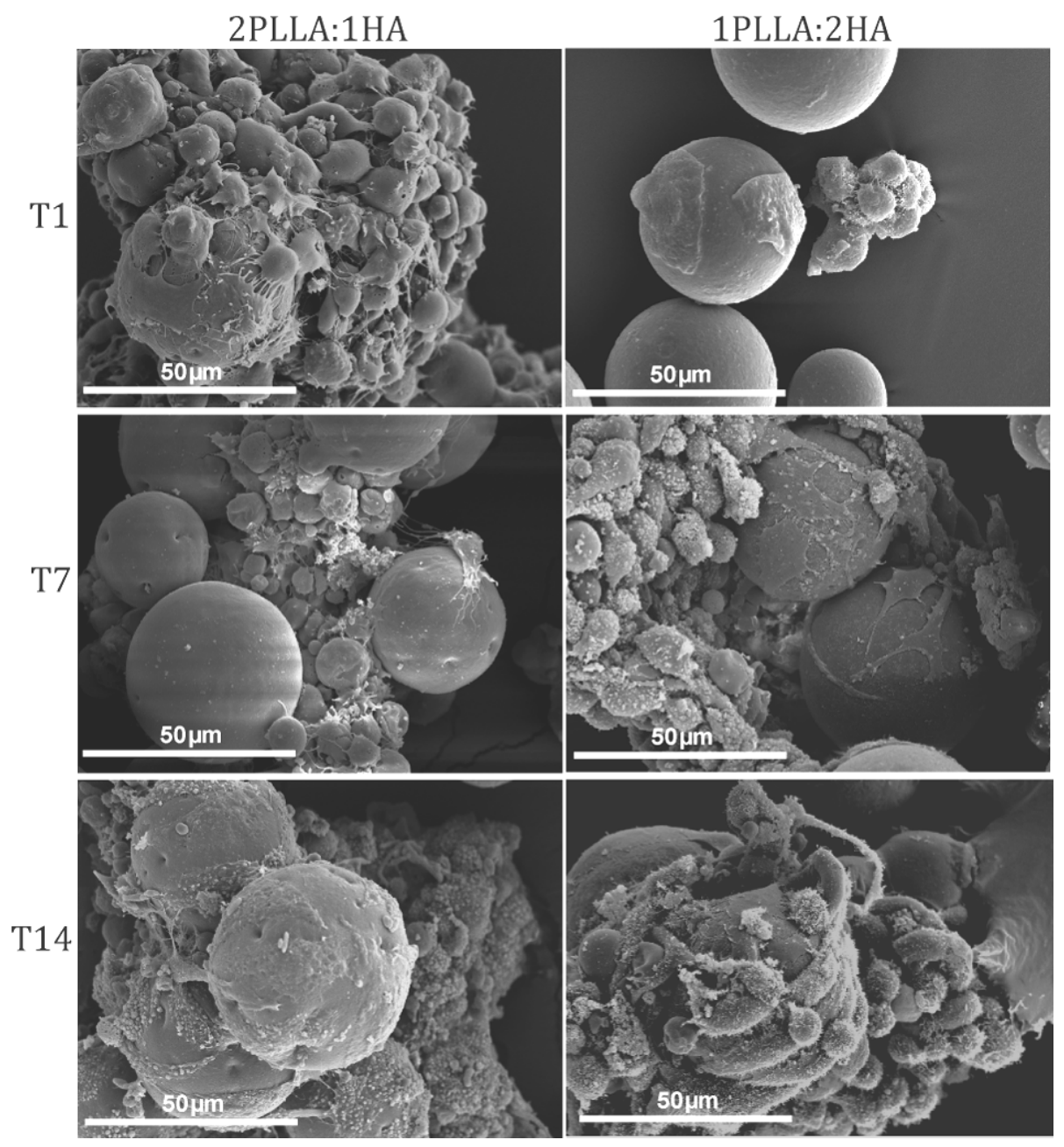

Fig. 3.26 Imágenes de SEM de la morfología de las L929 sobre las distintas combinaciones de micropartículas de PLLA y HA (2:1 y 1:2) después de 1, 7 y 14 días. 
Los resultados obtenidos en el cultivo de las L929 sobre los diferentes componentes de la prótesis (material trenzado y relleno, células, micropartículas de PLLA y HA) demuestran que la adhesión, supervivencia y proliferación celular se incrementa con el tiempo de cultivo. A los 14 días de cultivo, la superficie de los componentes de la prótesis está completamente cubierta por células y matriz extracelular, por lo que, los materiales seleccionados para la fabricación del prototipo de prótesis presentan un buen comportamiento biológico.

Con el objetivo de mimetizar "in vitro" el comportamiento biológico de la prótesis con células mesenquimales y su posterior diferenciación se procedió a validar cada uno de los componentes de la prótesis con células madre mesenquimales humanas, hMSCs provenientes de médula ósea.

\subsubsection{Estudio del comportamiento de las hMSCs in vitro en los distintos componentes de la prótesis}

Para estudiar el comportamiento de las hMSCs, sobre los componentes de la prótesis fueron realizados cultivos a tiempos largos sobre la trenza de PLA y las diferentes micropartículas (PLLA, CHT y HA). Se estudió la viabilidad, la morfología y la proliferación celular en los diferentes materiales ensayados. Asimismo, se realizó un ensayo de diferenciación de hMSCs a tenocitos, utilizando un medio de 
diferenciación suplementado con BMP-12 y otro con los factores de crecimiento, IGF-I y TGF- $\beta 1$.

\subsubsection{Material trenzado}

El cultivo sobre el material trenzado con las $h M S C s$, se realizó del mismo modo que el cultivo del material trenzado con las células L929. En la Fig. 3.27 se muestran los resultados del ensayo de MTS. Como se puede observar el número de células viables aumenta de forma significativa en el tiempo.

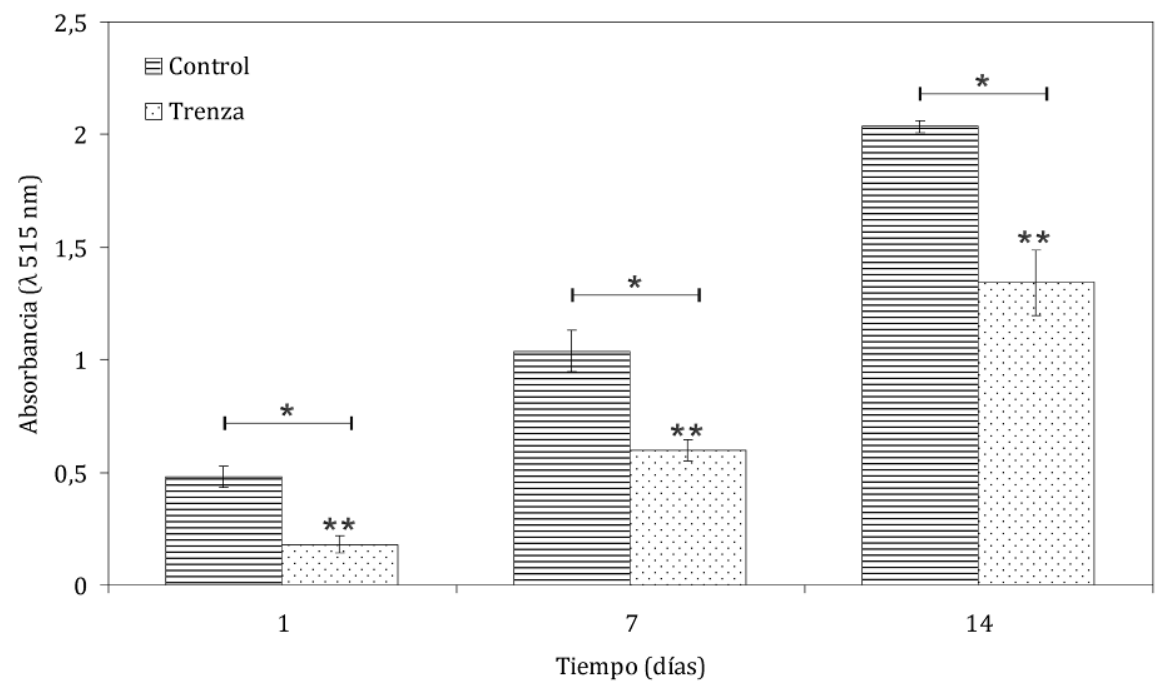

Fig. 3.27 Ensayo de MTS de las hMSCs cultivadas sobre el material trenzado a 1, 7 y 14 días de cultivo. ( $p<0,05$, *significa que hay diferencia significativa entre las diferentes muestras en un mismo tiempo y ${ }^{* *}$ entre la misma muestra a distintos tiempos de cultivo). 
Las hMSCs cultivadas sobre la trenza de PLA a 1, 7 y 14 días (Fig. 3.28) muestran una morfología alargada.

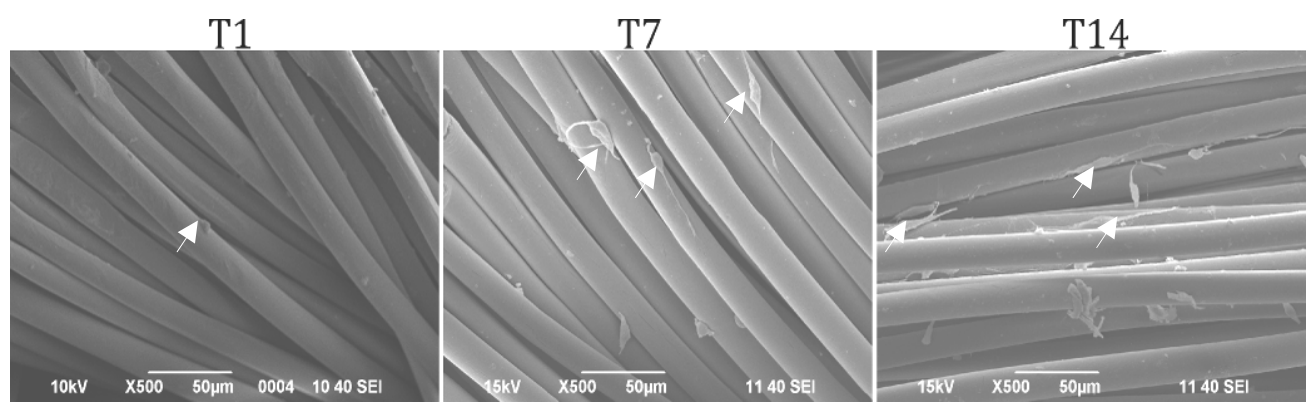

Fig. 3.28 Imágenes de SEM de la morfología de las $h M S C s$ sobre la trenza de PLA a 1, 7 y 14 días. Las flechas indican células en las microfibras.

Para visualizar mejor la distribución de las células en el material trenzado se realizó una tinción del citoesqueleto de actina. En la Fig. 3.29 se observa que las células se orientan en la dirección de las fibras mostrando una morfología alargada con un citoesqueleto de actina bien desarrollado.

Estos resultados revelan que las hMSCs muestran un buen comportamiento celular, adhiriéndose y proliferando correctamente sobre este material. Resultados similares han sido reportados en la literatura donde confirman el buen comportamiento de estas células cultivadas sobre materiales trenzados [75]. 
T1



T7
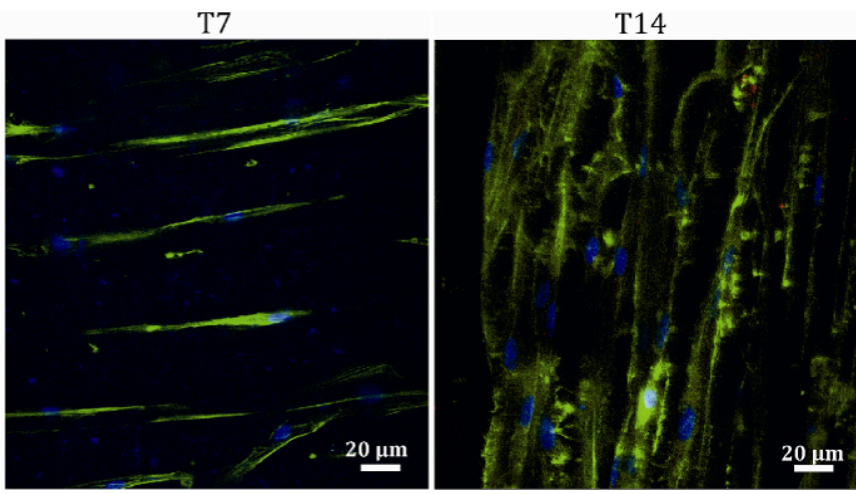

Fig. 3.29 Tinción del citoesqueleto de actina (verde) desarrollado por las hMSCs cultivadas sobre la trenza de PLA tras 1, 7 y 14 días. Los núcleos se tiñeron con DAPI (azul).

\subsubsection{Micropartículas}

El cultivo de las hMSCs sobre las distintas micropartículas (PLLA, HA y CHT) se realizó con el mismo propósito que con el cultivo de la línea celular L929, es decir, seleccionar el soporte que presente un mejor comportamiento celular.

En la Fig. 3.30, se muestran los resultados obtenidos de los ensayos de MTS a 1, 7 y 14 días de cultivo. El número de células viables sobre las diferentes micropartículas aumenta con el tiempo de cultivo. A 1 y 7 días, el número de células viables sobre las micropartículas de HA y PLLA es mayor comparado con las micropartículas de CHT, sin embargo a 14 días no se observan diferencias significativas. Resulta válido aclarar que la viabilidad de las células en la muestra control es similar a la observada en las micropartículas, lo cual nos sugiere que un soporte 
físico juega un papel fundamental en la viabilidad y proliferación celular.

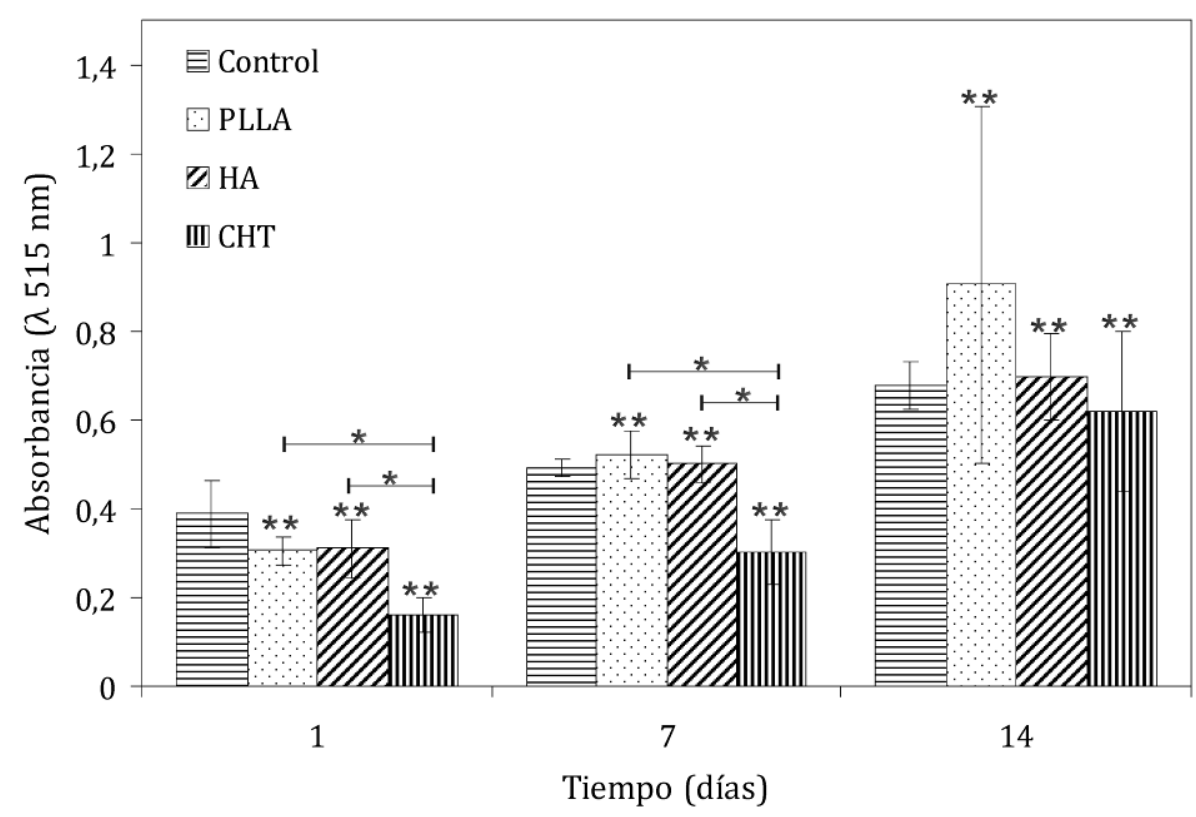

Fig. 3.30 Ensayo de MTS de las hMSCs cultivadas sobre las distintas micropartículas a 1,7 y 14 días de cultivo. $(p<0,05$, *significa que hay diferencia significativa entre las diferentes muestras en un mismo tiempo y** entre la misma muestra a distintos tiempos de cultivo)

En la Fig. 3.31 se muestran las micrografías de SEM obtenidas sobre las diferentes micropartículas a 1 y 14 días de cultivo. A un día de cultivo se observa que hMSCs sobre las micropartículas de PLLA se adhieren a la superficie del material emitiendo prolongaciones y adoptando una morfología extendida y plana (Fig. 3.31a). En cambio, la 
morfología de las células en las micropartículas de HA es más alargada llegándose a observar aglomerados células-micropartículas (Fig. 3.31b). Las hMSCs adheridas sobre las micropartículas de CHT muestran una morfología más redondeada en los primeros días de cultivo. A 14 días, las células proliferan perfectamente sobre los distintos soportes mostrando la misma morfología que mostraban para un día de cultivo en el caso de las células cultivadas sobre las micropartículas de PLLA y HA (Fig. 3.31a y b) y una morfología poliédrica y menos fibroblástica las células cultivadas sobre las micropartículas de CHT (Fig. 3.31c). 


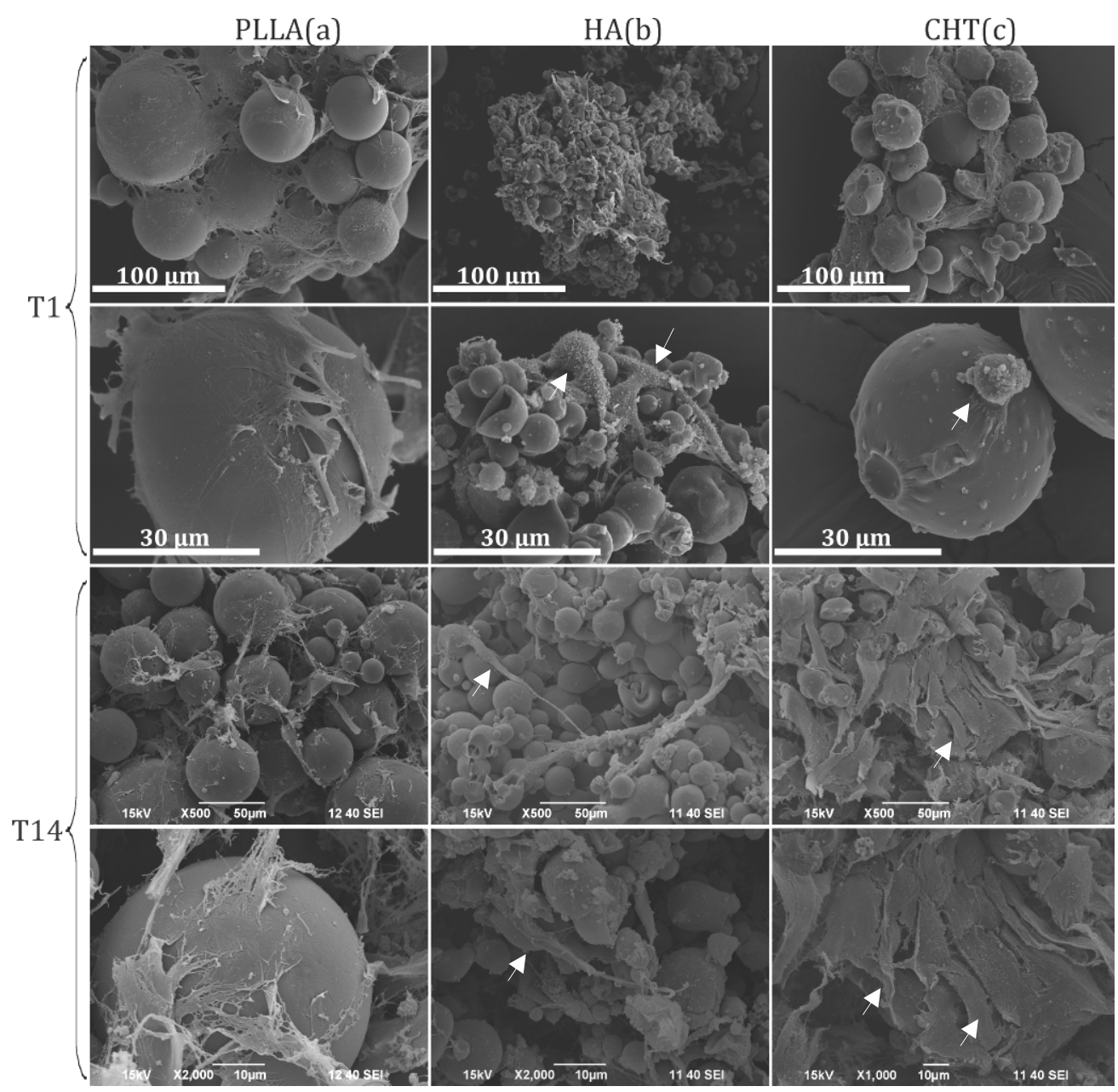

Fig. 3.31 Imágenes de SEM de la morfología de las de las hMSCs sobre las diferentes micropartículas siendo (a) las de PLLA, (b) las de HA, y (c) las de CHT a 1 y 14 días de cultivo. Se representa por cada tiempo una imagen panorámica y otra a mayores aumentos (T1 y T14). Las flechas indican células en las micropartículas. 
Para visualizar mejor la distribución de las células sobre las micropartículas se realizó la tinción del citoesqueleto de actina. En la Fig. 3.32 se observa que a un día de cultivo, las células cultivadas sobre las micropartículas de PLLA muestran la disposición de los filamentos de actina sobre toda la superficie de la micropartícula, demostrándose que las $h M S C s$ se adhieren correctamente sobre este sustrato. En el caso de las micropartículas de HA y CHT se observa una gran acumulación de células entre las micropartículas, con un citoesqueleto de actina bien desarrollado, que forman agregados celulares.

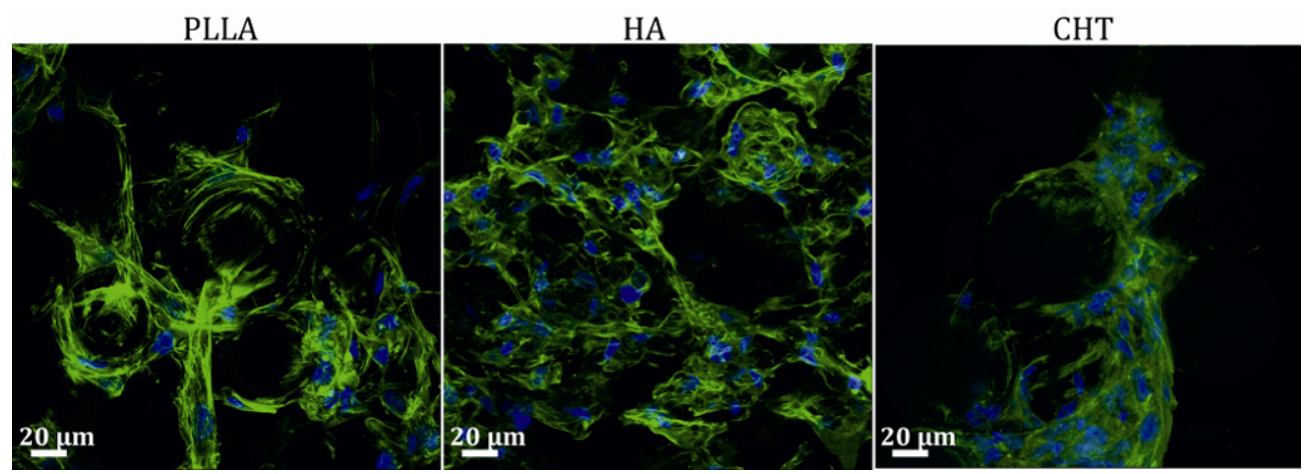

Fig. 3.32 Tinción del citoesqueleto de actina (verde) desarrollado por las hMSCs en las micropartículas de PLLA, HA y CHT a 1 día de cultivo. Los núcleos se han marcado con DAPI.

Posteriormente a la caracterización morfológica se realizó un ensayo de citometría de flujo para evaluar la expresión de distintos marcadores de superficie celular expresados por las hMSCs. Se ha evaluado y comparado la expresión de los marcadores: CD44, HLA-DR y CD166 a 
los 14 días de cultivo. La expresión positiva de los marcadores CD44 y CD166 indica que las células aisladas y empleadas en el estudio son hMSCs.

En la Fig. 3.33 se representa las células vivas y los porcentajes de cada uno de los marcadores de superficie existentes en la membrana de la célula. La línea negra representa el isotipo control, de la línea negra hacia la izquierda aparecen las células que no emiten fluorescencia debido a que no poseen este marcador en su membrana y de la línea negra hacia la derecha, se representan las células que sí expresan el marcador en su superficie. 

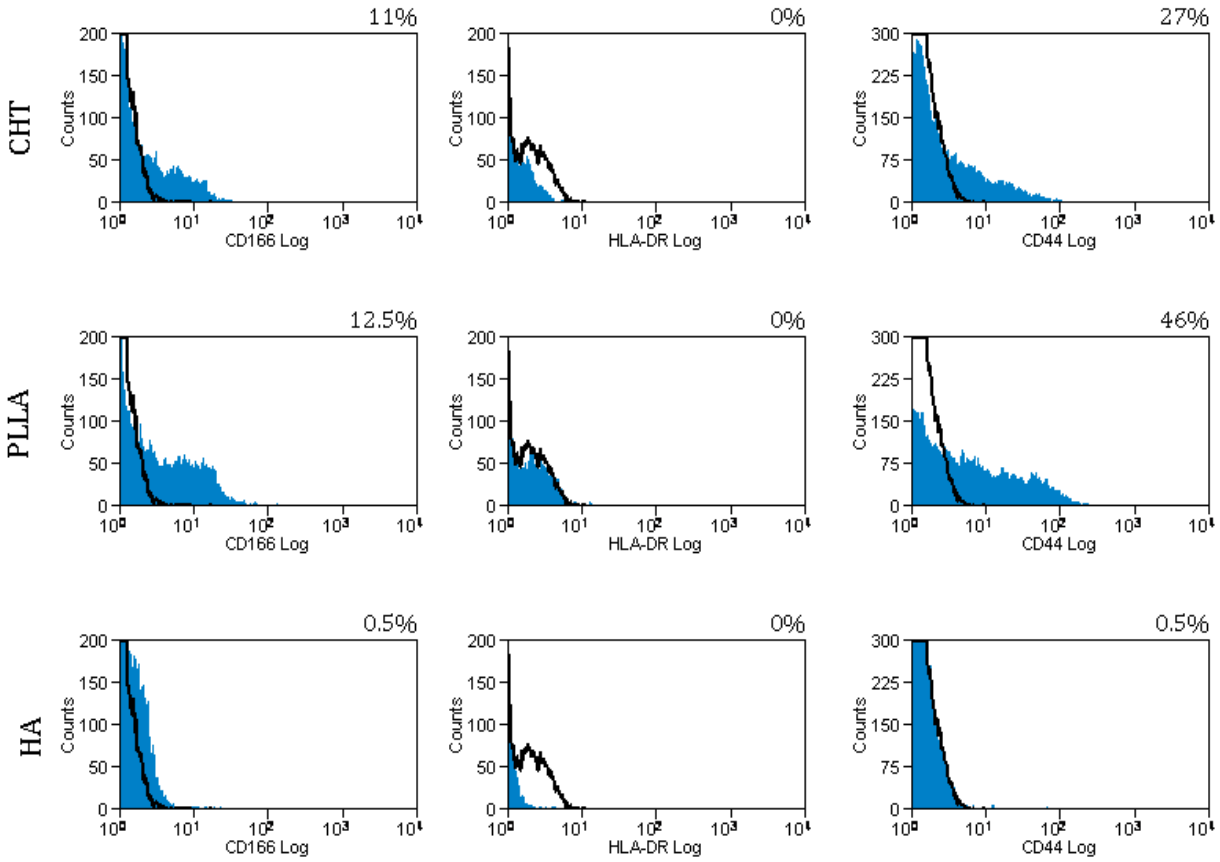

Fig. 3.33 Inmunofenotipo del cultivo de hMSCs sobre las micropartículas de distintos materiales CHT, PLLA y HA a tiempo T14. Representados 5000 eventos.

Como se puede apreciar las células cultivadas en las micropartículas de HA expresan un $0 \%$ en cada uno de los marcadores de superficie estudiado (CD44, CD166 y HLA-DR) lo cual puede ser debido a que el tamaño de las micropartículas y el de las células es muy similar y el equipo no es capaz de discernir entre lo que es micropartícula y lo que es una célula.

En el caso de las micropartículas de CHT y PLLA, como estas emiten fluorescencia al ponerles el marcador de viabilidad, el citómetro 
diferenciaba con facilidad entre células muertas y micropartículas, de las células vivas. Por lo tanto, se observa que las células no expresan el marcador HLA-DR (0\%), tal y como se esperaba ya que dicho marcador es negativo para las mesenquimales. Sin embargo, estas células si que expresan 2 receptores característicos de este tipo celular, el CD166 y el CD44. Los porcentajes obtenidos del marcador CD166 es muy similar en ambos materiales, obteniéndose valores de 11 y $12.5 \%$ para los materiales CHT y PLLA respectivamente. Sin embargo la expresión del CD44 es significativamente mayor en el PLLA, $46 \%$, respecto del CHT, $27 \%$. Estos datos sugieren que las células muestran características fenotípicas de las hMSCS después del cultivo sobre las micropartículas de PLLA y CHT.

En previos estudios se ha reportado que las micropartículas de PLLA actúan como buenos soportes para el transporte celular [107]. El buen comportamiento mostrado de las hMSCs sobre las micropartículas de PLLA desde el primer día de cultivo, sumado a la diferencia tan notable del porcentaje en la expresión del receptor CD44 y sabiendo que este marcador es el receptor de hialuronato [34] y lo expresan los tenocitos, se optó por este tipo de micropartícula como soporte celular frente al CHT.

Las hMSCs cultivadas en las micropartículas de HA también mostraron un buen comportamiento, por lo que se siguen manteniendo como material de relleno para ser combinado con las de PLLA en futuras inyecciones en el prototipo de prótesis. 
Una vez elegidas las micropartículas de PLLA como soporte celular, se decidió realizar un estudio de diferenciación tenocítica tanto en las micropartículas como en el material trenzado.

\subsubsection{Estudio de diferenciación tenocítica}

Las hMSCs fueron cultivadas sobre la trenza de PLA y sobre las micropartículas de PLLA durante 21 días utilizando dos medios de cultivo diferentes con la finalidad de estudiar su diferenciación in vitro: un medio suplementado con la proteína BMP-12 (medio M1) y medio suplementado con una mezcla de factores de crecimiento, TGF- $\beta 1$ y IGF-1 (medio M2).

La viabilidad celular sobre la trenza de PLA se evaluó mediante un ensayo de MTS. La Fig. 3.34 indica que el número de células viables aumenta significativamente en función del tiempo siguiendo la misma tendencia en ambos medios. Tanto en un medio como en otro, el control presenta un número de células viables mayor con respecto al que muestran las células sobre el material.

El análisis estadístico $t$ Student, indicó que había un aumento significativo en el número de células viables después de la adición del medio diferenciador. 

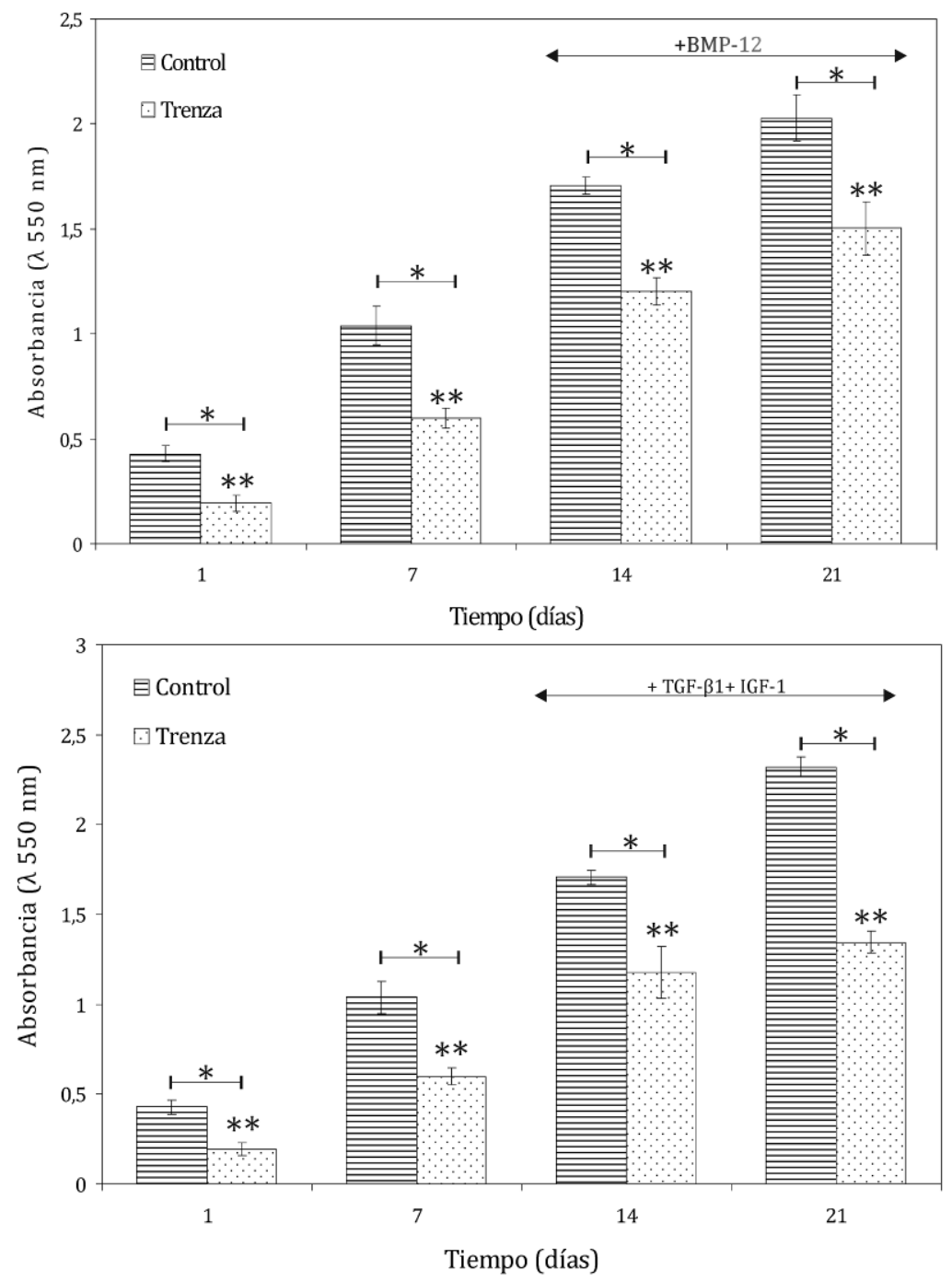

Fig. 3.34 Ensayo de MTS de las hMSCs cultivadas sobre la trenza de PLA utilizando dos medios distintos: medio suplementado con BMP-12 y medio suplementado con TGF- $\beta 1$ y IGF-1 a 1, 7, 14 y 21 días de cultivo. ( $p<0,05$, *significa que hay diferencia significativa entre las diferentes muestras en un mismo tiempo ${ }^{* *}$ entre la misma muestra a distintos tiempos de cultivo). 
La morfología de las células cultivadas sobre la trenza de PLA con los distintos medios a 14 y 21 días se muestra en la Fig. 3.35. Las células cultivadas con el medio suplementado con BMP-12, adoptan una morfología alargada y con aspecto fibroblástico. Sin embargo, las células cultivadas con el medio suplementado con TGF- $\beta$ y IGF-1 presentan una morfología más extendida formando una capa de células que recubren las fibras.

T14
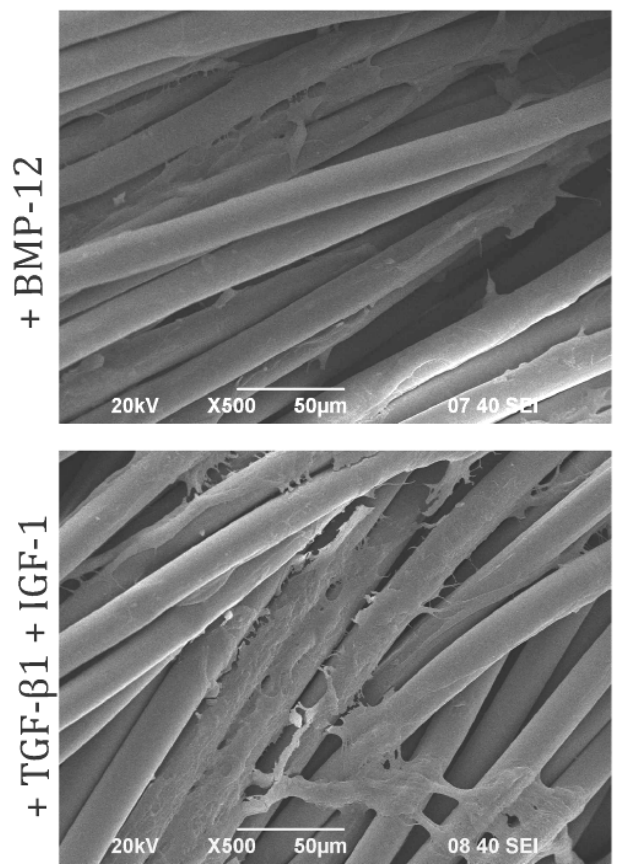

T21
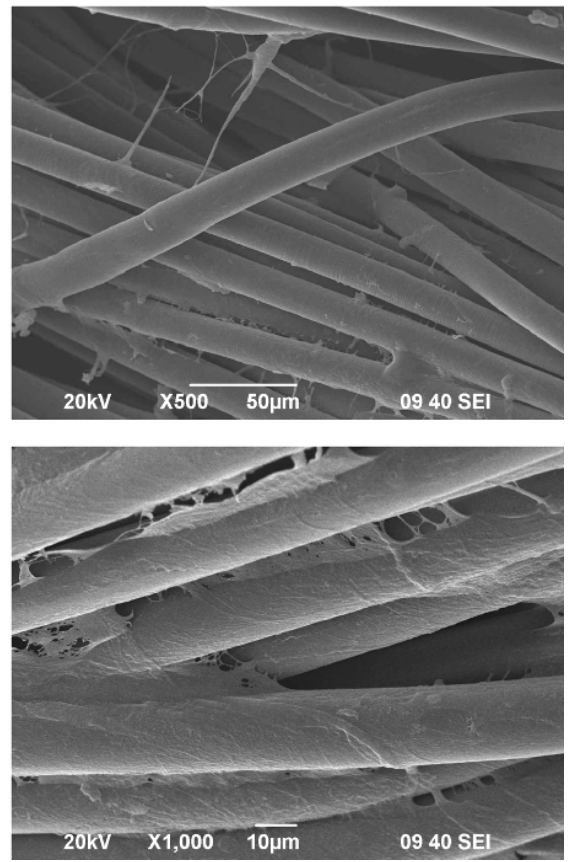

Fig. 3.35 Imágenes de SEM de la morfología de las hMSCs sobre la trenza de PLA utilizando distintos medios de diferenciación: medio suplementado con BMP-12, fila superior y medio suplementado con TGF- $\beta 1$ y IGF-1, fila inferior tras 14 y 21 días de cultivo. 
Para evaluar si se ha producido diferenciación de hMSCs a tenocitos fueron realizados ensayos de inmunofluorescencia para detectar la expresión de varios marcadores como son el colágeno tipo I y la tenomodulina presentes en los tenocitos. También se ha utilizado los marcadores de actina para corroborar la morfología celular (Fig. 3.36).

A partir de los 14 días, se observa la formación de matriz colagénica, siendo más evidente en las muestras con medio suplementado con BMP-12 (Fig. 3.36a y b). A partir de los 21 días de cultivo se observa una expresión positiva de la tenomodulina siendo más visible en las células cultivadas con el medio suplementado con la mezcla de factores TGF-ß1 y IGF-1 (Fig. 3.36c). La tinción de actina revela que las células cultivadas en ambos medios presentan una morfología alargada. 


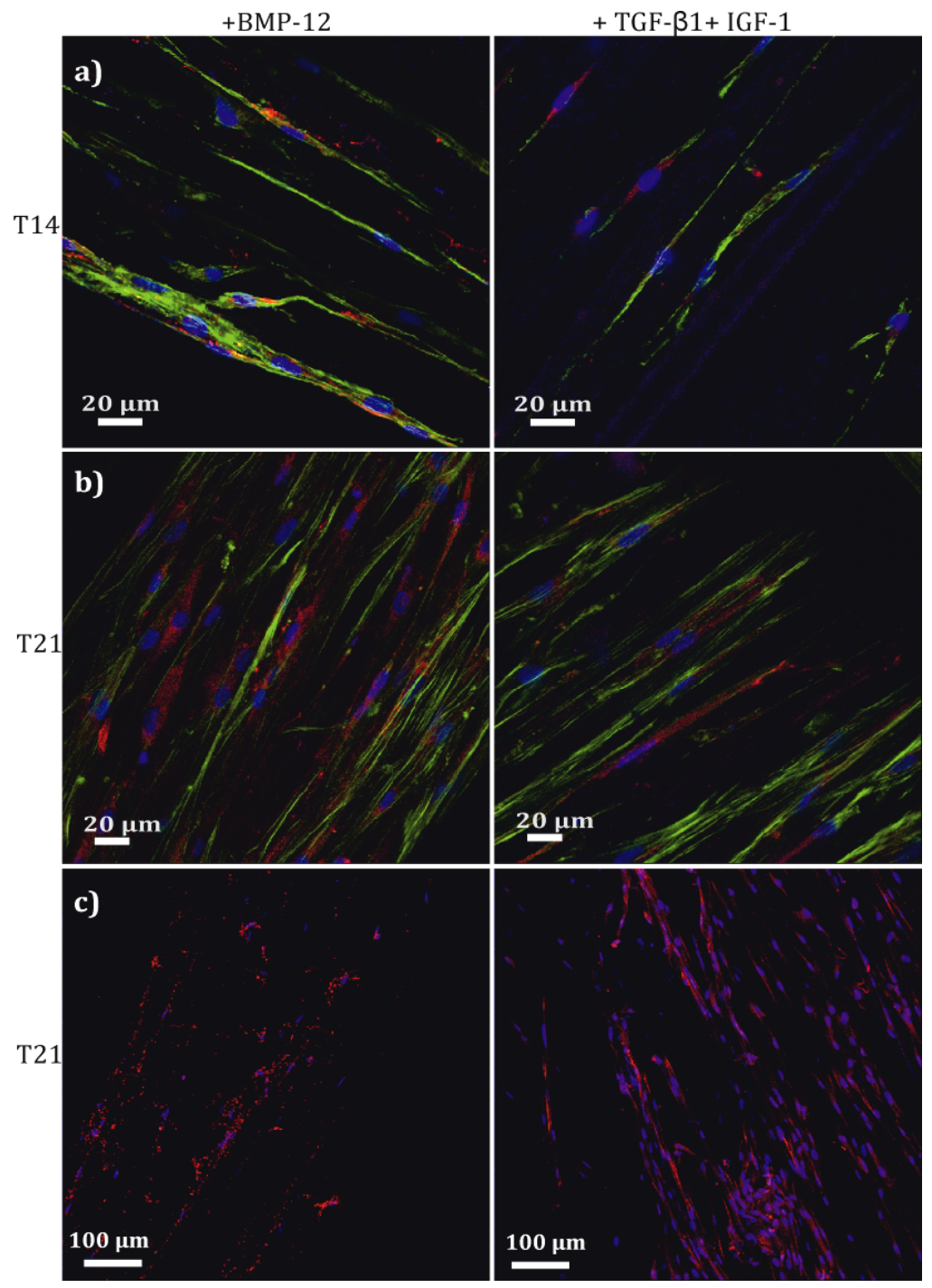

Fig. 3.36 Inmunofluorescencia de proteínas expresadas por las hMSCs cultivadas en la trenza de PLA utilizando los medios diferenciadores. a) y b) Expresión de colágeno tipo I (rojo) y tinción del citoesqueleto de actina (verde) a 14 y 21 días y, c) expresión de la tenomodulina (rojo) tras 21 días de cultivo . Los núcleos se han marcado con DAPI. 
De todos los resultados obtenidos pudimos confirmar que las $h M S C S$ cultivadas en el material trenzado muestran signos de diferenciación, no sólo por el cambio morfológico observado sino también por la expresión de las distintas proteínas. De forma cualitativa, se observó que las células cultivadas en el medio suplementado con la BMP-12 expresan más colágeno tipo I que las cultivadas en el medio suplementado con TGF- $\beta 1$ y IGF-1. En cambio, las células en contacto con este medio (TGF- $\beta 1$ y IGF-1) expresan más tenomodulina indicando que esta mezcla de factores favorece la adhesión, proliferación y diferenciación de las hMSCs.

Una vez finalizado el estudio de diferenciación en el material trenzado, se realizó la diferenciación de las hMSCs a tenocitos sobre las micropartículas de PLLA utilizando los mismos medios de cultivo que en el ensayo anterior.

En la Fig. 3.37 se muestran los resultados del ensayo de MTS obtenidos en los cultivos de las micropartículas de PLLA utilizando los dos medios diferenciadores. El número de células viables cultivadas en el medio suplementado con BMP-12 se mantiene constante hasta los 21 días de cultivo. Sin embargo, el número de células viables cultivadas en el medio suplementado con TGF- $\beta 1$ y IGF-1 disminuye significativamente. El número de células viables en la muestra control disminuye notablemente al adicionar ambos medios de diferenciación. 

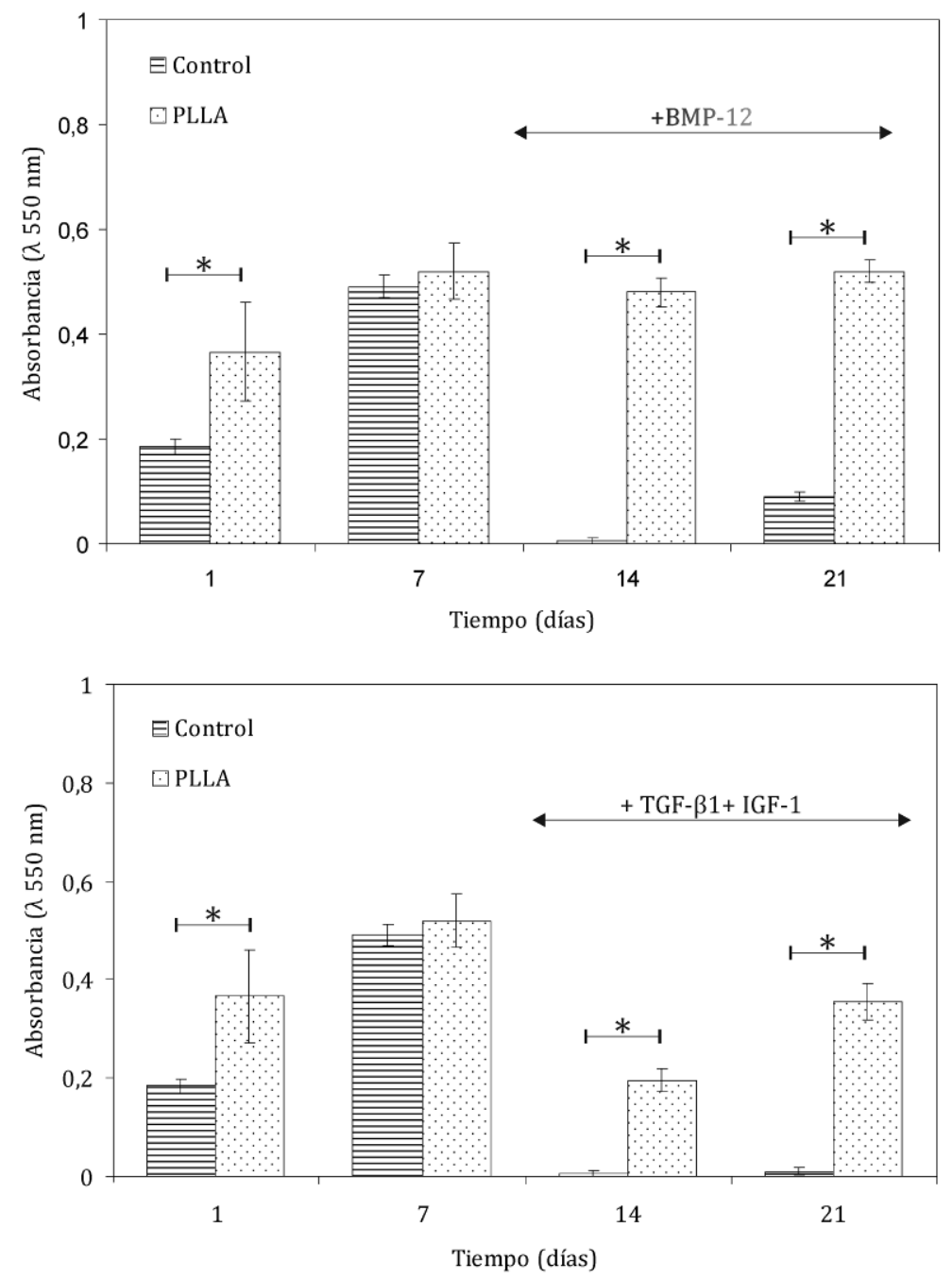

Fig. 3.37 Ensayo de MTS de las hMSCs cultivadas sobre las micropartículas de PLLA utilizando dos medios distintos: medio suplementado con BMP-12 y medio suplementado con TGF- $\beta 1$ y IGF-1 a 1, 7, 14 y 21 días de cultivo. ( $p$ $<0,05$, *significa que hay diferencia significativa entre las diferentes muestras en un mismo tiempo). 
Los resultados de MTS demuestran que el comportamiento de las hMSCs sobre las micropartículas es diferente al obtenido en la trenza de PLA, donde el número de células viables aumentaba en el tiempo en ambos medios. Este comportamiento revela que además de la influencia de los medios diferenciadores sobre las células, el soporte físico al cual se adhieren las células juega un papel fundamental.

La morfología de las hMSCs cultivadas sobre las micropartículas de PLLA a tiempos largos y empleando los distintos medios de diferenciación fue analizada mediante microscopía electrónica. En la Fig. 3.38 se muestran las micrografías a 14 y 21 días. En el medio suplementado con BMP-12 las células se adhieren a la superficie de las micropartículas y exhiben una morfología alargada. En el medio suplementado con TGF- $\beta 1$ y IGF-1 se observan un mayor número de células con una morfología extendida que recubren las micropartículas y forman fuertes uniones entre las micropartículas. 

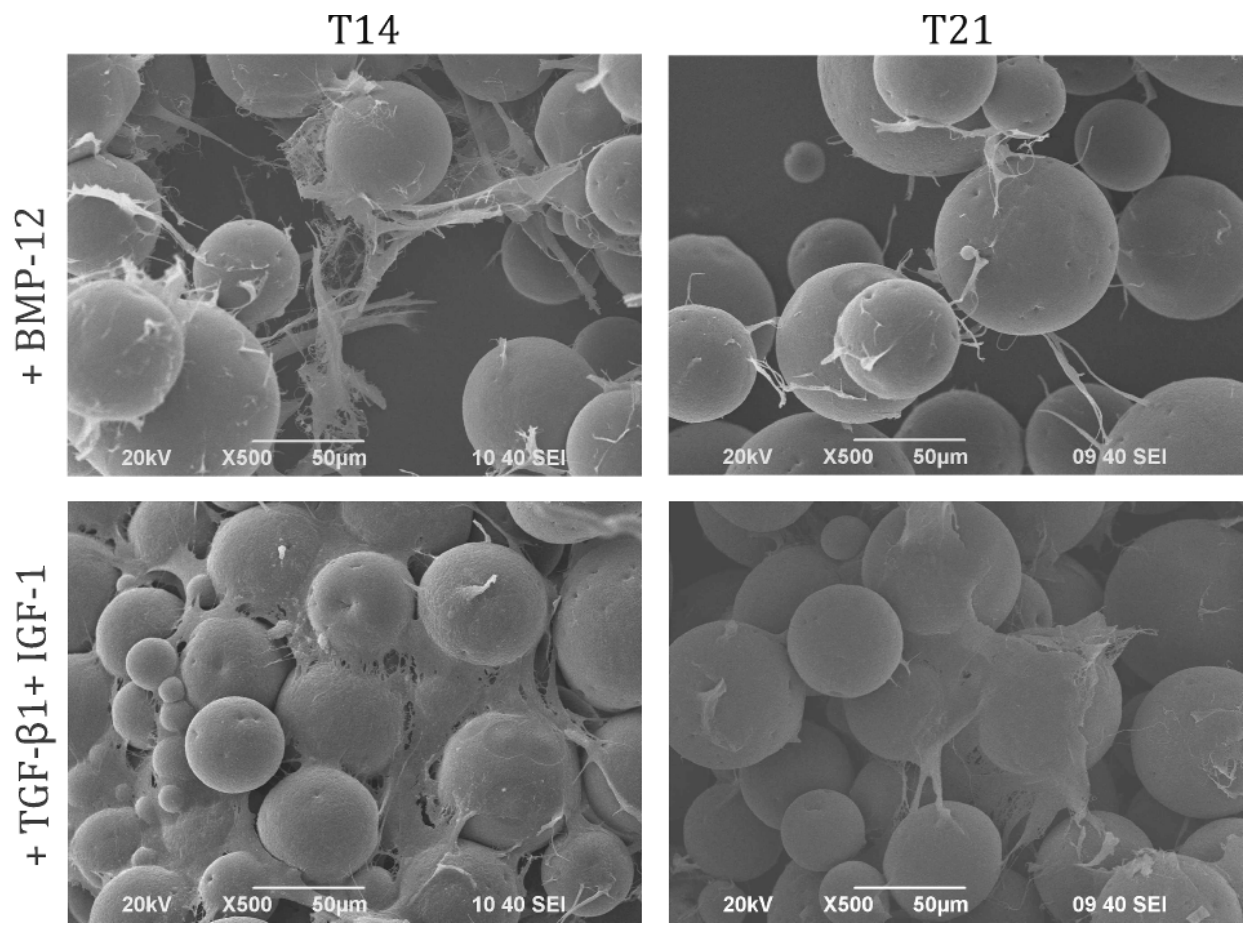

Fig. 3.38 Imágenes de SEM de la morfología de las hMSCs sobre las micropartículas de PLLA utilizando distintos medios de diferenciación: medio suplementado con BMP12, fila superior y medio suplementado con TGF- $\beta 1$ y IGF-1, fila inferior a 14 y 21 días de cultivo.

La morfología de las hMSCs cultivadas en el medio de diferenciación suplementado con TGF- $\beta 1$ y IGF-1 es muy similar a la observada cuando las células se cultivan en un medio no suplementado, sin factores (Fig. 3.38 y 3.31$)$. 
Para evaluar si se ha producido diferenciación celular a tenocitos fueron realizados ensayos de inmunofluorescencia para detectar la expresión de colágeno tipo I y tenomodulina y la tinción del citoesqueleto de actina (Fig. 3.39).

A partir de los 14 días de cultivo, las hMSCs cultivadas con medio suplementado con la BMP-12 comenzaron a expresar matriz colagénica, incrementándose esta expresión a los 21 días de cultivo. La tinción del citoesqueleto de actina revela la presencia de células con una morfología más alongada (Fig. 3.39a y b), lo cual coincide con los resultados observados en las micrografías de SEM (Fig. 3.38). Las células cultivadas en el medio suplementado con la mezcla de factores TGF- $\beta 1$ y IGF-1 expresan en menor medida el colágeno tipo I. La expresión de tenomodulina es positiva en ambos medios diferenciadores aunque resulta más evidente en las células cultivadas con el medio suplementado con la BMP-12 (Fig. 3.39c). 


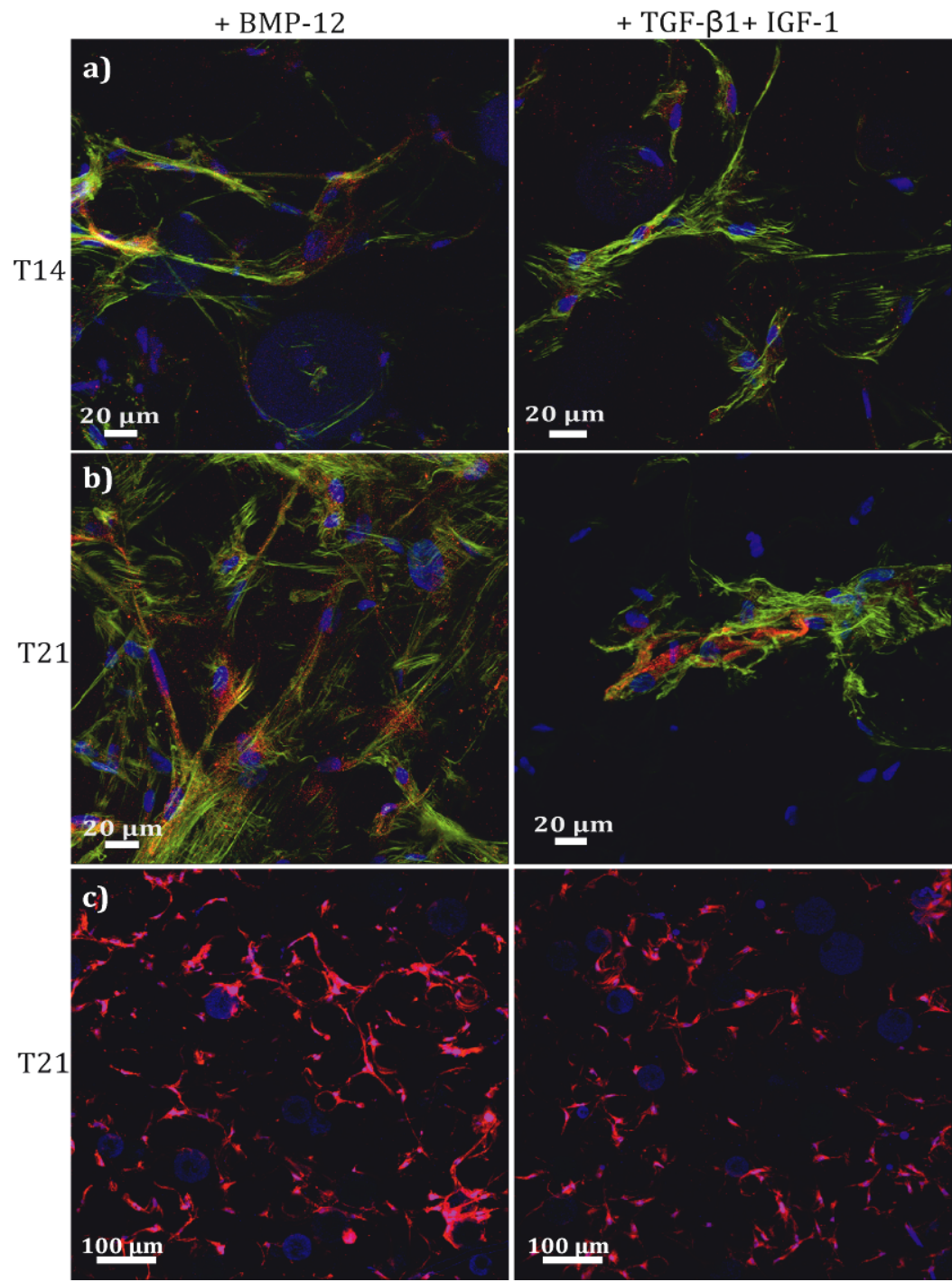

Fig. 3.39 Inmunofluorescencia de proteínas expresadas por las hMSCs cultivadas en las micropartículas de PLLA utilizando los medios diferenciadores. a) y b) expresión de colágeno tipo I (rojo) y tinción del citoesqueleto de actina (verde) a 14 y 21 días, y c) expresión de la tenomodulina (rojo) tras 21 días de. Los núcleos se han marcado con DAPI. 
Las inmunofluorescencias de colágeno tipo I y tenomodulina muestran indicios de que el medio con BMP-12 tiene mayor efecto inductor. Estos resultados coinciden con los obtenidos por Lou et al. [142] donde se demuestra que la BMP-12 mejora la producción de colágeno tipo I y acelera la curación tendinosa.

Para verificar de forma cuantitativa si las células cultivadas sobre las micropartículas de PLLA se han diferenciado a tenocitos se realizó una PCR cuantitativa. Mediante esta técnica se evaluó la expresión y la cuantificación de dos proteínas presentes en los tenocitos: la decorina y la tenomodulina, implicadas en el proceso de maduración de las fibrillas de colágeno.

En la Fig. 3.40 se muestran los resultados de la PCR cuantitativa de las células cultivadas en las micropartículas con los dos medios diferenciadores tras 21 días de cultivo.

Finalmente la cuantificación muestra que el uso de ambos medios promueve la diferenciación tenocítica, siendo el medio suplementado con BMP-12 el que induce una mayor expresión de tenomodulina y decorina. Esta proteína morfogenética ósea ha sido utilizada anteriormente en estudios de diferenciación tenocítica aportando buenos resultados [142, 143]. En esta línea, Violini et al. [91] utilizaron células madre de médula ósea procedente de equino demostrando que la BMP-12 induce a la diferenciación tenocítica. 

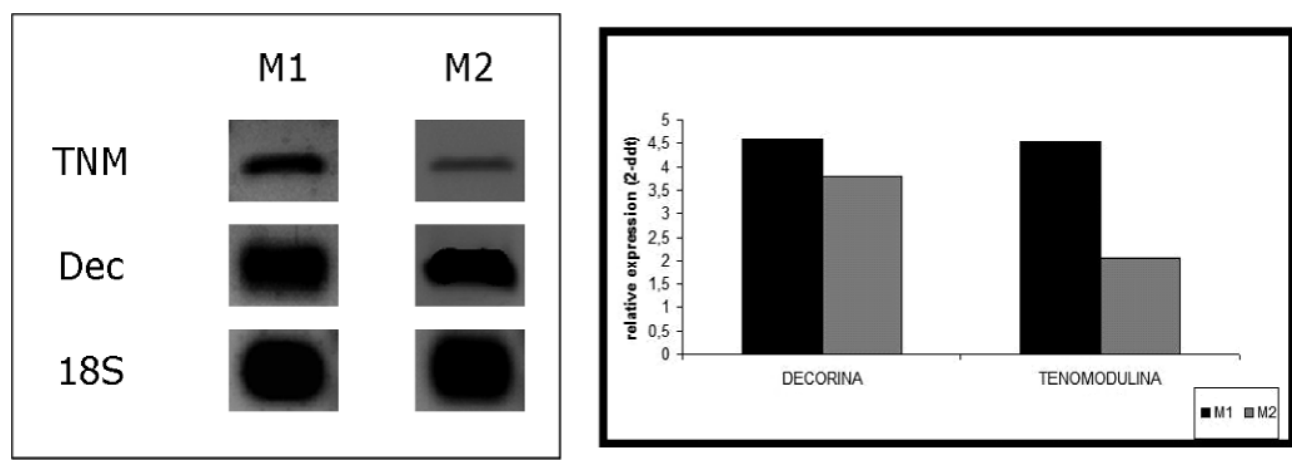

Fig. 3.40 q-PCR en las $h M S C s$ cultivadas sobre las micropartículas de PLLA con los dos medios de cultivo diferenciadores, siendo M1 el medio suplementado con BMP-12, y M2 el suplementado con TGF- $\beta 1$ e IGF-1, tras 21 días de cultivo

Para conocer el efecto de la diferenciación sobre la expresión de los marcadores de superficie expresado por las hMSCs, fueron evaluados los marcadores: CD44, HLA-DR y CD166. En este caso se han comparado las células cultivadas sobre las micropartículas de PLLA en medio de cultivo sin factores a tiempo 14 y las cultivadas con los dos medios de diferenciación a 21 días de cultivo.

En la Fig. 3.41 se observa que las células no expresan el marcador HLA-DR, como se esperaba y sí expresan los dos receptores característicos de las células mesenquimales, el CD166 y el CD44. El porcentaje de expresión del CD166 ha disminuido del $12.5 \%$ a $7.4 \%$ cuando el medio está suplementado con BMP-12 y de un 12.5\% a $10.4 \%$, cuando el medio está suplementado con TGF- $\beta 1$ y IGF-1. Esta 
disminución en el primer caso, puede deberse al cambio morfológico de las células, ya que se observó en las micrografías de SEM y confocal, que las células cultivadas con medio suplementado con BMP-12 adquirían una morfología alargada y estaban en menor contacto con el material pudiendo influir en el descenso de la expresión de este marcador. Otra causa podría ser que las células estén utilizando otra integrina de adhesión. Esta molécula de superficie celular es un mediador de las interacciones célula-célula [144] y la nueva morfología adoptada por las células implica que están en menor contacto entre sí y con la superficie del material. En cambio, la reducción en el porcentaje de la expresión del marcador CD44 sí ha sido significativa. Se observa que en los medios de diferenciación se reduce de un $46 \%$ a un $26 \%$, cuando el medio está suplementado con BMP-12 y de un $46 \%$ a un $18 \%$, cuando el medio está suplementado con TGF- $\beta 1$ y IGF-1. El CD44 también está implicado en la interacción célula-célula y célula-matriz, siendo así responsable de la migración, del crecimiento y de la supervivencia celular [145]. Por ello, el cambio morfológico puede haber afectado estas interacciones provocando un descenso en la expresión del marcador. Por el contrario, en el estudio realizado por Zhu et al.[146] muestra que las MSCs derivadas de médula ósea estimuladas mediante el factor de crecimiento derivado de las plaquetas (PDGF), aumentaba significativamente los niveles del marcador CD44 de la superficie celular. 
No se conoce bien la causa de esta reducción, la bibliografía indica que realmente expresan un porcentaje elevado cuando se le aplica un estímulo mecánico. En el resto de los casos, indican que este marcador se expresa positivamente pero no hacen referencia a porcentajes.
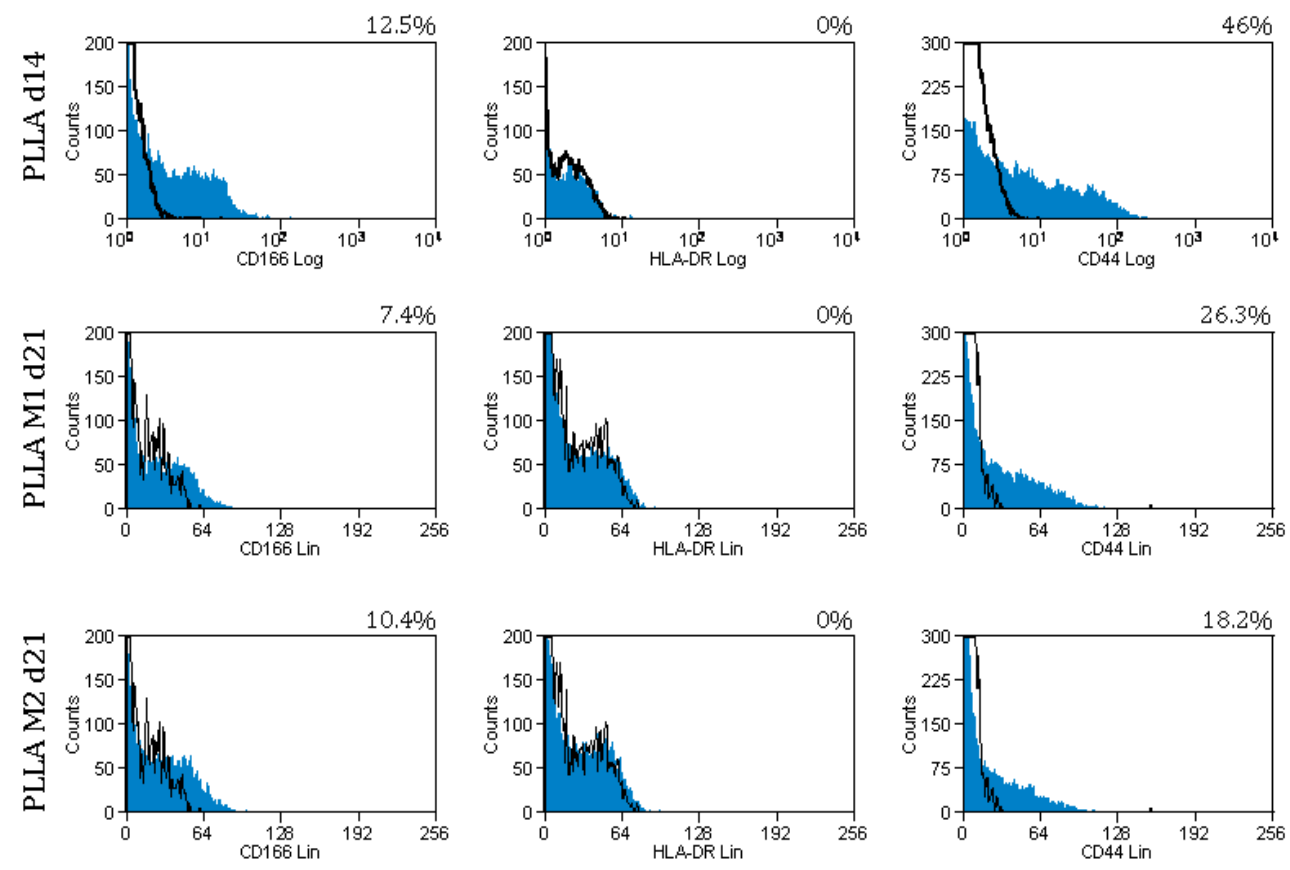

Fig. 3.41 Inmunofenotipo del cultivo de hMSCs sobre las micropartículas de PLLA utilizando los medios de diferenciación, M1, medio suplementado con BMP-12 y M2, medio suplementado con TGF- $\beta 1$ y IGF-1. Representados 5000 eventos. 
Teniendo en cuenta los resultados obtenidos podemos decir que las hMSCs derivadas de médula ósea son una fuente celular apropiada para la regeneración tendinosa. La inyección del relleno (micropartículas y células) en el interior del material trenzado y la estimulación con la proteína BMP-12 podría acelerar y mejorar la regeneración de estos tejidos. 


\subsection{COMPORTAMIENTO BIOLÓGICO DEL PROTOTIPO DE PRÓTESIS EN RÉGIMEN ESTÁTICO Y DINÁMICO}

En el apartado anterior se evaluó el comportamiento celular sobre los distintos componentes que forman el prototipo de prótesis (trenza de PLA y micropartículas de HA y PLLA) utilizando dos fuentes celulares diferentes, la línea fibroblástica L929 y las hMSCs, confirmándose en ambos casos una buena adhesión y proliferación celular sobre los diferentes soportes y revelando signos de diferenciación tenocítica cuando se empleó las células mesenquimales. En este apartado se presenta el estudio biológico realizado con los fibroblastos de línea celular L929 y células mesenquimales derivadas de tejido adiposo de oveja en el prototipo de prótesis final (Fig. 3.42).

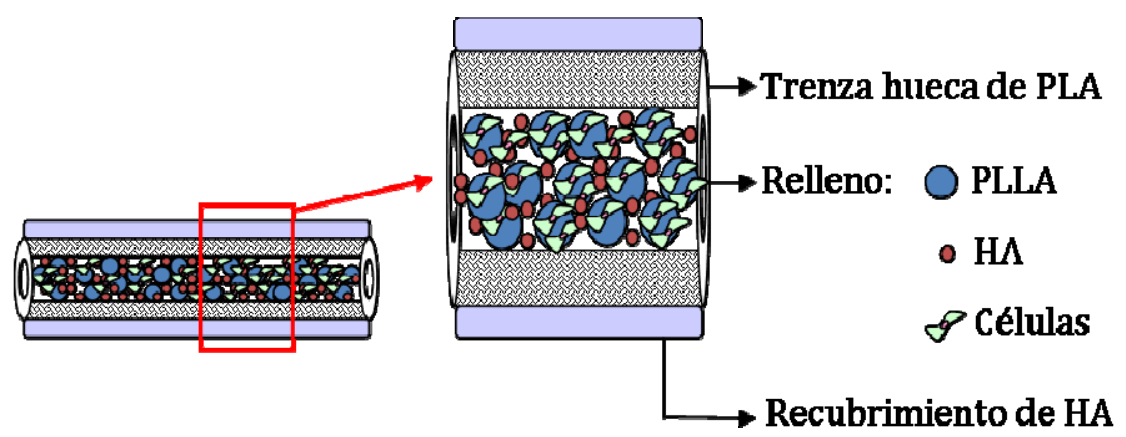

Fig. 3.42 Esquema del prototipo de prótesis 
Los ensayos biológicos fueron realizados en estático y en un biorreactor con la finalidad de reproducir en cierto modo las condiciones fisiológicas a la que está sometido el tejido tendinoso in vivo. Resulta válido señalar que aunque las células mesenquimales utilizadas son de origen animal, este modelo in vitro debería ser trasladable a un modelo in vivo en estudios futuros, donde se pueda utilizar células autólogas.

\subsubsection{Verificación de la funcionalidad del biorreactor}

Antes de empezar los ensayos biológicos tanto en estático como en dinámico del prototipo de prótesis final, se realizó un ensayo previo en régimen dinámico utilizando sólo el material trenzado para poner a punto el biorreactor diseñado en el CBIT. El cultivo se realizó durante 7 y 14 días como se ha descrito anteriormente en el apartado 2.3.4.1 de materiales y métodos.

Una vez esterilizado el biorreactor y las trenzas de PLA, se procedió a la siembra de las mismas y a su colocación en el biorreactor. Transcurrido el tiempo de cultivo (7 y 14 días), las muestras fueron fijadas y se analizó la morfología de los fibroblastos (línea celular L929) sembrados en la superficie de la trenza y en el interior de la misma mediante microscopía electrónica de barrido.

En la Fig. 3.43 se muestran las micrografías obtenidas de la superficie de la trenza a 7 y 14 días de cultivo en régimen dinámico. 
Como se puede observar las células se adhieren y se distribuyen por toda la superficie de la trenza. A los 14 días de cultivo se observa un incremento de la densidad celular, las células se orientan en la dirección de las fibras mostrando una morfología alongada y fusiforme.

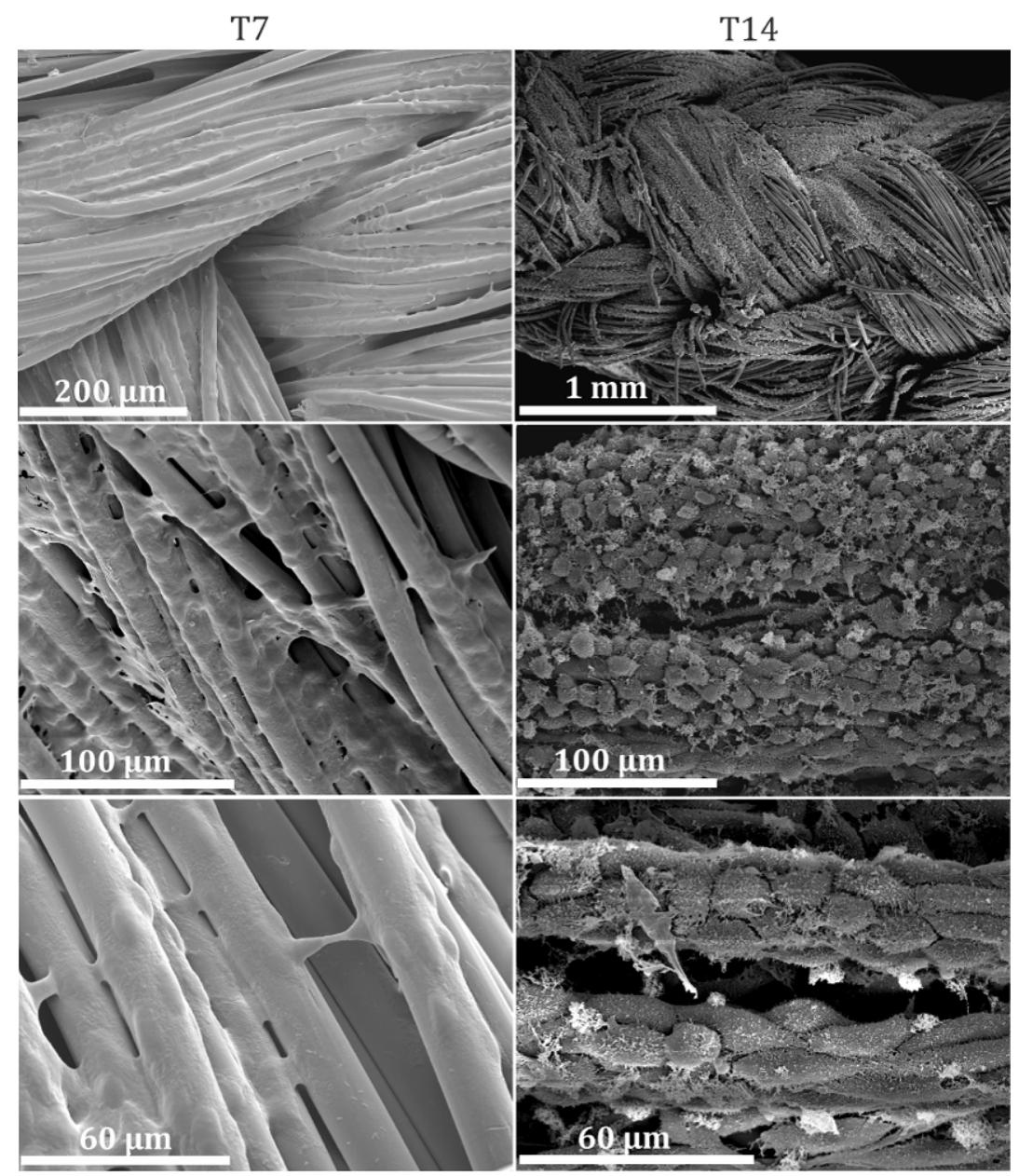

Fig. 3.43 Imágenes de SEM de la morfología de las L929 sobre la superficie de la trenza de PLA a 7 y 14 días de cultivo en régimen dinámico. 
Las imágenes de SEM tomadas en el interior de la trenza (Fig. 3.44) revelan la presencia de células en el interior de la misma lo cual es indicativo, de que las células han migrado desde la superficie hacia las fibras más internas. De manera similar a como ocurre en la superficie del material trenzado las células exhiben una morfología extendida y adaptada a la microfibra.
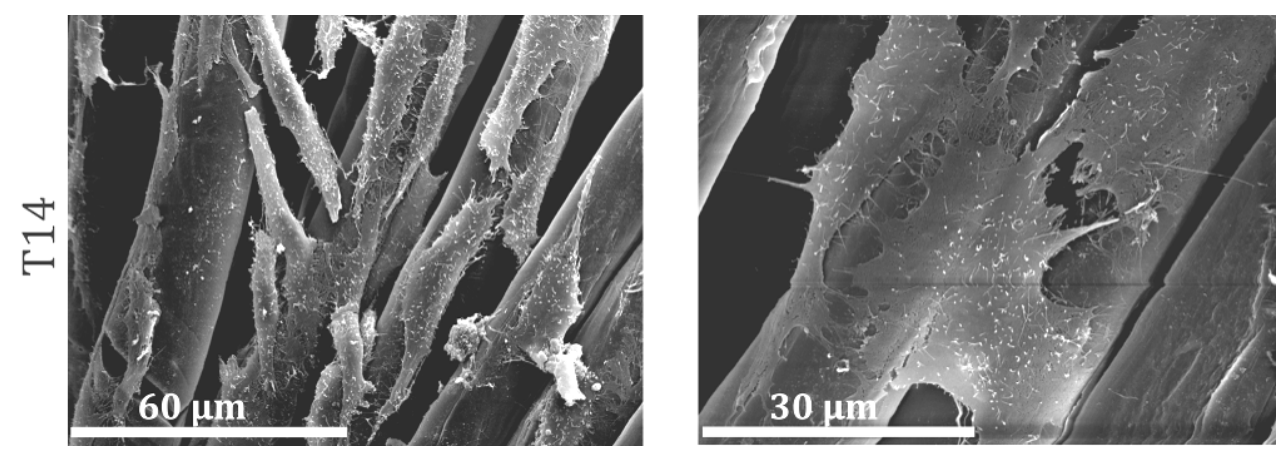

Fig. 3.44 Imágenes de SEM de la morfología de las L929 en el interior del material trenzado de PLA tras el cultivo in vitro en régimen dinámico después de 14 días de cultivo.

Para evaluar si se ha producido una respuesta celular al estímulo mecánico aplicado en el biorreactor, se analizó la expresión de colágeno tipo I mediante ensayos de inmunofluorescencia y la tinción del citoesqueleto de actina. En este caso, también se ha analizado a modo de comparación una muestra cultivada bajo las mismas condiciones pero en régimen estático (Fig. 3.45). 
Como se observa en la Fig. 3.45 las células parecen expresar más colágeno tipo I cuando están sometidas a un estímulo mecánico, en el biorreactor, que cuando se cultivan en régimen estático. El colágeno tipo I es la proteína predominante del tejido tendinoso y su expresión y secreción son determinantes en el proceso de formación de este tejido. En ambos casos, se observa un citoesqueleto de actina bien desarrollado. 


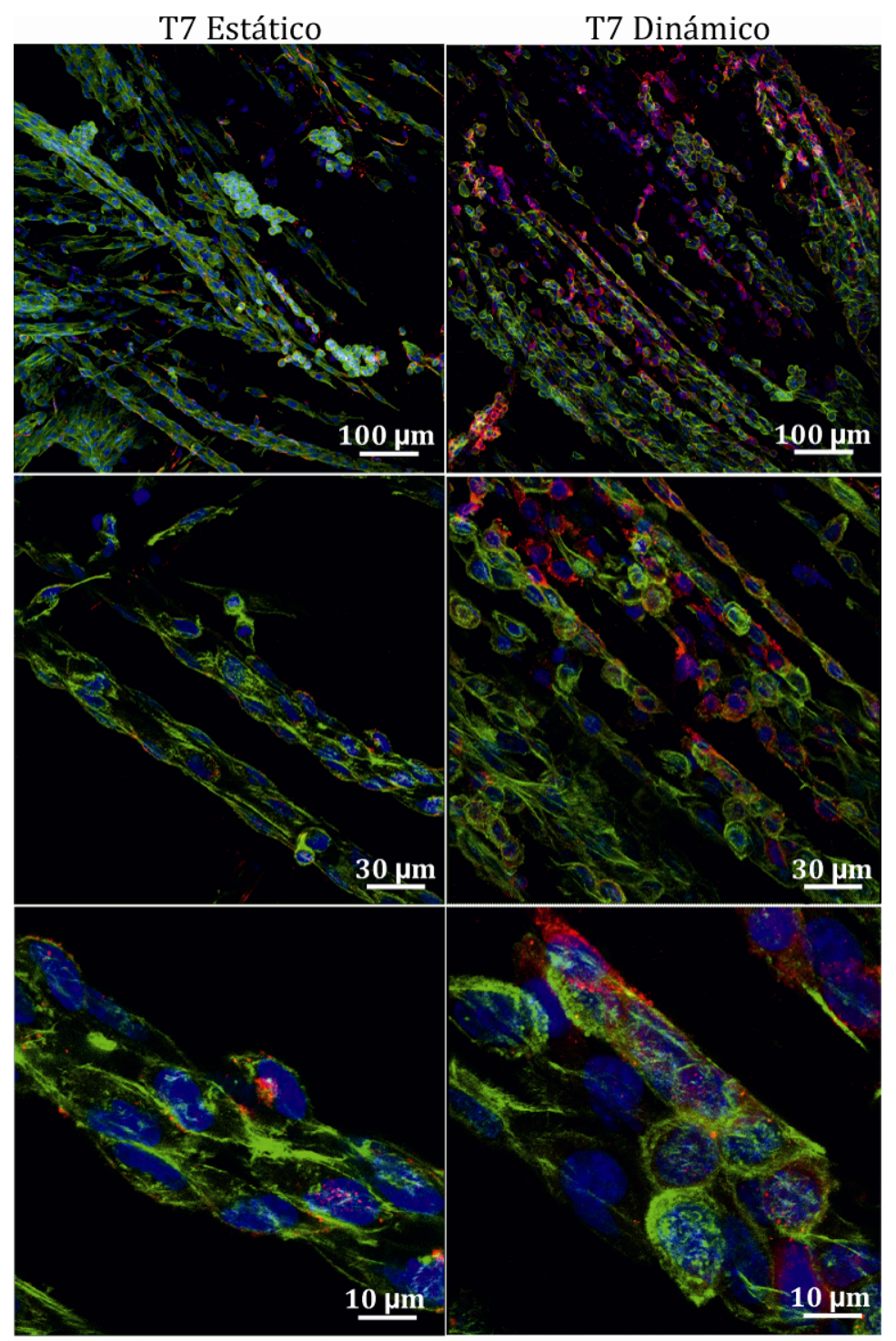

Fig. 3.45 Imágenes de inmunofluorescencia del colágeno tipo I (rojo) y tinción del citoesqueleto de actina (verde), de fibroblastos sembrados sobre la trenza de PLA en régimen estático y dinámico después de 7 días de cultivo. Los núcleos se han teñido con DAPI (azul). 
Con la realización de estos ensayos previos hemos podido poner a punto el protocolo de siembra y el anclaje del material trenzado en el biorreactor.

\subsubsection{Estudio del comportamiento in vitro de las L929 en el prototipo de prótesis final}

\subsubsection{Ensayo de viabilidad y análisis morfológico del prototipo.}

Antes de realizar los ensayos biológicos con el prototipo de prótesis en régimen estático y en el biorreactor se comprobó la viabilidad celular mediante un ensayo de MTS a 1, 7 y 14 días y se analizó la morfología de las células mediante SEM.

En la Fig. 3.46 se muestran los resultados del ensayo de MTS obtenido en el prototipo de prótesis. El número de células viables aumenta hasta el día 7 de cultivo y luego se mantiene constante hasta el final del experimento. La muestra control (pocillo) presenta un comportamiento similar. 


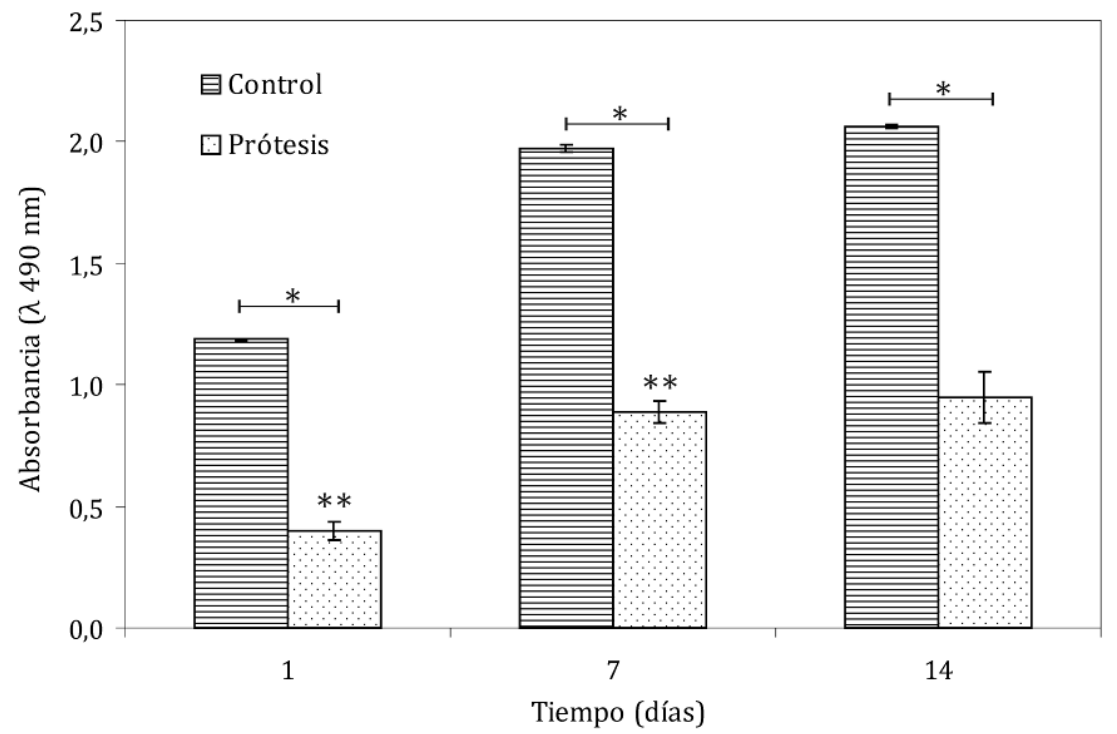

Fig. 3.46 Ensayo de MTS de las L929 cultivadas en la prótesis a 1, 7 y 14 días de cultivo. $(p<0,05, *$ significa que hay diferencia significativa entre las diferentes muestras en un mismo tiempo de cultivo $\mathrm{y}^{* *}$ entre la misma muestra a distintos tiempos de cultivo).

La morfología de las células en el interior de la prótesis examinada por SEM revela que las células se adhieren muy bien, tanto a las fibras como a las micropartículas (Fig. 3.47). 


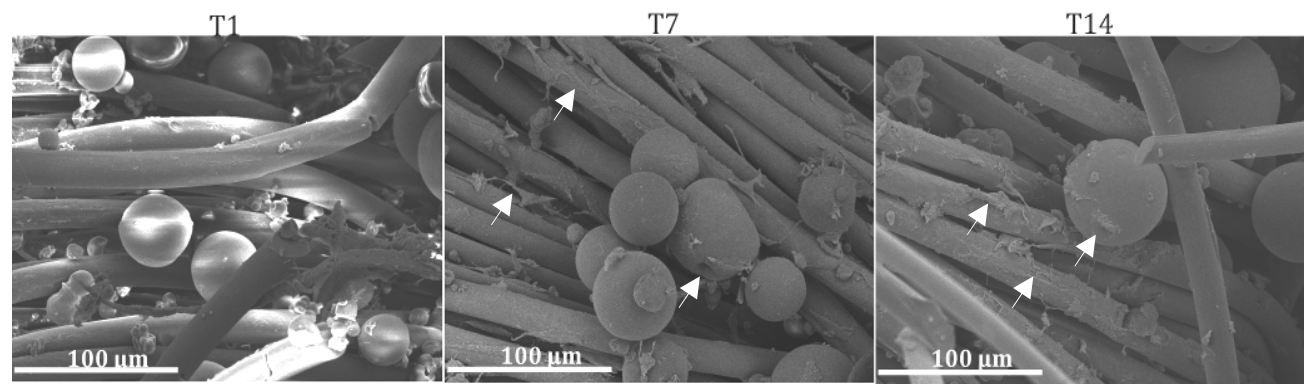

Fig. 3.47 Imágenes de SEM de la morfología de las L929 en el interior del prototipo a 1, 7 y 14 días de cultivo. Las flechas blancas indican la presencia de células adheridas a las micropartículas y a las fibras.

Los resultados obtenidos en este ensayo demuestran que los fibroblastos presentan una buena adhesión al soporte y se mantienen viables durante los 14 días de cultivo.

\subsubsection{Cultivo de fibroblastos en el prototipo de prótesis en régimen estático y dinámico}

Después de comprobar que el cultivo en el prototipo de prótesis era viable, se realizó un ensayo preliminar $(\mathrm{n}=1)$ en régimen estático y en el biorreactor durante 14 días. En este caso se analizó la morfología de los fibroblastos mediante SEM y la distribución de células mediante ensayos de tinción de núcleos celulares y citoesqueleto de actina. También fueron realizados ensayos de cuantificación de DNA, GAGs y colágeno tipo I. Como muestra control se utilizó el material trenzado recubierto de HA. 
Una vez esterilizado el biorreactor y las trenzas de PLA recubiertas previamente con HA, se procedió a la inyección del relleno (células y micropartículas) en el caso del prototipo de prótesis y de la suspensión celular en la muestra control siguiendo el protocolo de siembra descrito anteriormente en el apartado 2.3.4.2 de materiales y métodos.

En la Fig. 3.48 se muestra una imagen panorámica correspondiente a la sección transversal del prototipo de prótesis final. En la imagen se puede apreciar cada uno de los componentes que conforman la prótesis: (i) el recubrimiento de HA, (ii) el material trenzado de PLA y (iii) el relleno (células +micropartículas de PLLA y HA). La micrografía tomada a mayor aumento correspondiente al recubrimiento de HA nos confirma que se mantiene estable durante los 14 días del ensayo y no presenta células adheridas a su superficie, lo cual concuerda con los resultados esperados. La imagen que corresponde al relleno revela que las células están bien distribuidas en el interior del material trenzado. 


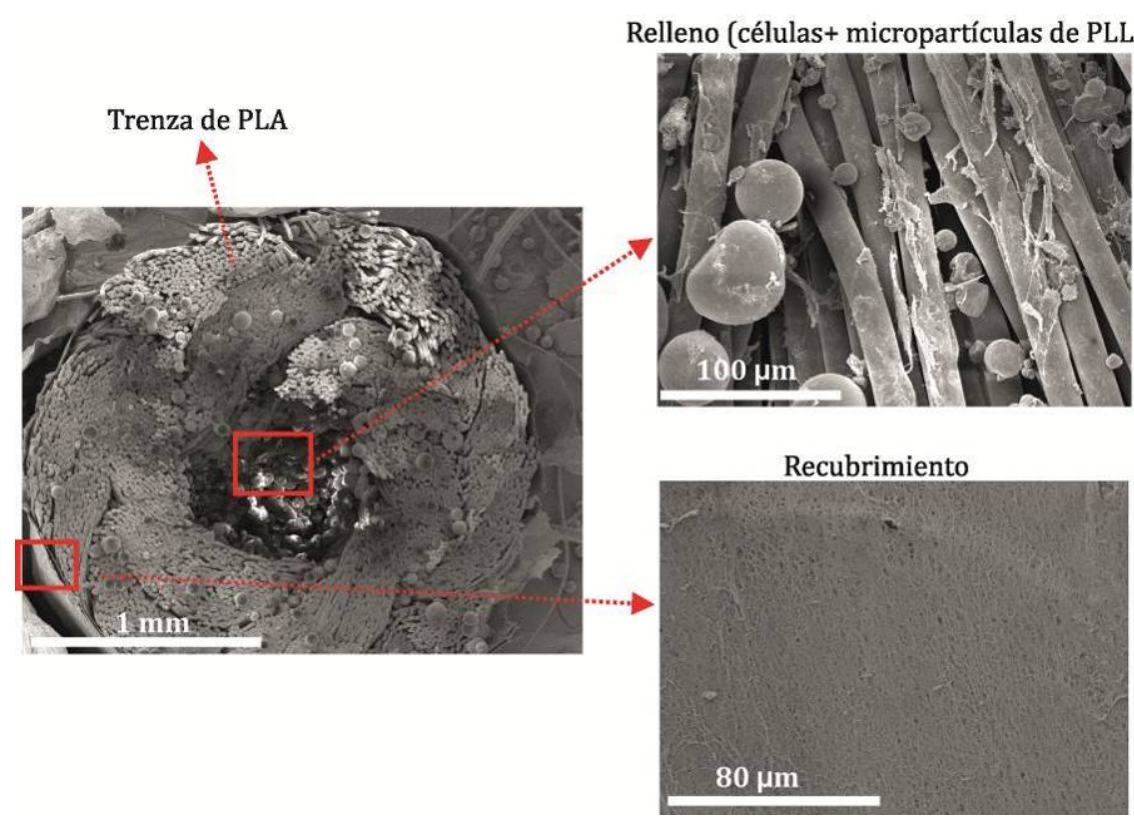

Fig. 3.48 Sección transversal del prototipo de prótesis.

En la Fig. 3.49 se muestran las micrografías de SEM correspondientes al interior de la prótesis de las muestras cultivadas durante 14 días en régimen estático y dinámico. Como se puede apreciar las células cultivadas en el prototipo de prótesis se adhieren tanto a las micropartículas como a las fibras del material trenzado mostrando una morfología más alargada, cuando son estimuladas mecánicamente en el biorreactor (Fig. 3.49b) que las cultivadas en régimen estático donde las células exhiben una morfología más extendida (Fig. 3.49a). En ambos casos se aprecia la formación de matriz extracelular. Las células cultivadas en la muestra control bajo las mismas condiciones presentan un comportamiento similar al observado en el prototipo (Fig. 3.49c y d). 
Al comparar la muestra control con el prototipo de prótesis en régimen estático y/o en el biorreactor no se aprecia un cambio notable en la morfología de las células.

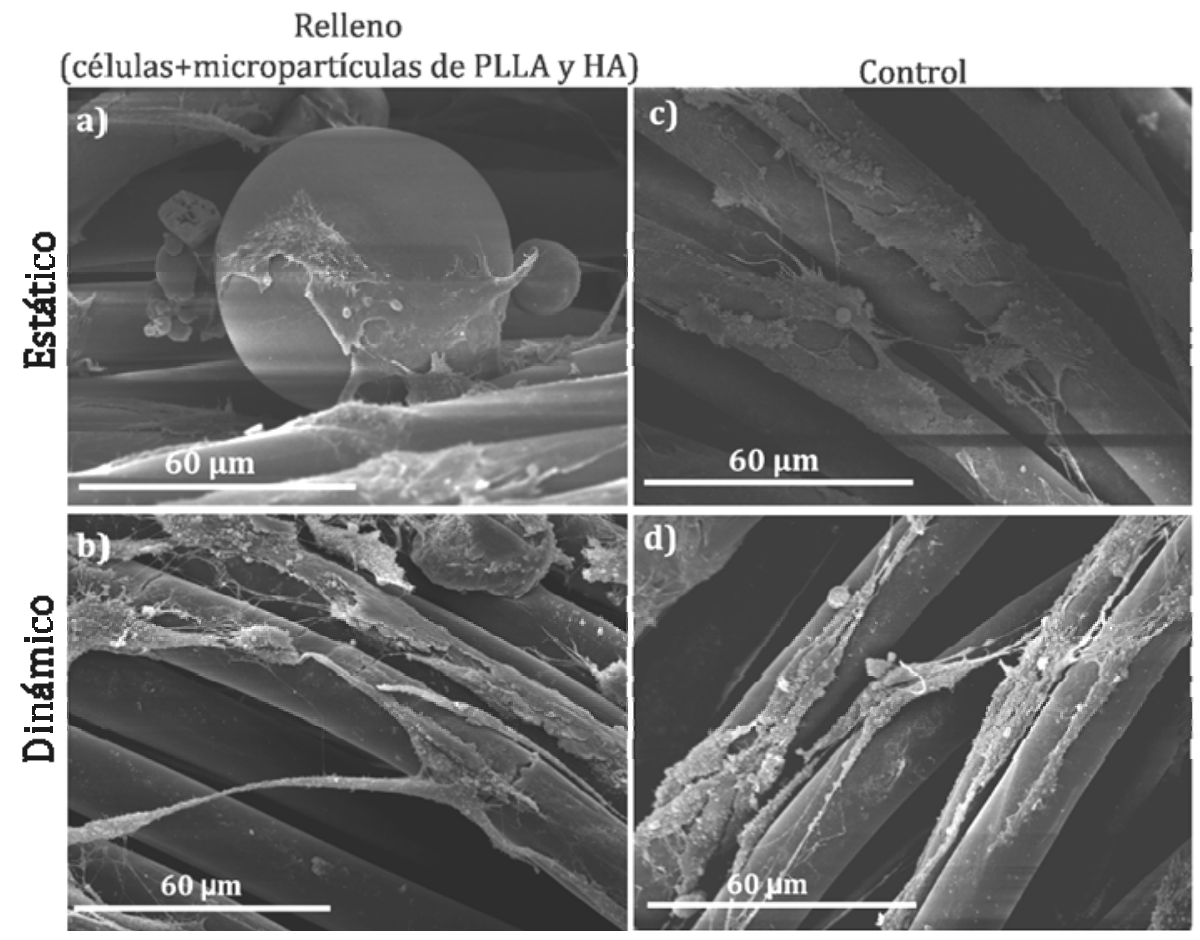

Fig. 3.49 Imágenes de SEM de la morfología de las L929 cultivadas en la prótesis mediante la combinación de micropartículas PLLA y HA (a y b) o en la muestra control como una suspensión celular (c y d) a 14 días de cultivo.

Para analizar la distribución de las células inyectadas en el prototipo en régimen estático y en el biorreactor fueron realizados ensayos de tinción del citoesqueleto de actina y DAPI. En la Fig. 3.50 se observa que 
las células pre-sembradas en las micropartículas están bien distribuidas en el interior del material trenzado. El soporte (micropartículas) en la etapa inicial de adhesión hace posible que haya una mejor eficiencia en la siembra, contrario a lo que sucede en la muestra control, que utiliza como relleno la suspensión celular, en donde se observan menos cantidad de células adheridas en el material trenzado y una distribución celular menos uniforme. Los ensayos en régimen dinámico inducen una alineación de las células, mientras que en régimen estático no se observan variaciones aparentes. La tinción del citoesqueleto de actina no ha sido muy efectiva, probablemente debido a problemas de difusión del marcador hacia el interior del material. 


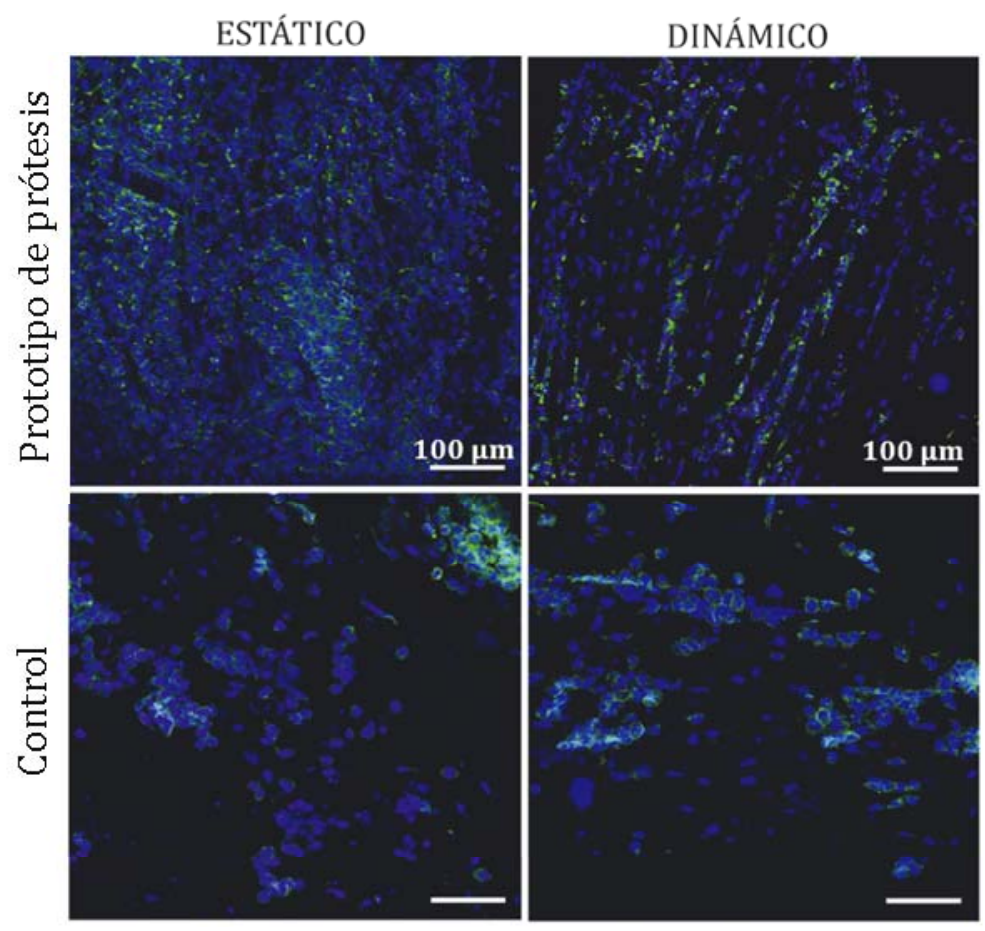

Fig. 3.50 Imágenes de la tinción del citoesqueleto de actina (verde), tanto en régimen estático como dinámico en el interior de la prótesis cultivada con L929 durante 14 días utilizando: una combinación de micropartículas PLLA:HA pre-sembradas previamente y una suspensión celular. Los núcleos fueron teñidos con DAPI.

Otros de los estudios realizados fue la cuantificación de DNA, GAGs, y colágeno tipo I (Fig. 3.51). La Fig. 3.51a muestra que el contenido de DNA es muy similar tanto en régimen estático como en el biorreactor tanto en el prototipo de prótesis como en la muestra control. 
La producción de colágeno tipo I normalizado (Col I/DNA) en el prototipo de prótesis es mayor en condiciones dinámicas con respecto al cultivo en estático (Fig. 3.51b). La muestra control cultivada en régimen estático no presenta diferencias en comparación con el biorreactor. Tanto en régimen estático como en el biorreactor, la producción de colágeno tipo I es aparentemente mayor en la muestra control que en el prototipo de prótesis.

La Fig. 3.51c muestra que la producción de GAGs normalizada (GAGs/DNA) en el prototipo de prótesis tanto en condiciones estáticas como en dinámicas es similar, mientras que en la muestra control el contenido de GAGs es superior en régimen estático que en dinámico. La producción de GAGs en el prototipo de prótesis, tanto en régimen estático como en el biorreactor, es mayor que en la muestra control. 


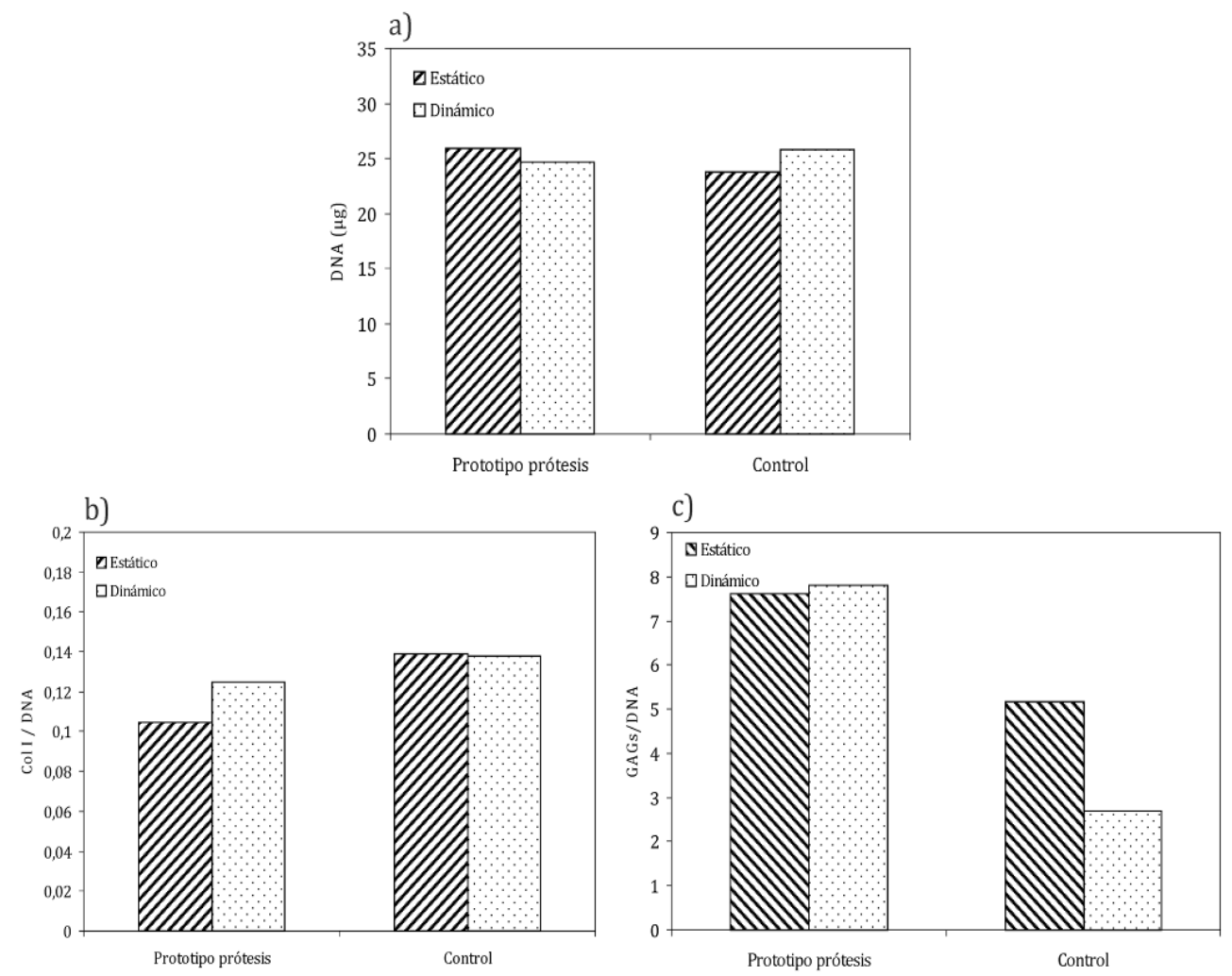

Fig. 3.51 Cuantificación de la producción de componentes de la matriz extracelular. a) DNA, b) Colágeno tipo I normalizado con el contenido de DNA c) GAGs normalizado con el contenido de DNA, y a 14 días de cultivo en estático y con el biorreactor en el prototipo de prótesis.

Los resultados obtenidos indican que el cultivo en el prototipo de prótesis donde se utiliza como relleno (células + micropartículas de PLLA y HA) aportan mejores resultados frente a la muestra control donde las células se inyectan directamente. 
Las imágenes de SEM y la tinción del citoesqueleto de actina y de los núcleos celulares en régimen dinámico en el prototipo de prótesis mostraron una distribución celular mimética a la que ocurre en el estado natural del tendón. La cuantificación de los componentes de la matriz extracelular (colágeno tipo I y GAGs) mostró un alto contenido de GAGs. Este alto contenido de GAGs puede desempeñar un papel esencial en el establecimiento, mantenimiento y remodelación de la arquitectura tisular en la fase temprana de la curación tendinosa. La producción de colágeno tipo I fue mayor en el prototipo de prótesis estimulado mecánicamente. Resultados similares han sido reportados por Yang et al.[94] y Surrao et al.[97] donde se confirma que las células responden a un estímulo mecánico produciendo más cantidad de GAGs y colágeno tipo I. No obstante, estos resultados realizados sobre una muestra no deben tomarse como concluyentes, deben ser considerados como resultados orientativos. Como los estudios con el biorreactor indican una respuesta celular al estímulo mecánico, se procedió a la realización de un ensayo con células de $A D S C$ de oveja.

\subsubsection{Estudio del comportamiento in vitro de $A D S C$ de oveja en el prototipo de prótesis}

Después de realizar el ensayo preliminar en el prototipo de prótesis con la línea celular L929, se realizó un ensayo $(\mathrm{n}=2)$ del prototipo de prótesis cultivado con células $A D S C$ de oveja. El ensayo se realizó en 
régimen estático y en el biorreactor durante 14 días. En este caso se analizó la morfología de las $A D S C$ mediante SEM y la distribución de células mediante ensayos de tinción del citoesqueleto de actina. También se realizó un ensayo de cuantificación de GAGs.

En la Fig. 3.52 se muestran las micrografías de SEM correspondientes al interior de la prótesis de las muestras cultivadas durante 14 días en régimen estático y dinámico. Como se puede apreciar las células cultivadas en el prototipo de prótesis adoptan una morfología extendida sobre toda la superficie de la microfibra tanto en condiciones dinámicas como estáticas. En régimen dinámico se observa la formación de matriz extracelular.

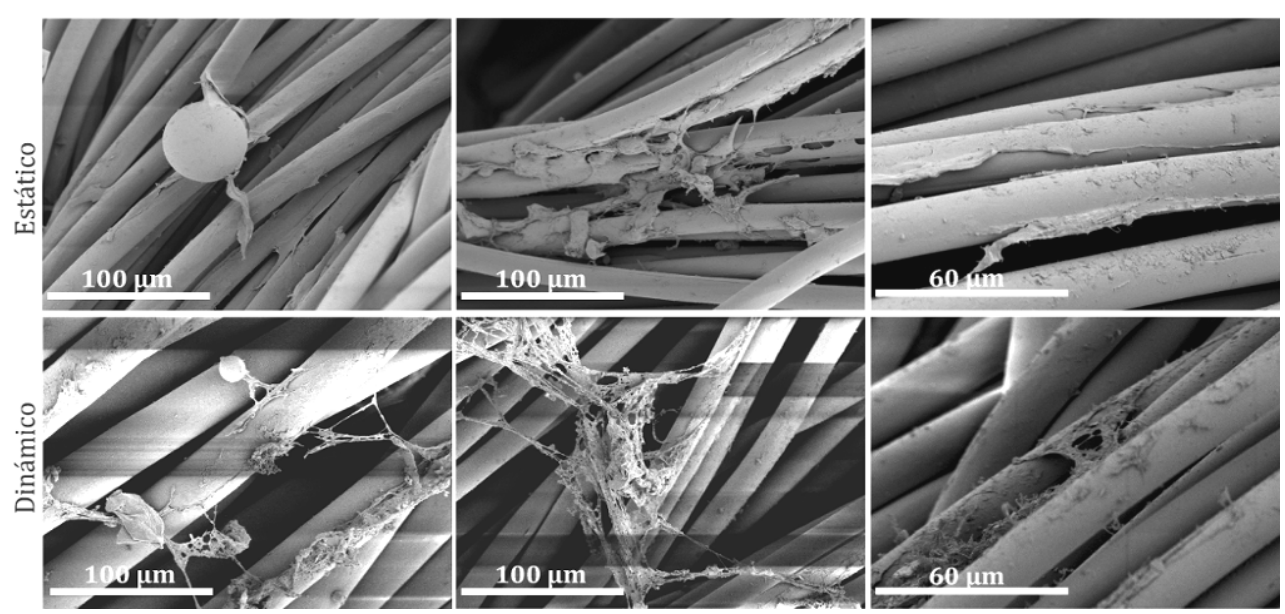

Fig. 3.52 Imágenes de SEM del interior del prototipo cultivado con un relleno de micropartículas pre-sembradas con $A D S C$ de oveja a 14 días de cultivo en régimen estático y dinámico a 14 días de cultivo in vitro. 
Para analizar la distribución de las células inyectadas en el prototipo en régimen estático y en el biorreactor fueron realizados ensayos de tinción del citoesqueleto de actina y DAPI. En la Fig. 3.53, se observa el interior de la prótesis cultivada a 14 días con las células $A D S C$ de oveja mostrando células bien adheridas en la superficie de la microfibra con un citoesqueleto de actina bien desarrollado. La prótesis estimulada mecánicamente muestra una mejor alineación celular en las fibras.
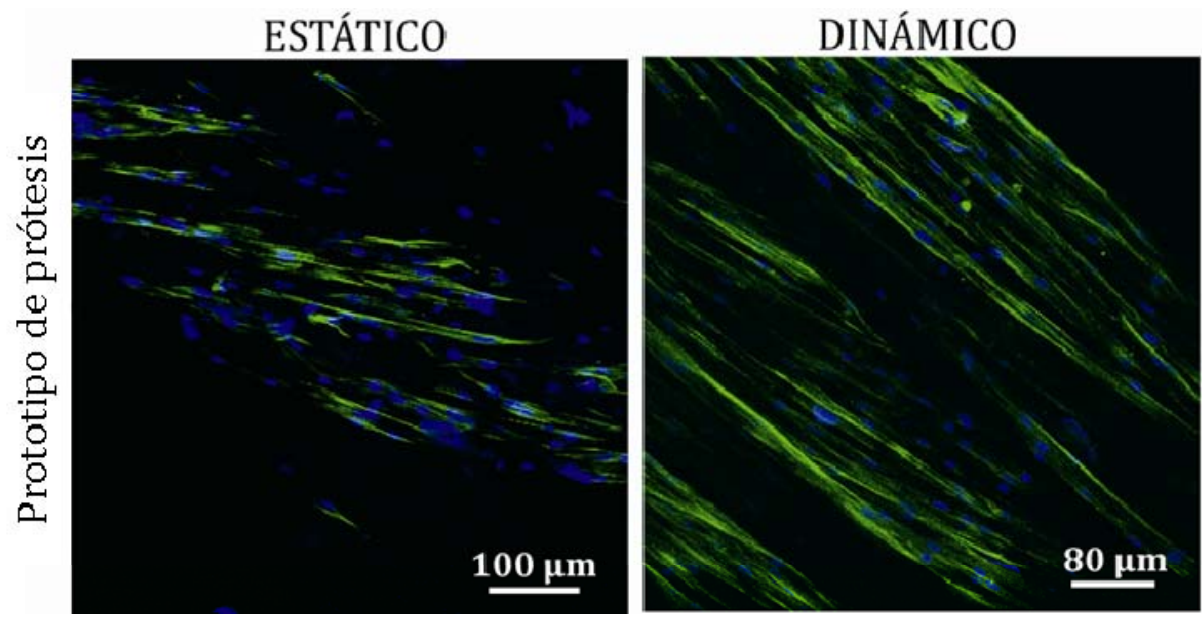

Fig. 3.53 Imágenes de la tinción del citoesqueleto de actina (verde), tanto en régimen estático como dinámico en el interior de la prótesis cultivada con ADSC de oveja durante 14 días utilizando como relleno una combinación de micropartículas PLLA:HA pre-sembradas. Los núcleos fueron teñidos con DAPI

Otro de los estudios realizados fue la cuantificación de GAGs. La Fig. 3.54 muestra que el contenido de GAGs en el prototipo sometido a un 
estímulo mecánico parece presentar una mayor producción de GAGs frente al régimen estático.

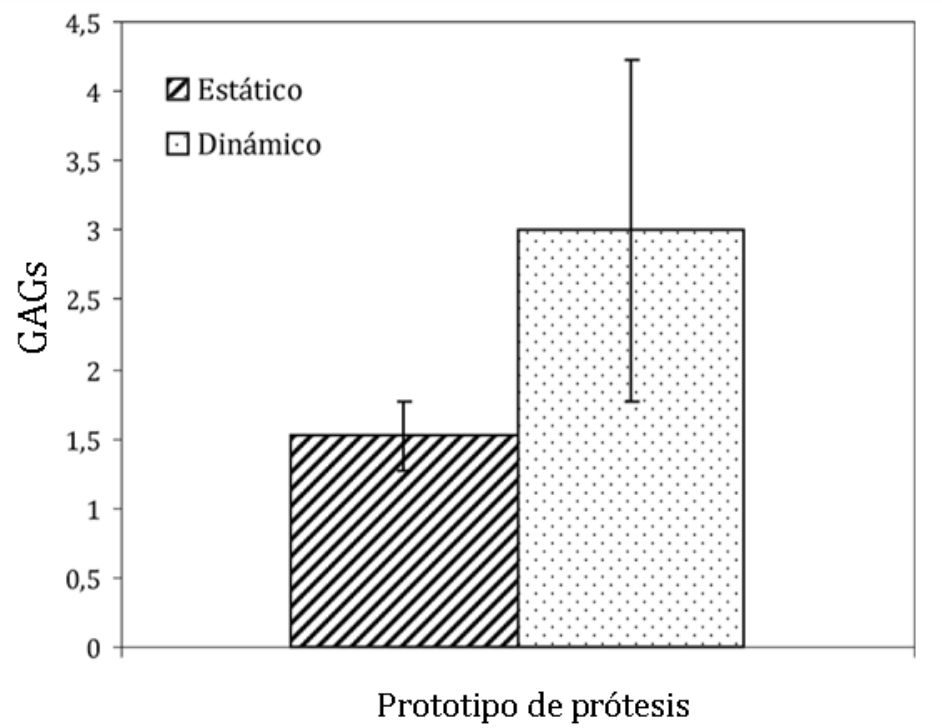

Fig. 3.54 Cuantificación del contenido de GAGs durante 14 días de cultivo de las $A D S C$ de oveja en régimen estático y dinámico, en el prototipo de prótesis. 
Los resultados obtenidos tras el cultivo de $A D S C$ de oveja mostraron un buen comportamiento en el interior del prototipo de la prótesis. Se observó una distribución uniforme de las células en el interior del prototipo y las células parecían mostrar buena adhesión a las fibras. Se observó que cuando se aplica un estímulo mecánico, las células responden adoptando una morfología más extendida y alineada en la dirección de la fibra, además de que parece aumentar la producción de GAGs. 


\section{Discusión final}

Debido a las limitaciones encontradas en las prótesis actuales, la ingeniería tisular ha abierto nuevas posibilidades en la reconstrucción de las roturas tendinosas. En la presente tesis doctoral se ha diseñado y fabricado un nuevo prototipo de prótesis tendinosa biodegradable, la cual se espera que sea totalmente reabsorbida por el organismo sin provocar ningún efecto negativo permaneciendo el nuevo tejido formado. Esto no sucede cuando se implanta una prótesis permanente, ya que no tienen la capacidad de regenerarse y con el tiempo sufren de alguna manera, un fallo mecánico que da lugar a una segunda cirugía [29].

La nueva prótesis diseñada está compuesta por tres componentes fundamentales: (i) el material trenzado de PLA, (ii) el relleno (células + micropartículas de PLLA y HA), y (iii) el recubrimiento de HA. Para validar el prototipo de prótesis, en primer lugar se analizó el comportamiento biológico de cada uno de sus componentes con dos líneas celulares diferentes (fibroblastos L929, hMSCS) y a continuación se analizó el comportamiento biológico del prototipo de prótesis final usando fibroblastos L929 y ADSC.

Uno de los componentes más importantes y novedosos que forman el prototipo de prótesis tendinosa diseñada en este trabajo es la trenza 
hueca de PLA. El original diseño que presenta el soporte trenzado reveló que sus propiedades mecánicas se correspondían con las propiedades biomecánicas que presenta el tendón natural, mostrando una deformación en la zona toe entre un 2-4\% de su longitud y un módulo de Young en la zona lineal entre 1-2GPa[116]. Estos ensayos demostraron que las propiedades mecánicas de la trenza hueca de PLA no diferían de las propiedades mecánicas de los trenzados convencionales demostrando que el material trenzado de PLA es idóneo para este tipo de reconstrucciones, tal y como se encuentra reportado en la literatura $[57,147,148]$

En estudios previos se han realizado cultivos in vitro sobre la superficie de materiales trenzados para la regeneración de tendón [80, 81], uno de los inconvenientes de esta estrategia es que las células quedan desprotegidas frente a cualquier estímulo externo. La ventaja adicional que aporta el uso del trenzado hueco frente al trenzado convencional, radica principalmente en que las células cultivadas en el interior de la trenza hueca de PLA quedan totalmente protegidas por el mismo soporte favoreciendo la regeneración y diferenciación celular de una manera localizada. Esta propiedad de mantener las células en la zona lesionada también es más efectiva frente a la terapia celular, en la cual la fuente celular se inyecta directamente en la lesión y por lo tanto es muy probable que las células se dispersen a zonas no deseadas trayendo como consecuencia una limitada regeneración del tejido. 
En cuanto al relleno utilizado dentro de la trenza de PLA (células más micropartículas) lo más destacable y novedoso es el efecto potenciador del crecimiento celular revelado en la mezcla de micropartículas PLLA y HA. Se comprobó que este relleno frente a una suspensión celular, provoca una mejora en la distribución, en la proliferación y en la diferenciación celular en el caso de utilizar factores estimulantes, como la BMP-12 en este caso. Sin lugar a duda, todo parece indicar que un soporte físico es de vital importancia para un buen comportamiento y supervivencia celular.

El recubrimiento de HA sobre la trenza hueca de PLA es totalmente necesario para evitar cualquier adhesión del prototipo de prótesis con los tejidos adyacentes una vez sea implantada. Este recubrimiento posee unas excelentes propiedades antiadherentes, tal y como se ha reportado en diversos estudios $[133,134]$. Con respecto al recubrimiento de HA realizado en este trabajo se ha comprobado que es estable y no hay adherencia celular durante 14 días de cultivo. Los resultados de viabilidad revelan una perfecta difusión de nutrientes y una adecuada eliminación de los desechos celulares.

El prototipo de prótesis diseñado ha sido validado con células mesenquimales, $A D S C$, en régimen dinámico utilizando un biorreactor diseñado en el CBIT que simula el comportamiento mecánico que se produce en estos tejidos in vivo. La movilización temprana en estos tejidos después de una lesión es muy importante para que no se 
produzcan adherencias y haya una buena funcionalidad del tejido. En nuestro caso los resultados obtenidos al estimular el prototipo de prótesis a tiempos cortos se observa una mayor alineación celular con respecto al contorno de las fibras de PLA y mayor producción de componentes de la matriz extracelular, lo cual concuerda con los estudios reportados por Lister et al. [14], que realizó estudios clínicos observando que la movilización temprana en la fase de reparación del tendón evita adherencias con los tejidos circundantes y muestra una mejora en la alineación de colágeno tipo I y un aumento de la tensión de rotura del tejido cicatrizado.

Los resultados obtenidos en este trabajo son muy prometedores y apuntan, a que el prototipo de prótesis diseñado es una buena opción como sustituto funcional para regenerar lesiones tendinosas. Aún así, se debe realizar más experimentación in vitro antes de pasar a modelos in vivo en animales con el fin de confirmar su viabilidad como una solución clínica para la regeneración del tendón. 
CONCLUSIONES 

1. Se comprobó que una trenza hueca de PLA con morfología tubular es capaz de reproducir la curva tensión-deformación de un tendón natural, indicando que es un material apto para formar parte del prototipo de prótesis diseñado.

2. La trenza de PLA, al degradarse hidrolíticamente, empezará a transferir más carga al tejido formado, mejorando su alineación y propiedades mecánicas.

3. Se logró sintetizar distintas micropartículas con los diámetros deseados. Se demostró que un soporte celular formado por la combinación de micropartículas de PLLA y HA en una proporción $2: 1$, provoca unas sinergias que conducen a una mayor proliferación celular que en cada una de las micropartículas por separado.

4. Se ha conseguido dotar a la trenza de un recubrimiento permeable y continuo de ácido hialurónico entrecruzado, que mantiene su estructura de forma estable tras 14 días de cultivo, tanto en régimen estático como en régimen dinámico.

5. Cultivos celulares in vitro de células con distintas procedencia, tanto en los materiales que forman el prototipo de prótesis como en el prototipo de prótesis final, mostraron una buena adhesión y proliferación indicando un buen comportamiento celular. 
6. Se comprobó que el uso de factores de crecimiento específicos puede inducir la diferenciación de las hMSCs a tenocitos sobre el soporte celular seleccionado, micropartículas de PLLA.

7. El cultivo in vitro mediante células de distinta procedencia en el prototipo de prótesis, garantiza una mayor densidad celular si se utiliza como relleno un soporte celular que una suspensión celular.

8. Se observó una respuesta celular cuando el prototipo de prótesis se cultiva bajo régimen dinámico, mostrando una mayor alineación celular y un incremento en la producción de GAGs. Este estímulo mecánico puede ser aplicado mediante un biorreactor construido ad hoc. 


\section{Líneas futuras}

En este punto, disponemos de un diseño candidato para una prótesis biodegradable y autoregenerativa de tendón y extensible a ligamento. Todos los ensayos efectuados hasta el momento nos confirman su aptitud, pero estos ensayos sólo han sido efectuados en unas condiciones no siempre idénticas a las existentes en el organismo.

Por otra parte, existen variables cuyos valores óptimos aún no hemos sido capaces de determinar, como podría ser el número de células a incorporar en el interior de la prótesis, las células idóneas o las condiciones de estimulación dinámica que conducen a una mejor regeneración del tejido.

Tampoco ha sido estudiado en esta tesis el procedimiento de anclaje distal y proximal aunque se podría utilizar cualquier solución de las existentes en la cirugía.

Así pues, y como primer paso para futuras líneas de trabajo, proponemos la realización de ensayos in vitro en los que seamos capaces de determinar el número y tipo de células a incorporar y las condiciones del estímulo aplicado. Un rediseño y mejora del biorreactor utilizado, que permita un mayor control del esfuerzo aplicado, es necesario. Los resultados podrían inducirnos a reconsiderar el diseño o materiales utilizados. 
Una vez determinados estos valores, acometeríamos ensayos in vivo en un modelo animal de un tamaño suficiente como para provocar esfuerzos comparables a los humanos. La resección del implante a distintos tiempos nos permitiría evaluar la evolución de la prótesis tras su implante; la ausencia de reacciones adversas, la evolución de las propiedades mecánicas, la cantidad y calidad del tejido regenerado, o la velocidad de degradación de la prótesis nos permitirían confirmar todas nuestras expectativas.

Finalmente, y tras verificar el comportamiento in vivo de la prótesis en el modelo animal, procederíamos a la validación del producto de acuerdo con la normativa existente, de modo que podríamos acometer la fase de ensayo clínico, conducente a la definitiva validación del producto. 


\section{ABREVIATURAS}

A

Ac

ADSC

AITEX

ANOVA

B

BSA

bFGF

BMPs

C

CBIT

CHT

Col I

$\mathrm{CO}_{2}$

D

DAPI

DMEM

DPBS

DMF

DNA

DSC

DVS

E

EtOH

F

FBS

FACS

FDA

G

GAGs

GPC

H
Anticuerpo

Células mesenquimales del tejido adiposo

Asociación de industriales del textil

Análisis de varianza

Albúmina de suero bovino

Factor de crecimiento fibroblástico

Proteínas morfogenéticas óseas

Centro de Biomateriales e Ingeniería Tisular

Quitosano

Colágeno tipo I

Dióxido de carbono

4'6-diamino-2-fenilindol

Dulbecco's modified eagle medium

Dulbecco's phosphate buffered saline

N, N-Dimetilformamida

Ácido desoxirribonucléico

Calorimetría diferencial de barrido

Divinil sulfona

Etanol

Suero fetal bovino

Selección de células activadas por fluorescencia

Food and Drug Administration

Glicosaminoglicanos

Cromatografía de permeabilidad en gel 


\begin{tabular}{|c|c|}
\hline $\mathrm{HA}$ & Ácido hialurónico \\
\hline HCL & Ácido clorhídrico \\
\hline HLA-DR & Anticuerpo monoclonal \\
\hline hMSCs & Células madre mesenquimales humanas \\
\hline $\mathrm{Hz}$ & Hercios \\
\hline I & \\
\hline $\begin{array}{l}\text { IGF-I } \\
\text { L }\end{array}$ & Factor de crecimiento insulínico \\
\hline LABRET & $\begin{array}{l}\text { Laboratorio de Bioingeniería y Regeneración } \\
\text { Tisular }\end{array}$ \\
\hline $\begin{array}{l}L R B \\
\mathbf{M}\end{array}$ & Laboratory of Biosurgical Research \\
\hline $\mathrm{M}_{\mathrm{w}}$ & Peso molecular promedio en peso \\
\hline $\mathrm{M}_{\mathrm{n}}$ & Peso molecular promedio en número \\
\hline MSC & Células madre mesenquimales \\
\hline MTS & $\begin{array}{l}\text { (3-(4,5-dimetiltiazol-2-il)-5-(3- } \\
\text { carboximetoxifenil)-2(4-sulfofenil)- } \\
\text { 2Htetrasolium) }\end{array}$ \\
\hline $\mathrm{MPa}$ & Megapascales \\
\hline $\mathbf{N}$ & \\
\hline $\begin{array}{l}\text { NADPH } \\
\mathbf{D}\end{array}$ & Nicotinamida-Adenina Dinucleotido fosfato \\
\hline $\mathrm{PB}$ & Buffer fosfato \\
\hline PBS & Buffer fosfato salino \\
\hline PCR & Reacción en cadena de la polimerasa \\
\hline PDGF & Factor de crecimiento derivado de plaquetas \\
\hline PDI & Índice de polidispersión \\
\hline PGA & Ácido poliglicólico \\
\hline PLGA & Copolímero ácido poli(láctico-co- glicólico) \\
\hline PLLA & Ácido poli(L-láctico) \\
\hline PDLA & Ácido Poli(D-láctico) \\
\hline PVA & Polivinil alcohol \\
\hline $\mathbf{S}$ & \\
\hline SEM & Microscópio electrónico de barrido \\
\hline SPSS & Statistical Package for the Social Sciences \\
\hline
\end{tabular}


T

TGA

TGF- $\beta$ s

TB

TBS

TE

THF

Tn

$\mathbf{U}$

UMA

UV

V

VEGF
Análisis termogravimétrico

Factor de crecimiento transformante $\beta$

Tampón bloqueo

Tris buffered saline

Buffer basado en tris-HCl y $1 \mathrm{mM}$ de EDTA

Tetrahidrofurano

Tenomodulina

Universidad de Málaga

Ultravioleta

Factor vascular de crecimiento endotelial 


\section{LISTADO DE FIGURAS}

Fig. 1.1 Fijación del tendón al músculo y al hueso. 4

Fig. 1.2 Formación de una fibrilla de colágeno tipo I: A) aminoácidos unidos formando una cadena $\alpha$, donde la glicina ocupa la tercera posición (círculos en negro), B y C) tres cadenas $\alpha$ formando la triple hélice de la molécula de procolágeno. Estas cadenas están rodeadas por una fina capa de proteoglicanos y glicosaminoglicanos, D) el procolágeno se convierte en tropocolágeno que se une para formar microfibrillas, E) microfibrillas rodeadas por proteoglicanos y glicosaminoglicanos. (Figura modificada de [2])........................................... 6

Fig. 1.3 Organización estructural y funcional del tendón [3]..................... 7

Fig. 1.4 Estructura del tendón. (Figura modificada [4]) ................................ 8

Fig. 1.5 Curva típica de tensión-deformación de un tendón [1]...............12

Fig. 1.6 Fases de la curación natural del tendón. (Figura modificada [4])

Fig. 1.7 Principales componentes de la ingeniería tisular [31] .26 
Fig. 1.8 Diferenciación de células madre mesenquimales en múltiples linajes mesodérmicos. (Figura modificada [33]) 27

Fig. 1.9 Proteínas de superficie positivas que expresan las células mesenquimales [34] .28

Fig. 1.10 Representación esquemática de las estrategias de reparación y regeneración de la ingeniería tisular del tendón y ligamento. (Figura modificada [29])

Fig. 1.11 Esquema del diseño de la prótesis biodegradable 48

Fig. 2.1 Esquema de la trenza de PLA suministrada por AITEX. 56

Fig. 2.2 Estructura química del ácido poli (L-láctico (PLLA) .56

Fig. 2.3 Estructura química del quitosano (CHT) 57

Fig. 2.4 Estructura química del ácido hialurónico (HA) .57

Fig. 2.5 Vista de perfil del biorreactor donde se observa la disposición de la placa petri y el material trenzado de PLA. .63

Fig. 2.6 Vista de planta del biorreactor. Muestras trenzadas fijadas mediante unos enganches fijos en el extremo izquierdo y en el extremo derecho, fijadas a una pieza móvil. .64 
Fig. 2.7 Diagrama de flujo de la fabricación de micropartículas de PLLA.

.67

Fig. 2.8 Diagrama de flujo de la fabricación de micropartículas de CHT.

.68

Fig. 2.9 Diagrama de flujo de la fabricación de micropartículas de HA..69

Fig. 2.10 Montaje de electrospinning utilizado para realizar el recubrimiento con HA sobre el material trenzado. .71

Fig. 2.11 Gráfica típica de tensión-deformación de un tendón representado las zonas típicas: basal, lineal y de cesión [111] ..................74

Fig. 2.12 Dimensiones de la trenza hueca de PLA. .......................................77

Fig. 2.13 Biorreactor y material de montaje a utilizar en el ensayo antes de proceder al cultivo (carcasa del biorreactor, cable, funda del cable, destornillador, llaves Allen y placa petri).

.87

Fig. 2.14 Ensayo in vitro en régimen dinámico del cultivo de L929 sobre el material trenzado a 7 y 14 días. a) Siembra sobre la trenza de PLA, b) montaje de las trenzas en el biorreactor, c) Añadir medio de cultivo y d) conexión del biorreactor al motor desde dentro del incubador. .89 
Fig. 2.15 Cultivo del prototipo de prótesis. a) Intercambio de EtOH 70\% a PBS del material trenzado recubierto con HA, b) inyección del relleno en la prótesis para el ensayo en estático, c) inyección del relleno en la prótesis para el ensayo en dinámico, d) ajuste de la prótesis en el biorreactor, e) adición de medio de cultivo y f) cultivo en el biorreactor y en placa petri para ensayo en régimen estático y dinámico a 14 días de cultivo. 91

Fig. 3.1 Trenza de PLA utilizada en el estudio: a) aspecto macroscópico de la trenza, b) sección transversal, c) ángulo de trenzado y d) microfibrillas. 106

Fig. 3.2 Curvas de DSC de la trenza de PLA. 108

Fig. 3.3 Degradación térmica de la trenza de PLA 109

Fig. 3.4 Típica curva tensión (fuerza) - deformación de 4 hilos pertenecientes a la trenza de PLA (a) y de la trenza de PLA (b)............110

Fig. 3.5 Propiedades mecánicas de la trenza hueca de PLA en el ensayo dinámico. a) Incremento de la máxima deformación con el número de ciclos. b) Decrecimiento de la histéresis mecánica con el número de ciclos. 112

Fig. 3.6 Pérdida de masa del material trenzado de PLA con respecto del tiempo de degradación en distintos medios. a) muestras inmersas en 
medio básico y ácido durante un mes, b) muestras inmersas en medio PBS a $37^{\circ} \mathrm{C}$ durante un año

Fig. 3.7 Micrografías de SEM de la trenza de PLA antes y después de ser degradada en PBS a distintos tiempos. $\mathrm{T}_{0}$, muestra sin degradar, $\mathrm{T}_{4}$ después de 4 meses y $\mathrm{T}_{6}$ después de 6 meses de degradación a $37^{\circ} \mathrm{C} .117$

Fig. 3.8 Micrografías de SEM de la trenza de PLA antes y después de ser expuesta a medio básico y ácido durante distintos tiempos. $\mathrm{T}_{0}$, indica el inicio del ensayo, $\mathrm{T}_{15 \mathrm{~d}}$ tras 15 días de degradación y $\mathrm{T}_{30 \mathrm{~d}}$ después de 30 días de degradación a $37^{\circ} \mathrm{C}$. 118

Fig. 3.9 Curvas de GPC de la trenza de PLA antes y después de la degradación hidrolítica para distintos tiempos en PBS. $\mathrm{T}_{0}$, muestra sin degradar, $\mathrm{T}_{6}$ después de 6 meses y $\mathrm{T}_{12}$ después de 12 meses de degradación.

Fig. 3.10 Curvas tensión-deformación de la trenza de PLA antes y después de la degradación a $37^{\circ} \mathrm{C}$ en a) medio básico, b) medio ácido y c) medio en PBS 125

Fig. 3.11 Fotografías realizadas con lupa para medir diámetros de micropartículas y respectivo histograma del tamaño de las micropartículas de: a) PLLA, b) CHT y c) HA................................................129 
Fig. 3.12 Micrografías de SEM de micropartículas de PLLA, HA y CHT. 130

Fig. $3.13 \%$ de pérdida de peso en función de la temperatura de las micropartículas de PLLA, CHT y HA comparada con los polímeros puros.

Fig. 3.14 Micrografías de SEM del recubrimiento de HA realizado con electrospinnig a distintos tiempos

Fig. 3.15 Trenza de PLA hinchada en PBS después de 1 día 134

Fig. 3.16 Imágenes del microscopio óptico de células L929 cultivadas durante 1, 7 y 14 días con: medio de cultivo suplementado con 10\% FBS $(\mathrm{CN})$, medio que ha estado en contacto con las trenzas esterilizadas por diferentes técnicas (EtOH 70\%, UV y autoclave), y medio en contacto con el látex (CP). 138

Fig. 3.17 Ensayo de MTS de las L929 cultivadas durante 1, 7 y 14 días para el ensayo de citotoxicidad de la trenza de PLA con: medio de cultivo suplementado con $10 \%$ FBS sin estar en contacto con el material (Control negativo), el medio que ha estado en contacto con las trenzas esterilizadas por diferentes técnicas (EtOH 70\%, UV y autoclave), y medio en contacto con el látex (Control positivo). ( $p<0,05$, *significa 
que hay diferencia significativa entre las diferentes muestras en un mismo tiempo)

Fig. 3.18 Ensayo de MTS de los fibroblastos cultivados sobre las trenzas de PLA después 1,7 y 14 días de tiempo de cultivo. $(p<0,05$, *significa que hay diferencia significativa entre las diferentes muestras en un mismo tiempo) 142

Fig. 3.19 Imágenes de SEM de la morfología del fibroblasto en la superficie del material trenzado de PLA a 1, 7 y 14 días de cultivo..... 145

Fig. 3.20 Tinción del citoesqueleto de actina (verde) y núcleos celulares (azul) de los fibroblastos L929 a 1, 7 y 14 días de cultivo sobre la trenza de PLA.

Fig. 3.21 Ensayo de MTS de los fibroblastos cultivados en las distintas micropartículas después de 1, 7 y 14 días de cultivo. ( $p<0,05$, *significa que hay diferencia significativa entre las diferentes muestras en un mismo tiempo $\mathrm{y}^{* *}$ entre la misma muestra a distintos tiempos de cultivo) 148

Fig. 3.22 Imágenes de SEM de la morfología de las L929 sobre las diferentes micropartículas siendo (a) las de PLLA, (b) las de HA, y (c) las de CHT a 1 y 14 días de cultivo. Se representa por cada tiempo una imagen panorámica y otra a mayores aumentos (T1 y T14) 150 
Fig. 3.23 Tinción del citoesqueleto de actina de las células L929 después de 7 días de cultivo sobre las micropartículas de PLLA, CHT y HA. Los núcleos fueron teñidos con DAPI. 151

Fig. 3.24 Micrografías de SEM de las micropartículas de PLLA sembradas con L929 durante 1, 2 ,3 y 6 horas. 154

Fig. 3.25 Ensayo de MTS de los fibroblastos cultivados en las micropartículas (PLLA y HA) y en las combinaciones entre ellas $(2: 1 \mathrm{y}$ 1:2, PLLA:HA) a 1,7 y 14 días de cultivo. ( $p<0,05$, *significa que hay diferencia significativa entre las diferentes muestras en un mismo tiempo ${ }^{* *}$ entre la misma muestra a distintos tiempos de cultivo)...156

Fig. 3.26 Imágenes de SEM de la morfología de las L929 sobre las distintas combinaciones de micropartículas de PLLA y HA (2:1 y 1:2) después de 1, 7 y 14 días. 158

Fig. 3.27 Ensayo de MTS de las hMSCs cultivadas sobre el material trenzado a 1,7 y 14 días de cultivo. ( $p<0,05$, *significa que hay diferencia significativa entre las diferentes muestras en un mismo tiempo ${ }^{* *}$ entre la misma muestra a distintos tiempos de cultivo)... 160

Fig. 3.28 Imágenes de SEM de la morfología de las $h M S C s$ sobre la trenza de PLA a 1, 7 y 14 días. Las flechas indican células en las microfibras. 
Fig. 3.29 Tinción del citoesqueleto de actina (verde) desarrollado por las $h M S C s$ cultivadas sobre la trenza de PLA tras 1, 7 y 14 días. Los núcleos se tiñeron con DAPI (azul). 162

Fig. 3.30 Ensayo de MTS de las hMSCs cultivadas sobre las distintas micropartículas a 1,7 y 14 días de cultivo. $(p<0,05$, *significa que hay diferencia significativa entre las diferentes muestras en un mismo tiempo ${ }^{* *}$ entre la misma muestra a distintos tiempos de cultivo)... 163

Fig. 3.31 Imágenes de SEM de la morfología de las de las hMSCs sobre las diferentes micropartículas siendo (a) las de PLLA, (b) las de HA, y (c) las de CHT a 1 y 14 días de cultivo. Se representa por cada tiempo una imagen panorámica y otra a mayores aumentos (T1 y T14). Las flechas indican células en las micropartículas 165

Fig. 3.32 Tinción del citoesqueleto de actina (verde) desarrollado por las hMSCs en las micropartículas de PLLA, HA y CHT a 1 día de cultivo. Los núcleos se han marcado con DAPI. 166

Fig. 3.33 Inmunofenotipo del cultivo de hMSCs sobre las micropartículas de distintos materiales CHT, PLLA y HA a tiempo T14. Representados 5000 eventos. 168

Fig. 3.34 Ensayo de MTS de las hMSCs cultivadas sobre la trenza de PLA utilizando dos medios distintos: medio suplementado con BMP-12 y 
medio suplementado con TGF- $\beta 1$ y IGF-1 a 1, 7, 14 y 21 días de cultivo. $\left(p<0,05,{ }^{*}\right.$ significa que hay diferencia significativa entre las diferentes muestras en un mismo tiempo ${ }^{* *}$ entre la misma muestra a distintos tiempos de cultivo)

Fig. 3.35 Imágenes de SEM de la morfología de las $h M S C s$ sobre la trenza de PLA utilizando distintos medios de diferenciación: medio suplementado con BMP-12, fila superior y medio suplementado con TGF- $\beta 1$ y IGF-1, fila inferior tras 14 y 21 días de cultivo.

Fig. 3.36 Inmunofluorescencia de proteínas expresadas por las hMSCs cultivadas en la trenza de PLA utilizando los medios diferenciadores. a) y b) Expresión de colágeno tipo I (rojo) y tinción del citoesqueleto de actina (verde) a 14 y 21 días y, c) expresión de la tenomodulina (rojo) tras 21 días de cultivo . Los núcleos se han marcado con DAPI. 174

Fig. 3.37 Ensayo de MTS de las hMSCs cultivadas sobre las micropartículas de PLLA utilizando dos medios distintos: medio suplementado con BMP-12 y medio suplementado con TGF- $\beta 1$ y IGF-1 a $1,7,14$ y 21 días de cultivo. ( $p<0,05$, *significa que hay diferencia significativa entre las diferentes muestras en un mismo tiempo)........176

Fig. 3.38 Imágenes de SEM de la morfología de las hMSCs sobre las micropartículas de PLLA utilizando distintos medios de diferenciación: 
medio suplementado con BMP12, fila superior y medio suplementado con TGF- $\beta 1$ y IGF-1, fila inferior a 14 y 21 días de cultivo 178

Fig. 3.39 Inmunofluorescencia de proteínas expresadas por las hMSCs cultivadas en las micropartículas de PLLA utilizando los medios diferenciadores. a) y b) expresión de colágeno tipo I (rojo) y tinción del citoesqueleto de actina (verde) a 14 y 21 días, y c) expresión de la tenomodulina (rojo) tras 21 días de. Los núcleos se han marcado con DAPI 180

Fig. 3.40 q-PCR en las hMSCs cultivadas sobre las micropartículas de PLLA con los dos medios de cultivo diferenciadores, siendo M1 el medio suplementado con BMP-12, y M2 el suplementado con TGF- $\beta 1$ e IGF-1, tras 21 días de cultivo

Fig. 3.41 Inmunofenotipo del cultivo de hMSCs sobre las micropartículas de PLLA utilizando los medios de diferenciación, M1, medio suplementado con BMP-12 y M2, medio suplementado con TGF- $\beta 1$ y IGF-1. Representados 5000 eventos 184

Fig. 3.42 Esquema del prototipo de prótesis 186

Fig. 3.43 Imágenes de SEM de la morfología de las L929 sobre la superficie de la trenza de PLA a 7 y 14 días de cultivo en régimen dinámico. 
Fig. 3.44 Imágenes de SEM de la morfología de las L929 en el interior del material trenzado de PLA tras el cultivo in vitro en régimen dinámico después de 14 días de cultivo. 189

Fig. 3.45 Imágenes de inmunofluorescencia del colágeno tipo I (rojo) y tinción del citoesqueleto de actina (verde), de fibroblastos sembrados sobre la trenza de PLA en régimen estático y dinámico después de 7 días de cultivo. Los núcleos se han teñido con DAPI (azul). 191

Fig. 3.46 Ensayo de MTS de las L929 cultivadas en la prótesis a 1, 7 y 14 días de cultivo. $\left(p<0,05,{ }^{*}\right.$ significa que hay diferencia significativa entre las diferentes muestras en un mismo tiempo de cultivo $\mathrm{y}^{* *}$ entre la misma muestra a distintos tiempos de cultivo) 193

Fig. 3.47 Imágenes de SEM de la morfología de las L929 en el interior del prototipo a 1, 7 y 14 días de cultivo. Las flechas blancas indican la presencia de células adheridas a las micropartículas y a las fibras...... 194

Fig. 3.48 Sección transversal del prototipo de prótesis. 196

Fig. 3.49 Imágenes de SEM de la morfología de las L929 cultivadas en la prótesis mediante la combinación de micropartículas PLLA y HA (a y b) o en la muestra control como una suspensión celular (c y d) a 14 días de cultivo. 
Fig. 3.50 Imágenes de la tinción del citoesqueleto de actina (verde), tanto en régimen estático como dinámico en el interior de la prótesis cultivada con L929 durante 14 días utilizando: una combinación de micropartículas PLLA:HA pre-sembradas previamente y una suspensión celular. Los núcleos fueron teñidos con DAPI. 199

Fig. 3.51 Cuantificación de la producción de componentes de la matriz extracelular. a) DNA, b) Colágeno tipo I normalizado con el contenido de DNA c) GAGs normalizado con el contenido de DNA, y a 14 días de cultivo en estático y con el biorreactor en el prototipo de prótesis..... 201

Fig. 3.52 Imágenes de SEM del interior del prototipo cultivado con un relleno de micropartículas pre-sembradas con $A D S C$ de oveja a 14 días de cultivo en régimen estático y dinámico a 14 días de cultivo in vitro.

Fig. 3.53 Imágenes de la tinción del citoesqueleto de actina (verde), tanto en régimen estático como dinámico en el interior de la prótesis cultivada con $A D S C$ de oveja durante 14 días utilizando como relleno una combinación de micropartículas PLLA:HA pre-sembradas. Los núcleos fueron teñidos con DAPI. 204

Fig. 3.54 Cuantificación del contenido de GAGs durante 14 días de cultivo de las $A D S C$ de oveja en régimen estático y dinámico, en el prototipo de prótesis. 205 


\section{LISTADO DE TABLAS}

Tabla 1.1 Factores de crecimiento relacionados con la formación del tendón

Tabla 1.2. Moléculas asociadas en el desarrollo y formación del tendón.

20

Tabla 1.3. Prótesis biológicas comerciales. 24

Tabla 3.1. Temperaturas de transición vítrea $\left(\mathrm{T}_{\mathrm{g}}\right)$, entalpía de cristalización de cristalización $\left(\Delta \mathrm{H}_{\mathrm{c}}\right)$, entalpía de fusión $\left(\Delta \mathrm{H}_{\mathrm{f}}\right), \mathrm{y}$ cristalinidad $\left(X_{C}\right)$ de la trenza de PLA tal y como fue recibida. 108

Tabla 3.2 Valores de GPC del peso molecular promedio en peso $\left(\mathrm{M}_{\mathrm{w}}\right)$, en número $\left(\mathrm{M}_{\mathrm{n}}\right)$ y el índice de polidispersión (PDI) de la trenza de PLA, antes y después de distintos periodos de degradación en PBS a $37^{\circ} \mathrm{C}$.

Tabla 3.3 Peso molecular promedio en peso $\left(\mathrm{M}_{\mathrm{w}}\right)$, en número $\left(\mathrm{M}_{\mathrm{n}}\right)$ y el índice de polidispersión (PDI) de la trenza de PLA, antes y después de distintos periodos de degradación en $\mathrm{NaOH}$ pH 12 a $37^{\circ} \mathrm{C}$ 121 
Tabla 3.4 Peso molecular promedio en peso $\left(\mathrm{M}_{\mathrm{w}}\right)$, en número $\left(\mathrm{M}_{\mathrm{n}}\right)$ y el índice de polidispersión (PDI) de la trenza de PLA, antes y después de distintos periodos de degradación en $\mathrm{HCl}$ pH 3 a $37^{\circ} \mathrm{C}$

Tabla 3.5 Propiedades térmicas de la trenza de PLA antes y después de la degradación en $\mathrm{PBS}$ a $37^{\circ} \mathrm{C}$ durante 12 meses de estudio. 123

Tabla 3.6 Propiedades térmicas de la trenza de PLA antes y después de la degradación en medio básico y en medio ácido a $37^{\circ} \mathrm{C}$ durante 1 meses de estudio. 123

Tabla 3.7 Módulo de Young, tensión de rotura rotura y \% de elongación de la trenza de PLA, antes y después de distintos periodos de

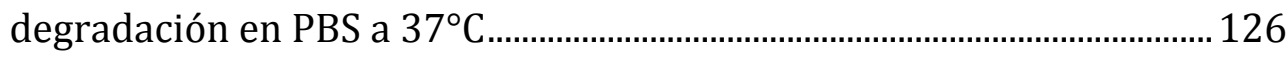

Tabla 3.8 Módulo de Young, tensión de rotura y \% de elongación de la trenza de PLA, antes y después de distintos periodos de degradación en $\mathrm{NaOH}$ y $\mathrm{HCl}$ 126 


\section{REFERENCIAS}

1. Wang, HC., Mechanobiology of tendon. J Biomechanics, 2006; 39(9):1563-1582.

2. Kannus, P., Structure of the tendon connective tissue. Scand J Med Sci Sports 2000; 10:312-320.

3. JU. Carmona, C. López, Superficial digital flexor tendon tendinopathy and suspensory ligament desmopathy in horses: pathophysiology and regenerative therapies. Arch Med Vet 2011; 43:203-214.

4. $\quad$ Berger R., Hand Surgery. Lippincott 2004; Vol. 2:24-35.

5. O'Brien M., Structure and metabolism of tendons. Scand J Med Sci Sports, 1997; 7:5541.

6. Yoon JH, Jalper H., Tendon proteoglycans: biochemistry and function. J Musculoskelet Neuronal Interact 2005; 5(1):22-34.

7. Järvinen TA., Kannus P., Järvinen TL., Jozsa L., Kalimo H., Järvinen M., Tenascin- $C$ in the pathobiology and healing process of musculoskeletal tissue injury. Scandinavian Journal of Medicine \& Science in Sports 2000; 10(6):376-382.

8. Patterson-Kane, JC., Firth EC., Goodship AE., Parry D., Age-related differences in collagen crimp patterns in the superficial digital flexor tendon core region of untrained horses. Australian Veterinary Journal, 1997. 75(1):39-44.

9. J. Nardi Vilardaga, A Viladot Voegeli, Biomecánica del tendón. Lesiones básicas de biomecánica del aparato locomotor. SpringerVerlag Ibérica, 2000.

10. Fenwick SA., Hazleman BL., Riley GP., The vasculature and its role in the damaged and healing tendon. Arthritis research, 2002;4(4):252-260.

11. L. Gil Santos, M. Monleón Pradas, V. Sanchis, L. Aguilella, F. Gomar Sancho, Conceptos actuales sobre reparación primaria de los tendones flexores de la mano. Rev Esp Cir Osteoart. 1993; 28:327-351. 
12. A. Jurado Bueno, Tendón: valoración y tratamiento en fisioterapia. Editorial Paidotribo, 2008.

13. Lin TW., Cardenas L., Soslowsky LJ., Biomechanics of tendon injury and repair. Journal of Biomechanics. 2004; 37(6): 865877.

14. Lister GD., Kutz JE., Atasoy E., Primary flexor tendon repair followed by immediate controlled mobilization. J Hand Surg Am. 1977; 2(6):441-51.

15. Molloy T., Wang Y., Murrell G., The Roles of Growth Factors in Tendon and Ligament Healing. Sports Medicine. 2003; 33(5):381-394.

16. James R., Kesturu, G., Balian G., Chhabra B., Tendon: Biology, Biomechanics, Repair, Growth Factors, and Evolving Treatment Options. The Journal of Hand Surgery. 2008; 33(1):102-112.

17. Deborah PL., The costs of musculoskeletal disease: health needs assessment and health economics. Best Practice \& Research Clinical Rheumatology, 2003. 17(3):529-539.

18. Nicola M., Jason W., Louis CA., Types and epidemiology of tendinopathy. Clin Sports Med. 2003; 22 675-692.

19. Cooper JA., Bailey LO., Carter JN.,Castiglioni CE., Kofron MD., Ko FK., Laurencin CT., Evaluation of the anterior cruciate ligament, medial collateral ligament, achilles tendon and patellar tendon as cell sources for tissue-engineered ligament. Biomaterials. 2006; 27(13):2747-2754.

20. Murray AW., Macnicol MF., 10 -16 year results of Leeds-Keio anterior cruciate ligament reconstruction. The Knee. 2004; 11(1):9-14.

21. Zheng MH., Chen J., Kirilak Y., Willers C., Xu J., Wood D., Porcine small intestine submucosa (SIS) is not an acellular collagenous matrix and contains porcine DNA: Possible implications in human implantation. Journal of Biomedical Materials Research Part B: Applied Biomaterials. 2005; 73B(1):61-67.

22. Metcalf MH., Savoie FH., Kellum B., Surgical technique for xenograft (SIS) augmentation of rotator-cuff repairs. Operative Techniques in Orthopaedics. 2002;12(3): 204-208. 
23. Daniel KL., Achilles Tendon Repair with Acellular Tissue Graft Augmentation in Neglected Ruptures. The Journal of Foot and Ankle Surgery. 2007; 46(6): 451-455.

24. Soler JA., Gidwani S., Curtis MJ., Early complications from the use of porcine dermal collagen implants (Permacol) as bridging constructs in the repair of massive rotator cuff tears. A report of 4 cases. Acta orthop. Belg. 2007; 73(4):432-6.

25. Seldes RM., Abramchayev I., Arthroscopic Insertion of a Biologic Rotator Cuff Tissue Augmentation After Rotator Cuff Repair. The Journal of Arthroscopic and Related Surgery. 2006; 22(1):113116.

26. Harvey L., The OrthADAPT Bioimplant provides excellent scaffold for posterior tibial tendon repair. Pegasus Biologics, 2006.

27. Miller MD., Peters CL., Allen B., Early aseptic loosening of a total knee arthroplasty due to Gore-Tex particle-induced osteolysis. The Journal of Arthroplasty. 2006;21(5): 765-770.

28. Dominkus M., Sabeti M., Toma C., Abdolvahab F., Trieb K., Kotz RI., Reconstructing the extensor apparatus with a new polyester ligament. Clinical orthopaedics and related research. 2006; 453:328-334

29. Rodrigues MT., Reis RL., Gomes ME., Engineering tendon and ligament tissues: present developments towards successful clinical products. Journal of Tissue Engineering and Regenerative Medicine. 2012.

30. Langer R., Vacanti JP., Tissue engineering. Science. 1993; 260:9206. 1993.

31. Jaén TF., Pazos FB., Jiménez AF., Vicente MG., García PG., Current concepts of the pathophysiology of tendinopathies. Apunts Med Esport. 2010;45(168):259-264.

32. Weissman IL., Anderson DJ., Gage F., Stem and progenitor cells: origins, phenotypes, lineage commitments, and transdifferentiations. Annual review of cell and developmental biology. 2001; 17:387-403. 
33. Caplan AI., Bruder SP., Mesenchymal stem cells: building blocks for molecular medicine in the 21st century. Trends in Molecular Medicine. 2001;7(6):259-264.

34. Forriol F., Esparza R., Tissue engineering: application of pluripotent stem cells in traumatology and orthopedic surgery. Trauma. 2008; 19 №2.

35. Awad HA., Butler DL., Harris MT., Ibrahim RE., Wu Y., Young RG., Kadiyala S., Boivin GP., In vitro characterization of mesenchymal stem cell-seeded collagen scaffolds for tendon repair: Effects of initial seeding density on contraction kinetics. Journal of Biomedical Materials Research. 2000; 51(2):233-240.

36. Tapp H., Hanley EN., Patt JC., Gruber HE., Adipose-derived stem cells: characterization and current application in orthopaedic tissue repair. Experimental biology and medicine. 2009; 234(1):1-9.

37. Babensee JE., McIntire LV., Mikos AG., Growth Factor Delivery for Tissue Engineering. Pharmaceutical Research. 2000;17(5):497504.

38. Lieberman JR, Daluiski A., Einhorn TA., The Role of Growth Factors in the Repair of Bon. Biology and Clinical Applications. The Journal of Bone \& Joint Surgery. 2002.

39. Vacanti P., Langer R., Tissue engineering: the design and fabrication of living replacement devices for surgical reconstruction and transplantation. The Lancet. 1999; 354:S32S34.

40. Langer R., Tirrell DA., Designing materials for biology and medicine. Nature. 2004;428(6982):487-492.

41. Fuchs JR., Nasseri BA., Vacanti JP., Tissue engineering: a 21st century solution to surgical reconstruction. The Annals of Thoracic Surgery. 2001; 72(2):577-591.

42. Ramakrishna S., Mayer J., Wintermantel E., Leong KW., Biomedical applications of polymer-composite materials: a review. Composites Science and Technology. 2001;61(9):1189-1224. 
43. O'Donnell PB., McGinity JW., Preparation of microspheres by the solvent evaporation technique. Advanced Drug Delivery Reviews. 1997;28(1):25-42.

44. Bruschi, ML., Cardoso ML., Lucchesi MB., Gremiao MP., Gelatin microparticles containing propolis obtained by spray-drying technique: preparation and characterization. International Journal of Pharmaceutics. 2003; 264:45-55.

45. Schafroth N., Arpagaus C., Jadhav UY., Makne S., Douroumis D., Nano and microparticle engineering of water insoluble drugs using a novel spray-drying process. Colloids and Surfaces B: Biointerfaces. 2012; 90(0):8-15.

46. Nihant N., Stassen S., Grandfils C., Teyssié P., Microencapsulation by coacervation of poly(lactide-co-glycolide) II: Encapsulation of a dispersed aqueous phase. Polymer International. 1993;32(2):171-176.

47. Bhattarai SR., Bhattarai N., Yi HK., Hwang PH., Cha DI., Kim HY., Novel biodegradable electrospun membrane: scaffold for tissue engineering. Biomaterials. 2004; 25(13):2595-2602.

48. Huang ZM., Zhang YZ., Kotaki M., Ramakrishana S., A review on polymer nanofibers by electrospinning and their applications in nanocomposites. Composites Science and Technology. 2003; 63(15):2223-2253.

49. Suh SW., Shin JY., Kim J., Beak CH., Kim H., Jeon SS., Choo IW., Effect of different particles on cell proliferation in polymer scaffolds using a solvent-casting and particulate leaching technique. ASAIO journal. 2002; 48(5):460-4.

50. Reignier J., Huneault MA., Preparation of interconnected poly( $\varepsilon$ caprolactone) porous scaffolds by a combination of polymer and salt particulate leaching. Polymer. 2006; 47(13):4703-4717.

51. Harris LD., Kim BS., Mooney DJ., Open pore biodegradable matrices formed with gas foaming. John Wiley \& Sons. 1998.

52. Ho MH., Huo PY., Hsieh HJ., Hsien TY., Hou LT., Lai JY., Wang DM., Preparation of porous scaffolds by using freeze-extraction and freeze-gelation methods. Biomaterials. 2004; 25(1):129-138. 
53. Lin CC., Metters AT., Hydrogels in controlled release formulations: Network design and mathematical modeling. Advanced Drug Delivery Reviews. 2006; 58:1379-1408.

54. Bernard-Beaubois K., Hecquet C., Houcine O., Hayem G., Adolphe M., Culture and characterization of juvenile rabbit tenocytes. Cell Biology and Toxicology. 1997; 13(2):103-113.

55. Zhang J., Wang JHC., Characterization of differential properties of rabbit tendon stem cells and tenocytes. BMC Musculoskeletal Disorders. 2010; 11(1):10.

56. Pauly S., Klatte F., Strobel C., Schmidmaier G., Greiner S., Scheibel M., Wildemann B., Characterization of tendon cell cultures of the human rotator cuff. European cells and materials. 2010; 20:8497.

57. Deng D., Liu W., Xu F., Yang Y., Zhou G., Zhang WJ., Engineering human neo-tendon tissue in vitro with human dermal fibroblasts under static mechanical strain. Biomaterials. 2009; 30(35):67246730.

58. Liu W., Chen B., Deng D., Xu F., Cui L., Cao Y., Repair of tendon defect with dermal fibroblast engineered tendon in a porcine model. Tissue Engineering. 2006; 12(4):775-788.

59. Gigante A., Cesari E., Busilacchi A., Manzotti S., Kyriakidou K., Greco F., Primio R., Belmonte M., Collagen I membranes for tendon repair: effect of collagen fiber orientation on cell behavior. J Orthop Res. 2009;27(6):826-32.

60. Ouyang, HW., Goh JC., Mo XM., Teoh SH., Lee EH., The efficacy of bone marrow stromal cell-seeded knitted PLGA fiber scaffold for Achilles tendon repair. in Symposium on Reparative Medicine Growing Tissues and Organs. 2001;126-129.

61. Park, A., Hogan MV., Kesturu GS., James R., Balian G., Chhabra AB., Adipose-derived mesenchymal stem cells treated with growth differentiation factor-5 express tendon-specific markers. Tissue engineering Part A. 2010; 16(9):2941-2951.

62. De Bari C., Dell'Accio F., Vandenabeele F., Vermeesch JR., Raymackers JM., Luyten FP., Skeletal muscle repair by adult 
human mesenchymal stem cells from synovial membrane. The Journal of Cell Biology. 2003; 160(6):909-918.

63. Pacini S., Spinabella S., Trombi L., Fazzi R., Galimberti S., Dini F., Carlucci F., Petrini M., Suspension of bone marrow-derived undifferentiated mesenchymal stromal cells for repair of superficial digital flexor tendon in race horses. Tissue engineering. 2007; 13(12):2949-2955.

64. Nixon AJ., Dahlgren LA., Haupt JL., Yeager AE., Ward DL., Effect of adipose-derived nucleated cell fractions on tendon repair in horses with collagenase-induced tendinitis. American journal of veterinary research. 2008; 69(7):928-937.

65. Gomes JL., Silva RC., Silla LMR., Abreu MR., Pellanda R., Conventional rotator cuff repair complemented by the aid of mononuclear autologous stem cells. Knee Surgery, Sports Traumatology, Arthroscopy. 2012; 20(2):373-377.

66. Fang Q., Chen D., Yang Z., Li M., In vitro and in vivo research on using Antheraea pernyi silk fibroin as tissue engineering tendon scaffolds. Materials Science and Engineering C. 2009; 29(5):1527-1534.

67. Fan H., Liu H., Toh SL., Goh CH., Anterior cruciate ligament regeneration using mesenchymal stem cells and silk scaffold in large animal model. Biomaterials. 2009; 30(28):4967-4977.

68. Awad, HA., Boivin GP., Dressler MR., Smith FN., Young RG., Butler DL., Repair of patellar tendon injuries using a cell-collagen composite. Journal of Orthopaedic Research. 2003; 21(3):420431.

69. Nirmalanandhan VS., Rao M., Shear JT., Melvin NJ., Gooch C., Butler DL., Effect of scaffold material, construct length and mechanical stimulation on the in vitro stiffness of the engineered tendon construct. Journal of Biomechanics. 2008; 41(4):822-828.

70. Kew SJ., Gwynne JH., Enea D., Brookes R., Rushton N., Best SM., Cameron RE., Synthetic collagen fascicles for the regeneration of tendon tissue. Acta Biomaterialia. 2012; 8(10):3723-3731.

71. Bayer ML., Yeung C., Kadler KE., Qvortrup K., Baar K., Svensson RB., Magnusson SP., Krogsgaard M., Koch M., Kjaer M., The 
initiation of embryonic-like collagen fibrillogenesis by adult human tendon fibroblasts when cultured under tension. Biomaterials. 2010; 31(18):4889-4897.

72. Thomopoulos S., Das R., Elbert SS., Silva MJ., Charlton N., Gelberman RH., bFGF and PDGF-BB for Tendon Repair: Controlled Release and Biologic Activity by Tendon Fibroblasts In Vitro. Annals of Biomedical Engineering. 2010; 38(2):225-234.

73. Liu Y., Ramanath HS., Wang DA. Tendon tissue engineering using scaffold enhancing strategies. Trends in Biotechnology. 2008; 26(4):201-209.

74. Cooper JA., Lu HH., Ko FK, Freeman JW., Laurencin CT., Fiberbased tissue-engineered scaffold for ligament replacement: design considerations and in vitro evaluation. Biomaterials. 2005; 26(13):1523-1532.

75. Ouyang HW., Goh JC., Mo XM., Teoh SH., Lee EH., Knitted polylactide-co-glycolide scaffold loaded with bone marrow stromal cells in repair and regeneration of rabbit Achilles tendon. Tissue Engineering. 2003; 9:431-439.

76. Cao DJ., Liu W., Wei X., Xu F., Cui L., Cao Y., In vitro tendon engineering with avian tenocytes and polyglycolic acids: $A$ preliminary report. Tissue Engineering. 2006;12(5):1369-1377.

77. Xu L., Cao D., Liu W., Zhou G., Zhang WJ., Cao Y., In vivo engineering of a functional tendon sheath in a hen model. Biomaterials. 2010; 31(14):3894-3902.

78. Kimura Y., Hokugo A., Takamoto T., Tabata Y., Kurosawa H., Regeneration of anterior cruciate ligament by biodegradable scaffold combined with local controlled release of basic fibroblast growth factor and collagen wrapping. Tissue Engineering Part CMethods. 2008;14(1):47-57.

79. Lu HH., Cooper JA., Manuel S., Freeman JW., Attawia MA., Ko FK., Laurencin CT., Anterior cruciate ligament regeneration using braided biodegradable scaffolds: in vitro optimization studies. Biomaterials. 2005; 26(23):4805-4816. 
80. Laurencin CT., Freeman JW., Ligament tissue engineering: An evolutionary materials science approach. Biomaterials. 2005; 26(36):7530-7536.

81. Freeman JW., Woods MD., Laurencin CT., Tissue engineering of the anterior cruciate ligament using a braid-twist scaffold design. Journal of Biomechanics. 2007; 40(9):2029-2036.

82. Yin Z., Chen X., Shen WL., Nguyen TMH., Gao L., Ouyang HW., The regulation of tendon stem cell differentiation by the alignment of nanofibers. Biomaterials. 2009; 31(8):2163-2175.

83. Surrao DC., Waldman SD., Amsden BG., Biomimetic Poly(Lactide) Based Fibrous Scaffolds for Ligament Tissue Engineering. Acta Biomaterialia. 2012; 8:3997-4006.

84. Chan BP., Fu S., Qin L., Lee K., Rolf CG., Chan K., Effects of basic fibroblast growth factor (bFGF) on early stages of tendon healing: A rat patellar tendon model. Acta Orthop Scand. 2000; 71(5):513518.

85. Kurtz, CA., Loebig TG., Anderson DD., Demeo PJ., Campbell PG., Insulin-like growth factor I accelerates functional recovery from Achilles tendon injury in a rat model. The American journal of sports medicine. 1999; 27(3):363-9.

86. Dahlgren LA., Meulen MCH., Bertram JEA, Starrak GS., Nixon AJ., Insulin-like growth factor-I improves cellular and molecular aspects of healing in a collagenase-induced model of flexor tendinitis. Journal of Orthopaedic Research. 2002; 20(5):910919.

87. Coloma ES., Rolon A., Khoury MA., La actualidad del plasma rico en plaquetas en traumatología del deporte. Revista de la asociación Argentina de traumatología del deporte. 2011;18(1).

88. Lyras DN., Kazakos K., Verettas D, Chronopoulos E, Folaranmi S, Agrogiannis G., Effect of combined administration of transforming growth factor-b1 and insulin-like growth factor $I$ on the mechanical properties of a patellar tendon defect model in rabbits. Acta Orthop Belg. 2010; 76(3):380-6.

89. Suwalski A., Dabboue H., Delalande A., Bensamoun SF., Canon F., Midoux P., Saillant G., Klatzmann D., Salvetat JP., Pichon C., 
Accelerated Achilles tendon healing by PDGF gene delivery with mesoporous silica nanoparticles. Biomaterials. 2010;31(19):5237-5245.

90. Schneider PRA., Buhrmann C., Mobasheri A., Matis U., Shakibaei M., Three-dimensional high-density co-culture with primary tenocytes induces tenogenic differentiation in mesenchymal stem cells. Journal of Orthopaedic Research. 2011; 29(9):1351-1360.

91. Violini S., Ramelli P., Pisani LF., Gorni C., Mariani p., Horse bone marrow mesenchymal stem cells express embryo stem cell markers and show the ability for tenogenic differentiation by in vitro exposure to BMP-12. BMC Cell Biology. 2009; 10(1):29.

92. Longo G., Lamberti A., Maffulli N., Denaro V., Tissue engineered biological augmentation for tendon healing: a systematic review. British Medical Bulletin. 2010;1-29.

93. Bilodeau K., Mantovani D., Bioreactors for tissue engineering: focus on mechanical constraints. A comparative review. Tissue engineering. 2006; 12(8):2367-83.

94. Yang G., Crawford RC., Wang JHC., Proliferation and collagen production of human patellar tendon fibroblasts in response to cyclic uniaxial stretching in serum-free conditions. Journal of Biomechanics. 2004; 37(10):1543-1550.

95. Skutek M., Griensven M., Zeiche J., Brauer N., Bosch U., Cyclic mechanical stretching modulates secretion pattern of growth factors in human tendon fibroblasts. European Journal of Applied Physiology. 2001; 86(1):48-52.

96. Petersen W., Varoga D., Zantop T., Hassenpflug J., Mentlein R., Pufe T., Cyclic strain influences the expression of the vascular endothelial growth factor (VEGF) and the hypoxia inducible factor 1 alpha $(H I F-1 \alpha)$ in tendon fibroblasts. Journal of Orthopaedic Research. 2004; 22(4):847-853.

97. Surrao DC., Fan JC., Waldman SD., Amsden BG., A crimp-like microarchitecture improves tissue production in fibrous ligament scaffolds in response to mechanical stimuli. Acta Biomaterialia. 2012: 8(10):3704-3713. 
98. Majeti NV., Kumar R., A review of chitin and chitosan applications. Reactive and Functional Polymers. 2000; 46(1):1-27.

99. Berger J., Reist M., Mayer JM., Felt O., Gurny R., Structure and interactions in chitosan hydrogels formed by complexation or aggregation for biomedical applications. European Journal of Pharmaceutics and Biopharmaceutics. 2004; 57(1):35-52.

100. Jin J., Song M., Hourston DJ., Novel Chitosan-Based Films CrossLinked by Genipin with Improved Physical Properties. Biomacromolecules. 2003; 5(1):162-168.

101. Mi FL., Sung HW., Shyu SS., Su CC., Peng CK., Synthesis and characterization of biodegradable TPP/genipin co-crosslinked chitosan gel beads. Polymer. 2003; 44(21):6521-6530.

102. Zhao X., Synthesis and characterization of a novel hyaluronic acid hydrogel. J. Biomaer. Sci. Polymer Edn. 2006;17(4):419-433

103. Price RD., Berry MG., Navsaria HA., Hyaluronic acid: the scientific and clinical evidence. Journal of Plastic, Reconstructive \& Aesthetic Surgery. 2007; 60(10):1110-1119.

104. Segura T., Anderson BC., Chung PH., Webber RE., Shull KR., Shea LD., Crosslinked hyaluronic acid hydrogels: a strategy to functionalize and pattern. Biomaterials. 2005; 26(4):359-371.

105. Schantè CE., Zuber G., Herlin C., Vandamme TF., Chemical modifications of hyaluronic acid for the synthesis of derivatives for a broad range of biomedical applications. Carbohydrate Polymers. 2011; 85(3):469-489.

106. Garlotta D., A Literature Review of Poly(Lactic Acid). Journal of Polymers and the Environment. 2001; 9(2):63-84.

107. Chen R., Curran SJ., Curran JM., Hunt JA., The use of poly(l-lactide) and RGD modified microspheres as cell carriers in a flow intermittency bioreactor for tissue engineering cartilage. Biomaterials. 2006; 27(25):4453-4460.

108. García Cruz DM., Escobar Ivirico JL., Gomes MM., Ribelles Gómez JL., Sanchez MS., Reis RL., Mano JF., Chitosan microparticles as injectable scaffolds for tissue engineering. Journal of Tissue Engineering and Regenerative Medicine. 2008; 2(6):378-380. 
109. Sahiner N., Jia X., One-Step Synthesis of Hyaluronic Acid-Based (Sub) micron Hydrogel Particles: Process Optimization and Preliminary Characterization. Turkish Journal of Chemistry. 2008;32:397-409

110. Tsuji H., Ikada Y., Properties and morphologies of poly(l-lactide): 1. Annealing condition effects on properties and morphologies of poly(l-lactide). Polymer. 1995; 36(14):2709-2716.

111. Rodríguez JM., Durán LM., Vicén JA., Cobo RC., Jódar XA., Neuromuscular taping: Do all the different tapes have similar mechanical properties? Apunts MedEsport. 2010; 45(166):61-67.

112. Quynh, TM., Mitomo H., Nagasawa N., Wada Y., Yoshii F., Tamada M., Properties of crosslinked polylactides (PLLA \& PDLA) by radiation and its biodegradability. European Polymer Journal. 2007; 43(5):1779-1785.

113. Balakrishnan H., Hassan A., Wahit MU., Mechanical, thermal, and morphological properties of polylactic acid/linear low density polyethylene blends. Journal of Elastomers and Plastics. 2010; 0095-2443:0223-17.

114. Hooley CJ., McCrum NG., Cohen RE., The viscoelastic deformation of tendon. Journal of Biomechanics. 1980;;13(6):521-528.

115. Johnson GA., Tramaglini DM., Levine RE., Ohno K., Choi NY., Woo SL., Tensile and viscoelastic properties of human patellar tendon. Journal of Orthopaedic Research. 1994; 12(6):796-803.

116. Maganaris CN., Narici MV., Reeves ND., In vivo human tendon mechanical properties: effect of resistance training in old age. J Musculoskel Neuron Interact. 2004; 4(2):204-208.

117. Wren, TA., Yerby SA., Beaupré GS., Carter DR., Mechanical properties of the human achilles tendon. Clinical Biomechanics. 2001; 16(3):245-251.

118. Magnusson SP., Aagaard P., Rosager S., Poulsen PD., Kjaer M., Load displacement properties of the human triceps surae aponeurosis in vivo. Journal of Physiology. 2001; 531(1):277-288.

119. Maganaris CN., Paul JP., Tensile properties of the in vivo human gastrocnemius tendon. Journal of Biomechanics. 2002; 35(12):1639-1646. 
120. Maganaris CN., Paul JP., Hysteresis measurements in intact human tendon. Journal of Biomechanics. 2000; 33(12):1723-1727.

121. Vasanthan N., Ly 0., Effect of microstructure on hydrolytic degradation studies of poly (1-lactic acid) by FTIR spectroscopy and differential scanning calorimetry. Polymer Degradation and Stability. 2009; 94(9):1364-1372.

122. Tsuji H., Nakahara K., Poly(L-lactide). IX. Hydrolysis in acid media. Journal of Applied Polymer Science. 2002; 86(1):186-194.

123. Tsuji H., Ishida T., Poly(L-lactide). X. Enhanced surface hydrophilicity and chain-scission mechanisms of poly(L-lactide) film in enzymatic, alkaline, and phosphate-buffered solutions. Journal of Applied Polymer Science. 2003; 87(10):1628-1633.

124. Tsuji H., Ikada Y., Properties and morphology of poly(L-lactide). II. Hydrolysis in alkaline solution. Journal of Polymer Science Part A: Polymer Chemistry. 1998; 36(1):59-66.

125. Yuan X., Mak AFT., Yao K., Surface degradation of poly(-lactic acid) fibres in a concentrated alkaline solution. Polymer Degradation and Stability. 2003; 79(1):45-52.

126. Yuan X., Mak AFT., Yao K., Comparative observation of accelerated degradation of poly(-lactic acid) fibres in phosphate buffered saline and a dilute alkaline solution. Polymer Degradation and Stability. 2002; 75(1):45-53.

127. Recum HA., Cleek RL., Eskin SG., Mikos AG., Degradation of polydispersed poly(l-lactic acid) to modulate lactic acid release. Biomaterials. 1995; 16(6):441-447.

128. Cam D., Hyon SH., Ikada Y., Degradation of high molecular weight poly(l-lactide) in alkaline medium. Biomaterials. 1995; 16(11):833-843.

129. Saha SK., Tsuji H., Effects of molecular weight and small amounts of d-lactide units on hydrolytic degradation of poly(l-lactic acid)s. Polymer Degradation and Stability. 2006; 91(8):1665-1673.

130. Zhang X., Hua H., Shen X., Yang Q., In vitro degradation and biocompatibility of poly(l-lactic acid)/chitosan fiber composites. Polymer. 2007; 48(4):1005-1011. 
131. Nair LS., Laurencin CT., Biodegradable polymers as biomaterials. Progress in Polymer Science. 2007; 32(8-9):762-798.

132. Maurus PB., Kaeding CC., Bioabsorbable implant material review. Operative Techniques in Sports Medicine. 2004; 12(3):158-160.

133. Yeo Y., Higley CB., Bellas E., Ito T., Marini R., Langer R., Kohane DS., In situ cross-linkable hyaluronic acid hydrogels prevent postoperative abdominal adhesions in a rabbit model. Biomaterials. 2006; 27(27):4698-4705.

134. Brunelli G., Longinotti C., Bertazzo C., Pavesio A., Pressato D., Adhesion reduction after knee surgery in a rabbit model by Hyaloglide $®$, a hyaluronan derivative gel. Journal of Orthopaedic Research. 2005; 23(6):1377-1382.

135. Shearer H., Ellis MJ., Perera SP., Chaudhuri JB., Effects of common sterilization methods on the structure and properties of poly $(D, L$ lactic-co-glycolic acid) scaffolds. Tissue engineering. 2006;12(10):2717-2727.

136. Chen J., Abatangelo G., Functions of hyaluronan in wound repair. Wound Repair and Regeneration. 1999; 7(2):79-89.

137. Nelson CM., Chen CS., Cell-cell signaling by direct contact increases cell proliferation via a PI3K-dependent signal. FEBS 2002;238-242.

138. Roach P., Farrar D., Perry CC., Interpretation of Protein Adsorption: Surface-Induced Conformational Changes. Journal of the American Chemical Society. 2005; 127(22):8168-8173.

139. García Cruz DM., Coutinho DF., Martinez EC., Mano JF., Ribelles JL., Sánchez MS., Blending polysaccharides with biodegradable polymers. II. Structure and biological response of chitosan/polycaprolactone blends.J. Biomedical materials research Part B. 2008;87(2):544-554.

140. Miyakoshi N., Kobayashi M., Nozaka K., Okada K., Shimada Y., Itoi E., Effects of intraarticular administration of basic fibroblast growth factor with hyaluronic acid on osteochondral defects of the knee in rabbits. Archives of Orthopaedic and Trauma Surgery. 2005; 125(10):683-692. 
141. Esposito E., Menegatti E., Cortesi R., Hyaluronan-based microspheres as tools for drug delivery: a comparative study. International Journal of Pharmaceutics. 2005. 288(1):35-49.

142. Lou, J., Tu Y., Burns M., Silva MJ., Manske P., BMP-12 gene transfer augmentation of lacerated tendon repair. Journal of Orthopaedic Research. 2001; 19(6):1199-1202.

143. Wang QW., Chen ZL., Piao YJ., Mesenchymal stem cells differentiate into tenocytes by bone morphogenetic protein (BMP) 12 gene transfer. Journal of Bioscience and Bioengineering. 2005; 100(4):418-422.

144. Bardin N., Anfosso F., Massé JM., Cramer E., Sabatier F., Bivic AL., Sampol J., George FD., Identification of CD146 as a component of the endothelial junction involved in the control of cell-cell cohesion. Blood. 2001; 98(13):3677-3684.

145. Sotiropoulou PA., Perez SA., Salagianni M., Baxevanis CN., Papamichail M., Characterization of the Optimal Culture Conditions for Clinical Scale Production of Human Mesenchymal Stem Cells. Stem cells. 2006; 24(2):462-471.

146. Zhu H., Mitsuhashi N., Klein A., Barsky LW., Weinberg K., Barr ML., Demetriou A., Wu GD., The Role of the Hyaluronan Receptor CD44 in Mesenchymal Stem Cell Migration in the Extracellular Matrix. Stem cells. 2006; 24(4):928-935.

147. Eijk FV., Saris DB., Riesle J., Willems WJ., Blitterswijk CA., Verbout AJ., Dhert WJ., Tissue engineering of ligaments: A comparison of bone marrow stromal cells, anterior cruciate ligament, and skin fibroblasts as cell source. Tissue Engineering. 2004;10:5-6.

148. Ellä V., Gomes ME.,Reis RL., Törmälä P., Kellomäki M., Studies of $P(L / D) L A$ 96/4 non-woven scaffolds and fibres; properties, wettability and cell spreading before and after intrusive treatment methods. Journal of Materials Science: Materials in Medicine. 2007; 18(6):1253-1261. 